\title{
Evaluation of regulated emissions from heavy-duty diesel vehicles in the South Coast Air Basin
}

Thomas M. Buffamonte

West Virginia University

Follow this and additional works at: https://researchrepository.wvu.edu/etd

\section{Recommended Citation}

Buffamonte, Thomas M., "Evaluation of regulated emissions from heavy-duty diesel vehicles in the South Coast Air Basin" (2003). Graduate Theses, Dissertations, and Problem Reports. 1343.

https://researchrepository.wvu.edu/etd/1343

This Thesis is protected by copyright and/or related rights. It has been brought to you by the The Research Repository @ WVU with permission from the rights-holder(s). You are free to use this Thesis in any way that is permitted by the copyright and related rights legislation that applies to your use. For other uses you must obtain permission from the rights-holder(s) directly, unless additional rights are indicated by a Creative Commons license in the record and/ or on the work itself. This Thesis has been accepted for inclusion in WVU Graduate Theses, Dissertations, and Problem Reports collection by an authorized administrator of The Research Repository @ WVU. For more information, please contact researchrepository@mail.wvu.edu. 


\title{
Evaluation of Regulated Emissions from Heavy-Duty Diesel Vehicles in the South Coast Air Basin
}

\section{Thomas M. Buffamonte}

\author{
Thesis submitted to \\ the College of Engineering and Mineral Resources \\ at West Virginia University \\ in partial fulfillment of the requirements \\ for the degree of
}

\author{
Master of Science \\ in \\ Mechanical Engineering \\ Nigel Clark, Ph.D., Chair \\ Mridul Gautam, Ph.D. \\ Gregory Thompson, Ph.D. \\ Ralph Nine, M.S.
}

Department of Mechanical and Aerospace Engineering

Morgantown, West Virginia

2003

Keywords: Diesel Emissions, In-Use Emissions Testing, Chassis Dynamometer 


\title{
Evaluation of Regulated Emissions from Heavy-Duty Diesel Vehicles in the South Coast Air Basin
}

\author{
Thomas M. Buffamonte
}

\begin{abstract}
It is important to know how heavy-duty diesel vehicles affect the air quality in the United States. Twenty-five heavy-duty diesel vehicles in the CRC E55/59 Phase I study were tested on the Urban Dynamometer Driving Schedule (UDDS), AC50/80 and the Heavy Heavy-Duty Diesel Truck (HHDDT) Schedule using the West Virginia University Transportable Emissions Laboratory (TransLab). Every vehicle in the CRC E55/59 Phase I study was tested at 30,000 lbs. (Unladen) and 56,000 lbs. (Laden) on the HHDDT, except for one tanker truck that was tested at 45,000 lbs (Laden). Also, the first thirteen vehicles in the study were tested on Long Idle Modes (2 Idle Modes combined) and on the Long Creep Mode (4 Creep Modes combined).

All twenty-five heavy-duty diesel vehicles were examined in relation to engine model year to understand how emissions production from diesel vehicles has improved in recent years. Emissions of $\mathrm{CO}, \mathrm{CO}_{2}, \mathrm{HC}, \mathrm{NO}_{\mathrm{X}}$ and $\mathrm{PM}$ were sampled during each test run for every diesel vehicle in the CRC E55/59 Phase I study. A relationship was established between test weight and its effect on emissions production. The cycles were also compared to each other to see if the AC50/80 provided a comparative relationship to the lengthier UDDS and HHDDT Schedule. The AC50/80 is a possible choice for screening heavy-duty diesel vehicles in the United States and it is important to see how it relates to other cycles developed from real-world heavy-duty travel. $\mathrm{NO}_{\mathrm{X}}$ and $\mathrm{PM}$
\end{abstract}


emissions were also examined to see if the results from the various tests performed on a sample of heavy-duty vehicles in the CRC E55/59 Phase I study related.

Overall, it was determined that $\mathrm{NO}_{\mathrm{X}}$ emissions did not decrease in relation to the Engine Model Year, but PM emissions did decrease in relation to Engine Model Year. $\mathrm{HC}$ and $\mathrm{CO}$ emission also showed a slight decrease in relation to Engine Model Year for some of the cycles performed on the twenty-five heavy-duty diesel vehicles in the CRC E55/59 Phase I study. 


\section{ACKNOWLEDGMENTS}

I would like to take this opportunity to thank Dr. Nigel Clark for giving me the opportunity to attend the Mechanical Engineering Graduate Program at West Virginia University. At the last minute you took me under your wing and allowed me to benefit from the wealth of knowledge you had to offer. The benefits that I have received over the last two years will last a lifetime in the field of engineering. I would also like to thank Dr. Nigel Clark for allowing me to use his personal shop to work on my vehicle. Without it, I wouldn't have been able to keep my car going during the two years of graduate school.

I would like to thank Dr. Greg Thompson, Dr. Mridul Gautam and Ralph Nine for their assistance over the last two years educating me on the various aspects of heavy-duty diesel emissions. I would also like to thank each one of them for participating in the development of my thesis. Dr. W. Scott Wayne has assisted throughout my graduate studies with explanations of the stationary and transportable laboratories and I thank him for contributing to my education in diesel emissions studies.

A thank you should also be given to the West Virginia University transportable laboratory crew. Their hard work day after day has helped me succeed as a graduate. I would like to thank Richard Atkinson, Andy Pertl, Tom Spencer, Jason England, Gary England, Chris Rowe, Andy Williams, Ryan Barnett, Ted Christian, Kurt Leasor, and Byron Rapp for there assistance with the transportable laboratory.

I would also like to thank my family, and friends for their support of my attending

the graduate program at West Virginia University. I would also like to thank Jennifer Conforti and her family for their support during my pursuit of a master's degree. 


\section{TABLE OF CONTENTS}

ABSTRACT
TABLE OF CONTENT S.
TABLE OF FIGURES.
TABLE OF TABLES
NOMENCLATURE

$1 \quad$ INTRODUCTION ..........................................................................................................................................................

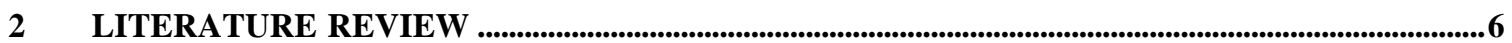

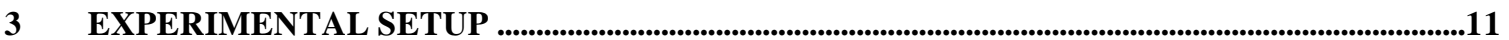

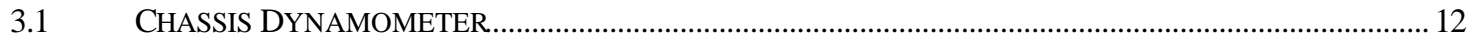

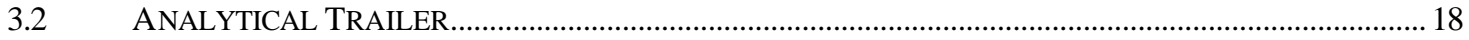

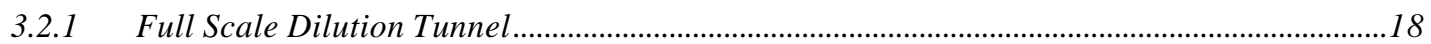

3.2.2 Secondary Dilution Tunnel .................................................................................................

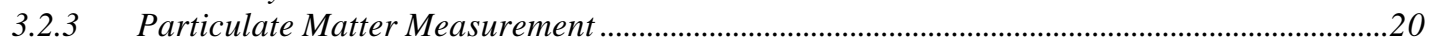

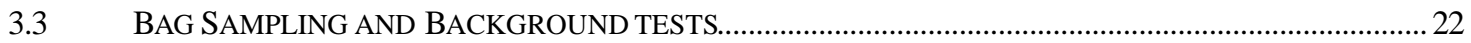

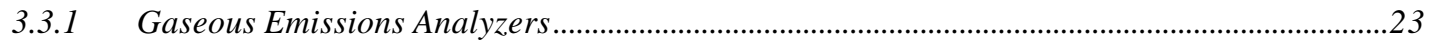

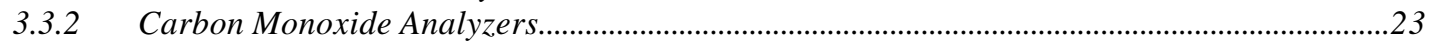

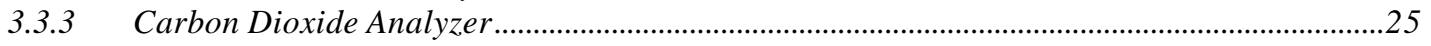

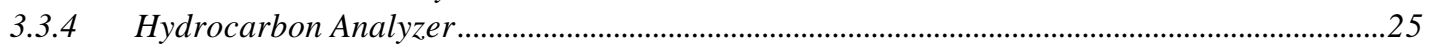

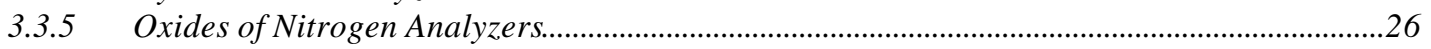

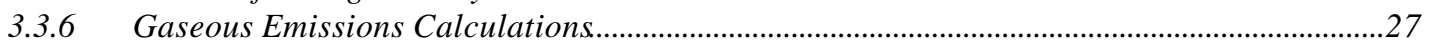

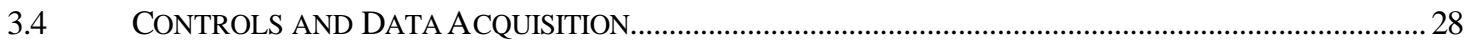

4 TEST PLAN AND PROCEDURE ................................................................................................................30

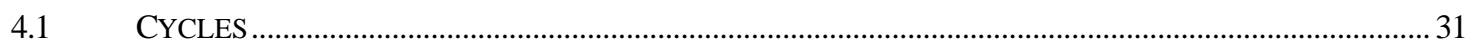

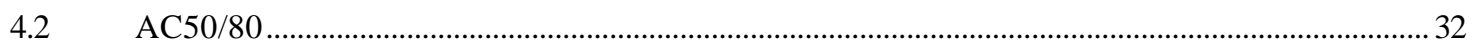

4.3 URBAN DYNAMOMETER DRIVING SCHEDULE...………………………………………….... 34

4.4 HEAVY HEAVY-DUTY DIESEL TRUCK (HHDDT) SCHEDULE ........................................................... 35

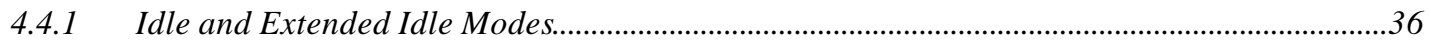

4.4.2 Creep and Extended Creep Modes.........................................................................................

4.4.3 Transient Mode

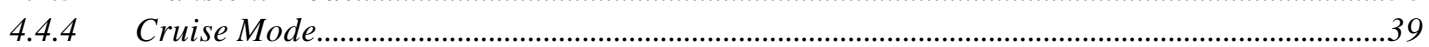

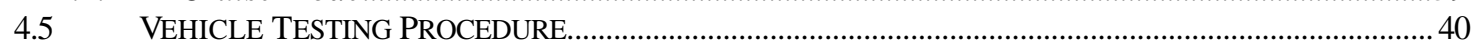

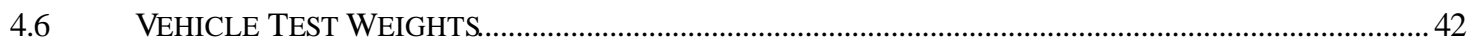

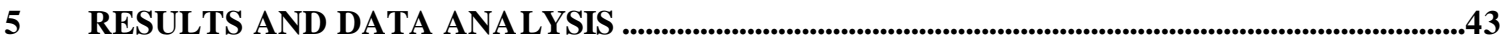

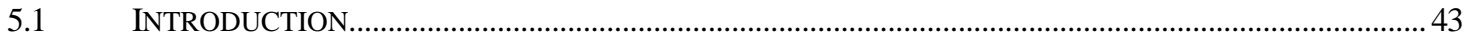

5.1.1 Comparison Between Emissions and Model Year for the AC50/80...........................................43

5.1.2 Comparison Between Regulated Emissions and Model Year for the UDDS .............................47

5.1.3 Comparison Between Regulated Emissions and Model Year for the Idle Mode.......................50

5.1.4 Comparison Between Regulated Emissions and Model Year for the Creep Mode...................52

5.1.5 Comparison Between Regulated Emissions and Model Year for the Transient Mode.............54

5.1.6 Comparison Between Regulated Emissions and Model Year for the Cruise Mode.................59

5.2 EFFECTS OF DIFFERENT TEST WEIGHTS FOR THE CREEP, TRANSIENT AND HIGHWAY MODES... 61

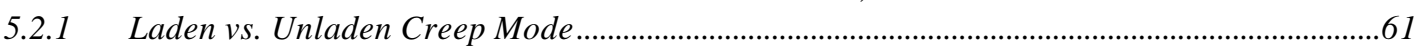

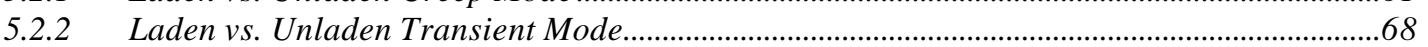

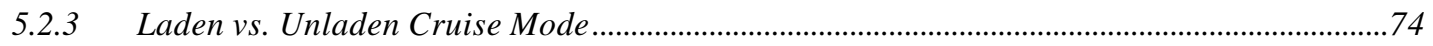

5.3 COMPARISON BETWEEN THE TEST LENGTH FOR THE IDLE AND CREEP MODE ................................ 80

5.3.1 Comparison Between the Idle and Long Idle Mode.................................................................80

5.3.2 Comparison Between the Creep and Long Creep Mode ..........................................................8 


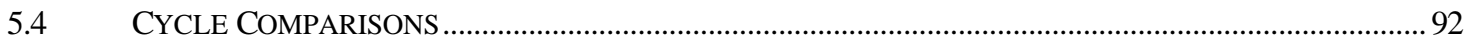

5.4.1 Comparison Between the AC50/80 and the Creep Mode of the HHDDT ……..........................92

5.4.2 Comparison Between the AC50/80 and the Transient Mode of the HHDDT ............................96

5.4.3 Comparison Between the AC50/80 and the Cruise Mode of the HHDDT ............................. 100

5.4.4 Comparison Between the AC50/80, UDDS and the Combined HHDDT.............................. 104

5.4.5 Comparison Between the Transient Mode and the Cruise Mode From the HHDDT ........... 109 5.5 COMPARISON BETWEEN NO X AND PM EMISSIONS WHEN COMPARING SEVERAL DIFFERENT

CYCLES PERFORMED ON THE SAME HEAVY-DUTY VEHICLE............................................................................. 113

CONCLUSIONS .

7 REFERENCES 128 


\section{TABLE OF FIGURES}

Figure 1: Chassis dynamometer with rear wheels removed and being lowered into position for testing.

Figure 2: The vehicle's outside rear wheel was removed and replaced with a hub adapter.

Figure 3: Layout of the Transportable Chassis Dynamometer flatbed.

Figure 4: Illustration of the AC50/80 test. The x-axis has a time scale in seconds and is only an approximation of the test time since the heavy-duty vehicle is allowed to accelerate freely at two ramps in the test.

Figure 5: Actual speed vs. time trace for E55CRC- 2. Vehicle 2 is a 1995 Freightliner with a Caterpillar 3406B engine. 34

Figure 6: Urban Dynamometer Driving Schedule (UDDS). 35

Figure 7: The Creep Mode is a 253-second test that has an average speed of $1.80 \mathrm{mph} .37$

Figure 8: The Extended Creep Mode is four Creep Modes combined for a total of 1012

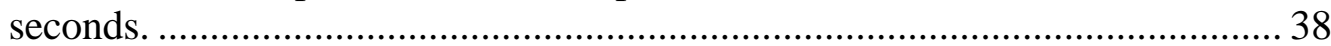

Figure 9: The Transient Mode was developed to represent driving in urban areas.......... 39

Figure 10: The Cruise Mode represents high-speed driving with minimal stops that are often found in more highway styles of driving. 40

Figure 11: $\mathrm{NO}_{\mathrm{X}}$ and $\mathrm{PM}$ for the AC50/80. Averages and ranges are shown for the data. The pre-1990 group has a high range due to E55CRC-16, which was a very high PM emitter.

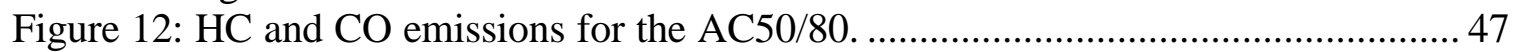

Figure 13: $\mathrm{NO}_{\mathrm{X}}$ and PM vs. Engine Model Year Group for the UDDS. ......................... 49

Figure 14: CO and HC vs. Engine Model Year Group for the UDDS. ........................... 49

Figure 15: $\mathrm{NO}_{\mathrm{X}}$ and PM vs. Engine Model Year Group for the Idle Mode. ....................51

Figure 16: $\mathrm{CO}$ and $\mathrm{HC}$ vs. Engine Model Year Group for the Idle Mode........................5 52

Figure 17: $\mathrm{NO}_{\mathrm{X}}$ and PM vs. Engine Model Year Group for the Creep Mode.................. 53

Figure 18: HC and CO vs. Engine Model Year Group for the Creep Mode. .................... 54

Figure 19: $\mathrm{NO}_{\mathrm{X}}$ and PM vs. Engine Model Year Group for the Transient Mode. ........... 55

Figure 20: HC and CO vs. Engine Model Year Group for the Transient Mode............... 56

Figure 21: $\mathrm{NO}_{\mathrm{X}}$ and PM emissions vs. Engine Model Year Group with units of g/ahp-hr.

The data are from the Transient Mode.

Figure 22: HC and CO vs. Engine Model Year Group with units of g/ahp-hr. The data is from the Transient Mode.

Figure 23: $\mathrm{NO}_{\mathrm{X}}$ and PM emissions vs. Engine Model Year Group with units of g/gallon.

The data are from the Transient Mode.

Figure 24: HC and CO emissions vs. Engine Model Year Group with units of g/gallon.

The data are from the Transient Mode.

Figure 25: $\mathrm{NO}_{\mathrm{X}}$ and PM vs. Engine Model Year Group for the Cruise Mode.

Figure 26: HC and CO vs. Engine Model Year Group for the Cruise Mode.

Figure 27: $\mathrm{NO}_{\mathrm{X}}$ emissions for the Laden and Unladen tests operated on the Creep Mode.

The graph is also divided up into groups based on California Emissions

Regulations. 
Figure 28: PM emissions from the Laden and Unladen Creep Mode. The graph is also divided up into groups based on California Emissions Regulation.

Figure 29: Comparison between $\mathrm{NO}_{\mathrm{X}}$ emissions for the Unladen and Laden test weights Creep Modes.

Figure 30: $\mathrm{CO}_{2}$ emissions production for the Laden and Unladen Creep Modes. The graph is also divided up into groups based on California Emissions Regulations.

Figure 31: CO emissions for the Laden and Unladen Creep Modes. The graph is also divided up into groups based on California Emissions Regulations.

Figure 32: HC emissions for the Laden and Unladen Creep Modes. The graph is also divided up into groups based on California Emissions Regulations. 68

Figure 33: $\mathrm{NO}_{\mathrm{X}}$ emissions for the Laden and Unladen Transient Mode. The graph is also divided up into groups based on California Emissions Regulations.

Figure 34: PM emissions for the Laden and Unladen Transient Mode. The graph is also divided up into groups based on California Emissions Regulations. ............... 70

Figure 35: Relationship between Laden and Unladen test weights for the Transient Mode.

Figure 36: $\mathrm{CO}_{2}$ emissions for the Laden and Unladen Transient Modes. The graph is also divided up into groups based on California Emissions Regulations.

Figure 37: CO emissions for the Laden and Unladen Transient Modes. The graph is also

divided up into groups based on California Emissions Regulations. 73

Figure 38: HC emissions for the Laden and Unladen Transient Modes. The graph is also divided up into groups based on California Emissions Regulations.

Figure 39: $\mathrm{NO}_{\mathrm{X}}$ emissions for the Laden and Unladen Cruise Modes. The graph is also divided up into groups based on California Emissions Regulations................ 76

Figure 40: PM emissions for the Laden and Unladen Cruise Modes. The graph is also divided up into groups based on California Emissions Regulations. 76

Figure 41: Relationship between Unladen and Laden test weights for the Cruise Modes.

Figure 42: $\mathrm{CO}_{2}$ emissions from the Laden and Unladen Cruise Modes. The graph is also divided up into groups based on California Emissions Regulations.

Figure 43: CO emissions for the Laden and Unladen Cruise Modes. The graph is also divided up into groups based on California Emissions Regulations.

Figure 44: HC emissions for the Unladen and Laden Cruise Modes. The graph is also divided up into groups based on California Emissions Regulations. 80

Figure 45: Comparison of $\mathrm{NO}_{\mathrm{X}}$ emissions between the Idle and Long Idle Modes......... 83

Figure 46: Comparison of PM emissions between the Idle and Long Idle Modes. 84

Figure 47: Comparison between the $\mathrm{CO}_{2}$ emissions produce during the Idle and Long Idle Modes.

Figure 48: Comparison between the Idle and Long Idle Modes for $\mathrm{CO}$ emissions.......... 86

Figure 49: Comparison between the Idle and Long Idle Modes for $\mathrm{HC}$ emissions.......... 86

Figure 50: $\mathrm{NO}_{\mathrm{X}}$ emissions comparison between the Creep Mode and the Long Creep Mode.

Figure 51: PM emissions comparison between the Creep and Long Creep Modes. ........ 89

Figure 52: CO emissions comparison for the Creep and Long Creep Modes. ................. 90

Figure 53: Comparison between the Creep and Long Creep Modes HC emissions. 
Figure 54: Comparison between the Creep and Long Creep Modes $\mathrm{CO}_{2}$ emissions. ...... 91

Figure 55: Cycle comparison between the AC50/80 and Creep Mode for $\mathrm{NO}_{\mathrm{X}}$ and PM. 93

Figure 56: $\mathrm{CO}, \mathrm{HC}$ and $\mathrm{CO}_{2}$ emissions for the $\mathrm{AC50/80}$ and Creep Mode..................... 94

Figure 57: Comparison between $\mathrm{NO}_{\mathrm{X}}$ emissions for the Creep Mode and the AC50/80. 95

Figure 58: Comparison between the Creep Mode and AC50/80 for PM emissions........ 96

Figure 59: $\mathrm{NO}_{\mathrm{X}}$ and PM emissions for the AC50/80 and Transient Mode..................... 97

Figure 60: Vehicle emissions vs. Engine Model Year Group for the AC50/80 and

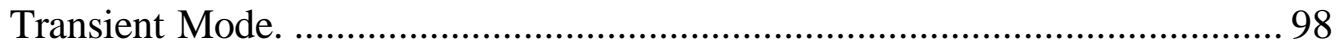

Figure 61: Comparison between the AC50/80 and the Transient Mode for $\mathrm{NO}_{\mathrm{X}}$

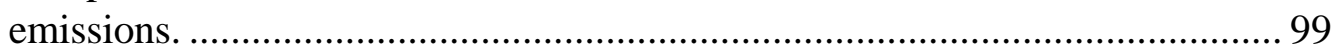

Figure 62: Comparison between the AC50/80 and the Transient Mode for the PM

emissions. E55CRC-16 is responsible for producing a high $\mathrm{R}^{2}$ value......... 100

Figure 63: $\mathrm{PM}$ and $\mathrm{NO}_{\mathrm{X}}$ emissions for the AC50/80 and Cruise Mode........................ 101

Figure 64: $\mathrm{CO}, \mathrm{HC}$, and $\mathrm{CO}_{2}$ emissions for the AC50/80 and Cruise Mode.................. 102

Figure 65: Comparison between the AC50/80 and the Cruise Mode for $\mathrm{NO}_{\mathrm{X}}$ emissions.

Figure 66: Comparison between the AC50/80 and the Cruise Mode for PM emissions. 104

Figure 67: Comparison of the AC50/80, UDDS, and the combined HHDDT for $\mathrm{NO}_{\mathrm{X}}$ and PM emissions.

Figure 68: Comparison of the AC50/80, UDDS, and the combined HHDDT for CO, HC,

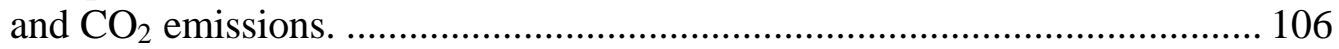

Figure 69: Comparison between the AC50/80, the combined HHDDT and the UDDS for $\mathrm{NO}_{\mathrm{X}}$ emissions.

Figure 70: Comparison between the AC50/80, the combined HHDDT and the UDDS for PM emissions.

Figure 71: Comparison between the Transient and the Cruise Modes for $\mathrm{NO}_{\mathrm{X}}$ and $\mathrm{PM}$ emissions.

Figure 72: Comparison between the Transient and Cruise Modes for $\mathrm{CO}, \mathrm{HC}$ and $\mathrm{CO}_{2}$ emissions.

Figure 73: Relationship between the Transient and Cruise Modes for $\mathrm{NO}_{\mathrm{X}}$ emissions from the twenty-five heavy-duty vehicles tested.

Figure 74: Relationship between the Transient and Cruise Modes for PM emissions from the twenty-five heavy-duty vehicles tested.

Figure 75: Comparison between $\mathrm{NO}_{\mathrm{X}}$ and $\mathrm{PM}$ for the E55CRC-13 heavy-duty vehicle. The heavy-duty vehicle had a 1978 model year Cummins 350 diesel engine.

Figure 76: Comparison between $\mathrm{NO}_{\mathrm{X}}$ and PM emissions for the E55CRC-12 heavy-duty vehicle. The heavy-duty vehicle had a 1986 model year Cummins 300 diesel engine.

Figure 77: Comparison between $\mathrm{NO}_{\mathrm{X}}$ and PM emissions for the E55CRC-20 heavy-duty
vehicle. The heavy-duty vehicle had a 1992 model year Detroit Diesel Series

Figure 77: Comparison between $\mathrm{NO}_{\mathrm{X}}$ and $\mathrm{PM}$ emissions for the E55CRC-20 heavy-duty
vehicle. The heavy-duty vehicle had a 1992 model year Detroit Diesel Series 60 engine. Comparison between $\mathrm{NO}_{\mathrm{X}}$ and PM emissions for the E55CRC-22 heavy-duty vehicle. The heavy-duty vehicle had a 1993 model year Cummins L10-280 diesel engine. 
Figure 79: Comparison between $\mathrm{NO}_{\mathrm{X}}$ and $\mathrm{PM}$ emissions for the E55CRC-6 heavy-duty vehicle. The heavy-duty vehicle had a 1995 model year Cummins M11-370 diesel engine.

Figure 80: Comparison between $\mathrm{NO}_{\mathrm{X}}$ and PM emissions for the E55CRC-1 heavy-duty vehicle. The heavy-duty vehicle had a 1994 model year Detroit Diesel Series 60 diesel engine.

Figure 81: Comparison between $\mathrm{NO}_{\mathrm{X}}$ and PM emissions for the E55CRC-9 heavy-duty vehicle. The heavy-duty vehicle had a 1998 model year Cummins C12 diesel engine.

Figure 82: Comparison between $\mathrm{NO}_{\mathrm{X}}$ and $\mathrm{PM}$ for the E55CRC-11 heavy-duty vehicle. The heavy-duty had a 2000 model year Cummins ISM diesel engine. 


\section{TABLE OF TABLES}

Table 1: Federal and California Heavy-Duty Truck Emissions Standards [2,3].

Table 2: Information about the twenty-five heavy-duty vehicles in the CRC E55/59 Phase

I study. Some of the heavy-duty vehicles in the study have different engine model years from vehicle model years........................................................... 31

Table 3: AC50/80 Test Methodology. ............................................................................. 33

Table 4: Average, maximum and minimum percent difference between the Laden and Unladen Transient Mode............................................................................. 74

Table 5: Average, maximum and minimum percent difference between the Laden and Unladen Cruise Mode. 


\section{NOMENCLATURE}

$\begin{array}{ll}\text { CARB } & \text { California Air Resource Board } \\ \text { CBD } & \text { Central Business District } \\ \text { CFV-CVS } & \text { Critical Flow Venturi - Constant Volume System } \\ \text { CRC } & \text { Coordinating Research Council, Inc. } \\ \mathrm{CO} & \text { Carbon Monoxide } \\ \mathrm{CO}_{2} & \text { Carbon Dioxide } \\ \mathrm{CSHVR} & \text { City Suburban Heavy-Duty Vehicle Route } \\ \mathrm{CTA} & \text { California Trucking Association } \\ \text { DRI } & \text { Desert Research Institute } \\ \text { EPA } & \text { Environmental Protection Agency } \\ \mathrm{g} & \text { Grams } \\ \text { g/bhp-hr } & \text { Grams per brake horsepower-hour } \\ \text { g/mile } & \text { Grams per mile } \\ \text { GVWR } & \text { Gross Vehicle Weight Rating } \\ \mathrm{HC} & \text { Hydrocarbons } \\ \mathrm{HDT} & \text { Heavy-Duty Transient } \\ \mathrm{HHDDT} & \text { Heavy Heavy-Duty Diesel Truck } \\ \mathrm{HHDDV} & \text { Heavy Heavy-Duty Diesel Vehicle } \\ \mathrm{Km} / \mathrm{h} & \text { Kilometers per hour } \\ \mathrm{NDIR} & \text { Non-dispersive Infrared } \\ \mathrm{NO} & \text { Nitric Oxide } \\ \mathrm{NO} \mathrm{H}_{2} & \text { Nitrogen Dioxide } \\ \mathrm{NO} & \text { Oxides of Nitrogen } \\ \mathrm{NREL} & \text { National Renewable Energy Laboratory } \\ \mathrm{O}_{2} & \text { Oxygen } \\ \mathrm{O}_{3} & \text { Ozone } \\ \text { PM } & \text { Particulate Matter } \\ \text { ppm } & \text { Parts per million } \\ \mathrm{SAE} & \text { Society of Automotive Engineers } \\ \mathrm{UDDS} & \text { Urban Dynamometer Driving Schedule } \\ \mathrm{USDOE} & \text { United States Department of Energy } \\ \text { WVT } & \text { West Virginia Truck } \\ \text { WVU } & \text { West Virginia University } \\ & \end{array}$




\section{Introduction}

The Environmental Protection Agency (EPA) was formed December 2, 1970 under President Richard Nixon. The mission of the EPA was simple, to "Protect human health and to safe guard the natural environments air, water, and land under which life depends" [1]. This simple mission statement proved to be a monumental task. The sources of emissions in the United States needed to be identified and regulations needed to be implemented to reduce the damage they inflect on the environment. One of the sources that was identified as a large contributor to environmental pollution was transportation. Once the source was identified, acceptable emissions regulations needed to be introduced in a timely manner to reduce the environmental effects and allow for technological improvements to be made regulation standards to be achieved.

In 1971, the EPA set National Air Quality Standards for six common classes of pollutants: oxides of sulfur, particulate matter, carbon monoxide, photochemical oxidants, oxides of nitrogen and hydrocarbons [1]. Since transportation such as cars, buses, heavy-duty vehicles and off-road vehicles was identified as a main contributor to the common classes of pollutants, standards needed to be implemented to regulate emissions production and control the environmental damage that they were causing. The EPA implemented emissions standards for vehicles in the 1970's and has since then lowered the acceptable levels to improve the air quality of the United States of America.

A large source of air pollution comes from heavy-duty vehicles operating on the road today. Some of the heavy-duty chassis or vehicle manufacturers in the United States of America purchase engines from another company. When the regulations were put in place for the heavy-duty vehicles it was decided to test the engine instead of the vehicle 
for emissions. The EPA passed regulations that required engine companies that produce heavy-duty engines for heavy-duty vehicles to meet certain regulation standards. The Federal and California Heavy-Duty Truck Emissions Standards are located in Table 1. These emission regulations have tightened over time to improve the emissions produced from heavy-duty vehicles. The regulations for urban buses are slightly different than the regulations for heavy-duty trucks. The emissions regulations for $\mathrm{CO}$ and $\mathrm{HC}$ are similar between the truck standards and urban bus standards. The emissions of $\mathrm{NO}_{\mathrm{X}}$ and $\mathrm{PM}$ differ slightly between truck and urban bus regulations. The $\mathrm{NO}_{\mathrm{X}}$ and $\mathrm{PM}$ standards for urban buses have lower permitted emissions levels and are enforced earlier than truck $\mathrm{NO}_{\mathrm{X}}$ and PM standards.

Table 1: Federal and California Heavy-Duty Truck Emissions Standards [2,3].

\begin{tabular}{|c|c|c|c|c|c|c|c|c|c|c|c|}
\hline \multicolumn{6}{|c|}{ Federal Heavy-Duty Truck Standards } & \multicolumn{6}{|c|}{ California Heavy-Duty Truck Standards } \\
\hline \multirow{2}{*}{$\begin{array}{l}\text { Model } \\
\text { Year }\end{array}$} & $\mathrm{HC}^{1}$ & $\mathrm{CO}$ & $\mathrm{NO}_{\mathrm{x}}$ & PM & $\mathrm{HC}+\mathrm{NO}$ & \multirow{2}{*}{$\begin{array}{l}\text { Model } \\
\text { Year }\end{array}$} & $\mathrm{HC}^{1}$ & $\mathrm{CO}$ & $\mathrm{NO}_{x}$ & PM & $\mathrm{HC}+\mathrm{NO}_{\mathrm{x}}$ \\
\hline & \multicolumn{5}{|c|}{ g/bhp-hr } & & \multicolumn{5}{|c|}{ g/bhp-hr } \\
\hline & & & & & 16.0 & $1975-76$ & --- & 30.0 & --- & --- & 10.0 \\
\hline $1974-78$ & --- & 40.0 & --- & --- & 10.0 & $1977-79$ & 1.0 & 25.0 & 7.5 & --- & --- \\
\hline $1979-83$ & 1.5 & 25.0 & --- & --- & --- & $1980-83$ & 1.0 & 25.0 & --- & --- & 6.0 \\
\hline $1984-87$ & 1.3 & 15.5 & 10.7 & --- & --- & $1984-86$ & 1.3 & 15.5 & 5.1 & --- & --- \\
\hline 1988-90 & 1.3 & 15.5 & 10.7 & 0.60 & --- & 1987-90 & 1.3 & 15.5 & 6.0 & 0.60 & --- \\
\hline 1991-93 & 1.3 & 15.5 & 5.0 & 0.25 & --- & 1991-93 & 1.3 & 15.5 & 5.0 & 0.25 & --- \\
\hline 1994-97 & 1.3 & 15.5 & 5.0 & 0.10 & --- & 1994-97 & 1.3 & 15.5 & 5.0 & 0.10 & --- \\
\hline 1998-02 & 1.3 & 15.5 & 4.0 & 0.10 & --- & 1998-02 & 1.3 & 15.5 & 4.0 & 0.10 & --- \\
\hline $2003+$ & $0.5^{2}$ & 15.5 & 2.0 & 0.10 & --- & $2003+$ & $0.5^{2}$ & 15.5 & 2.0 & 0.10 & --- \\
\hline
\end{tabular}

Some heavy-duty engine families are tested on an engine dynamometer following federal testing procedures (FTP) in order to be certified by the EPA and sold in the 
United States 20]. The older vehicles were certified under steady state conditions. Since the engines are tested out of the vehicle, it is difficult to determine the emissions produced from heavy-duty vehicles. The difficulty in relating the heavy-duty vehicle emissions to the engine emissions lies in the losses associated with the drivetrain of the vehicle. The drivetrain varies in its efficiency from vehicle to vehicle and the same engine maybe used in several different vehicles.

Three options maybe pursued to determine the emissions production from a heavy-duty vehicle in operation. One is to test the vehicle on a chassis dynamometer, which tests the vehicle for emissions on a cycle developed from travel information taken from vehicles operating under real world conditions. The second method is to remove the engine from the vehicle and test it on an engine dynamometer. This method relates to the certification methods, but it is difficult to relate to vehicle emissions because of drivetrain losses directly. Some of the newer trucks equipped with ECU's are able to provide real time data from the engine and the torque produced from the engine can be gathered. Also, the engine can be removed from the vehicle and tested on an engine dynamometer, but this can be costly. The third test method is to use mobile source emissions measurement equipment that accompanies the vehicle during its regular travel. There are a number of mobile emissions equipment packages on the market, but most are still in the developmental stages and chassis testing remains one of the main methods for determining heavy-duty vehicle emissions. West Virginia University is currently logging data from an operational mobile emissions equipment system (MEMS) [4], but the system was not used in the CRC E55/59 Phase I study. McCormick et al. [5], did a comparison between chassis dynamometer results and engine dynamometer results to see 
if they could find conversion factors that would relate engine certification testing to chassis testing. The EPA has developed conversion factors, but the conversion factors were developed from pre-1992 heavy-duty vehicles [5]. The comparison study concluded that the conversion factors from the EPA were different from heavy-duty vehicles tested. It is important to test with a chassis dynamometer to better understand the emissions produced from heavy-duty vehicles.

The Coordinating Research Council (CRC) E55/59 Phase I study was setup to gather data from on-road heavy-duty vehicle operation in California. Twenty-five diesel vehicles were examined during the study on various tests and at different test weights to determine emissions production. The CRC E55/59 Phase I study was sponsored by the following organizations:

- Coordinating Research Council, Inc.

- California Air Resources Board

- United States Environmental Protection Agency

- United States Department of Energy, Office of FreedomCAR \& Vehicle Technologies through the National Renewable Energy Laboratory

- South Coast Air Quality Management District

- Engine Manufacturers Association

The West Virginia University TransLab was assisted in this emissions testing program by the California Trucking Association (CTA) and the Desert Research Institute (DRI). There is a limited amount of emissions data on heavy-duty diesel vehicles operating in the United States. Therefore it is important to gather data on heavy-duty vehicles from different heavy-duty vehicle manufacturers with different engine manufacturers and model years that represent the types of heavy-duty vehicles operating on the roads in the United States. The CRC E55/59 Phase I study was setup to sample the heavy-duty vehicles operating in the state of California. 
Twenty-five heavy-duty vehicles were selected for Phase I of the CRC E55/59 study that represented the types of heavy-duty vehicles operating in the state of California. The heavy-duty vehicles were selected after a survey study was done by CTA to determine the amount of heavy-duty vehicles on the road and the types of heavy-duty vehicles on the road for each model year. After the twenty-five heavy-duty vehicles were determined, CTA and WVU proceeded in recruiting the vehicles for the study. All of the vehicles were then tested on various cycles and at different test weights to establish an accurate model of emissions produced by heavy-duty vehicles operating in the state of California.

There are a limited amount of data at present for heavy-duty vehicles operating on the road. The objective of this thesis is to report the data from several heavy-duty vehicles with different model years and different engines that represent the types of vehicles operating in the state of California. It is important to understand the level of emissions produced from heavy-duty vehicles operating as close to real world environments under controlled practices to understand how regulations have influenced heavy-duty vehicle emissions. 


\section{Literature Review}

Diesel emissions are known to affect human health in the United States every year, but how diesel emissions affect human health, and how much is an acceptable level for the human body are important questions. So the EPA recorded the levels of emissions in various high traffic areas and compared it to the effect it has on human health. The EPA set standards in the 1971 Clean Air Act that was considered acceptable at the time for air quality. A presentation by Kevin A. Stewart, Director of environmental health from the American Lung Association of Pennsylvania, discussed the health effects associated with diesel emissions. He stated that, "Diesel engines produce a significant amount of fine particulate matter that may be responsible for about 50,000 premature deaths in the U.S. every year" [6]. It is estimated that 125,000 people in the United States have cancer because of diesel particulate matter exposure [6]. Approximately one in twelve Americans have a chronic lung disease and are at risk from air pollution. Also, infants, children, and the elderly are at an increased risk level from air pollution [6]. Alan C. Lloyd and Thomas A. Cackette recently wrote an overview paper titled "Diesel Engines: Environmental Impact and Control" [7]. Lloyd and Cackette examined the exposure levels that people are in contact with and how they influence human health. They found that "long-term occupational exposures to diesel exhaust were associated with an increase of $\sim 40 \%$ in the relative risk of lung cancer" [7]. They also highlighted an increase risk of lung cancer for truck drivers, railroad workers, heavy equipment operators and miners [7].

It is known that diesel engines produce $\mathrm{NO}_{\mathrm{X}}, \mathrm{HC}, \mathrm{CO}$ and $\mathrm{PM}$ emissions. The production of $\mathrm{CO}$ and $\mathrm{HC}$ are low on diesel engines and receive little attention. $\mathrm{CO}$ and 
$\mathrm{HC}$ are regulated and the acceptable emissions levels have been lowered since 1970. $\mathrm{NO}_{\mathrm{X}}$ and $\mathrm{PM}$ emissions from diesel engines are of greater concern to the human population because of their health effects in relation to the production levels produced from a diesel engine. Oxides of nitrogen increase the chance of respiratory illnesses and decrease lung function growth [6]. Fine particulate matter is known to cause premature death, increase respiratory illnesses, and cause severe asthma related problems. $\mathrm{NO}_{\mathrm{X}}$ emissions are also an ozone precursor and forms secondary particulate when in contact with nitrates and sulfate.

Reduced lung ventilation and emphysema are recorded among highly exposed persons, and an increased incidence of lung cancer is observed among people occupationally exposed. Studies in experimental animals suggest that the particulate phase of diesel emissions have tumor-promoting properties. Factors that may contribute to a tumor-promoting effect are inflammation, cell proliferation, impairment of lung clearance, intrinsic toxicity of particulate matter, and the generation of reactive oxygen species [8].

It has also been noted that the dramatic increase in human allergic airway diseases in the past 200 years has paralleled the increase in the use of fossil fuels. The burning of fossil fuels generates airborne particulates and polyaromatic hydrocarbons (PAH). These particulates are universally found in indoor air, often in concentrations equal to or exceeding those found in ambient outdoor air [9].

A number of studies found it difficult to determine a relationship between diesel emissions and the health effects. The epidemiological data are consistent in showing weak associations between exposure to diesel exhaust and lung cancer. The available 
evidence suggests that long-term exposure to diesel exhaust in a variety of occupational circumstances is associated with a 1.2-fold to 1.5 -fold increase in the relative risk of lung cancer compared with workers classified as unexposed [10]. Recent epidemiological studies have shown strong correlation between elevated outdoor particulate matter (PM) levels and a range of adverse health effects, including early mortality, exacerbation of respiratory tract disease, reduced lung function, and cardiovascular disease. The mechanisms by which PM exposure affects human health are unclear and are the subject of much current research [11]. It is clear that more research is needed to better understand the health effects of diesel emissions. William D. Ruckelshaus, Administrator of the Environmental Protection Agency from 1970-1973 and 1983-1985, said it best when he addressed the new Air Quality Standards in 1971, "If we have erred at all in setting these standards, we have erred on the side of public health" [12].

Several studies in recent years have aided in better understanding the level of emissions produced from heavy-duty diesel vehicles operating in the United States. The PM Split study was funded by the USDOE and NREL to determine the emissions produced from heavy-duty vehicles operating in the southern California area [14]. A total of thirty-four heavy-duty vehicles was tested on an Idle test, the CSHVR and the Highway Cycle. The study also sampled a number of the heavy-duty vehicles under different test weights, different fuels, cold start Idle tests, and cold start CSHVR Schedules [14]. Tim Hall examined how test weight, fuels, and cold starts effect heavyduty diesel emissions in his thesis [13].

The heavy-duty vehicles were separated into model year groups in relation to California emissions and Gross Vehicle Weight Rating (GVWR). Sixteen heavy-duty 
vehicles were examined in the PM Split study that had a GVWR over 33,000 lbs. and an overview of the heavy-duty vehicles are examined in Clark et al. [14]. The study showed that PM emissions decreased as model year increased and $\mathrm{NO}_{\mathrm{X}}$ showed no change in emissions. The $\mathrm{NO}_{\mathrm{X}}$ emissions for one of the oldest trucks produced less $\mathrm{g} / \mathrm{mile}$ than any of the other vehicles in the study. The $\mathrm{NO}_{\mathrm{X}}$ and PM showed no correlation between emissions regulations and engine model year groups.

The Northern Front Range Air Quality Study (NFRAQS) in Colorado examined the sources of pollution in the Northern Front Range that contributed to Denver's visibility reduction [15]. The State of Colorado did not violate the national ambient air quality standards in 1996, but in Denver, visibility standards were violated about $40 \%$ of the year [15]. The NFRAQS examined twenty-one heavy-duty vehicles with a GVWR between 11,000 and 80,000 lbs. operating in the Northern Front Range Area of Colorado. The vehicle model years ranged from 1981 to 1995 . The twenty-one heavy-duty vehicles were tested on the Central Business District (CBD), the UDDS, and the West Virginia University 5-peak cycle. The CBD cycle produced the highest emissions with an average $\mathrm{PM}_{10}$ of $2.85 \mathrm{~g} / \mathrm{mile}$, average $\mathrm{NO}_{\mathrm{X}}$ of $30.4 \mathrm{~g} / \mathrm{mile}$, average $\mathrm{CO}$ of $30.4 \mathrm{~g} / \mathrm{mile}$, and an average $\mathrm{HC}$ of $1.98 \mathrm{~g} / \mathrm{mile}$. The $\mathrm{CBD}$ was the most aggressive driving cycle with the highest average speed, so it was anticipated that the CBD would produce the highest emissions when compared to the HDT, and the WVT. The average emissions rates for the HDT cycle were $1.68 \mathrm{~g} / \mathrm{mile}$ for $\mathrm{PM}_{10}, 21.0 \mathrm{~g} / \mathrm{mile}$ for $\mathrm{NO}_{\mathrm{X}}, 16.8 \mathrm{~g} / \mathrm{mile}$ for $\mathrm{CO}$, and $1.31 \mathrm{~g} / \mathrm{mile}$ for $\mathrm{HC}$. The WVT cycle produced on average $1.24 \mathrm{~g} / \mathrm{mile}$ for $\mathrm{PM}_{10}, 17.8$ $\mathrm{g} /$ mile for $\mathrm{NO}_{\mathrm{X}}, 9.75 \mathrm{~g} / \mathrm{mile} \mathrm{CO}$, and $1.90 \mathrm{~g} /$ mile for $\mathrm{HC}$. The averages were taken from the entire fleet of heavy-duty vehicles and include all the model years and the weight 
classes. Of the 21 heavy-duty vehicles tested in the study, 15 of the vehicles were in the HHDDV class $(33,000+$ lbs.). The CRC E55/59 Phase I study evaluates vehicles in the HHDDV weight class only.

There is a number of different cycles on which heavy-duty vehicles are tested to determine vehicle emissions production in relation to real work application. The cycles chosen for the CRC E55/59 Phase I study were the AC50/80, the UDDS, and the HHDDT. Since the HHDDT is a fairly new cycle that contains four modes setup to represent idle, creep, transient, and cruise modes, it is important to see how it relates as far as emissions production to other cycles [22]. The AC50/80 is a relatively short test with two ramps and two cruises at 50 and $80 \mathrm{Km} / \mathrm{h}$ respectively. 


\section{Experimental Setup}

In 1991, WVU and the United States Department of Energy (USDOE) developed a transportable chassis dynamometer testing facility that was capable of testing heavyduty vehicles operating on various types of fuels and at various test weights. At the time of development, there was a limited supply of emissions data on heavy-duty chassis tested vehicles. After building one chassis dynamometer transportable laboratory, the interest in heavy-duty vehicle emissions data exceeded the capability of one transportable chassis dynamometer and a second laboratory was constructed. The second laboratory was used for the CRC E55/59 Phase I study.

The TransLab arrives on site with four vehicles. The chassis dynamometer is transported by a tractor trailer truck and the testbed has detachable rear wheels so that the bed of the trailer can be lowered to a height of 13 inches off the ground from the top of the deck. There are four posts with hydraulic cylinders that allow the test bed to be lowered. In Figure 1 the chassis dynamometer has already been delivered to the test site and the four hydraulic legs were dropped to support the test bed and allow the vehicle to pull away and the rear wheels to be removed, which are to the right of the chassis dynamometer.

The second vehicle is a straight truck with a flatbed and crane on the back. The straight truck pulls the analytical trailer. The crane is used to unload the flatbed and the testbed, since the deck of the testbed is used as a cargo area during transit. The equipment from the straight truck is setup next to the chassis dynamometer to minimize the distance from the test vehicle's exhaust to the full-scale dilution tunnel mounted in the analytical trailer. The third vehicle carries a transportable workstation trailer needed 
to provide supplies and tools for TransLab support. The fourth vehicle is used to transport the field crew and supplies. If required, the laboratory can operate completely self sufficiently, but house power is desired if available.

\section{Figure 1: Chassis dynamometer with rear wheels removed and being lowered into position for testing.}

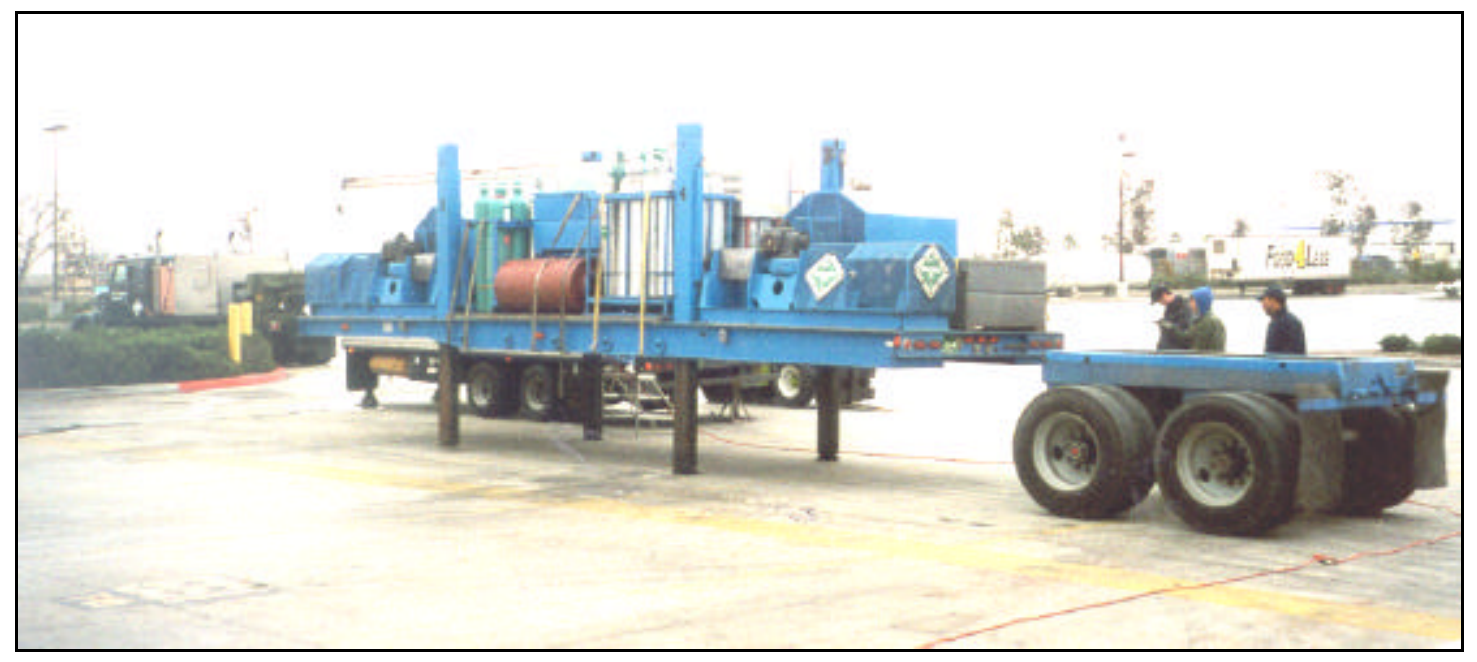

\subsection{Chassis Dynamometer}

The transportable chassis dynamometer was designed in house to test buses, roadtractors and utility trucks between test weights of 30,000 lbs. and 65,000 lbs. The TransLab is able to accommodate tire diameter sizes between 35.1 and 46.4 inches, but is capable of testing larger and smaller tire diameters. The chassis dynamometer is capable of testing single and tandem axle vehicles varying in rear axle separation between 49 and 60 in. [19]. The layout of the transportable chassis dynamometer also allows for heavyduty vehicles with widths of up to 108 inches to be tested.

To test a heavy-duty vehicle on the chassis dynamometer, the outer rear wheels (single axle) or outer forward rear wheels (tandem) need to be removed and replaced with a hub adapter. Several hub adapters were available for testing to accommodate the various wheel rim types. The benefit of having hub adapters instead of pulling power 
from the vehicle through the rollers is to reduce slip, between the wheels and the rollers that occurs during testing. If tire slip occurs during the test, the test would be considered invalid. Therefore, to improve testing reliability, power was removed from the vehicle through the hub adapters. Some chassis dynamometers use large diameter rollers to transfer power between the vehicle and the dynamometer. The drums need to have large surface areas to keep the tires cool and to transfer power from the vehicle to the dynamometer. It would be difficult to setup the chassis dynamometer this way because the vehicle would have to be lifted a considerable distance to level the vehicle. Therefore, the TransLab was setup to take power from the wheels through a hub adopter connected to the flywheels and power absorbers.

The heavy-duty vehicle was placed on the testbed and allowed to rest on the rollers. The vehicle was then leveled and chained down to the testbed to prevent the vehicle from leaving the rollers. An illustration of the vehicle on the testbed and the hub adapter connected are presented in Figure 2. 
Figure 2: The vehicle's outside rear wheel was removed and replaced with a hub adapter.

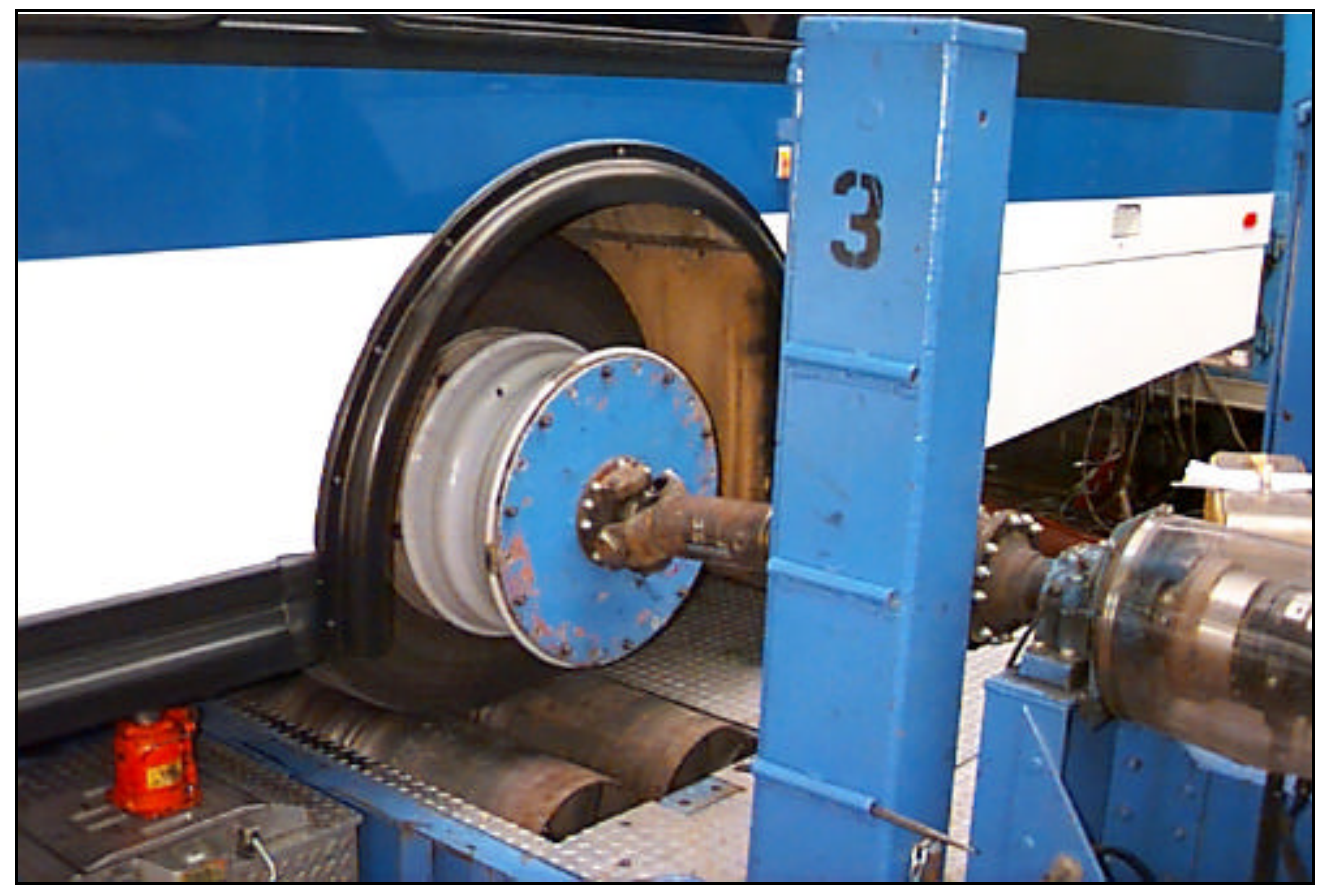

The Transportable chassis dynamometer is symmetrical on both sides of the test vehicle. Power is transferred through the hub adapter and drive shaft to the flywheels and power absorber. The drive shafts pass through in-line speed and torque transducers that are capable of measuring up to 200,000 in-lbs. (Lebow model 1241-118). The power is transferred through the torque cell into a Mack differential rated to 40,000 lbs. The Mack differentials powering the flywheels have a reduction ratio of $3.65: 1$ and increases the speed to the flywheels. The power is also delivered through the Mack differentials into an inline transmissions to power the Mustang air-cooled eddy current power absorbers and has a ratio of 3:1 [1]. Figure 3 illustrates the layout of the transportable chassis dynamometer. 
Figure 3: Layout of the Transportable Chassis Dynamometer flatbed.

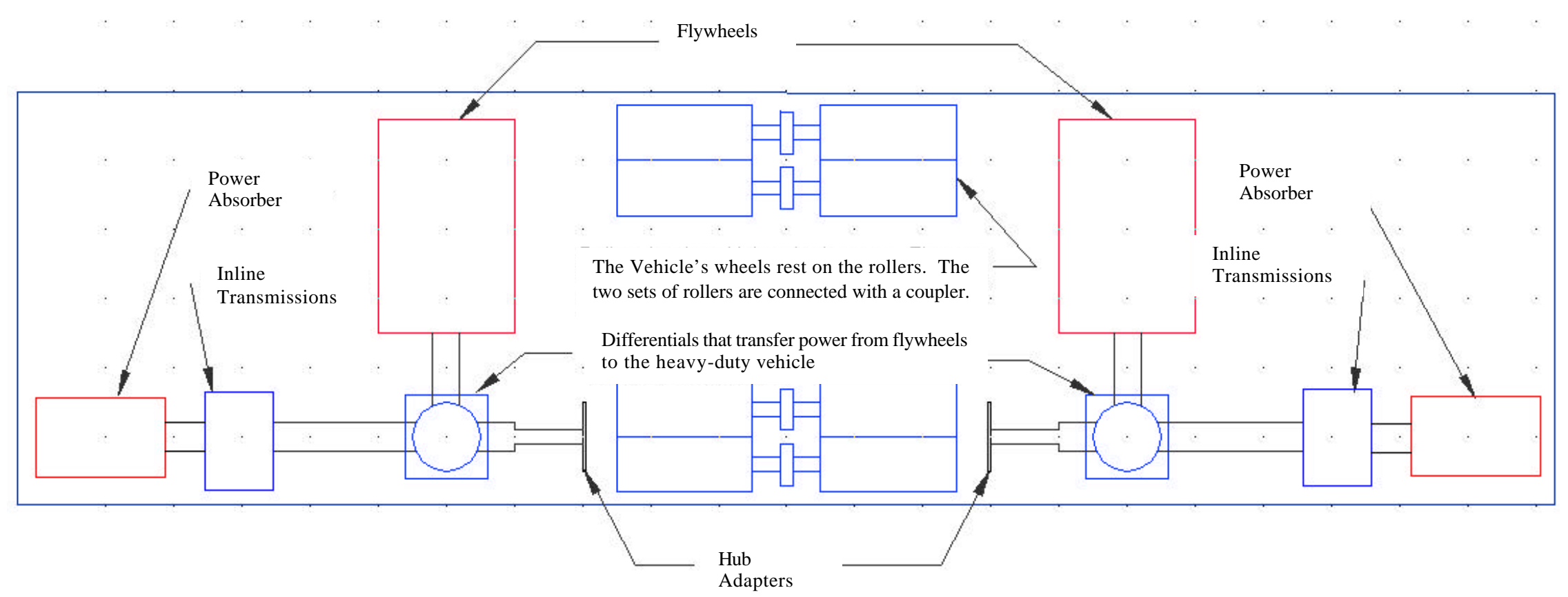


The inertia flywheels on the testbed are needed to simulate the test weight of the test vehicle. The flywheels contain 3 locked in inertia disks and 6 unlocked inertia disks. The locked flywheels also know as "drivers" are connected to the unlocked flywheels to create multiple combinations of test weights from 30,000 lbs. to $65,000 \mathrm{lbs}$., in increments of $250 \mathrm{lbs}$. approximately [19]. The flywheels are attached to the locked inertia disk through connector plates. If the flywheel is not needed, it is connected to the outer protective frame to keep it from spinning during testing. The eight inertia flywheels have a center bearing around the driveshaft that allows the driveshaft to spin freely if the inertia flywheel is disengaged.

The two power absorbers on the transportable chassis dynamometer were Mustang, model CC300. The Mustang power absorbers were air-cooled eddy current types capable of absorbing $225 \mathrm{~kW}$ continuously and $750 \mathrm{~kW}$ peak [1]. The load at any specific speed is controlled by direct current to the coils while the energy is dissipated in the disk rotors [1]. The Mustang eddy current power absorber is controlled by a Dyne Systems, Dyn-Loc controller. The Mustang eddy current power absorbers are needed to simulate the rolling resistance of the tires and wind drag on the test vehicle.

When a test is performed on a heavy-duty vehicle the driver controls the test vehicle's speed. The losses of the laboratory along with the wind and tire bsses of the test vehicle are based off of the test vehicle's speed. The measured torque is compared to the desired torque and the current sent to the power absorbers is adjusted. Gautam et al. [1] stated, "the time constant was determined to be 0.4 seconds, which is suitable for transient operation such as in the UDDS". 


\subsection{Analytical Trailer}

The West Virginia University Analytical Trailer houses the controls, the analyzer bench, dilution tunnel, particulate filter environmental chamber and weighing station. The trailer is setup next to the exhaust of the test vehicle. It is suggested in the Code of Federal Regulations, Title 40, Part 86, Subpart N [20], that the pipe attached to the exhaust and the full-scale dilution tunnel have a minimal number of bends and distance between the full-scale dilution tunnel and the exhaust pipe. The Code of Federal Regulations, Title 40, Part 86, Subpart N also suggests that the duct be constructed of smooth wall pipe so as not to affect the exhaust sample entering the full-scale dilution tunnel [20].

\subsection{1 $\quad$ Full Scale Dilution Tunnel}

West Virginia University designed their full-scale dilution tunnel based on the Code of Federal Regulations, Title 40, Part 86, Subpart N [20]. The full-scale dilution tunnel was made of stainless steel, which is a non-corrosive, electrically conductive material that will not react with the corrosive exhaust from the test vehicle. The fullscale dilution tunnel has an opening on the inlet that allows the exhaust pipe to rest in the middle of the main dilution tunnel and for ambient air to enter and mix with the exhaust stream. The diameter of the main dilution tunnel was 18 inches and the sampling plane was 10 diameters downstream from the entrance to ensure adequate mixing of the exhaust sample with ambient air. It should be noted that the main tunnel temperature could not be maintained in the same manner presented in the Code of Federal Regulation because the testing was done outside and the laboratory can not control the ambient temperature and humidity. The exhaust stream and ambient air are pulled through the 
system by a critical flow venturi-constant volume system (CFV-CVS). The CFV-CVS system chokes the flow through the venturi allowing for a constant flow rate through the main tunnel. The dilution tunnel is operated at sonic flow and the pressure and temperature are measured to determine the flowrate of the tunnel. The primary dilution tunnel was designed to test several different heavy-duty vehicles with several different exhaust flow rates, so it was important to be able to change the flow rate of the primary dilution tunnel. The primary dilution tunnel flow rates are 1000, 1,500, 2,000, 2,500 and 3,000 CFM, nominally. The reason for having several different flow rates involves discrete analyzer ranges, discrete calibration gas concentration, and the PM filter face temperature. If the analyzer is over-ranged and cannot be set to a higher range, the increase in flow rate of the primary dilution tunnel will increase the dilution of the sample and allow for the analyzer to span properly. It is also important to keep the particulate filter at a maximum of $125^{\circ} \mathrm{F}$ in the secondary dilution tunnel. The main dilution tunnel is fitted with a HEPA filter at the intake to remove ambient PM in the dilution ambient air during testing.

\subsubsection{Secondary Dilution Tunnel}

The Code of Federal Regulations, Title 40, Part 86, Subpart N allows for a single dilution tunnel or double dilution tunnel to measure particulate matter (PM) [20]. The single dilution tunnel setup requires that enough ambient air mixes with the exhaust air to drop the sample temperature at the sample plane in the tunnel to $125^{\circ} \mathrm{F}$ or below in order to maintain the PM filter face temperature below $125^{\circ} \mathrm{F}$. The double dilution tunnel allows for a secondary dilution tunnel, with an inlet at the sample plane in the main dilution tunnel, to be added. The double dilution tunnel adds more air to the sample 
taken from the primary dilution tunnel to allow for cooling of the sample before it reaches the primary particulate filter. The benefit of the double dilution tunnel is that it allows the main dilution tunnel temperature to operate at a temperature above $125{ }^{\circ} \mathrm{F}$ without effecting the PM filters. The other benefit of the secondary dilution tunnel is the control over the flow rate in the secondary tunnel, which is accomplished by a mass flow controller. The double dilution setup was preferred because the entire sample passing through the dilution tunnel did not have to meet the particulate filter temperature requirements. It also allowed for two different flow rates in the system to more easily measure gaseous and particulate emissions. The double dilution tunnel is setup to allow more ambient air to mix with the main dilution tunnel sample, but this method was not used during the CRC E55/59 Phase I study, because of the effect the added air has on temperature. The secondary dilution tunnels primary function is to allow for increase cooling of the main dilution tunnel sample. West Virginia University opted to use the double dilution system for their laboratory. The secondary dilution tunnel measures 3 inches in diameter and 36 inches in length. At the end of the tunnel is a primary and secondary filter that collects a PM sample during the test. The secondary dilution tunnel allows for an adequate cooling and mixing of the sample from the primary dilution tunnel. The secondary dilution tunnel is made of stainless steel so as not to react with the corrosive exhaust flows.

\subsubsection{Particulate Matter Measurement}

The secondary dilution tunnel pulls a sample from the sampling plane in the main dilution tunnel and then passes through a dual filter holder. The filters for testing are stored before and after testing in an environmental chamber that maintains a temperature 
within $+/-10^{\circ} \mathrm{F}$ of a set point between $68^{\circ} \mathrm{F}$ and $86^{\circ} \mathrm{F}$ [20]. The relative humidity in the environmental chamber is kept within $+/-10 \%$ of a set point between 30 and $70 \%$ relative humidity [20]. The TransLab has a temperature set point of $70^{\circ} \mathrm{F}$ and $50 \%$ relative humidity. The filters are placed in petri dishes for at least 1 hour, but no more than 80 hours in advance of testing to ensure the samples are weighed at the control temperature and relative humidity [20]. After the test, the filters are placed back into the petri dish and conditioned for 1 hour, but no more than 80 hours before being weighed to determine the amount of PM from the tests [20]. The petri dishes allow for the exchange of temperature and relative humidity, but protect against filter loading that could occur if left exposed to ambient air for a period of time after testing.

The particulate filters were weighed on a Cahn32 microbalance, that consisted of a remote weighing station, that housed a vibration isolation chamber, and a digital readout box. The Cahn32 microbalance is calibrated daily and two reference filters are left in the environmental chamber and measured daily to make sure the environmental chamber is operating properly.

PM was measured for every test performed during the CRC E55/59 Phase I study and at least one background was performed daily to measure the amount of PM in the ambient air. In the CRC E55/59 Phase I study used the UDDS test for backgrounds and the test was performed similarly to a regular test except for the vehicle being turned off. The background test measures the PM emissions in the air and then subtracts it from the regular tests to remove the ambient air PM emissions from the test. The background filter and test filters were weighted and entered into the data reduction program. The 
equation for calculating for the PM mass per test run is presented in Equation 1 with correction for background.

Equation 1: $\quad P_{\text {mass }}=\left(V_{m i x}+V_{s f}\right) *\left[\frac{P_{f}}{V_{s f}}-\left(\left(\frac{P_{b f}}{V_{b f}}\right) *[1-(1 / D F)]\right)\right]$

$\mathrm{P}_{\text {mass }}=\quad$ Mass of particulate emitted per test phase [grams per test phase]

$\mathrm{DF}=\quad$ Dilution factor $=13.4 /\left[\mathrm{CO}_{2 \mathrm{e}}+\left(\mathrm{HC}_{\mathrm{e}}+\mathrm{CO}_{\mathrm{e}}\right)^{*} 10^{-4}\right]$ for petroleum fuel, see Equation 5 for the definition of $\mathrm{CO}_{2 \mathrm{e}}, \mathrm{HC}_{\mathrm{e}}$ and $\mathrm{CO}_{\mathrm{e}}$

$\mathrm{V}_{\text {mix }}=\quad$ Total dilute exhaust volume corrected to standard conditions $\left(273^{\circ} \mathrm{K}, 101.3\right.$ $\mathrm{kPa})\left[\mathrm{m}^{3}\right.$ per test phase at standard conditions]

$\mathrm{V}_{\mathrm{sf}}=\quad$ Total volume of sample removed from the primary dilution tunnel at standard conditions $\left[\mathrm{m}^{3}\right]$

$\mathrm{P}_{\mathrm{f}}=\quad$ Mass of particulate on the sample filters [grams per test phase]

$\mathrm{P}_{\mathrm{bf}}=\quad$ Net weight of particulate on the background particulate filters [grams]

$\mathrm{V}_{\mathrm{bf}}=\quad$ Actual volume of primary dilution air sampled during the background test at standard conditions $\left[\mathrm{m}^{3}\right]$

\subsection{Bag Sampling and Background tests}

A background bag sample is taken during every test performed to measure the gaseous emission in the ambient air while the test is in operation. The background bag is a continuous flow of ambient air and represents the average ambient emissions while testing. Two background tests are performed throughout the day to measure the PM in the air. The background test length is on average around 30 minutes, but some studies are requiring longer backgrounds to obtain a better background average sample.

A dilute bag from the dilution tunnel was also gathered during vehicle tests to determine the average emissions produced. Since continuous data are taken during the test, the sample bag serves as a good reference to check the continuous data. At the conclusion of the test the dilute bag and background bag are pumped through the analyzers and the average gaseous emissions are recorded. 


\subsubsection{Gaseous Emissions Analyzers}

The Code of Federal Regulations, Title 40, Part 86, Subpart N required that the gaseous sampling probes be placed 10 tunnel diameters downstream from the mixing chamber 20]. It also required that the sampling probes be placed in a pattern that would not cause eddies or ripples in the air stream at the sampling plane [20]. Therefore the probes were placed in a pattern in the sampling plane that would allow for continuous sampling for all the analyzers. Three heat probe lines were needed for the measurement of gaseous emissions. The first heated probe and sampling line was used to sample hydrocarbon emissions (HC). The second probe and sample line was for measuring oxides of nitrogen. The third probe and sample line sent samples to the two carbon monoxide $(\mathrm{CO})$ analyzers and carbon dioxide $\left(\mathrm{CO}_{2}\right)$ analyzer.

\subsubsection{Carbon Monoxide Analyzers}

A "low" CO and "high" $\mathrm{CO}$ analyzer was used in the laboratory setup to measure different concentration levels of $\mathrm{CO}$ emissions. Diesel engines, on average, tend to produce low levels of $\mathrm{CO}$ emissions during operation. During testing, the $\mathrm{CO}$ emissions levels tend to be low for most of the test with a few "spikes" of high $\mathrm{CO}$ level throughout. If there are spikes in the low $\mathrm{CO}$ continuous data that over-range the analyzer, the low CO continuous data can not be used. The default in the Data Analysis Program is to use the low $\mathrm{CO}$ continuous data and if it can not be used than the low $\mathrm{CO}$ dilution bag data is used in its place. Very rarely does the low $\mathrm{CO}$ dilution bag data overrange, but in the event that it does, the high $\mathrm{CO}$ continuous data is used and if the high $\mathrm{CO}$ continuous data over-ranges, the high $\mathrm{CO}$ bag data is used. For most of the heavy- 
duty vehicles in the CRC E55/59 Phase I study used the low CO continuous data for determination of $\mathrm{CO}$ emissions.

The low CO analyzer was a Horiba AIA-210 NDIR analyzer. The low CO analyzer has ranges of $0-25,0-50,0-100,0-200 \mathrm{ppm}$ 27]. An NDIR has an infrared source that sends a beam of infrared light through a chopper that breaks the light up into pulses and then sends it through two separate tubes [25]. One is a sealed tube containing the reference $\mathrm{CO}$ that the analyzer was calibrated to and the other tube contains a continuous flow of sample from the dilution tunnel 25]. The reference tube is sealed and calibrated to specific infrared wavelengths absorbed by $\mathrm{CO}[25]$. The $\mathrm{CO}$ absorbs he infrared light at certain frequencies and the detector captures any infrared light left over [25]. The luft detector continuously measures the difference in the amount of infrared energy absorbed within each of the two cells 25]. The detector collects the infrared light on two different sides of a membrane in the detector 25]. The different concentrations of infrared light cause the membrane in the detector cell to vibrate, and an electric output signal is generated. Since moisture can also absorb infrared light, a continuous dry sample must pass through the analyzer for accurate measurement [25]. The sample line is kept at $225^{\circ} \mathrm{F}$ and the sample passes through a heated filter to remove any particles in the sample. A Hankinson refrigerator/dryer is also inline to remove any water that may have entered the sample line.

The Rosemount Analytical Model $880 \mathrm{~A}$ is a non-dispersive infrared analyzer that was used to measure high $\mathrm{CO}$ emissions. Ranges for the high $\mathrm{CO}$ analyzer was 01,000 ppm and 0-5,000 ppm. The high CO analyzer worked on the same principles presented for the low $\mathrm{CO}$ analyzer. 


\subsubsection{Carbon Dioxide Analyzer}

The Carbon Dioxide $\left(\mathrm{CO}_{2}\right)$ analyzer was also a Horiba AIA-210 NDIR analyzer. This analyzer had been equipped from the manufacturer for detection of $\mathrm{CO}_{2}$ by having the reference gas sealed under conditions such that $\mathrm{CO}_{2}$ absorption was detected and measured. Detection range for this analyzer was $0-1 \%$ volume to $0-20 \%$ volume [27].

\subsubsection{Hydrocarbon Analyzer}

The Rosemount Analytical Inc. Model 402 hydrocarbon analyzer measured continuous hydrocarbon emissions during testing. The hydrocarbon analyzer had a range from 1 to 5,000 ppm and produced a full-scale linear output of 01 volt. The analyzer allowed a sample gas to pass through a flame sustained by regulated flows of a fuel gas (40\% hydrogen, $60 \%$ helium) and zero air. The sample interacts with the flame and undergoes a complex ionization that produces electrons and positively charged ions. Polarized electrodes collect these ions, causing a change in current. The change in current represents the amount of carbon atoms in the sample and the value is continuously recorded [29].

The Rosemount Analytical Inc. Model 402 hydrocarbon analyzer has a glass fiber filter that removes particulate matter from the sample stream and is changed out daily to maintain an acceptable sample flow rate across the flame. A zero air generator and $40 \%$ hydrogen and $60 \%$ helium gas bottle maintains a continuous reference flame. The analyzer is also calibrated every time the $60 \% / 40 \%$ bottle is reattached to the analyzer whether it is due to a location change or the bottle needs to be replaced with a new bottle. Also the $\mathrm{HC}$ sample path must be maintained above $180{ }^{\circ} \mathrm{C}\left(356^{\circ} \mathrm{F}\right)$ and shall not exceed 
$230{ }^{\circ} \mathrm{C}\left(446^{\circ} \mathrm{F}\right)$ in order to keep the hydrocarbons from depositing on the surface of the sample line. The TransLab maintains a sample line temperature of $375^{\circ} \mathrm{F}$.

\subsubsection{Oxides of Nitrogen Analyzers}

Two Rosemount Analytical Inc. Model 955 analyzers were used to measure $\mathrm{NO}_{\mathrm{X}}$ emissions continuously during testing. Model 955 has the capability of measuring NO and $\mathrm{NO}_{\mathrm{X}}$ in the sample stream. Ranges for the first $\mathrm{NO}_{\mathrm{X}}$ analyzer $\left(\mathrm{NO}_{\mathrm{X}} 1\right)$ and the second $\mathrm{NO}_{\mathrm{X}}$ analyzer $\left(\mathrm{NO}_{\mathbf{X}} 2\right)$ Model 955 analyzers are $0-10,0-25,0-100,0-250,0-1000,0$ 2,500 , and $0-10,000 \mathrm{ppm}$. The sample line from the probe to the analyzers was maintained at $225{ }^{\circ} \mathrm{F}$ to eliminate condensation formation in the sample line. The sample also passed through a heated filter to remove any particulate matter. The process by which the analyzers measured $\mathrm{NO}$ and $\mathrm{NO}_{\mathrm{X}}$ employs the chemiluminescent method. The analyzers starts out by producing ozone from ambient air and exposing it to ultraviolet radiation. Equation 2 shows the chemical equation for the conversion of oxygen to ozone. The $\mathrm{h}$ in the equation represents Plank's constant and $v$ is the frequency [Hertz]. The $\mathrm{h}$ and $v$ are the energy need to convert the oxygen to ozone.

\section{Equation 2: $\quad 3 \mathrm{O}_{2} \stackrel{h \mathrm{v}}{\longrightarrow} 2 \mathrm{O}_{3}$}

In order to determine the amount of NO present in the sample it has to react with the ozone $\left(\mathrm{O}_{3}\right)$ to produce $\mathrm{NO}_{2}$ and $\mathrm{O}_{2}$. About $10 \%$ of the $\mathrm{NO}_{2}$ is in an excited state and returns to an unexcited state through the release of photons. Equation 2 and Equation 3 show the chemical equation and the removal of photons from the $\mathrm{NO}_{2}$. 
Equation 3: $\quad \mathrm{NO}+\mathrm{O}_{3} \rightarrow \mathrm{NO}_{2}^{*}+\mathrm{O}_{2}$

Equation 4: $\quad \mathrm{NO}_{2}^{*} \rightarrow \mathrm{NO}_{2}+h \mathrm{v}$

The analyzer is also capable of measuring $\mathrm{NO}_{\mathrm{X}}$ and uses the same process as the $\mathrm{NO}$ method with one extra step. The $\mathrm{NO}_{2}$ is converted into $\mathrm{NO}$ and mixed with the $\mathrm{NO}$ already present in the sample. The photons emitted from the excited $\mathrm{NO}_{2}$ are sent through a photomultiplier tube and then an amplifier to determine the concentration of $\mathrm{NO}_{\mathrm{X}}$ present in the sample. The signal is then sent to the data acquisition computer for recording. During the CRC E55/59 Phase I study both analyzers were set to $\mathrm{NO}_{\mathrm{X}}$ mode.

\subsubsection{Gaseous Emissions Calculations}

The emissions of $\mathrm{NO}_{\mathrm{X}}, \mathrm{HC}, \mathrm{CO}$, and $\mathrm{CO}_{2}$ are measured based on the regulations found in the Code of Federal Regulations, Title 40, Part 86, Subpart N [20]. Equation 5 presents the mass calculation for $\mathrm{HC}$ emissions and does not require humidity correction. A similar equation to Equation 5 is also used for the calculation of $\mathrm{CO}$ and $\mathrm{CO}_{2}$ emissions.

\section{Equation 5:}

$$
\begin{aligned}
& H C_{\text {mass }}=\sum_{i=1}^{n}\left[\frac{\left(H C_{e}\right)_{i}}{10^{6}} *\left(V_{\text {mix }}\right)_{i} *\left(\rho_{H C}\right) * \Delta T\right] \\
& -\frac{H C_{d}}{10^{6}}\left(1-\frac{1}{D F}\right) * V_{\text {mix }} * \rho_{H C}
\end{aligned}
$$

$H C_{\text {mass }}=$ Hydrocarbon emissions in [grams per test phase]

$H C_{e}=$ Instantaneous concentration of hydrocarbons [ppm carbon equivalent, for $\mathrm{CO}, \mathrm{NO}_{\mathrm{X}}$ and $\left.\mathrm{CO}_{2} \mathrm{ppm}\right]$

$\rho_{H C}=\quad$ Density of hydrocarbons $\left[\mathrm{g} / \mathrm{ft}^{3}\right.$ or $\left.\mathrm{kg} / \mathrm{m}^{3}\right]$

$\Delta T=\quad$ Change in time [sec]

$H C_{d}=\quad$ Concentration of hydrocarbons in dilution air as measured by the FID [ppm carbon equivalent, for $\mathrm{CO}, \mathrm{NO}_{\mathrm{X}}$ and $\left.\mathrm{CO}_{2} \mathrm{ppm}\right]$

$D F=\quad$ Dilution factor $=13.4 /\left[\mathrm{CO}_{2 \mathrm{e}}+\left(\mathrm{HC}_{\mathrm{e}}+\mathrm{CO}_{\mathrm{e}}\right)^{*} 10^{-4}\right]$ for petroleum fuel 
$V_{\text {mix }}=\quad$ Total dilute exhaust volume corrected to standard conditions $\left[\mathrm{m}^{3}\right]$

$\left(V_{\text {mix }}\right)_{i}=$ Instantaneous dilute exhaust volume corrected to standard conditions $\left[\mathrm{m}^{3}\right]$

$\mathrm{i}=\quad$ Data point index. Total number of data points.

Equation 6 is used to determine the mass of $\mathrm{NO}_{\mathrm{X}}$ during the test. The calculation of $\mathrm{NO}_{\mathrm{X}}$

is similar to the calculation of $\mathrm{CO}, \mathrm{CO}_{2}$ and $\mathrm{HC}$ except for the correction of humidity.

The correction for humidity is Equation 7.

\section{Equation 6:}

$$
\begin{aligned}
& N O_{X \text { mass }}=K_{H} * \sum_{i=1}^{n}\left[\frac{\left(N O x_{e}\right)_{i}}{10^{6}} *\left(V_{\text {mix }}\right)_{i} *\left(\rho_{N O_{2}}\right) * \Delta T\right] \\
& -K_{H} * \frac{N O x_{d}}{10^{6}}\left(1-\frac{1}{D F}\right) * V_{\text {mix }} * \rho_{N O_{2}}
\end{aligned}
$$

\section{Equation 7:}

$$
K_{H}=\frac{1}{1-.0026(H-75)}
$$

$K_{H}=\quad$ Humidity correction factor for diesel fueled vehicles

$H=\quad$ Absolute humidity of the engine intake air [grams of water per kilogram of dry air]

\subsection{Controls and Data Acquisition}

The data acquisition computer manages the controls for the West Virginia University TransLab. Two monitors were connected to the data acquisition computer; one in the test vehicle to display the real time visual speed versus time plot that the driver was to follow during the test and the other monitor was in the analytical trailer for the engineer to oversee the testing. The engineer was able to calibrate the analyzers and check the laboratory for any problems with the test equipment through the data acquisition computer. The control and data acquisition hardware consisted of Dyne Systems Co. Dyn-Loc IV digital dynamometer controllers, two RTI-815 boards, and Analog Devices 3B signal conditioning modules. The Dyn-Loc IV digital dynamometer 
controllers were connected to the data acquisition computer to allow continuous closed loop feedback for load control to simulate tire friction and aerodynamic losses.

The signals from the sensors and analyzers measure continuous data and were sent through Analog Devices 3B signal conditioning modules. The signals are then sent through two RTI- 815 boards. Once the signals pass through the RTI- 815 boards, they are logged in the data acquisition computer.

At the end of the test, the data are sent to a separate computer that contains the data reduction program that produces the averages for the test runs and continuous data for analysis and comparisons. 


\section{Test Plan and Procedure}

The goal of CRC E55/59 Phase I study was to gather emissions on several heavy heavy-duty diesel trucks operating in the state of California. Therefore a survey of all of the heavy heavy-duty trucks in the state of California needed to be generated in order to represent the types of heavy-duty vehicles operating on the road. The types of heavy heavy-duty vehicles were limited to vehicles with a GVWR greater than 33,000 lbs. or "full size" single axle tractors since they tend to have a combined GVWR of 52,000 lbs. to $80,000 \mathrm{lbs}$. Since this is a study of all heavy heavy-duty diesel vehicles, all medium heavy-duty vehicles were excluded from the study [21].

The CTA surveyed the types of heavy-duty vehicles on the road, and miles traveled. The CTA survey produced 11,525 heavy-duty diesel engines in the State of California [21]. The CRC and ARB also looked at $\mathrm{NO}_{\mathrm{X}}$ and PM estimated emissions and divided the vehicles up based on emissions regulation years to determine the twenty-five heavy-duty diesel vehicles needed per emissions regulation years for Phase I of the CRC E55/59 study. CTA took into account the engine model year and the engine type in order to determine the heavy-duty vehicles that would most closely represent the types of vehicles selected by CRC. A final list of vehicles was presented to West Virginia University and CTA to determine which vehicles would be selected for the study [21].

The heavy-duty vehicles selected for the CRC E55/59 Phase I study are listed in Table 2. There were 25 vehicles selected for the study to represent a range of model years and a number of different engine companies that represented an average of the vehicles on the road. Over $60 \%$ are Cummins engines since they represent a majority of the engines in trucks on the road. 
Table 2: Information about the twenty-five heavy-duty vehicles in the CRC E55/59 Phase I study. Some of the heavy-duty vehicles in the study have different engine model years from vehicle model years.

\begin{tabular}{|c|c|c|c|c|c|c|c|}
\hline $\begin{array}{l}\text { Vehicle Test } \\
\text { Number }\end{array}$ & $\begin{array}{c}\text { Engine } \\
\text { Model } \\
\text { Year }\end{array}$ & $\begin{array}{c}\text { Vehicle } \\
\text { Model } \\
\text { Year }\end{array}$ & Vehicle Manufacture & Engine Type & GVW & $\begin{array}{c}\text { Odometer } \\
\text { Reading (miles) }\end{array}$ & $\begin{array}{c}\text { Engine } \\
\text { Power } \\
(\mathrm{hp} / \mathrm{kW})\end{array}$ \\
\hline E55CRC-1 & 1994 & 1994 & Freightliner & DDC Series 60 & 52000 & 639105 & $470 / 350$ \\
\hline E55CRC-2 & 1995 & 1995 & Freightliner & Caterpillar 3406B & 50000 & 241843 & $370 / 280$ \\
\hline E55CRC-3 & 1985 & 1985 & International & Cummins NTCC-300 & 32000 & 501586 & $300 / 224$ \\
\hline E55CRC-4 & 2000 & 2000 & Navistar International & Caterpillar C-10 & 52000 & 42362 & $270 / 201$ \\
\hline E55CRC-5 & 2000 & 2000 & Freightliner & Cummins N14-435E1 & 52000 & 166980 & $435 / 324$ \\
\hline E55CRC-6 & 1995 & 1995 & Freightliner & Cummins & 45020 & 689536 & $370 / 280$ \\
\hline E55CRC-7 & 1990 & 1990 & Peterbilt & DDC Series 60 & 50000 & 399224 & $450 / 336$ \\
\hline E55CRC-8 & 1996 & 1996 & Kenworth & Cummins M11-300 & 32000 & 34815898 & $370 / 280$ \\
\hline E55CRC-9 & 1998 & 1998 & Peterbilt & Caterpillar C12 & 48000 & 607968 & $410 / 306$ \\
\hline E55CRC-10 & 1998 & 1998 & Sterling & DDC Series 60 & 52000 & 21631 & $470 / 350$ \\
\hline E55CRC-11 & 2000 & 2000 & Freightliner & Cummins ISM & $\mathrm{N} / \mathrm{A}$ & 117048 & $330 / 246$ \\
\hline E55CRC-12 & 1986 & 1986 & International & Cummins 300 & 32000 & 533377 & $300 / 224$ \\
\hline E55CRC-13 & 1978 & 1978 & Freightliner & Cummins 350 & 63000 & 570546 & $350 / 261$ \\
\hline E55CRC-14 & 1985 & 1986 & International & Cummins LTA10 & 30800 & 565927 & $270 / 201$ \\
\hline E55CRC-15 & 1986 & 1973 & Kenworth & Cummins NTC-350 & 30800 & 340486 & $350 / 261$ \\
\hline E55CRC-16 & 1979 & 1979 & White & Caterpillar 3208 & 30800 & 200000 & $200 / 149$ \\
\hline E55CRC-17 & 1993 & 1993 & Freightliner & Cummins L-10 & 52000 & 733868 & $330 / 246$ \\
\hline E55CRC-18 & 1991 & 1991 & Ford & Cummins L-10 & 32200 & 440456 & $300 / 224$ \\
\hline E55CRC-19 & 1987 & 1987 & International & Cummins L-10 & 30800 & 465061 & $300 / 224$ \\
\hline E55CRC-20 & 1992 & 1992 & Peterbilt & DDC Series 60 & 50000 & 514188 & $450 / 336$ \\
\hline E55CRC-21 & 1990 & 1990 & Freightliner & Caterpillar 3406B & 48000 & 937438 & $400 / 298$ \\
\hline E55CRC-22 & 1993 & 1993 & Ford & Cummins L10-280 & 33000 & 232829 & $280 / 209$ \\
\hline E55CRC-23 & 1983 & 1983 & Peterbilt & Cummins & 50000 & 320885 & $\mathrm{~N} / \mathrm{A}$ \\
\hline E55CRC-24 & 1975 & 1975 & Kenworth & Cummins NTCC-350 & 36000 & 773487 & $350 / 261$ \\
\hline E55CRC-25 & 1983 & 1983 & Freightliner & Cummins & 32560 & 806068 & $\mathrm{~N} / \mathrm{A}$ \\
\hline
\end{tabular}

\subsection{Cycles}

Several schedules were used in this study to evaluate heavy-duty diesel vehicle emissions. The schedules in this study were the Heavy Heavy-Duty Diesel Truck (HHDDT) Schedule, the AC50/80 and the Urban Dynamometer Driving Schedule 
(UDDS) from the Code of Federal Regulations, Title 40, Part 86, Subpart N, Appendix I $[20]$.

\section{2 $\underline{\mathrm{AC50/80}}$}

The AC50/80 is a short test that was developed by Parsons in Australia for inspection and maintenance [21]. The AC50/80 has two ramps and two steady-states at 50 and $80 \mathrm{~km} / \mathrm{h}$. The two ramps in the test allowed the driver to use a maximum acceleration and the two steady-states started when the vehicle reaches 50 and $80 \mathrm{~km} / \mathrm{h}$ respectively. The cycle begins with the driver prompted to start the vehicle along with three horn blasts to inform everyone in the laboratory vicinity that the test is beginning. The driver then starts the vehicle and allows it to idle for 60 seconds (Position 1 in Figure 4). After 60 seconds, data capture commences and the vehicle idles for 10 more seconds (Position 2 in Figure 4). A ramp is drawn on the screen to tell the driver to use a maximum acceleration up to $50 \mathrm{~km} / \mathrm{h}(31.1 \mathrm{mph})$, which is Position 3 . Once the vehicle reaches $48 \mathrm{~km} / \mathrm{h}(30 \mathrm{mph})$, a 60 second (Position 4 in Figure 4) steady state at $50 \mathrm{~km} / \mathrm{hr}$ begins. Since heavy-duty vehicles accelerate at different speeds the 60 second cruise at $50 \mathrm{~km} / \mathrm{h}$ started once the vehicle reached $48 \mathrm{~km} / \mathrm{h}$ during the first ramp. The cruise is then drawn in real time during the test. After 60 seconds, a maximum acceleration to 80 $\mathrm{km} / \mathrm{h}(49.71 \mathrm{mph}$ ) commenced (Position 5 in Figure 4). The $80 \mathrm{~km} / \mathrm{h}$ acceleration was treated the same way as the $50 \mathrm{~km} / \mathrm{h}$ acceleration. When the vehicle reached $78.5 \mathrm{Km} / \mathrm{h}$ (49 $\mathrm{mph}$ ) the second steady state began. The driver then cruised at $80 \mathrm{~km} / \mathrm{h}$ for 80 seconds and the test ended (Position 6 in Figure 4). At position 6, the sampling is turned off and the driver is allowed to coast the heavy-duty vehicle down without having to 
follow a trace. Figure 5 is an actual speed versus time trace of a heavy-duty vehicle tested on the AC50/80 and Table 3 outlines the time format for the AC50/80.

Table 3: AC50/80 Test Methodology.

\begin{tabular}{|l|l|l|}
\hline Path & Description of Operation & Duration \\
\hline \hline$(1-2)$ & Idle. Select low gear. & 10 seconds \\
\hline$(2-3)$ & Rapidly accelerate to $50 \mathrm{kph}(31.1 \mathrm{mph})$. & Vehicle Dependent \\
\hline$(3-4)$ & Maintain $50 \mathrm{kph}(31.1 \mathrm{mph})$. & 60 seconds \\
\hline$(4-5)$ & Rapidly accelerate to $80 \mathrm{kph}(49.7 \mathrm{mph})$. & Vehicle Dependent \\
\hline$(5-6)$ & Maintain $80 \mathrm{kph}(49.7 \mathrm{mph})$. & 80 seconds \\
\hline (6-Stop) & Return vehicle to stop with engine at idle. & Vehicle Dependent \\
\hline
\end{tabular}

Figure 4: Illustration of the AC50/80 test. The $x$-axis has a time scale in seconds and is only an approximation of the test time since the heavy-duty vehicle is allowed to accelerate freely at two ramps in the test.

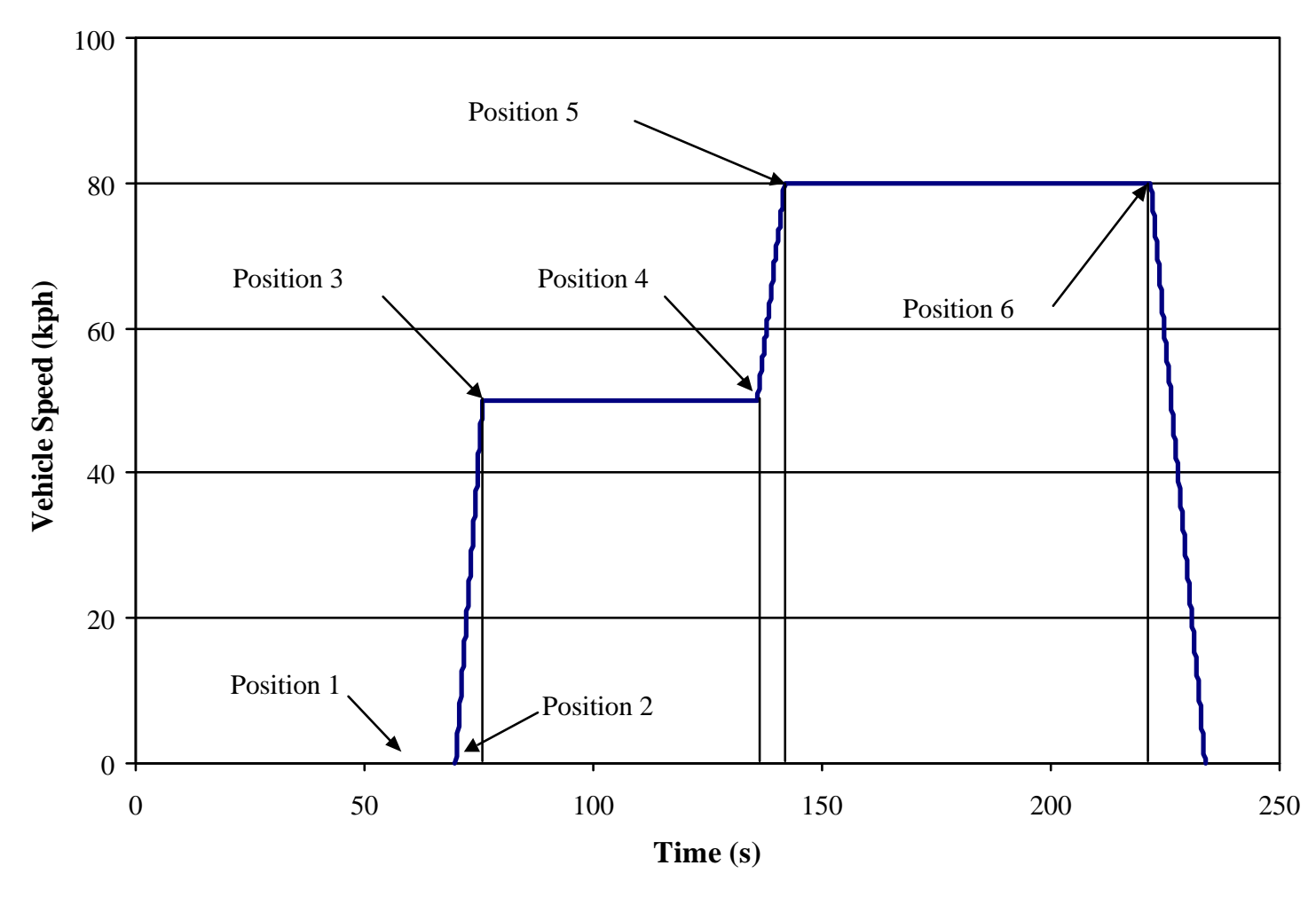


Figure 5: Actual speed vs. time trace for E55CRC- 2. Vehicle 2 is a 1995 Freightliner with a Caterpillar 3406B engine.

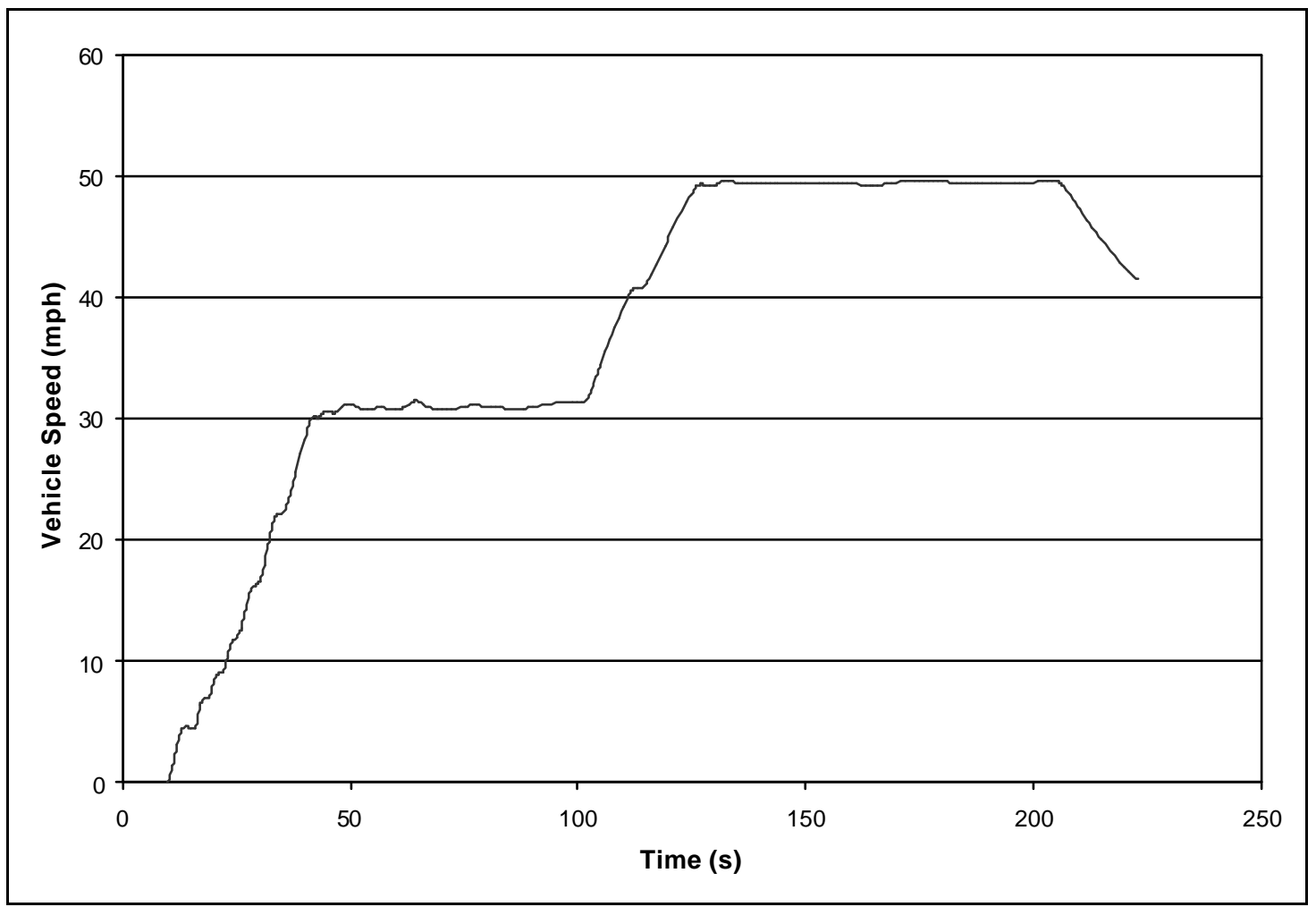

\subsection{Urban Dynamometer Driving Schedule}

The Urban Dynamometer Driving Schedule (UDDS) is a speed versus time cycle. The UDDS is located in the Code of Federal Regulations, Title 40, Part 86, Subpart N, Appendix I, Part (d) [20]. Figure 6 illustrates the UDDS. The target distance for the cycle is 5.54 miles. The maximum speed during the cycle is $58 \mathrm{mph}$ and the vehicle idles for $32.5 \%$ of the test. 
Figure 6: Urban Dynamometer Driving Schedule (UDDS).

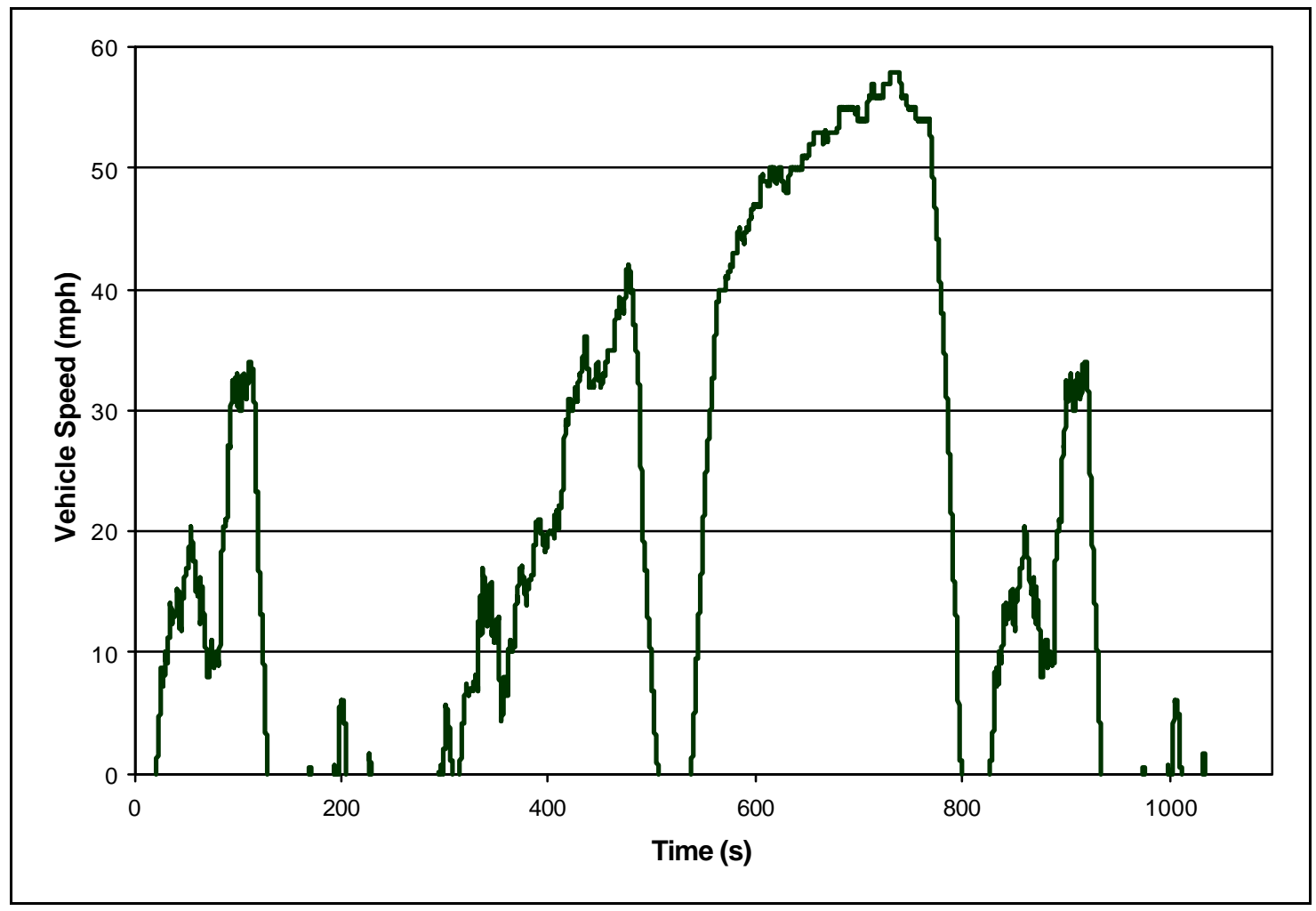

\subsection{Heavy Heavy-Duty Diesel Truck (HHDDT) Schedule}

The Heavy Heavy-Duty Diesel Truck (HHDDT) Schedule is comprised of four modes. The four modes are Idle, Creep, Transient and Cruise. The HHDDT test schedule was developed using real-world driving data collected during two California Air Resources Board (CARB) sponsored heavy-duty vehicle activity studies conducted during 1997-2000 [22]. 140 heavy-duty vehicles were used for data logging. The heavyduty vehicles were equipped with Global Positioning System (GPS) receivers and data loggers. Battelle Memorial Institute, Inc. and Jack Faucett Associates gathered the data from the 140 heavy-duty vehicles in the two activity studies [22]. 


\subsubsection{Idle and Extended Idle Modes}

The Idle Mode is the first mode in the HHDDT Schedule. The Idle Mode starts by turning on the vehicle and starting the test 30 to 60 seconds after the vehicle is running. The Idle Mode is 15 minutes long at idle speed and then after the 15 minutes, the vehicle idles for 30 more seconds and turned off. The Extended Idle Mode follows the same procedure as the Idle Mode. The vehicle is started 30 to 60 seconds before the test begins and then the vehicle idles for 30 minutes, then continues to idle for 30 more seconds before being turned off [22]. The Idle Mode and Extended Idle Mode were both used because there was some concern over how the auxiliary loads would affect the emissions results. The Extended Idle Mode offered a longer sampling time for speciation testing. More information about the Idle Mode is located in the paper by Gautam et al. $[22]$.

\subsubsection{Creep and Extended Creep Modes}

The Creep Mode was developed to represent short trips at low speeds found in the data taken from on-road heavy-duty vehicles. The test was a speed versus time cycle that runs for 253 seconds. The vehicle was turned on after 10 minutes from the Idle Mode and allowed to idle for 30 to 60 seconds prior to the start of the Creep Mode. The vehicle was then exercised through the cycle and once the test was over, the vehicle idled for 30 more seconds and turned off. The Creep Mode has a target distance of 0.124 miles. Information about the Creep Mode is presented in the paper by Gautam et al. [22]. Figure 7 illustrates the Creep Mode. The Creep Mode has a maximum acceleration of 4.7 $\mathrm{mph} / \mathrm{s}$ and a top speed of $8.2 \mathrm{mph}$. The percentage of idle time for the Creep Mode is 44.4\%. The Extended Creep Mode follows the same procedure, but is four times as long. 
The Creep Mode is a fairly short test and their was some concern over the auxiliary loads affecting the emissions results, so an Extended Creep Mode was also used to increase the sampling time of the test. It should also be noted that the Extended Creep Mode was done only for the first thirteen heavy-duty vehicles in the CRC E55/59 Phase I study to provide enough time for speciation testing. See Figure 8 for a graph of the cycle of the Extended Creep Mode. The Extended Creep falls into the same criteria for the Creep Mode as far as the cycle operation, but the test is four Creep modes combined.

Figure 7: The Creep Mode is a 253-second test that has an average speed of 1.80 mph.

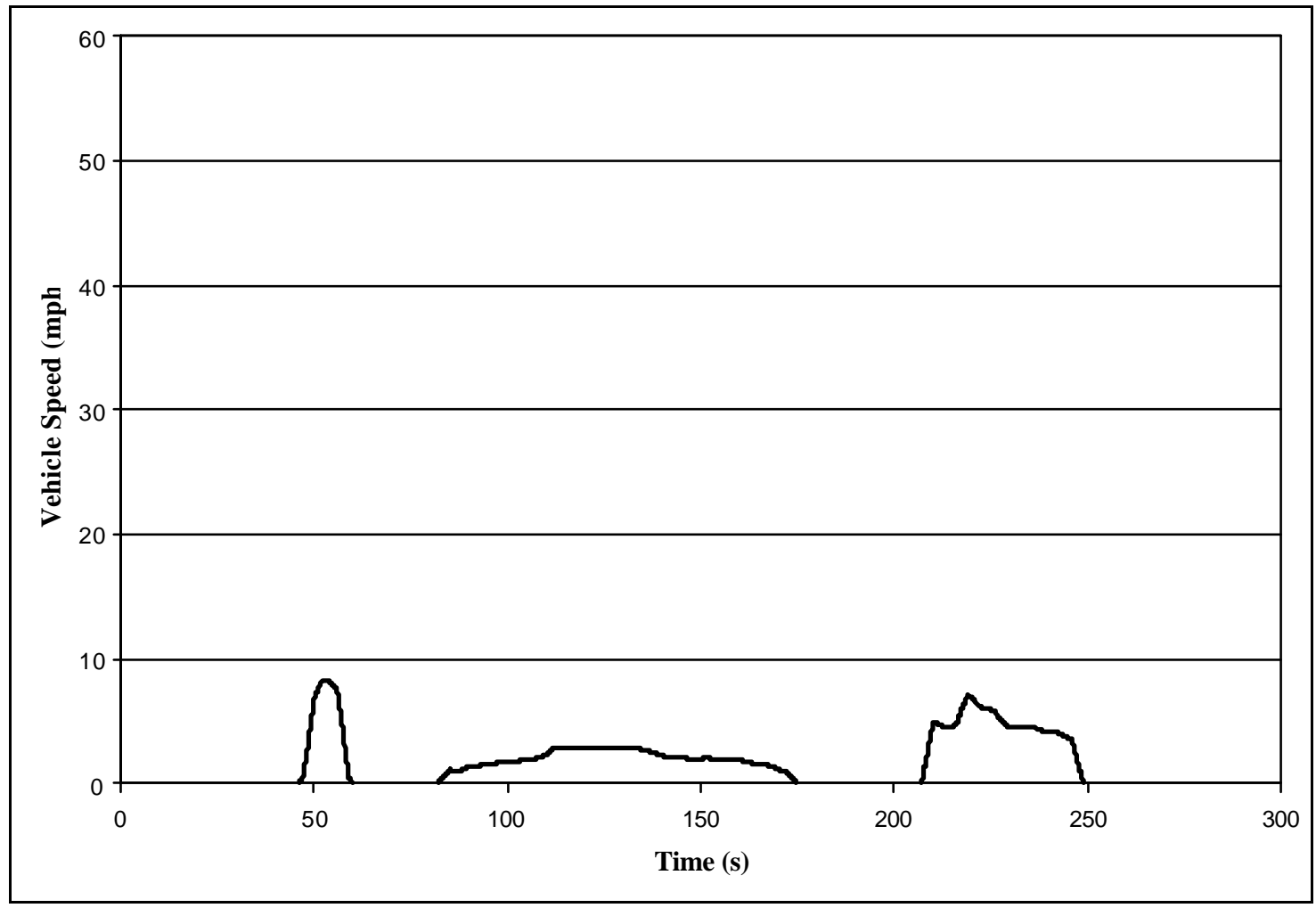


Figure 8: The Extended Creep Mode is four Creep Modes combined for a total of 1012 seconds.

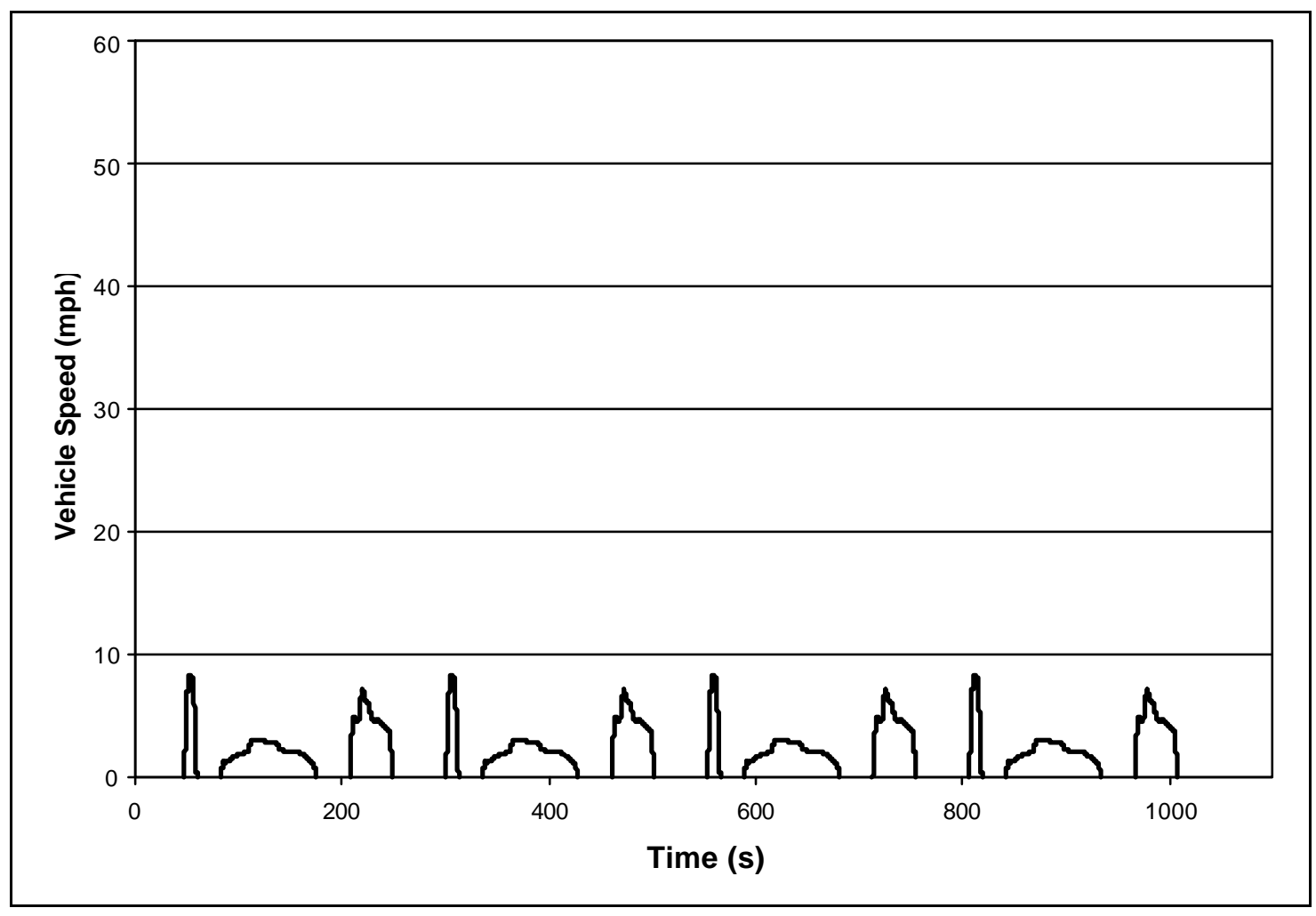

\subsubsection{Transient Mode}

The Transient Mode is the third mode in the HHDDT Schedule. The vehicle was turned on 10 minutes after the Creep Mode and the test was started 30 to 60 seconds after the engine starts. After the test, the vehicle idled for 30 more seconds and then turned off. The target distance for the Transient Mode is 2.85 miles. The maximum speed of the Transient Mode is $47.5 \mathrm{mph}$ with a maximum acceleration of $4.5 \mathrm{mph} / \mathrm{s}$. The vehicle idles for $24.4 \%$ of the test. The Transient Mode is illustrated in Figure 9. More information about the Transient Mode is presented in Gautam et al. [22]. 
Figure 9: The Transient Mode was developed to represent driving in urban areas.

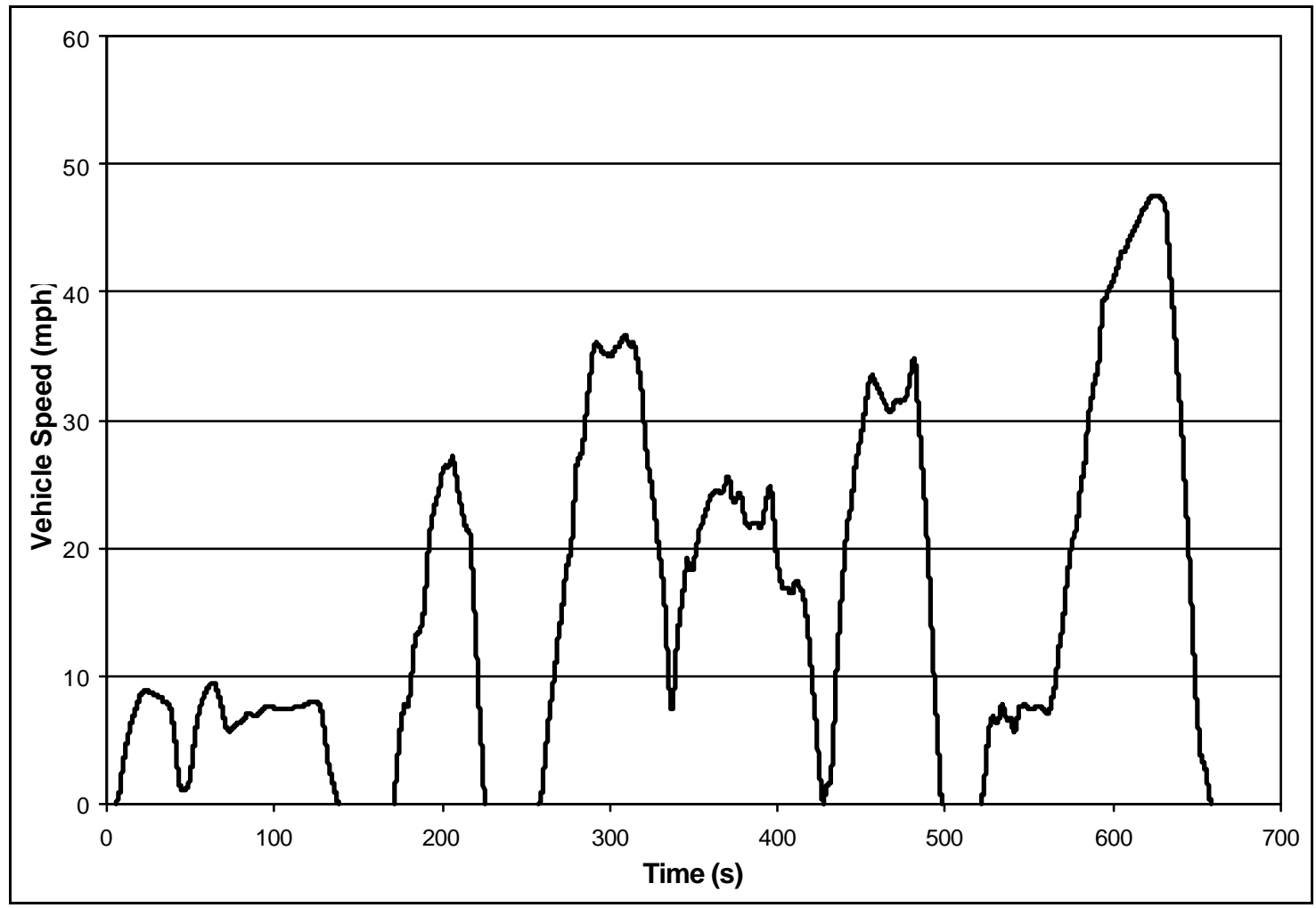

\subsection{4 $\underline{\text { Cruise Mode }}$}

The Cruise Mode is the fourth mode in the Four-Mode HHDDT Schedule. The

Cruise Mode was developed based on heavy-duty vehicle data that represented highway driving for long periods of time. The Cruise Mode is 2,083 seconds long and is a speed versus time cycle. Figure 10 illustrates the Cruise Mode. The target distance for the Cruise Mode is 23.07 miles and the top speed in the cycle is $59.5 \mathrm{mph}$. The Cruise Mode also has a short percent idle of $8.7 \%$ and the maximum acceleration is $4.5 \mathrm{mph} / \mathrm{s}$. The Cruise Mode starts 10 minutes after the vehicle was turned off after the Transient Mode. The vehicle idles between 30 and 60 seconds before the Cruise Mode begins. After the Cruise Mode was completed the vehicle idled for 30 seconds and then turned off. The Cruise Mode is also described in the paper by Gautam et al. [22]. 
Figure 10: The Cruise Mode represents high-speed driving with minimal stops that are often found in more highway styles of driving.

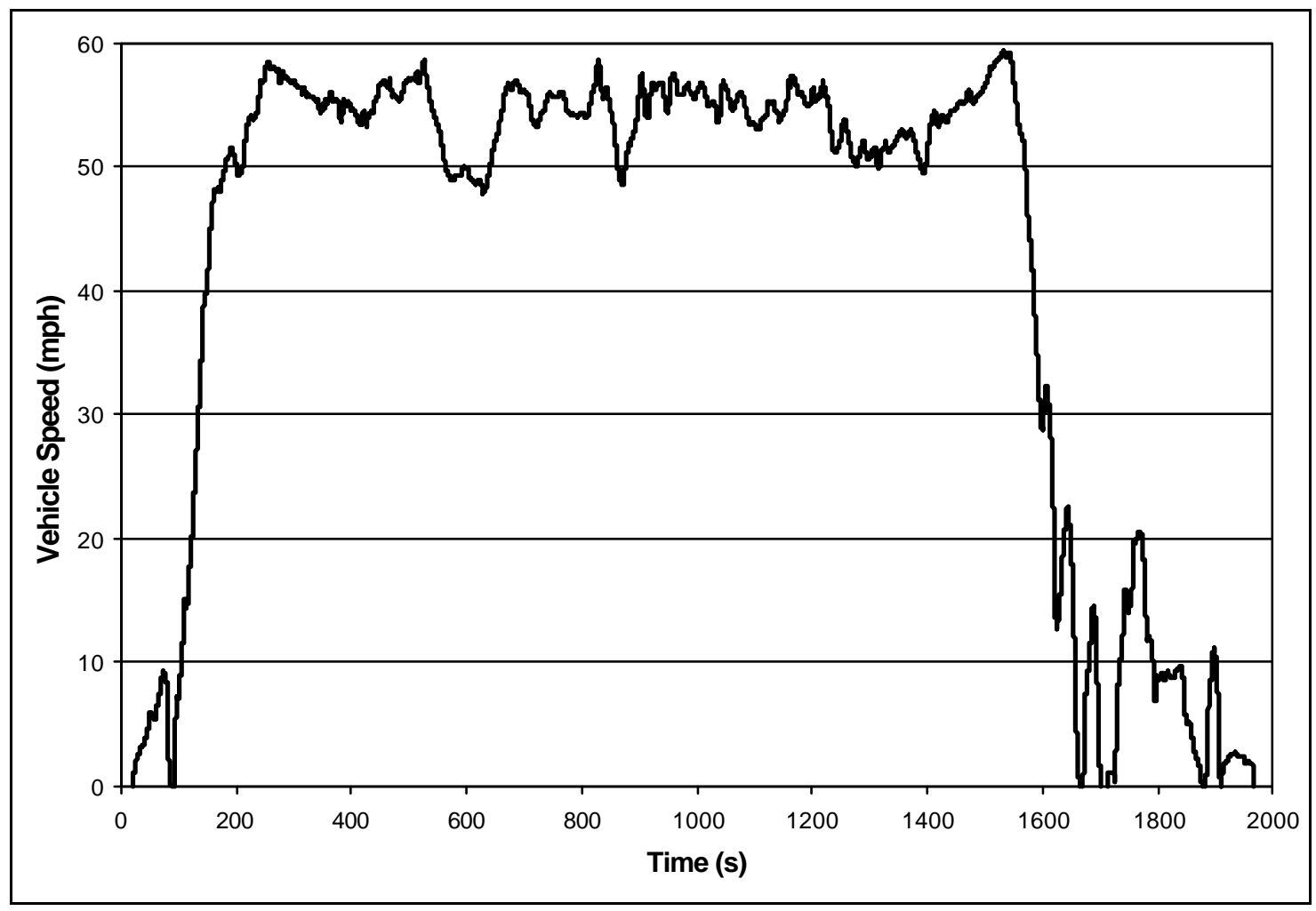

\subsection{Vehicle Testing Procedure}

Once the heavy-duty vehicle was located, it was delivered to the laboratory and the necessary information was taken from the vehicle and recorded. The vehicle was also inspected for safe operation during testing. The engine was inspected for any leaks in the exhaust, low fluid levels and fluid leaks. Once the vehicle information was recorded and the inspection was completed and recorded, the outer rear tires of the front drive axle were removed and replaced with the tire adapters. The vehicle was then connected to the chassis dynamometer laboratory and leveled. The flywheels were set to the proper simulated weight described in Section 4.6, Vehicle Test Weight. The vehicle's exhaust was connected to the dilution tunnel with the smallest distance and number of bends in the pipe between the vehicles exhaust and the dilution tunnel. The pipe was inserted into 
the exhaust tunnel a distance of 12 inches, but no greater than 18 inches to allow for proper mixing of the ambient air with the vehicle exhaust.

The vehicle was then turned on and driven until the laboratory's mechanical components were at operating temperature. The vehicle was then tested on a coast down to determine the losses of the laboratory in order to allow the power absorbers to compensate for the chassis dynamometer losses. The coast down procedure consisted of taking the vehicle up to $55 \mathrm{mph}$ and then placing it into neutral and allowing it to coast down to rest. This allowed the vehicle to be tested accurately based on the road-load equation [24]. Once the vehicle was tested for losses, an actual test was performed to allow the driver to become familiar with how the vehicle should be driven during testing. The Urban Dynamometer Driving Schedule was used as the conditioning cycle. The conditioning run was treated just like a regular test. All of the analyzers are checked for zero and span before the test and particulate filters are prepared for testing. After the test, the background bag and sample bags are measured and the data is reduced to determine if any of the analyzers over-ranged or under-ranged. The over-range criterion is when the analyzer reads a higher ppm value then the bottle connect to the analyzer as the reference gas. The under-range criterion is when the analyzer reads at $1 / 3$ of the otal ppm scale for most of the test. A higher or lower concentration bottle is connected and a calibration of the analyzer is performed, if the resolution of the analyzer was too high or too low. After the vehicle is conditioned and the laboratory is ready for testing, the vehicle can begin testing for the record.

It is important to note that several factors affect heavy-duty vehicle emissions testing and could affect the outcome of the data in the CRC E55/59 Phase I study. Clark 
et al. [16] presented the factors affecting heavy-duty diesel vehicle emissions in a recent paper in the Journal of Air \& Waste Management Association. Factors such as vehicle class and weight, driving cycle, vehicle vocation, fuel type, engine exhaust aftertreatment, vehicle age, the terrain traveled and the engine control strategy can all influence emissions production. In the CRC E55/59 Phase I study, all the heavy-duty vehicles were from the same class and weight, tested on the same cycles, operated on the same fuel and had no aftertreatment devices. The drivers followed the trace as close as possible to ensure consistency in testing and the mileage travel and error limits were placed on the emissions results to ensure the heavy-duty vehicle was tested in the same manner for each test performed.

There is a number of factors that need to be controlled during testing to ensure the testing is valid. The number of heavy-duty vehicles tested in the CRC E55/59 Phase I study represents one of the largest groups of heavy-duty vehicles tested for heavy-duty diesel emissions under the same conditions. All of the heavy-duty vehicles were tested more than once on the same test to limit the run-to-run variability associated with just one test run.

\subsection{Vehicle Test Weights}

Two weights were selected for the HHDDT Schedule. The first test weight was 56,000 lbs. (except for E55CRC-6, which was tested at 45,000 lbs. instead of 56,000 lbs.)

and was labeled as the "Laden" test weight and the second test weight was 30,000 lbs. and was labeled as the "Unladen" test weight. The test weight of 56,000 lbs. was selected for the AC50/80 test and the UDDS. 


\section{Results and Data Analysis}

\subsection{Introduction}

All twenty-five heavy-duty vehicles were tested on the AC50/80, the UDDS, and the HHDDT Schedule. The vehicles were also tested under Laden and Unladen test weights for the HHDDT Schedule. $\mathrm{HC}, \mathrm{CO}, \mathrm{NO}, \mathrm{PM}$, and $\mathrm{CO}_{2}$ emissions were recorded during each test and average cycle values were presented in $\mathrm{g} / \mathrm{mile}$ (except the Idle Mode which was recorded in g/cycle). The vehicles were separated into Engine Model Year Groups based on the California Emissions Regulations, except for model years earlier than 1991, which were grouped together since their emissions were only partially regulated. The other emissions regulation groups were 1991-1993, 1994-1997, and 1998-2002. It should be noted that only vehicles up to 2000 were tested, but emissions regulations are the same for the 1998-2002 Engine Model Year Group. The test length was examined to see if it has any effect on emissions production. Also, the effect test weight has on emissions results were compared between the 30,000 lbs. test weight and the 56,000 lbs. test weight. Since the HHDDT is a new test mode, a comparison was made between the four separate modes and the combined four modes of the HHDDT, to the AC50/80 and the UDDS. Several tests were performed on each vehicle in the CRC E55/59 Phase I study and two vehicles from each Engine Model Year Group were examined to see how $\mathrm{NO}_{\mathrm{X}}$ and $\mathrm{PM}$ related for the various cycles.

\subsubsection{Comparison Between Emissions and Model Year for the AC50/80}

Parsons in Australia developed the AC50/80 as an inspection and maintenance test 21]. The California Air Resource Board is also considering it as a screening test for 
inspecting heavy-duty vehicles. An average of the test runs for each vehicle was determined and then grouped based on California Emissions Standards. The results are presented in Figure 11 and Figure 12 for $\mathrm{NO}_{\mathrm{X}}, \mathrm{PM}, \mathrm{CO}$ and $\mathrm{HC}$. The graphs also present the ranges of the data to show the highest and lowest emissions for each of the Engine Model Year Groups.

In Figure 11, $\mathrm{NO}_{\mathrm{X}}$ and $\mathrm{PM}$ are presented. The PM values were multiplied by ten to be presented with the $\mathrm{NO}_{\mathrm{X}}$ data on the same graph (example; $10.9 \mathrm{~g} / \mathrm{mile}$ on the graph is actually $1.09 \mathrm{~g} / \mathrm{mile}$ ). The variation between the two $\mathrm{NO}_{\mathrm{X}}$ analyzers during testing was on average less than 5.0\%. The PM emissions decreased as Engine Model Year increased to the present. The California Emissions Regulations followed the same trend with Emissions Standards decreasing from $0.6 \mathrm{~g} / \mathrm{bhp}-\mathrm{hr}$ in 1988 to $0.1 \mathrm{~g} b \mathrm{bp}-\mathrm{hr}$ in 1998. California Emissions Standards for PM emissions in the 1994-1997 and 1998-2002 were $0.1 \mathrm{~g} / \mathrm{bhp}-\mathrm{hr}$ and the average $\mathrm{g} / \mathrm{mile}$ for the two groups were 0.40 and $0.38 \mathrm{~g} / \mathrm{mile}$ respectively. The PM emissions relate to the California Emissions Standards with a downward trend. Truck E55CRC-16 produced a considerably higher amount of emissions in relation to the other vehicles in the Pre-1990 Engine Model Year Group. The average g/mile for the Pre-1990 group would be lower if the E55CRC-16 vehicle were removed, but a similar downward trend would still be prevalent for the AC50/80. $\mathrm{NO}_{\mathrm{X}}$ emissions on the other hand do not follow the same downward trend that the PM emissions and the California Emissions Standards followed. The lowest level of $\mathrm{NO}_{\mathrm{X}}$ emissions occurred during the 1991-1993 Engine Model Year Group. The highest average emissions were in the 1994-1997 and 1998-2002 Engine Model Year Groups, but little change occurred between the Engine Model Year Groups. 
The $\mathrm{CO}$ and $\mathrm{HC}$ averages were analyzed in the same manner as the $\mathrm{PM}$ and $\mathrm{NO}_{\mathrm{X}}$ emissions and are presented in Figure 12. The $\mathrm{HC}$ and $\mathrm{CO}$ showed a decrease in emissions production as model year increased. A number of vehicles in the last decade have seen improvements in engine design and fuel delivery, such as electronically controlled fuel injection systems that are able to regulate the delivery of fuel to the cylinder more precisely. Higher injection pressures improve the fuel atomization and allow for improved fuel efficiency and decreased unburned fuel in the exhaust. This lowers the amount of unburned fuel leaving the engine and reduces $\mathrm{HC}$ emissions. $\mathrm{CO}_{2}$ emissions were also sampled during the testing of the $\mathrm{AC} 50 / 80$, but since $\mathrm{CO}_{2}$ emissions are not regulated and they tend to stay relatively constant with respect to model year and were not presented in this section. 
Figure 11: $\mathrm{NO}_{\mathrm{X}}$ and $\mathrm{PM}$ for the AC50/80. Averages and ranges are shown for the data. The pre-1990 group has a high range due to E55CRC-16, which was a very high PM emitter. The PM*10 is PM emissions times by 10 so that the PM could go on the same graph with $\mathrm{NO}_{\mathrm{x}}$ emissions.

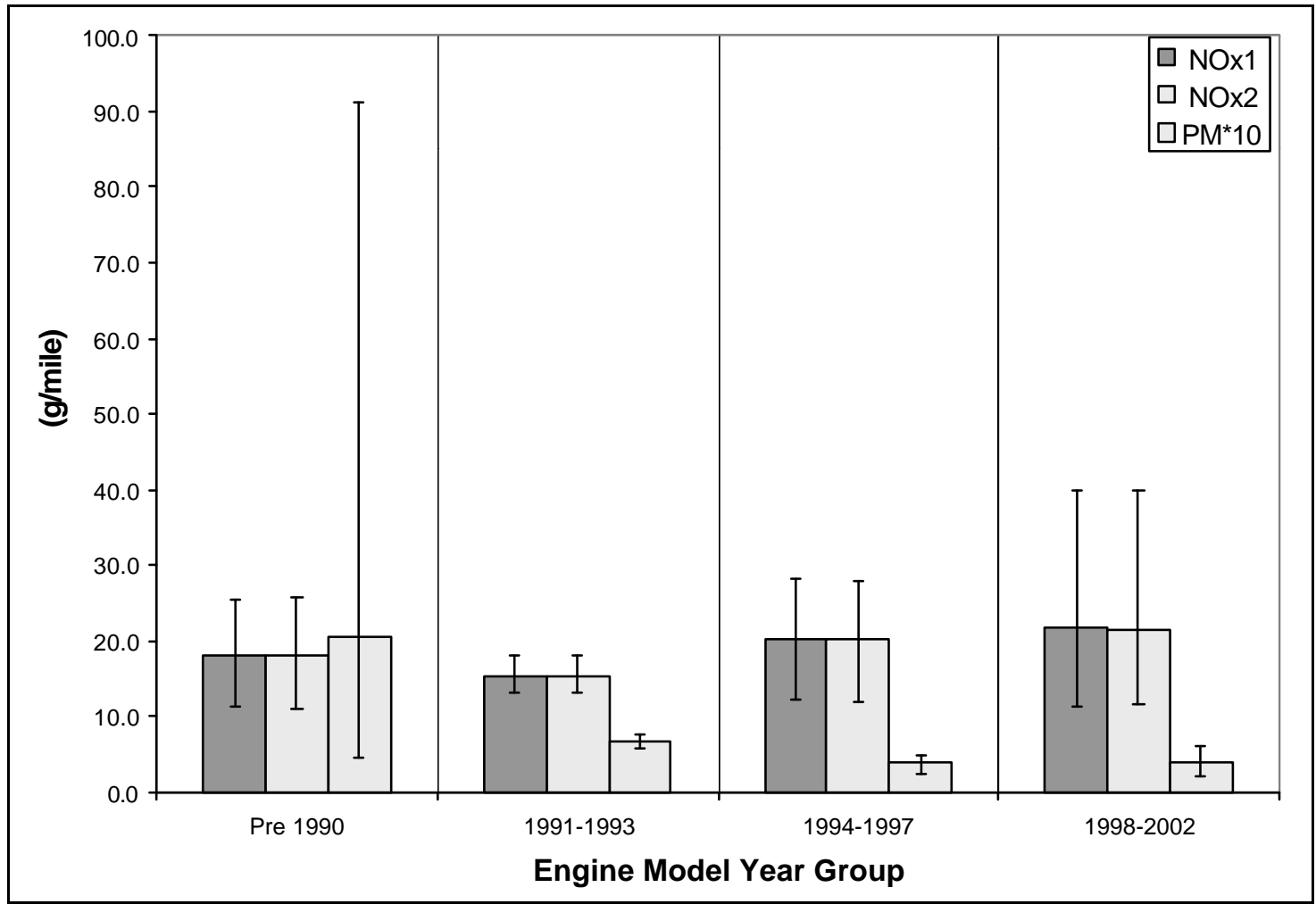


Figure 12: $\mathrm{HC}$ and $\mathrm{CO}$ emissions for the AC50/80.

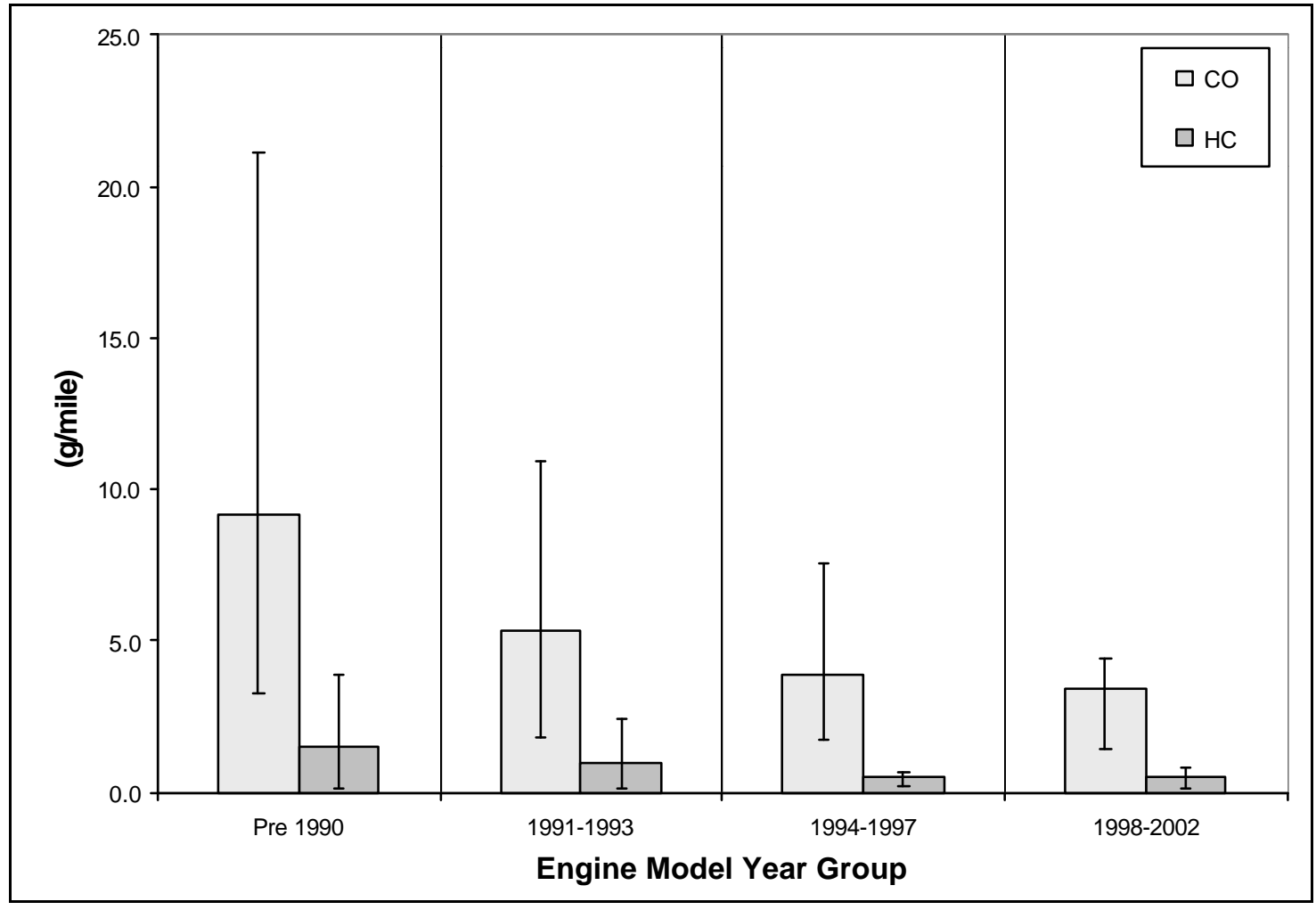

\subsubsection{Comparison Between Regulated Emissions and Model Year for the UDDS}

The UDDS is found in the Code of Federal Regulations, Title 40, Part 86, Subpart N, Appendix I [20]. The test was used in the CRC E55/59 Phase I study as a conditioning cycle and as a regular test. All twenty-five vehicles were tested on the UDDS and the averages for the two tests, in most cases, were determined for $\mathrm{NO}_{\mathrm{X}}, \mathrm{CO}$, HC, and PM. The vehicles were then separated based on California Emission Standard years and averaged. The bars on Figure 13 and Figure 14 represent the range of emissions for the emissions in each Engine Model Year Group.

The PM emissions presented in Figure 13 are multiplied by 10 in order to fit the $\mathrm{PM}$ and $\mathrm{NO}_{\mathrm{X}}$ emissions on the same graph with units of $\mathrm{g} / \mathrm{mile}$. The PM emissions followed the same downward trend found in the AC50/80 graph of PM vs. Engine Model 
Year Group, but the values across the board are higher than the AC50/80 when expressed in units of g/mile. The average values for the 1994-1997 and 1998-2002 Engine Model Year Groups were 0.59 and $0.56 \mathrm{~g} /$ mile respectively. The PM emissions tended to level off in relation to the California Emission Standards for the 1994-1997 and 1998-2002 Engine Model Year Groups. E55CRC-16 was a 1986 truck that fell into the Pre-1990 Engine Model Year Group. This vehicle produced considerable higher PM emissions levels in relation to other vehicles in the same group. If E55CRC-16 were removed from the group the range bars would decrease along with the average emissions. The $\mathrm{NO}_{\mathrm{X}}$ emissions followed the same trend in the AC50/80. They did not decrease in relation to the California Emissions Standards. The lowest Engine Model Year Group for $\mathrm{NO}_{\mathrm{X}}$ emissions was the 1991-1993 and the highest Engine Model Year Group was the 19941997. In Figure 14, the $\mathrm{HC}$ and $\mathrm{CO}$ emissions are presented in relation to Engine Model Year Group. The $\mathrm{CO}$ and $\mathrm{HC}$ follow the same trend as for the AC50/80, but the test itself doesn't follow a trend. 
Figure 13: NOx and PM vs. Engine Model Year Group for the UDDS.

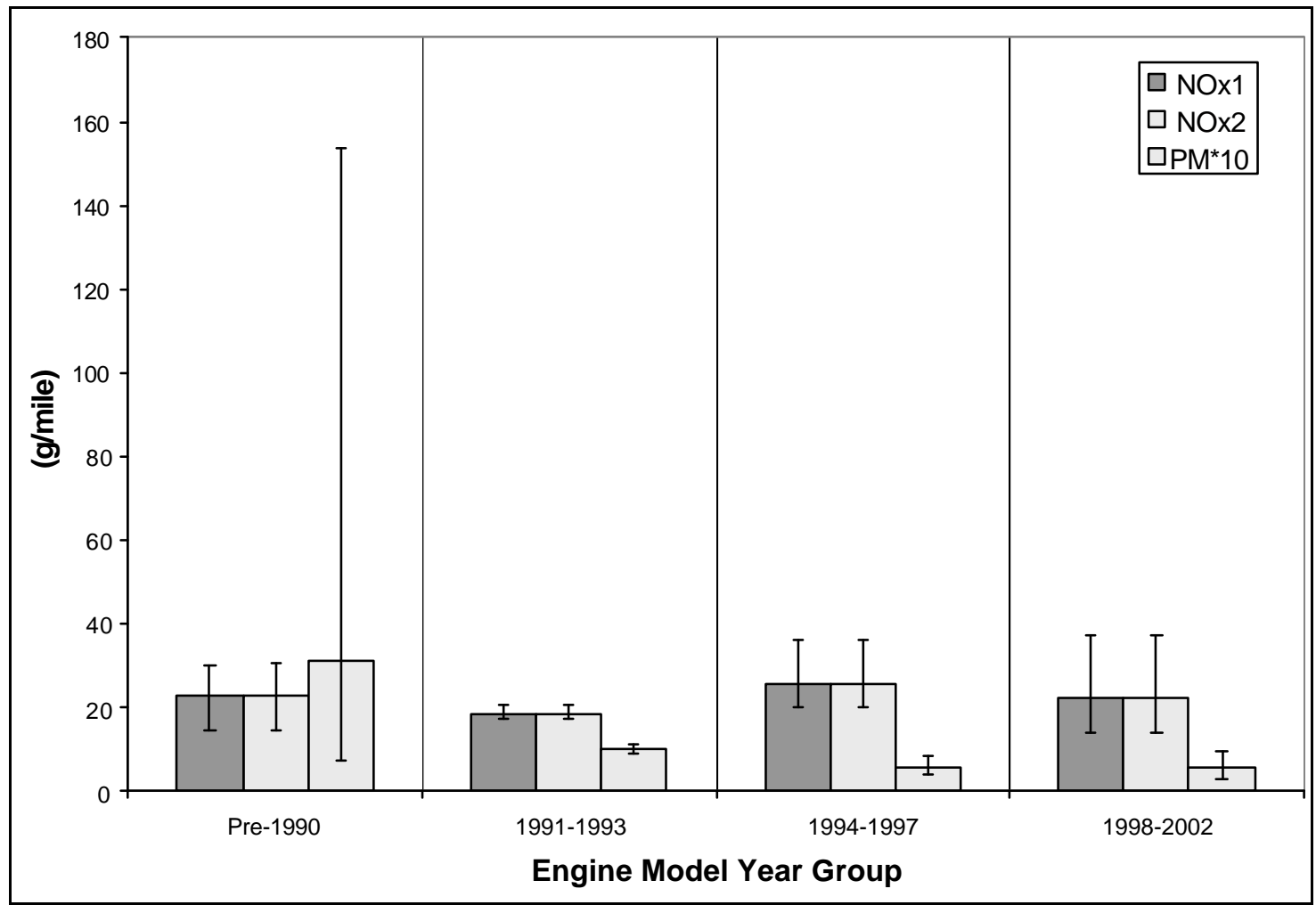

Figure 14: CO and HC vs. Engine Model Year Group for the UDDS.

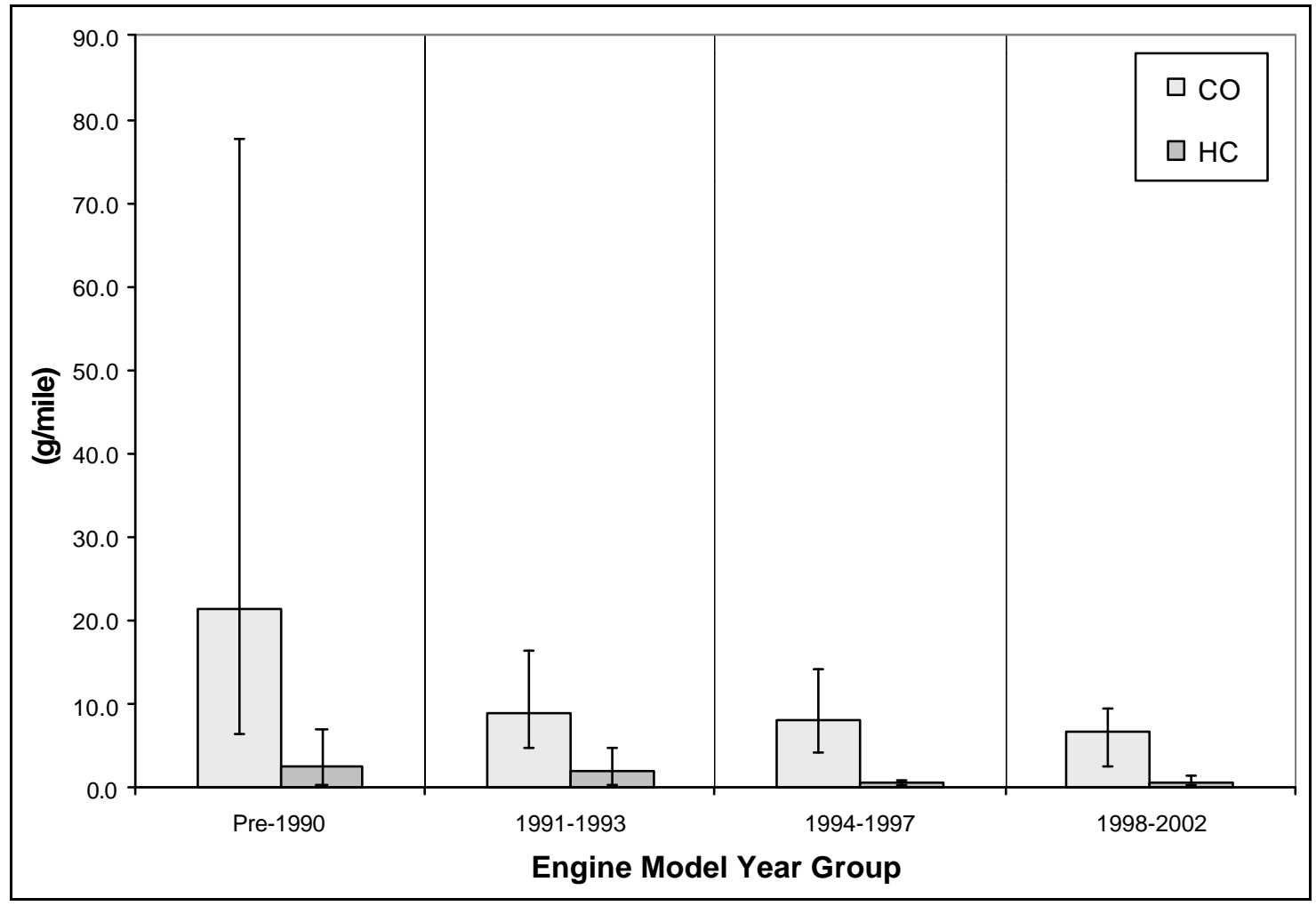




\subsubsection{Comparison Between Regulated Emissions and Model Year for the Idle Mode}

The first mode of the HHDDT Schedule was the Idle Mode. A large number of heavy-duty vehicles spend their time idling and it is important to understand their emissions production while stationary. The percent differences between the two or three tests performed on each vehicle were fairly large. The variation in the test-to-test results for each vehicle tested on the Idle Mode could have been due to the low levels of emissions that would reduce the accuracy of the results. Auxiliary loads turning on and off during the test could also affect the results of each test performed on the same heavyduty vehicle. In a journal, currently under review, it examined the effects of accessory loads on heavy heavy-duty vehicles when tested under idle conditions B0]. The resulted showed a considerable test-to-test variation in emissions production [30]. The idle emissions are also affected by the displacement of the engine, which will vary the amount of emissions produced between different engines.

The results from the Idle Mode still serve as important data when all the heavyduty vehicles are divided into the California Emissions Standards and compared between the different Engine Model Year Groups. In Figure 15 and Figure 16, the emissions of $\mathrm{NO}_{\mathrm{X}}, \mathrm{PM}, \mathrm{HC}$ and $\mathrm{CO}$ are presented. The PM in Figure 15 shows a downward trend in sympathy with California Emissions Standards. Improvements in engine design (like electronic fuel injection) improves the fuel delivery to the cylinder and decreases the amount of unburned fuel, which could have lead to a decrease in PM and HC emissions.

Another benefit the electronically controlled fuel injected engines have over the mechanically controlled fuel injected engines is the ability to vary the injection timing to allow for a more complete combustion of the fuel and reduce "white smoking." The $\mathrm{NO}_{\mathrm{X}}$ emissions increased from the Pre-1990 to the 1994-1997 Engine Model Year Group 
possibly due to variation in the timing strategy allowed by electronic fuel injection. In Figure 16, $\mathrm{HC}$ and $\mathrm{CO}$ emissions are presented. The results tend to vary from model year to model year and it is difficult to draw conclusions based on the limited amount of data.

Figure 15: NOx and PM vs. Engine Model Year Group for the Idle Mode.

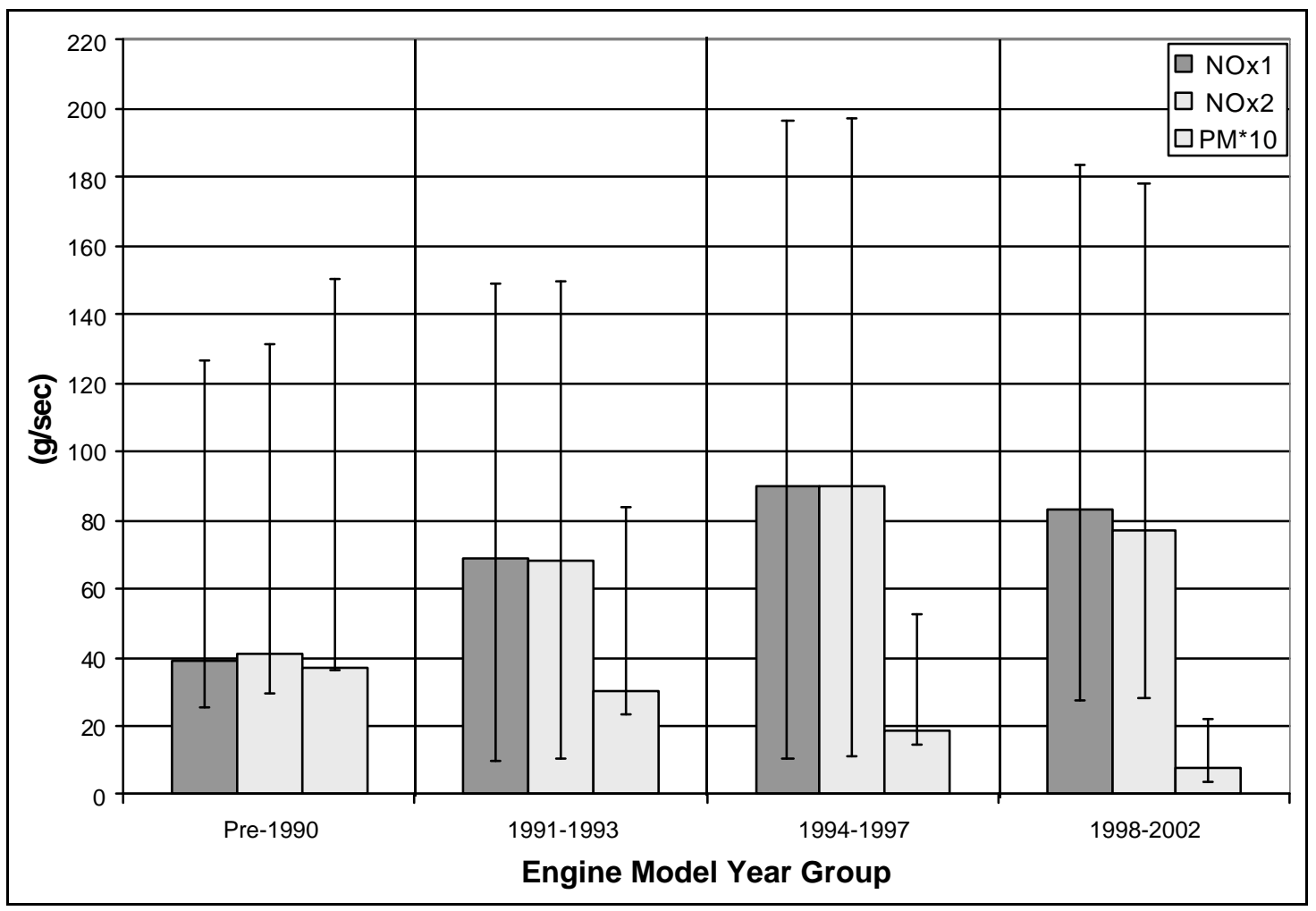


Figure 16: CO and HC vs. Engine Model Year Group for the Idle Mode.

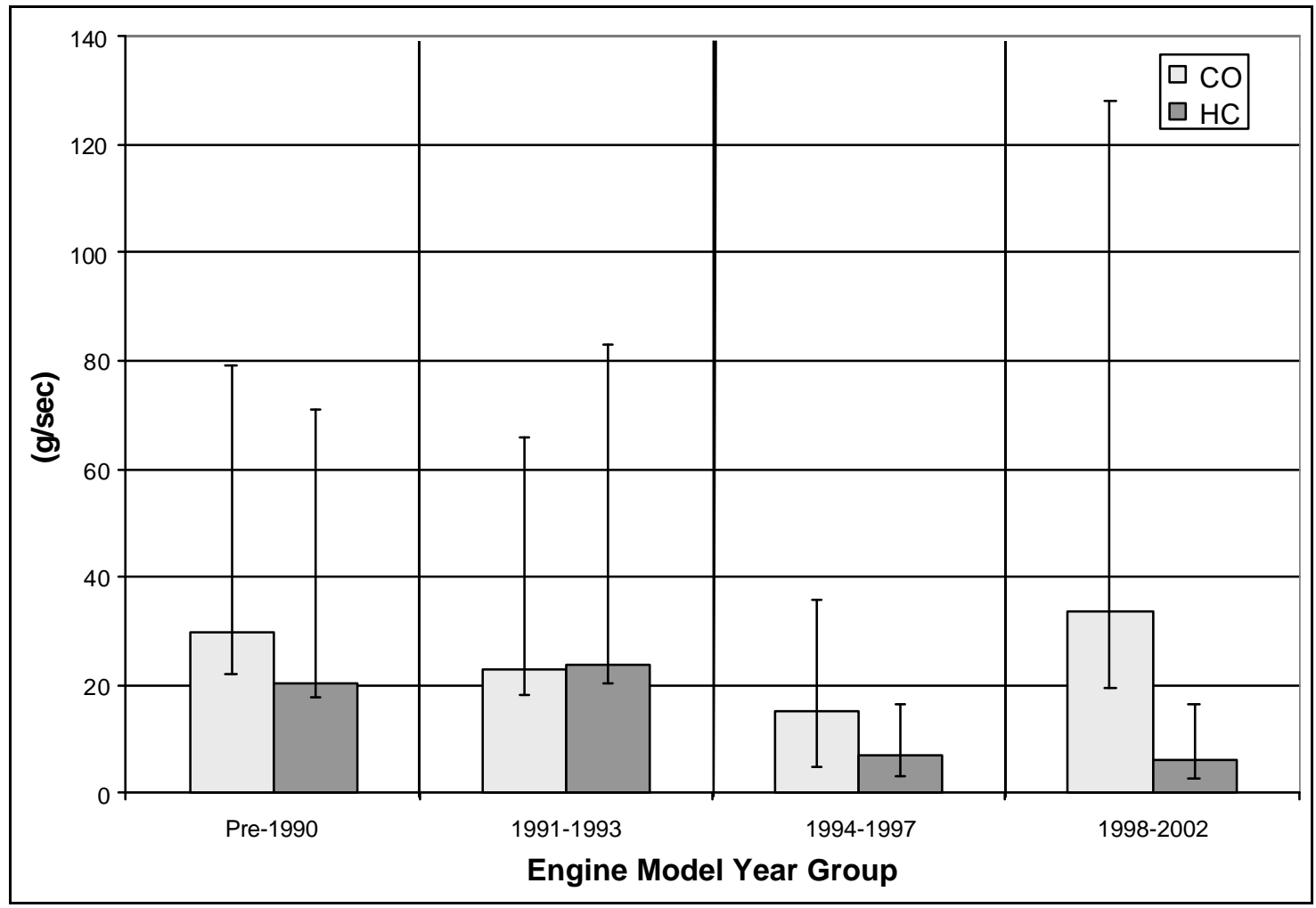

\subsubsection{Comparison Between Regulated Emissions and Model Year for the Creep Mode}

The second mode of the HHDDT Schedule was the Creep Mode. The results from each heavy-duty vehicle tested at 56,000 lbs. (except for E55CRC-6) were averaged and then grouped based on California Emissions Standards. The Unladen tests are compared to the Laden tests for the Creep Mode in section 5.2.1. Figure 17 and Figure 18 present the average values for the gaseous emissions and PM from the Creep Mode.

The PM levels presented in Figure 17 showed a similar trend as the Idle Mode, UDDS, and AC50/80. The PM decreased as the Engine Model Year Group become newer. The $\mathrm{NO}_{\mathrm{X}}$ emissions do not show a downward trend in relation to California Emissions Standards. In Figure 18, the results for the $\mathrm{HC}$ and $\mathrm{CO}$ are presented for the Creep Mode. It is important to note that the test to test results for each vehicle improved 
in relation to the Idle Mode, but there was some variation between each run performed on the same vehicle.

Figure 17: $\mathrm{NO}_{\mathrm{x}}$ and PM vs. Engine Model Year Group for the Creep Mode.

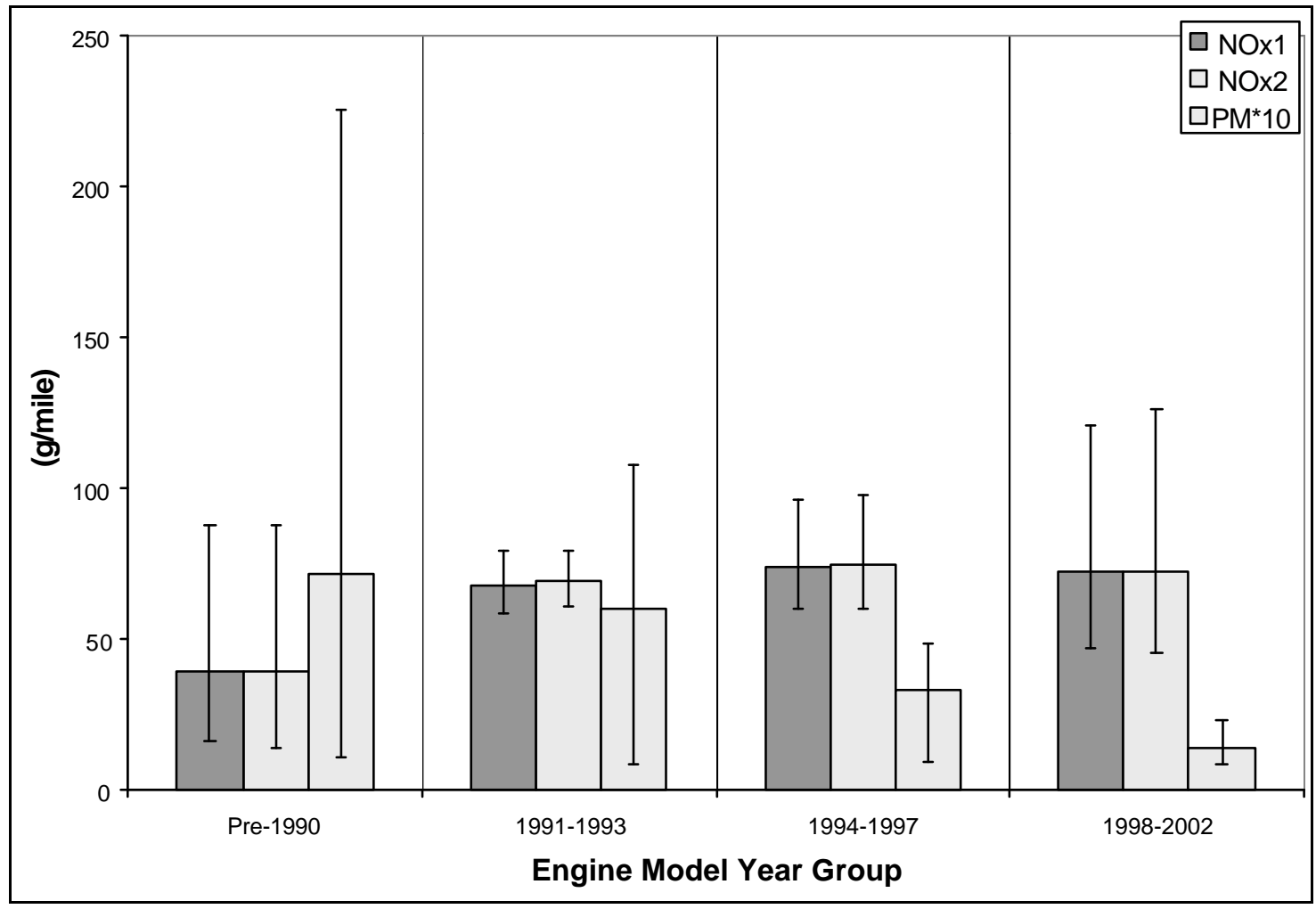


Figure 18: HC and CO vs. Engine Model Year Group for the Creep Mode.

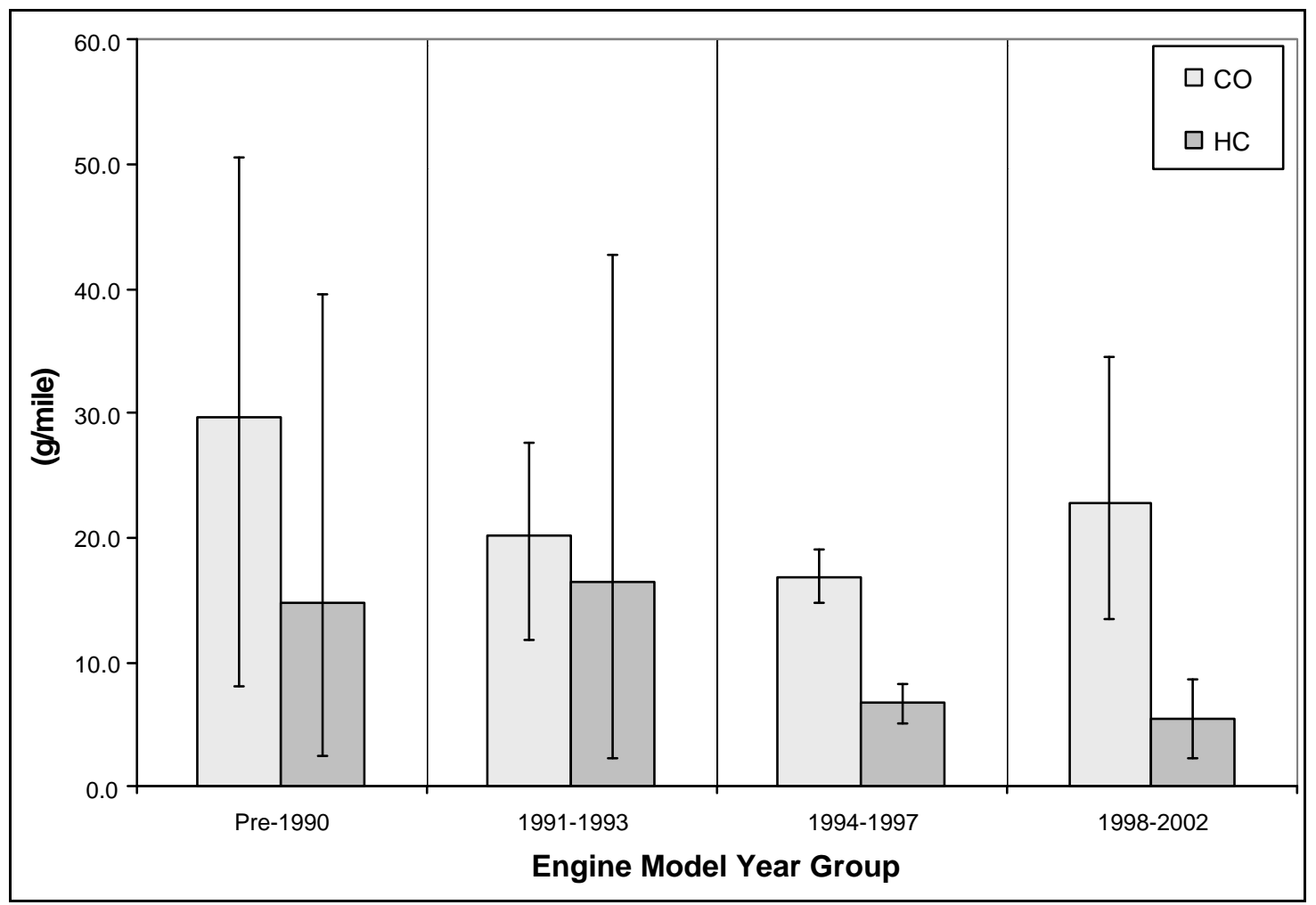

\subsubsection{Comparison Between Regulated Emissions and Model Year for the Transient $\underline{\text { Mode }}$}

The Transient Mode was the third mode in the HHDDT Schedule. All twentyfive vehicles were tested at 56,000 lbs. (except for E55CRC-6) and the results from the runs for each vehicle were averaged. The Unladen tests are compared to the Laden tests for the Creep Mode in section 5.2.2. The vehicles were then separated into the four Engine Model Year Groups. Figure 19 and Figure 20 present the regulated emissions averages for each of the Engine Model Year Groups and the bars in the two figures represents the highest and lowest emissions levels.

The emissions of $\mathrm{NO}_{\mathrm{X}}$ tended to stay relatively unchanged as model year increased to the present and the PM emissions followed the same downward trend as the California Emissions Regulations and the other test already presented. The emissions of 
$\mathrm{HC}$ and $\mathrm{CO}$ also followed a downward trend as the Engine Model Year Group increased. The decreases in $\mathrm{HC}, \mathrm{CO}$ and PM emissions were most likely due to the same reasons mentioned in the previous sections.

Figure 19: $\mathrm{NO}_{\mathrm{x}}$ and PM vs. Engine Model Year Group for the Transient Mode.

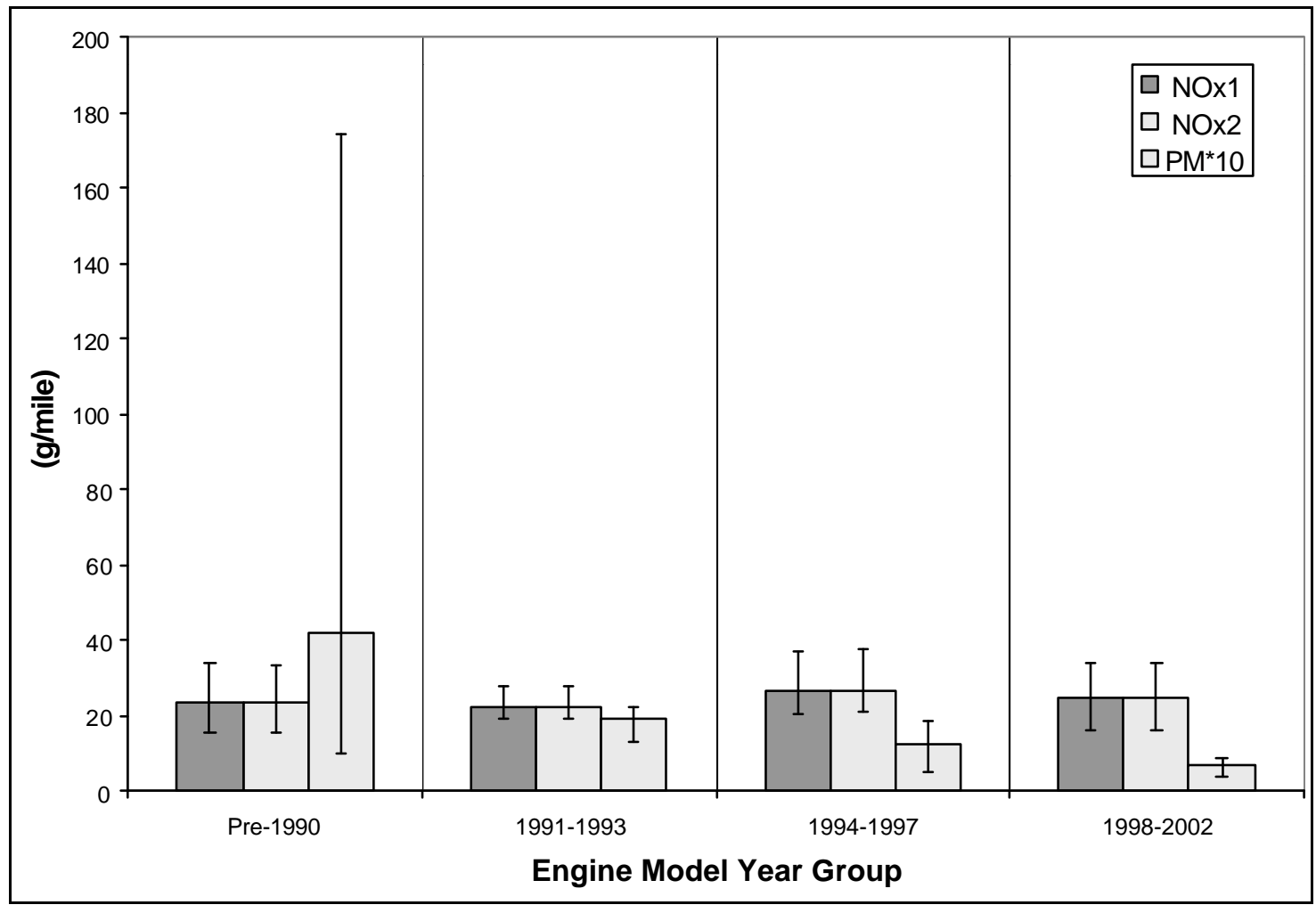


Figure 20: HC and CO vs. Engine Model Year Group for the Transient Mode.

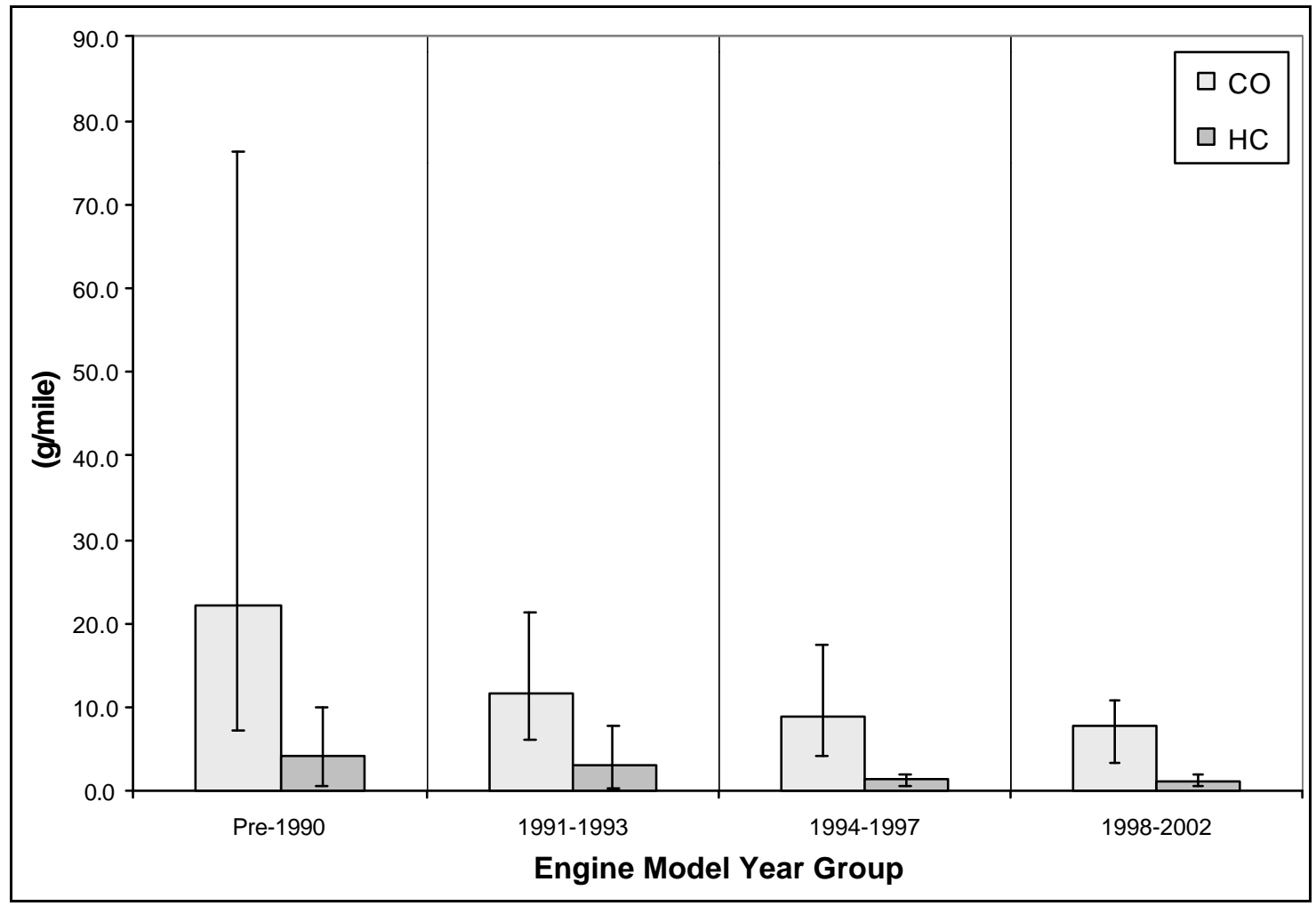

The twenty-five vehicles were also examined in g/ahp-hr and g/gallon to see if the results varied. In Figure 21 and Figure 22 the emissions of $\mathrm{NO}_{\mathrm{X}}, \mathrm{PM}, \mathrm{HC}$ and $\mathrm{CO}$ are presented in g/ahp-hr for the Transient Mode. Since the TransLab is a chassis dynamometer and not an engine dynamometer, the emissions must be reported based on the power at the wheels instead of at the engine. ECU's today are capable of presenting real time torque measurements, but not all of the vehicle were equipped with an ECU and could not be performed on every vehicle in the CRC E55/59 Phase I study. The trends presented for the g/mile are also prevalent in the g/ahp-hr. The PM emissions decreased as the Engine Model Year increased and $\mathrm{NO}_{\mathrm{X}}$ stayed fairly constant. The $\mathrm{HC}$ and $\mathrm{CO}$ emissions also followed the same trends for the g/ahp-hr as the g/mile results. The HC and CO emissions decreased as Engine Model Year Group increased. 
Figure 21: $\mathrm{NO}_{\mathrm{X}}$ and PM emissions vs. Engine Model Year Group with units of g/ahp-hr. The data are from the Transient Mode.

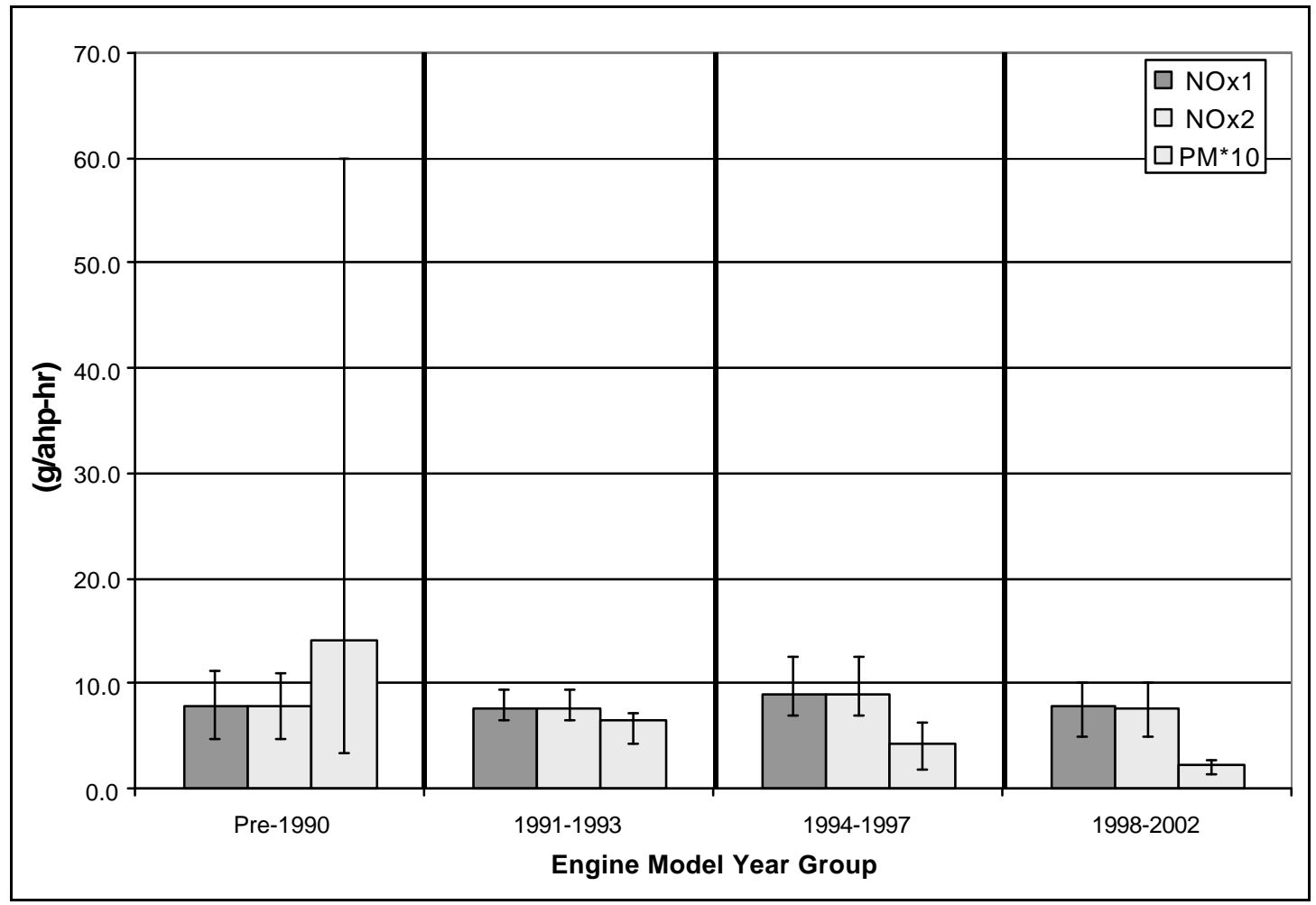

Figure 22: HC and CO vs. Engine Model Year Group with units of g/ahp-hr. The data is from the Transient Mode.

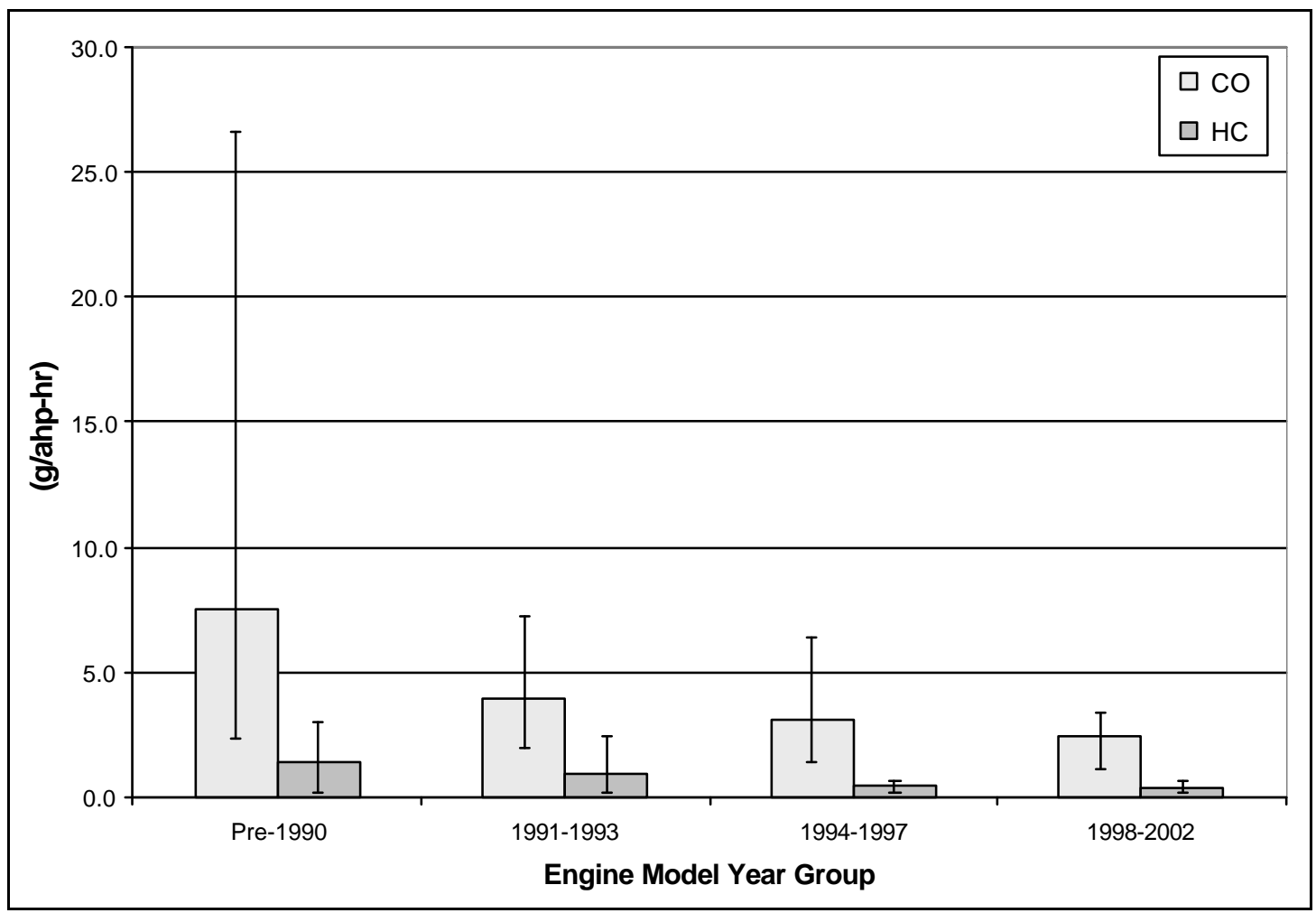


The gallons of fuel consumed during testing are derived from $\mathrm{CO}_{2}$ emissions measurement. There are two methods for determining fuel consumption from a heavyduty diesel vehicle during emissions testing. The first method is to directly measure the fuel delivered to the engine. The second method is based off of the measurement of $\mathrm{CO}_{2}$ emissions, which is described in the Code of Federal Regulations, Title 40, Part 86, Subpart N [20]. The second method was used by the TransLab to determine the fuel consumed by the test vehicle. The data presented in Figure 23 and Figure 24 are the emissions produced from the Transient Mode. The trends explained for the $\mathrm{g} / \mathrm{mile}$ and g/ahp-hr gaseous emissions and PM still apply to the g/gallon results. The PM emissions decreased and the $\mathrm{NO}_{\mathrm{X}}$ stayed the same as model year increased. Also, the $\mathrm{HC}$ and $\mathrm{CO}$ emissions decreased as model year increased.

Figure 23: $\mathrm{NO}_{\mathrm{X}}$ and PM emissions vs. Engine Model Year Group with units of g/gallon. The data are from the Transient Mode.

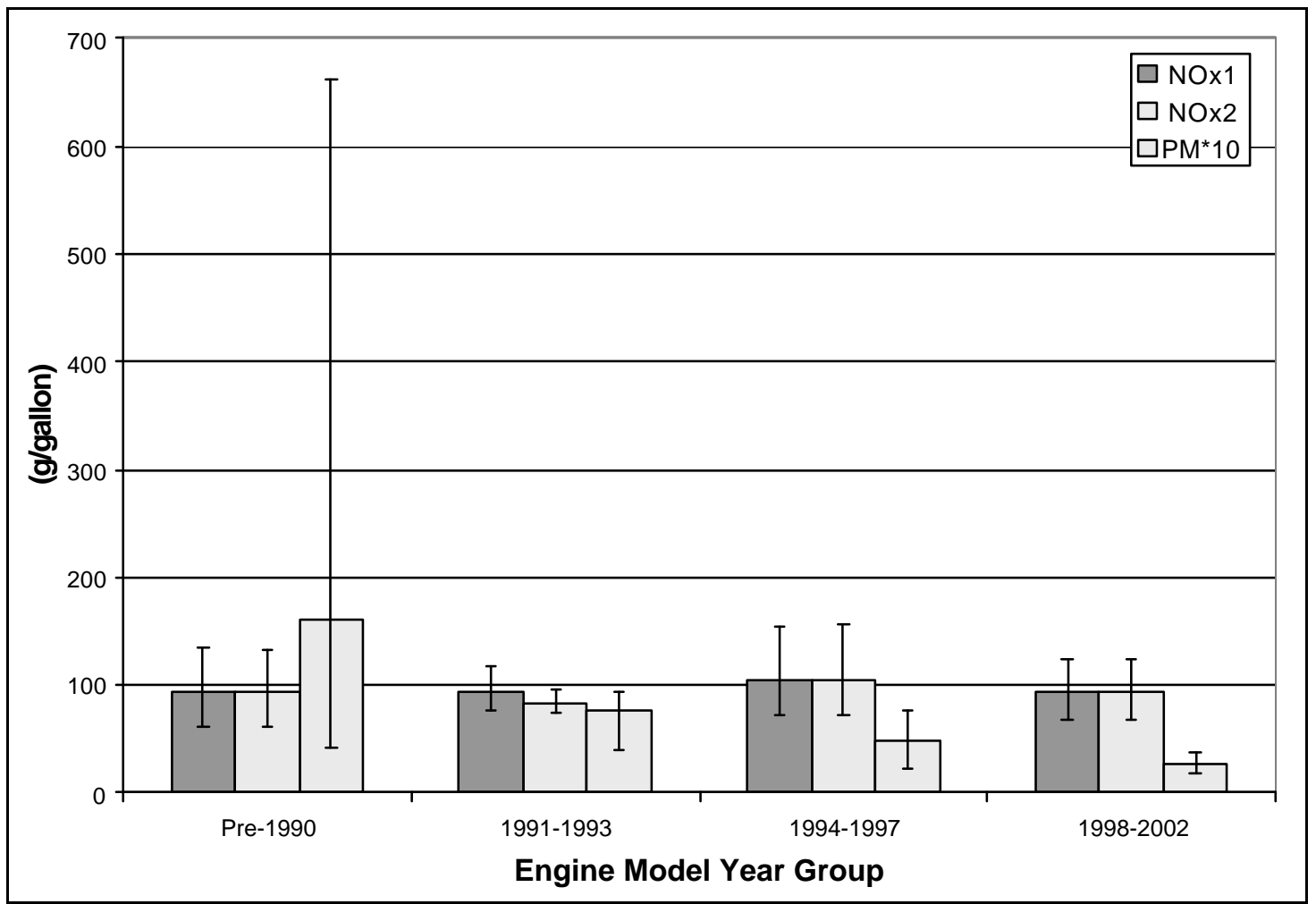


Figure 24: HC and CO emissions vs. Engine Model Year Group with units of g/gallon. The data are from the Transient Mode.

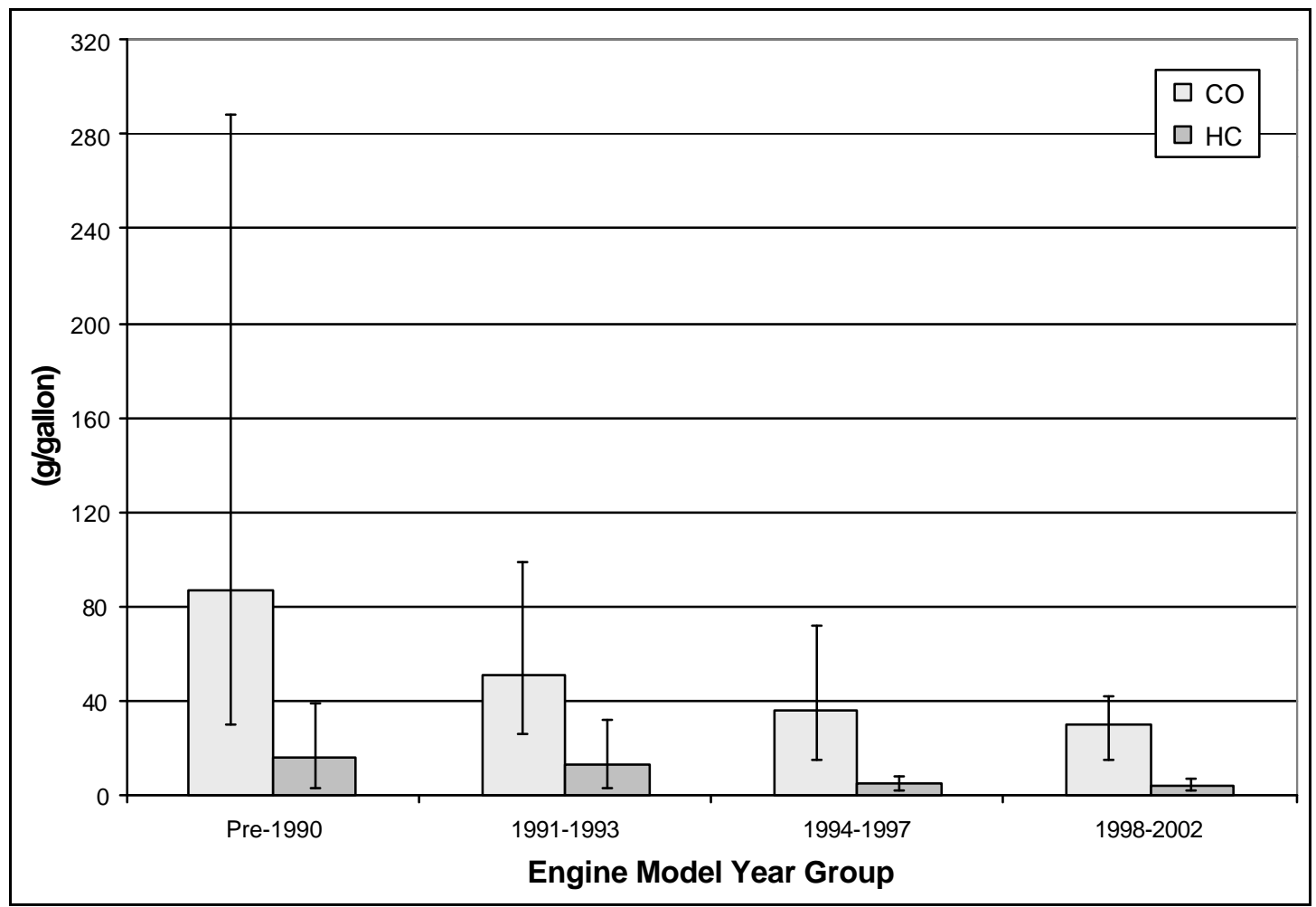

\subsubsection{Comparison Between Regulated Emissions and Model Year for the Cruise Mode}

The fourth mode in the HHDDT Schedule was the Cruise Mode, which resembles a vehicle operating at highway speeds. All twenty-five vehicles were tested on the Cruise Mode of the HHDDT at 56,000 lbs. (except E55CRC-6). The Unladen tests are compared to the Laden tests for the Cruise Mode in section 5.2.3. The gaseous emissions and PM are presented in Figure 25 and Figure 26 and the bars on each of the graphs represent the range of the data for each emission in the Engine Model Year Groups.

The PM emissions followed the same trend as the other three modes of the HHDDT Schedule and the $\mathrm{NO}_{\mathrm{X}}$ emissions did not follow the same trend as the PM emissions. The highest $\mathrm{NO}_{\mathrm{X}}$ emitters are the most recent Engine Model Year Groups and the lowest $\mathrm{NO}_{\mathrm{X}}$ emitters are the 1991-1993 Engine Model Year Group. However, there was strong truck-to-truck variation for the 1998-2002 Engine Model Year Group. The 
HC emissions followed a slight decrease as model year increased. $\mathrm{CO}$ emissions also followed a downward trend except for the 1998-2002 Engine Model Year Group.

Figure 25: $\mathrm{NO}_{\mathrm{x}}$ and PM vs. Engine Model Year Group for the Cruise Mode.

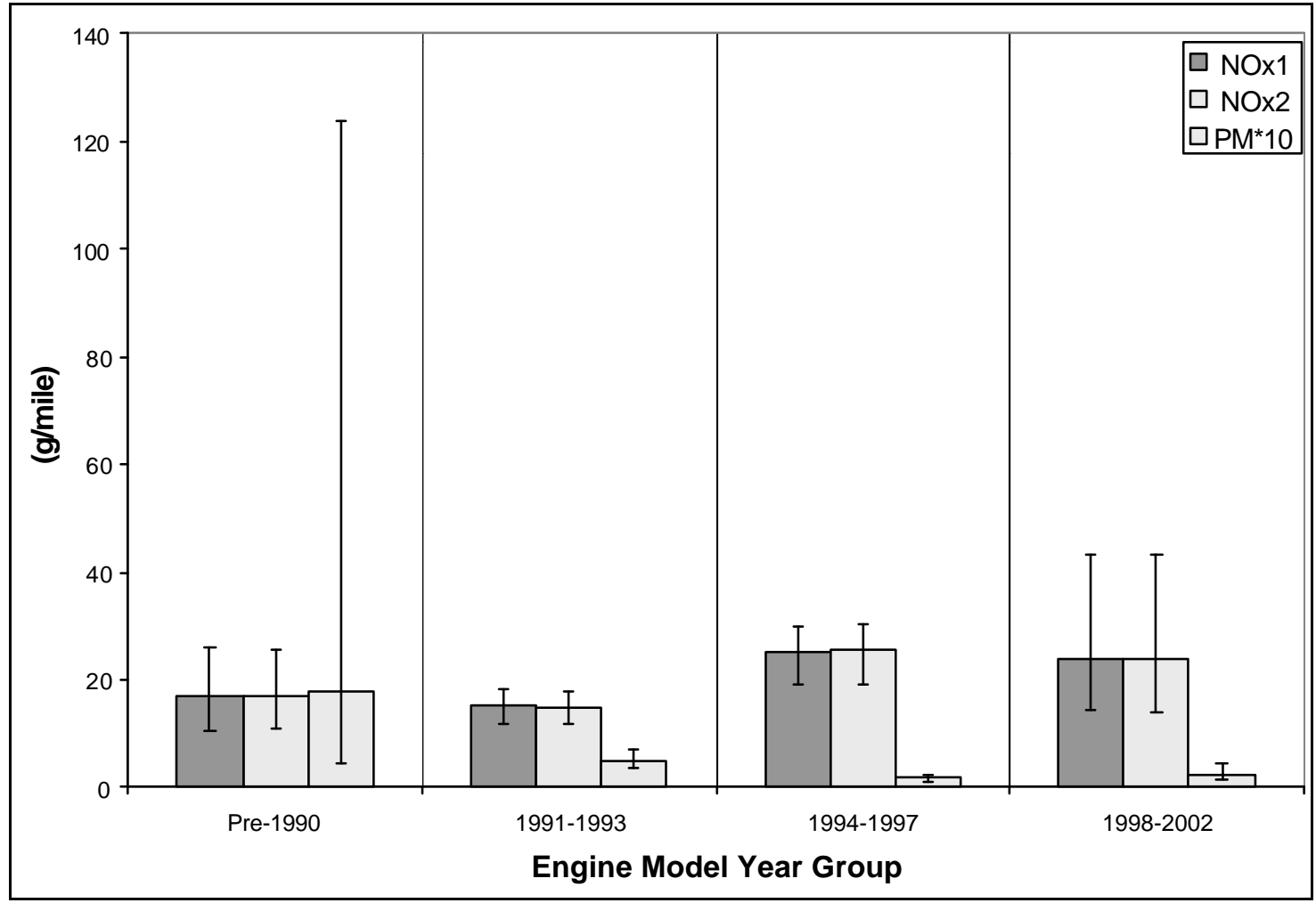


Figure 26: HC and CO vs. Engine Model Year Group for the Cruise Mode.

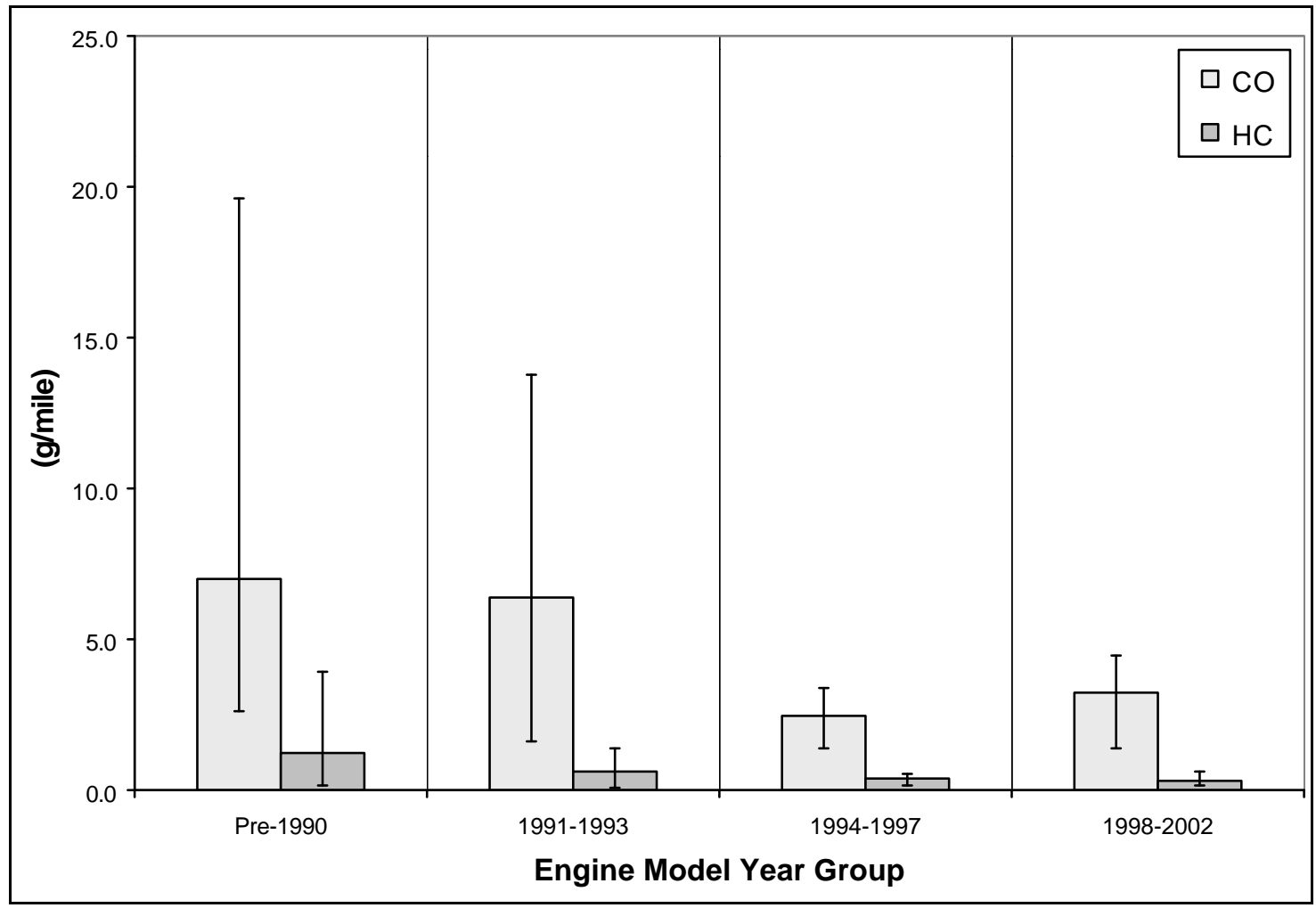

\subsection{Effects of Different Test Weights for the Creep, Transient and Highway Modes}

Every vehicle was tested on the Four-Mode HHDDT at a Laden weight of 56,000 lbs. (except E55CRC-6) and an Unladen weight of 30,000 lbs. Since the Idle Mode is not affected by weight, the results were similar for the Laden and Unladen test weight.

\subsubsection{Laden vs. Unladen Creep Mode}

Each vehicle was tested more than once on the Laden and Unladen Creep Mode to determine the effects on emissions production. The vehicle averages were then organized based on California Emissions Standards and the results for the Laden and Unladen gaseous and PM emissions are presented in Figure 27 through Figure 32. In Figure 27, the emissions of $\mathrm{NO}_{\mathrm{X}}$ showed a moderate increase between 1990-2000 in relation to the Pre-1990 vehicles. Almost half of the vehicles tested in the CRC E55/59 Phase I study 
produced less $\mathrm{NO}_{\mathrm{X}}$ emissions at the Laden test weight than the Unladen test weight. Clark et al. [14] used the relationship between $\mathrm{NO}_{\mathrm{X}}$ emissions and test weight to compare heavy-duty vehicles tested at different test weights on the same cycle. The relationship used in Clark et al. [14] does not apply to the Creep Mode Laden and Unladen data, because a large number of vehicles tested at the Unladen test weight produced more emissions then the Laden test weight. The Creep Mode operates the test vehicle through a number of low speed short travels and idle periods. The relationship between test weight and $\mathrm{NO}_{\mathrm{X}}$ emissions is based on vehicles operating on longer tests with several transients at various speeds and could be why the relationship does not hold for the Creep Mode. There are also considerable variations in the test-to-test data for each of the vehicles tested on the Creep mode and an accurate relationship is difficult with the limited amount of data available in the CRC E55/59 Phase I study. 
Figure 27: $\mathrm{NO}_{\mathrm{x}}$ emissions for the Laden and Unladen tests operated on the Creep Mode. The graph is also divided up into groups based on California Emissions Regulations.

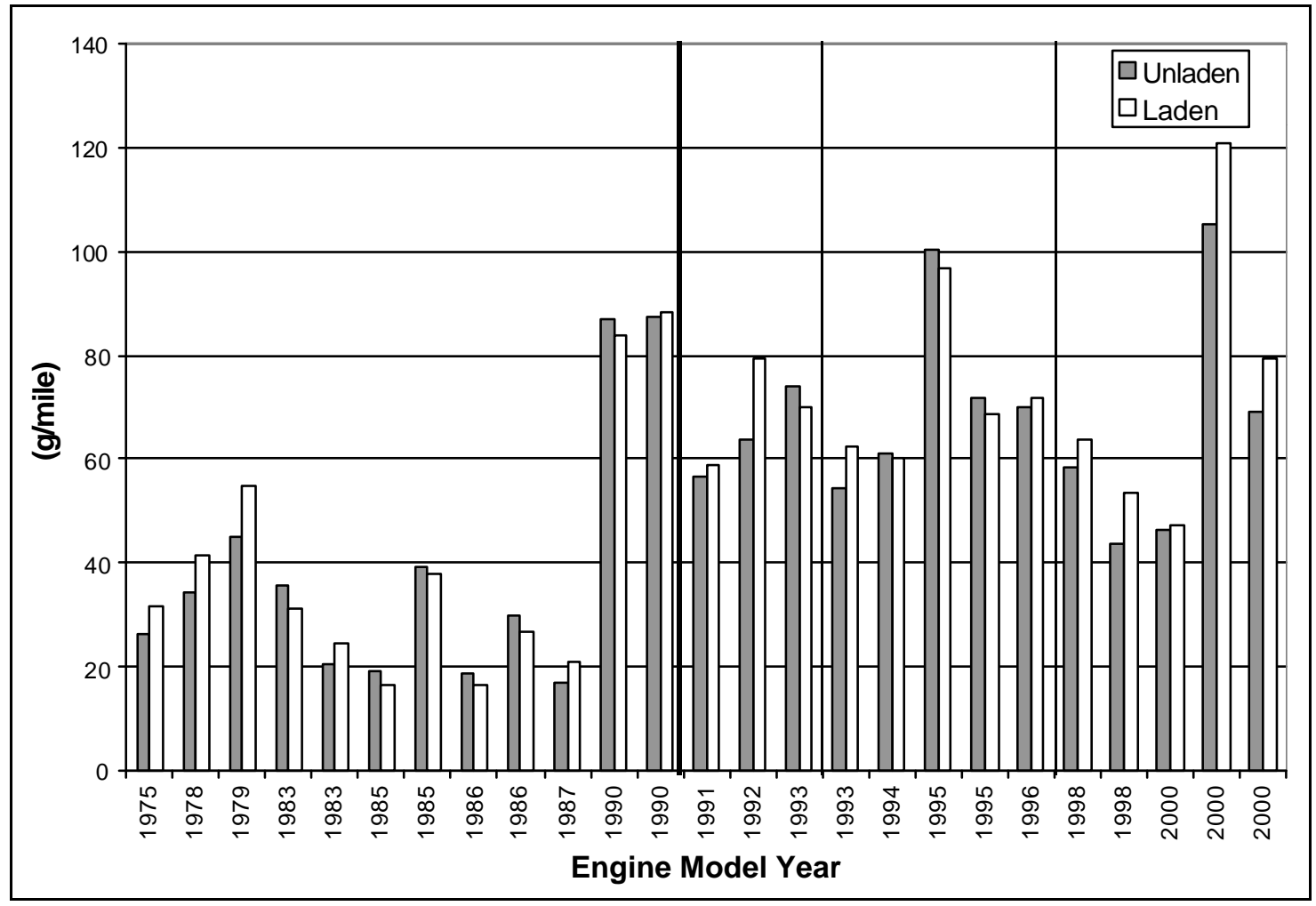

In Figure 28, the emissions of PM for the Laden and Unladen test weights are presented. Some of the highest emitters are in the 1985 to 1987 range and decreased as Engine Model Year increased. The lowest PM levels are in the 1998 to 2002 group, which also has the toughest emissions standards for the vehicles tested. A little over a third of the vehicles had lower PM emissions from the engine at the Laden test weight compared to the Unladen test weight, but no past correlation between PM emission and test weight has been determined. The 1991 and 1994 vehicles showed a considerable difference between the Laden and Unladen test weights for the PM emissions. $\mathrm{NO}_{\mathrm{X}}$ emissions were compared to $\mathrm{CO}_{2}$ emission for the twenty-five vehicles tested at the Laden and Unladen test weights. The results from the $\mathrm{CO}_{2}$ to $\mathrm{NO}_{\mathrm{X}}$ relationship are presented in Figure 29. A "best-fit" line was fitted through the Laden and Unladen test 
weights for the Creep Mode, but the data was fairly scattered and a relationship could not be made. The "best-fit" line did overlap for the Laden and Unladen test weights.

Figure 28: PM emissions from the Laden and Unladen Creep Mode. The graph is also divided up into groups based on California Emissions Regulations.

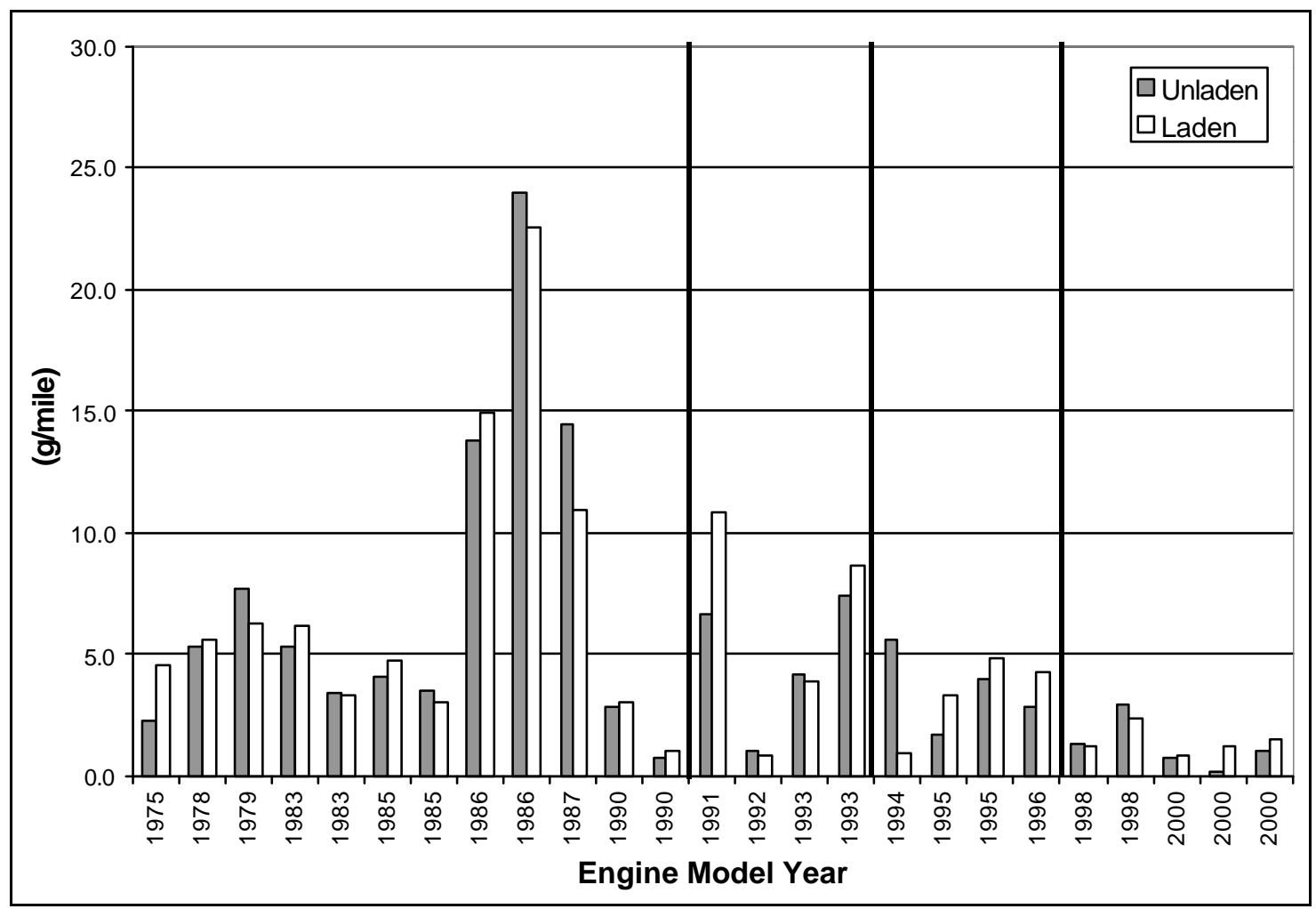


Figure 29: Comparison between $\mathrm{NO}_{\mathrm{X}}$ emissions for the Unladen and Laden test weights Creep Modes. The $\mathbf{R}^{2}$ values suggest that a linear fit is not acceptable.

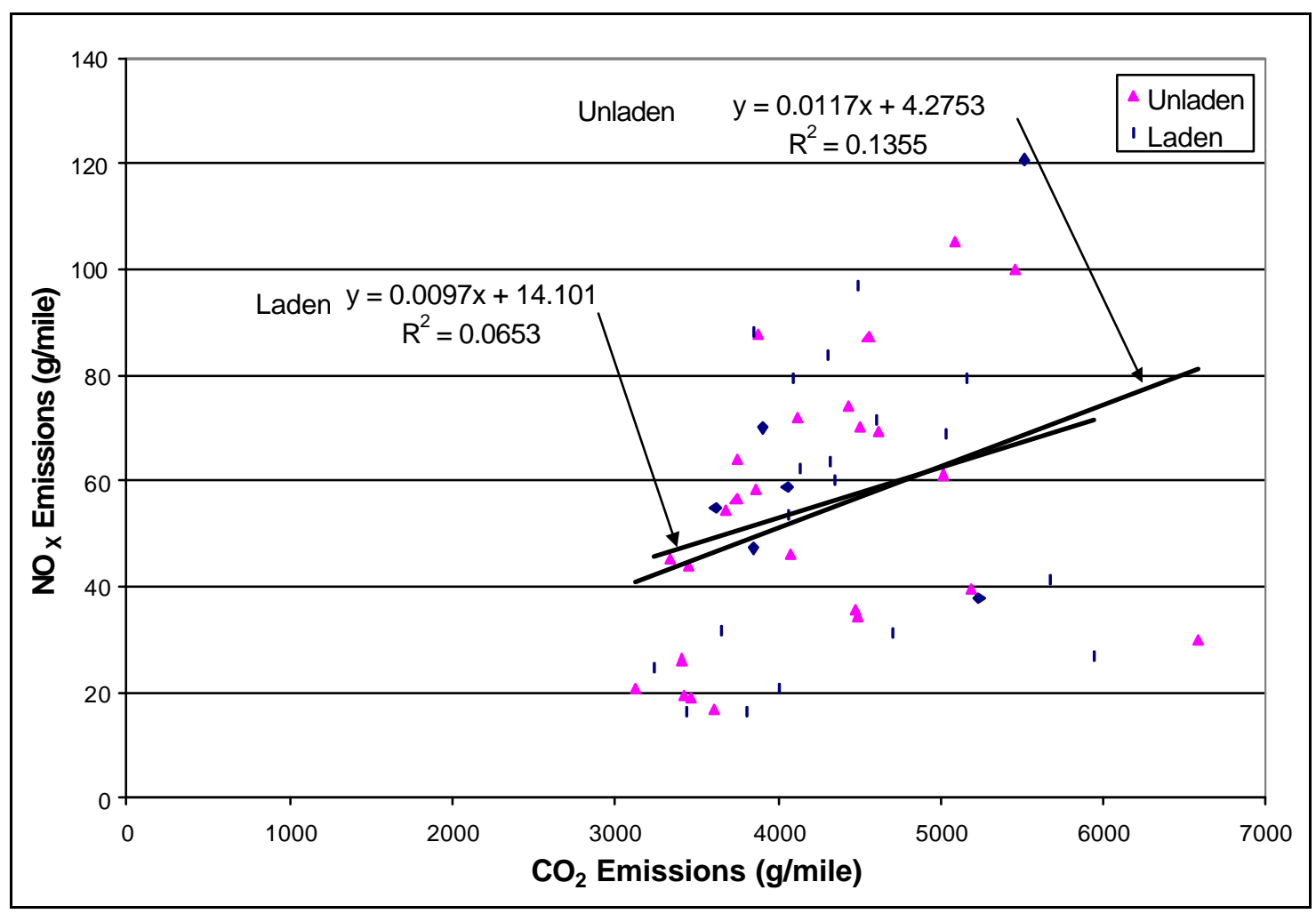

At the present there are no regulations placed on $\mathrm{CO}_{2}$ emissions, but in the future regulations may be instituted to control the $\mathrm{CO}_{2}$ production from heavy-duty diesel engines. In Figure 30, the $\mathrm{CO}_{2}$ emissions are presented for the Laden and Unladen test weights for all of the vehicles tested on the Creep Mode to see how test weight affects $\mathrm{CO}_{2}$ emissions. The data presented in this section are an average of the tests performed on each vehicle. A third of the vehicles tested on the Creep Mode have lower $\mathrm{CO}_{2}$ emissions for the Laden test weight in comparison to the Unladen test weights. It would be expected that a vehicle operating with a heavier load would require more fuel to produce more power, but for some of the vehicles it is not the case. Once again the vehicle operates at low load throughout the Creep Mode, so it is difficult to assess what the engine is actually doing. The run-to-run variability in the emissions results makes it 
difficult to derive any conclusions based on the limited amount of data from each vehicle tested on the Creep Mode.

Figure 30: $\mathrm{CO}_{2}$ emissions production for the Laden and Unladen Creep Modes. The graph is also divided up into groups based on California Emissions Regulations.

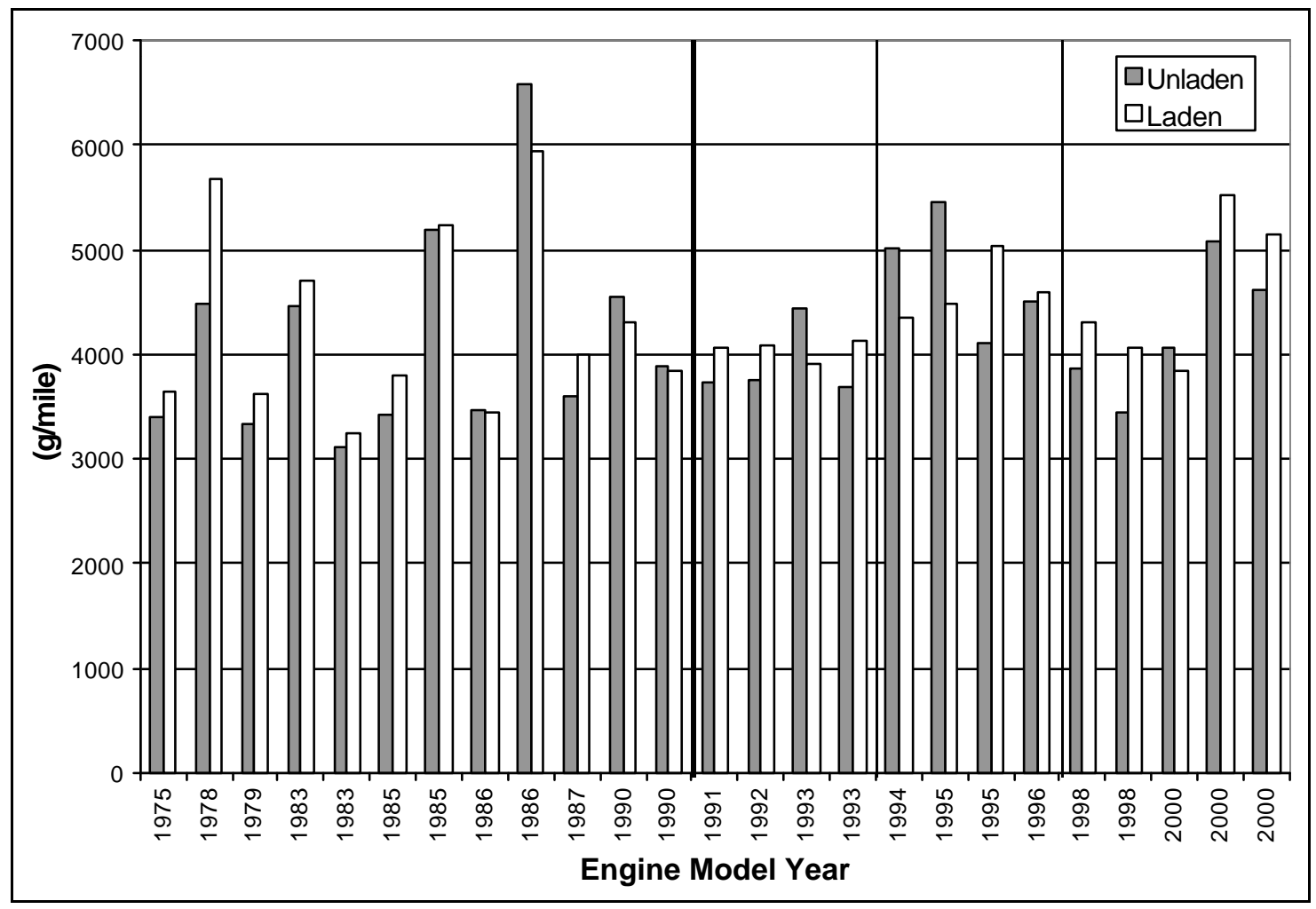

The emissions of $\mathrm{CO}$ and $\mathrm{HC}$ are presented in Figure 31 and Figure 32 for the Unladen and Laden test weights. The CO emissions for the Creep Mode showed some variability from vehicle to vehicle. The run-to-run data for each vehicle operating on the Creep Mode at the Laden test weight tended to have a high variation. The Unladen tests presented the same problem. On average the $\mathrm{CO}$ emissions in Figure 31 were highest for the Pre-1990 Engine Model Year Group. Improvements in engine design may have had some effect on the emissions production, but more data on each vehicle would need to be gathered to determine the reason for run-to-run variability. The $\mathrm{HC}$ emissions were low 
overall with a few vehicles having considerably higher values in comparison to the other vehicles.

Figure 31: CO emissions for the Laden and Unladen Creep Modes. The graph is also divided up into groups based on California Emissions Regulations.

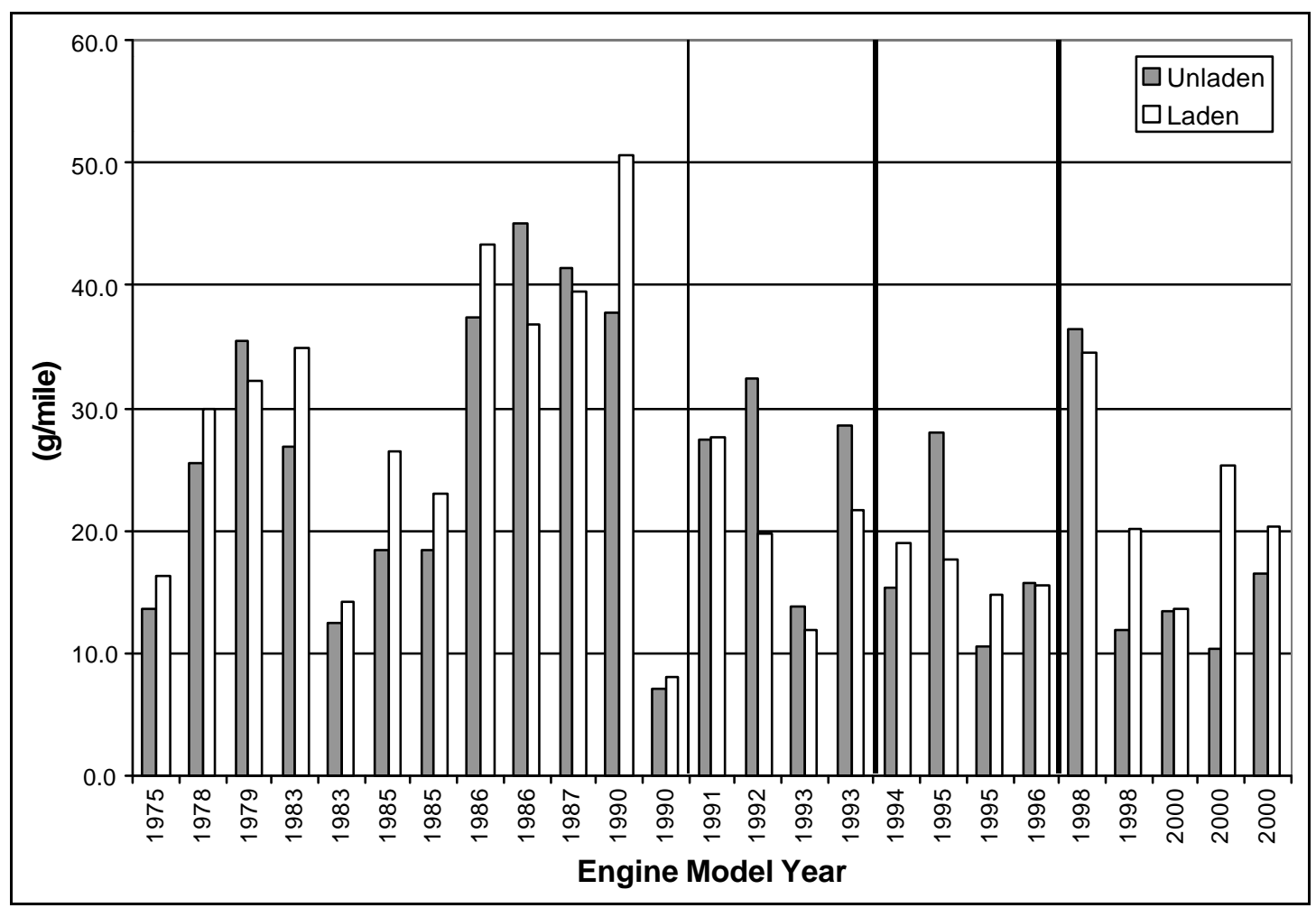


Figure 32: HC emissions for the Laden and Unladen Creep Modes. The graph is also divided up into groups based on California Emissions Regulations.

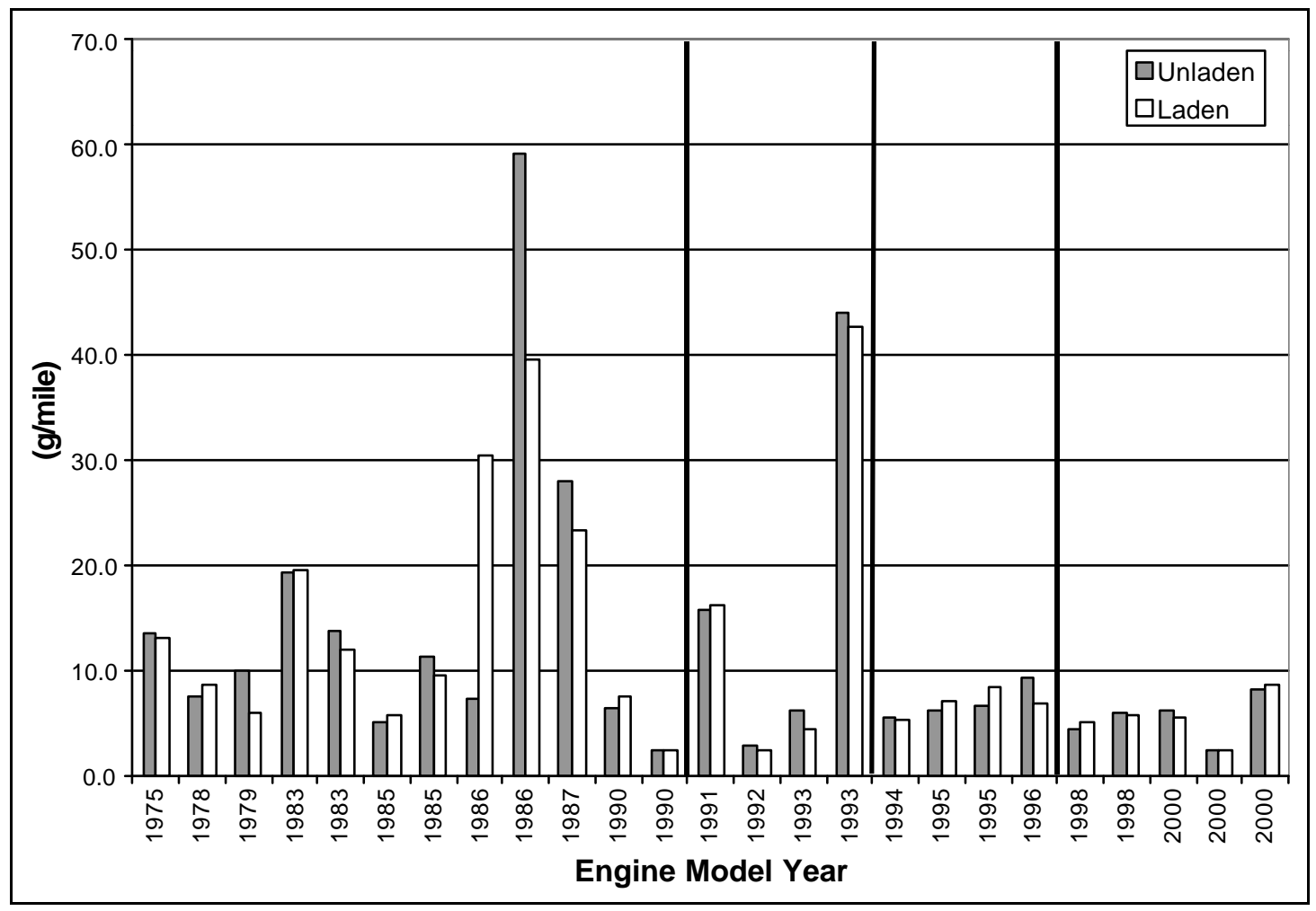

\subsubsection{Laden vs. Unladen Transient Mode}

All the vehicles in this study were tested more than once at a Laden and Unladen test weight on the Transient Mode. An average of the emissions from the test runs were determined for each of the heavy-duty vehicle and presented in Figure 33 through Figure 38. The vehicles are also separated into groups based on California Emissions Standards.

The $\mathrm{NO}_{\mathrm{X}}$ data for each vehicle are presented in Figure 33. As illustrated in the previous $\mathrm{NO}_{\mathrm{X}}$ graphs, the emissions did not follow the same downward trend prevalent in all of the PM emissions data. There is also a large variation in $\mathrm{NO}_{\mathrm{X}}$ between the Laden and Unladen test weights. The $\mathrm{NO}_{\mathrm{X}}$ emissions tend to increase when the test weight is increased. In the Creep Mode comparison, the relationship did not occur and some of the vehicles had higher $\mathrm{NO}_{\mathrm{X}}$ emissions for the Unladen test weights. In Figure 33, the $\mathrm{NO}_{\mathrm{X}}$ emissions are higher for all the Laden test weights when compared to the Unladen test 
weight except for one of the 1983 test vehicles. The Transient Mode is a much longer test then the Creep Mode and operates the vehicle through a much broader spectrum of speeds and a large number of acceleration ramps. In Table 4 the average percent increase between the Unladen and Laden test weights was almost $50 \%$ and the maximum percent increase in $\mathrm{NO}_{\mathrm{X}}$ was over $100 \%$ for one of the 1986 vehicles tested. If the Unladen $\mathrm{NO}_{\mathrm{X}}$ emissions were corrected for test weight to match up with the Laden $\mathrm{NO}_{\mathrm{X}}$ emissions for the 1986 vehicle the corrected $\mathrm{NO}_{\mathrm{X}}$ value would have been $15 \mathrm{~g} / \mathrm{mile}$. The $15 \mathrm{~g} / \mathrm{mile}$ is a little less than the Laden $\mathrm{NO}_{\mathrm{X}}$ value, but this comparison was for the most extreme case and would work for the rest of the data.

The PM emissions for all the vehicles tested are presented in Figure 34. There are a few high emitters in the graph that allowed the rest of the data to look acceptable, but the lowest emitting vehicles are in the most recent Engine Model Year Group. About a third of the vehicles produced higher PM emissions for the Unladen test weight than the Laden test weight. In Table 4 the average increase for the PM emissions was $31 \%$ with a maximum increase of $113 \%$ coming from the 1979 test vehicle.

A comparison between $\mathrm{CO}_{2}$ emissions and $\mathrm{NO}_{\mathrm{X}}$ emissions was made in Figure 35 for the Laden and Unladen test weights. The different test weights data for the Transient Mode were fitted with "best-fit" lines and like the Creep Mode the data was fairly scattered and a poor correlation between $\mathrm{NO}_{\mathrm{X}}$ and $\mathrm{CO}_{2}$ was made. However, the Laden "best-fit" line was much higher then the Unladen "best-fit" line. This follows the relationship between test weight and $\mathrm{NO}_{\mathrm{X}}$ production. The Laden Transient Mode data was on average higher then the Unladen Transient Mode data. 
Figure 33: $\mathrm{NO}_{\mathrm{x}}$ emissions for the Laden and Unladen Transient Mode. The graph is also divided up into groups based on California Emissions Regulations.

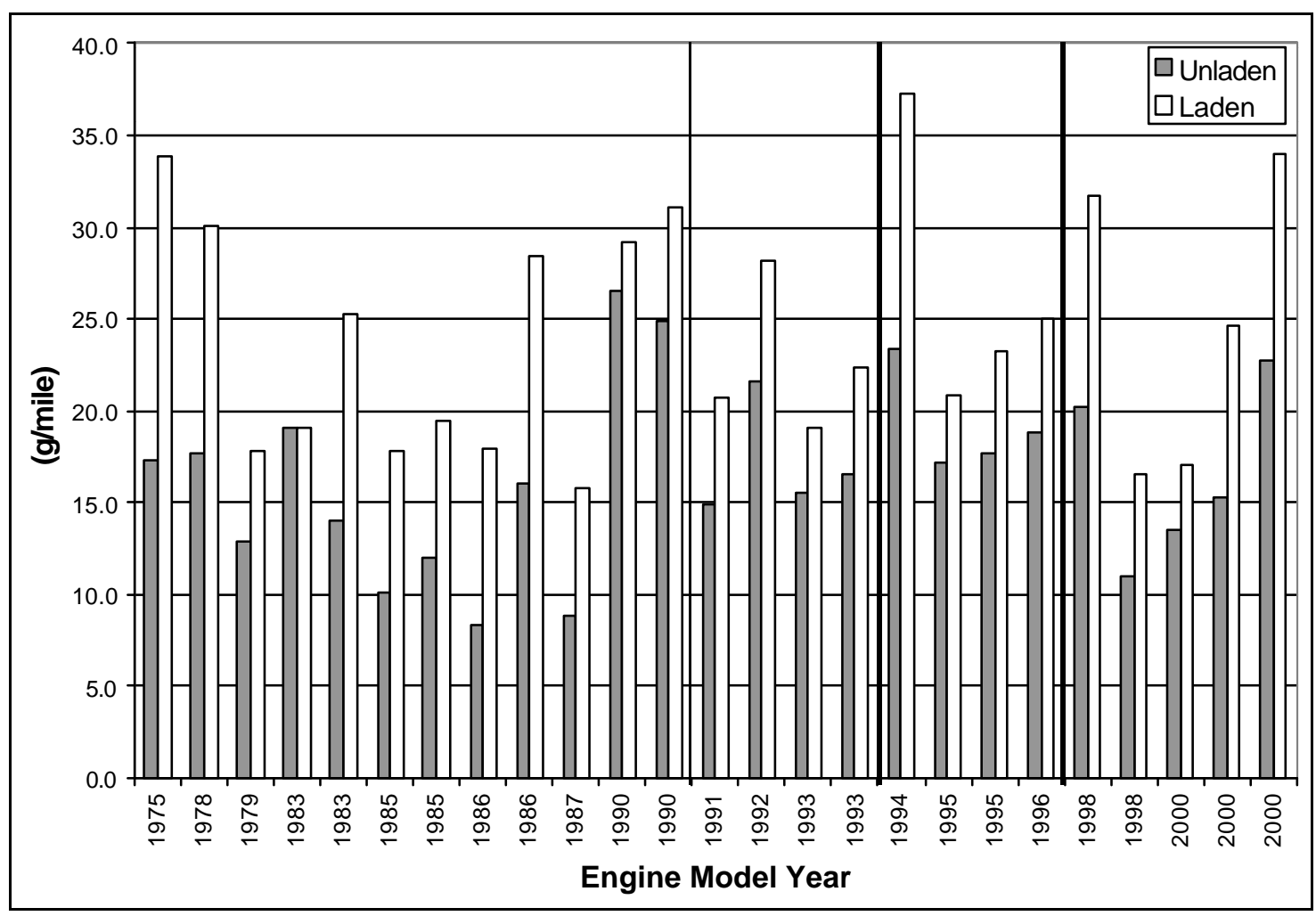

Figure 34: PM emissions for the Laden and Unladen Transient Mode. The graph is also divided up into groups based on California Emissions Regulations.

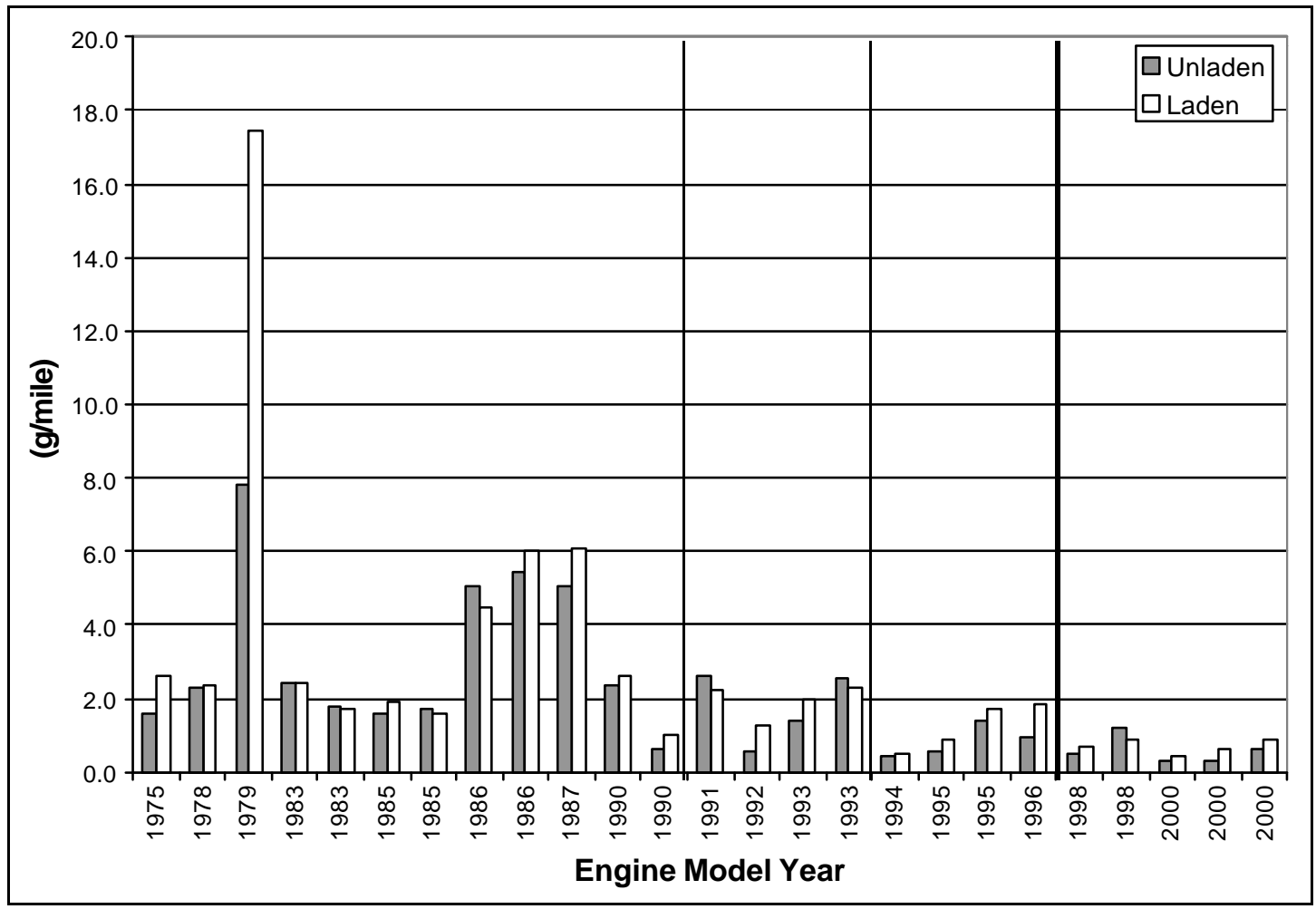


Figure 35: Relationship between Laden and Unladen test weights for the Transient Mode. The linear fits are poor, but provide a visual indication that $\mathrm{NO}_{\mathrm{x}}$ emissions (relative to $\mathrm{CO}_{2}$ emissions) are higher for the laden operation.

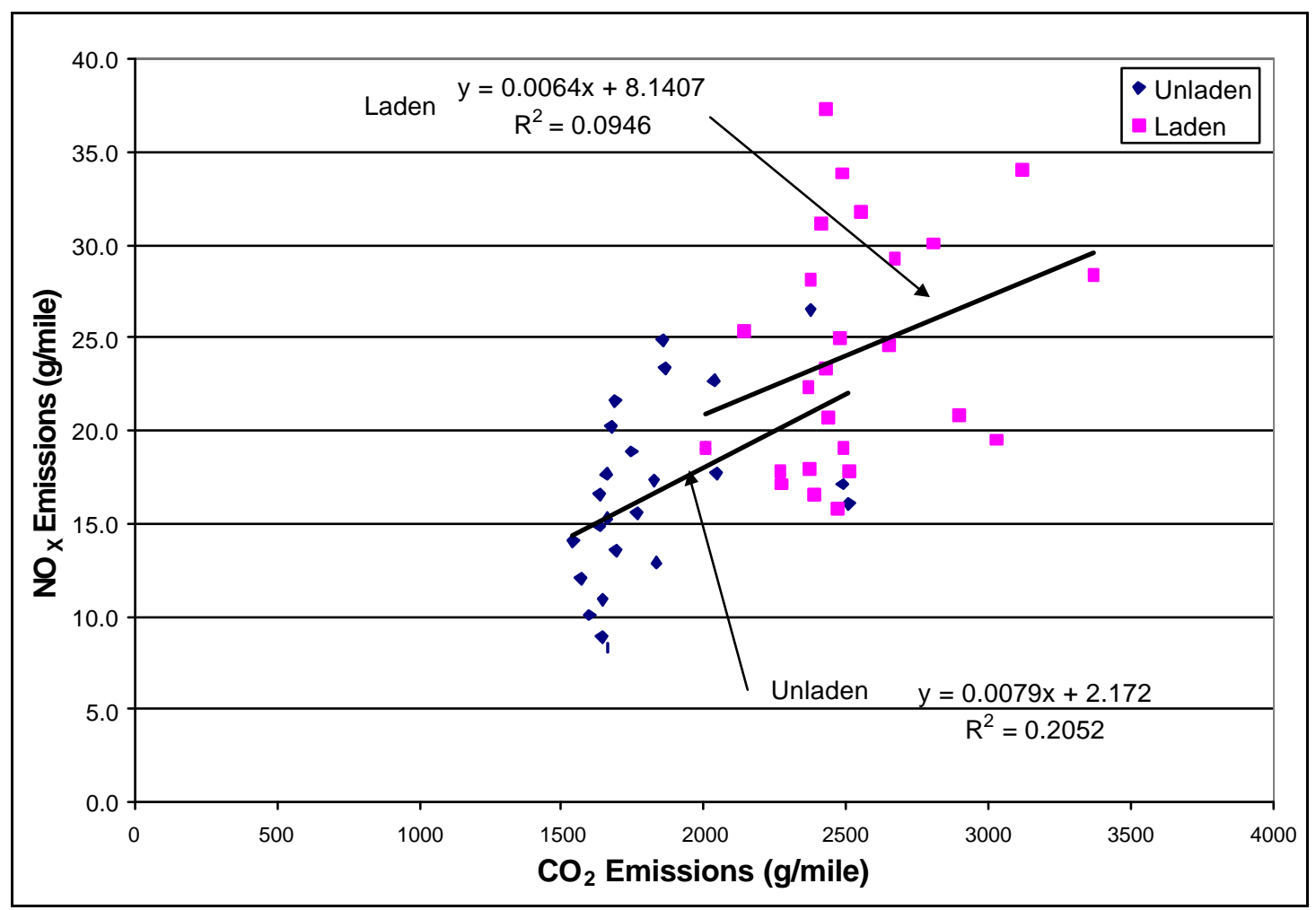

The emissions of $\mathrm{CO}_{2}$, for the Laden and Unladen Transient Mode, are shown in

Figure 36. It was anticipated that it would take more fuel to operate the vehicle at a higher load on the same cycle. Every vehicle in the study produced more $\mathrm{CO}_{2}$ emissions for the Laden Transient Mode than the Unladen Transient Mode. The average, maximum and minimum percent increases are presented in Table 4. The average increase between the Unladen and Laden test weight for $\mathrm{CO}_{2}$ was $40 \%$ and the maximum percent increase was $93 \%$. 
Figure 36: $\mathrm{CO}_{2}$ emissions for the Laden and Unladen Transient Modes. The graph is also divided up into groups based on California Emissions Regulations.

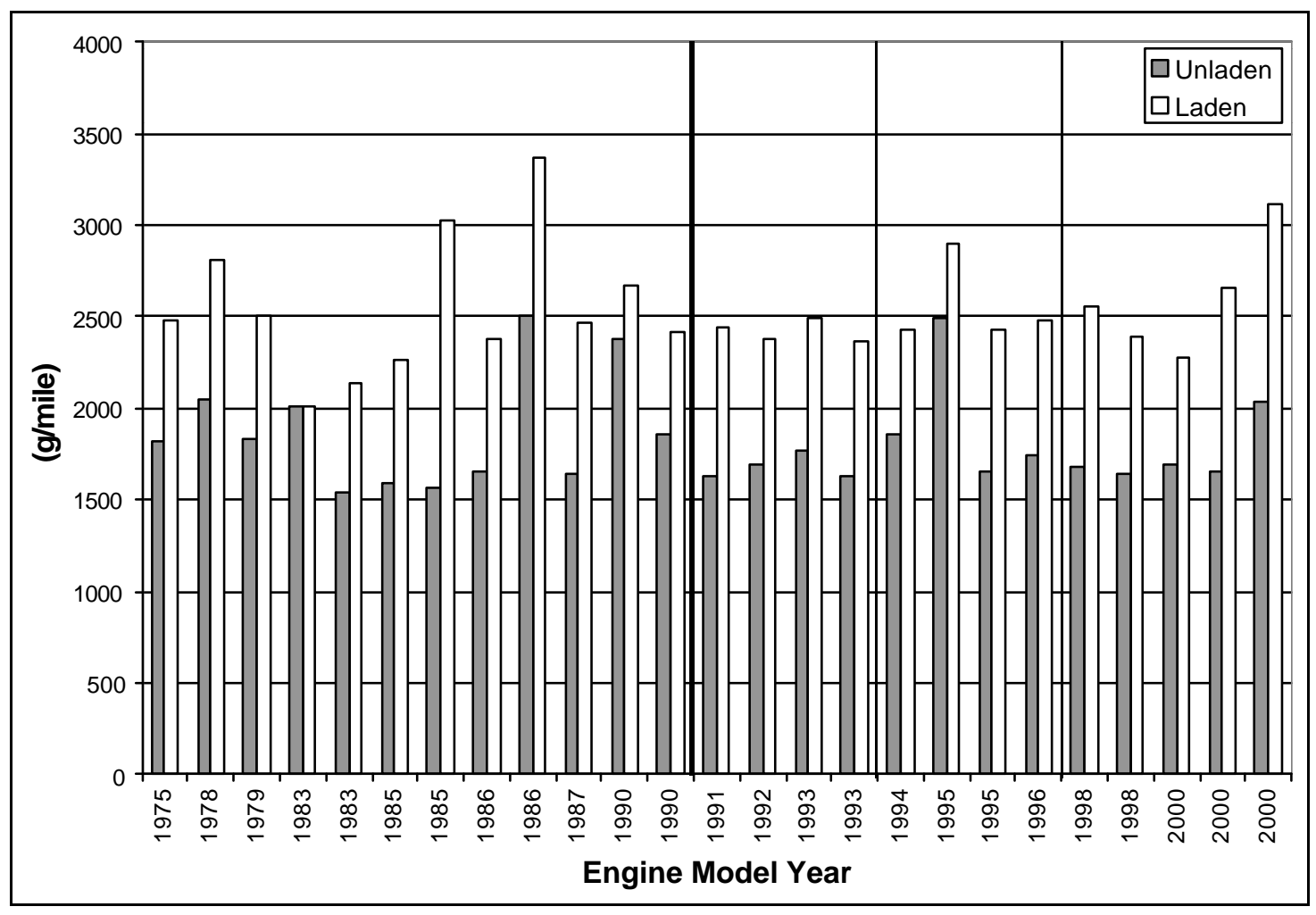

The emissions of $\mathrm{CO}$ and $\mathrm{HC}$ are presented in Figure 37 and Figure 38 for the Unladen and Laden Transient Mode. The CO emissions tended to drop as model year increased and HC followed the same trend except for one of the 1993 heavy-duty vehicles, which had fairly high $\mathrm{HC}$ emissions. The emission regulations for $\mathrm{CO}$ and $\mathrm{HC}$ have not changed since 1984 and tend to be low for diesel engines; there is more concern over $\mathrm{NO}_{\mathrm{X}}$ and $\mathrm{PM}$ emissions levels that are relatively high in diesel engines. In Table 4 the average, maximum and minimum percent difference between the Unladen and Laden test weights were determined. The average increase for $\mathrm{HC}$ was not high, less then $1 \%$. The CO on the other hand had an average increase of $56 \%$. 
Figure 37: CO emissions for the Laden and Unladen Transient Modes. The graph is also divided up into groups based on California Emissions Regulations.

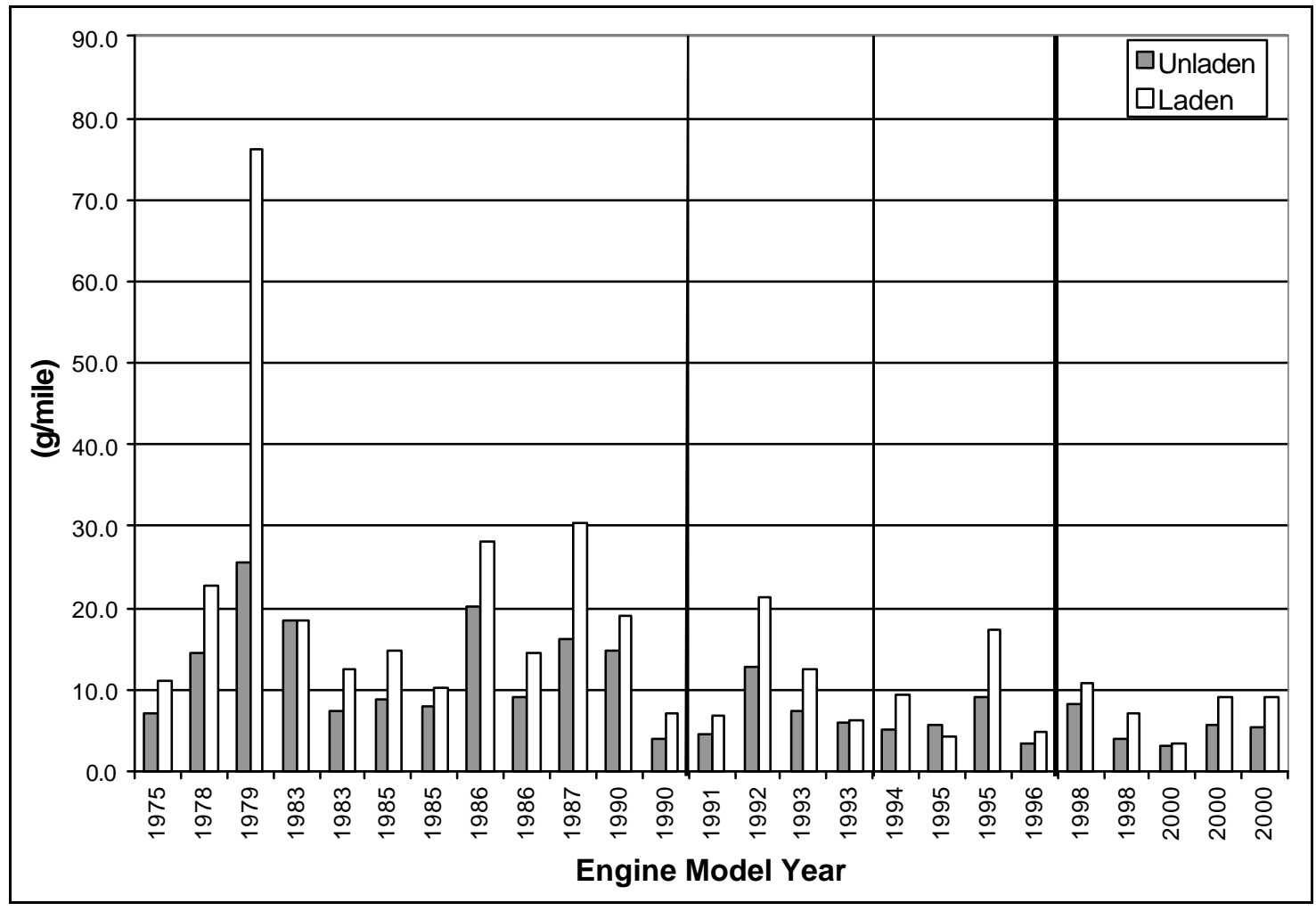


Figure 38: HC emissions for the Laden and Unladen Transient Modes. The graph is also divided up into groups based on California Emissions Regulations.

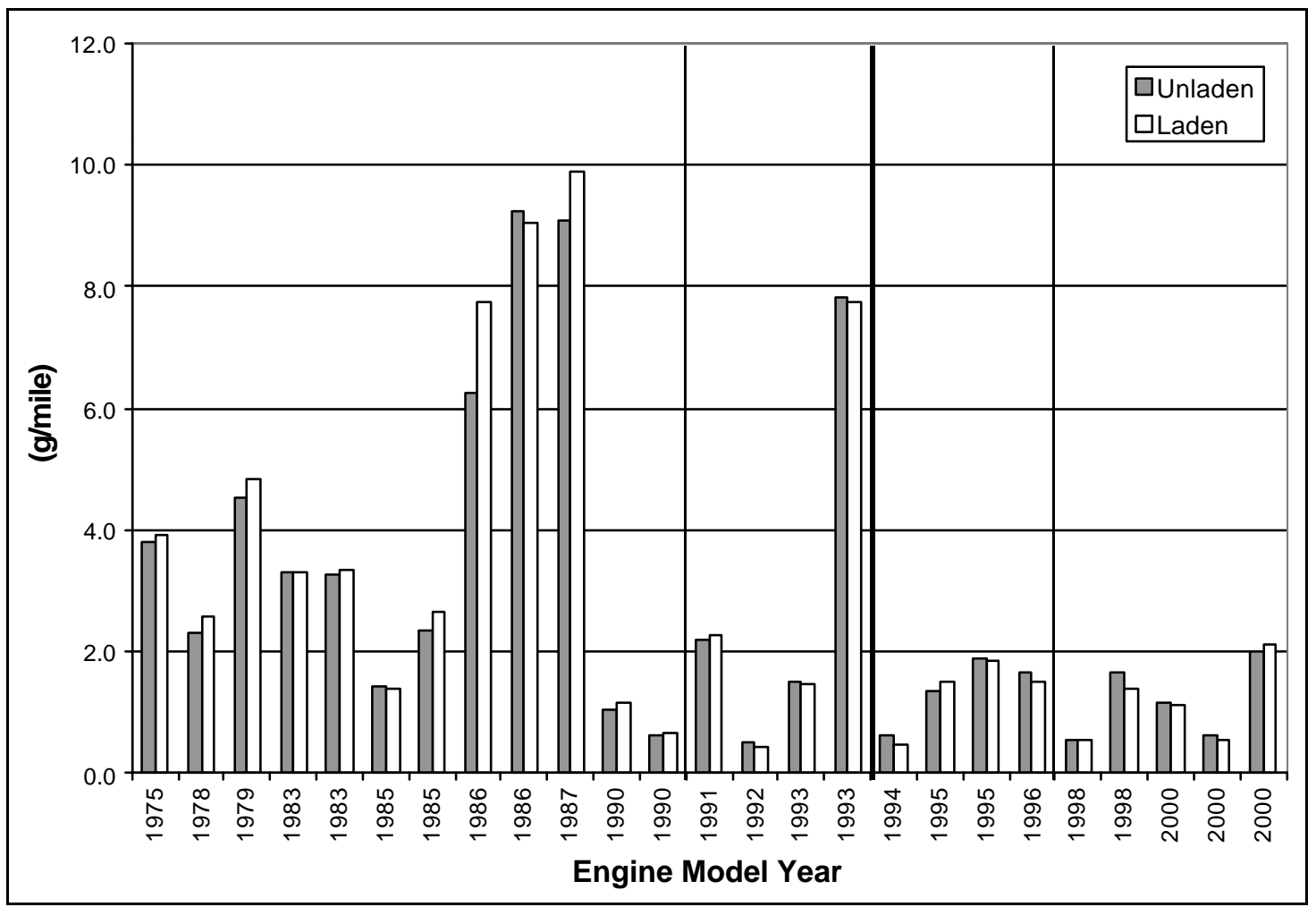

Table 4: Average, maximum and minimum percent difference between the Laden and Unladen Transient Mode.

\begin{tabular}{|l|c|c|c|c|c|}
\cline { 2 - 6 } \multicolumn{1}{c|}{} & $\mathrm{CO}$ & $\mathrm{NO}_{x}$ & $\mathrm{HC}$ & $\mathrm{PM}$ & $\mathrm{CO}_{2}$ \\
\hline Average Percent Difference & 56.71 & 49.83 & 0.84 & 31.88 & 40.43 \\
\hline Maximum Percent Difference & 196.88 & 116.09 & 23.92 & 123.41 & 93.08 \\
\hline Minimum Percent Difference & -25.77 & 0.00 & -23.49 & -24.07 & 0.00 \\
\hline
\end{tabular}

\subsubsection{Laden vs. Unladen Cruise Mode}

All twenty-five vehicles in the study were tested on the Cruise Mode under Laden and Unladen test weight conditions to determine the effects it had on emissions while operating under high-speed cruising conditions. $\mathrm{NO}_{\mathrm{X}}, \mathrm{PM}, \mathrm{CO}_{2}, \mathrm{CO}$ and $\mathrm{HC}$ are presented in Figure 39 through Figure 44.

The Laden and Unladen Cruise Mode $\mathrm{NO}_{\mathrm{X}}$ emissions are presented in Figure 39. The emissions in general did not follow the same downward trend that the PM emissions 
followed and do not relate to California Emissions Standards. Some of the highest emitting vehicles for the Laden and Unladen test weights were in the two most recent Engine Model Year Groups. The Laden $\mathrm{NO}_{\mathrm{X}}$ emissions followed the same general rule of thumb presented in the Transient Mode. As the load on the vehicle increased, the $\mathrm{NO}_{\mathrm{X}}$ emissions increased and every vehicle, except one, followed this trend. The average, maximum and minimum percent increase is presented in Table 5 for $\mathrm{NO}_{\mathrm{X}}$ emissions. The average increase in $\mathrm{NO}_{\mathrm{X}}$ emissions was $56 \%$ with a maximum increase of $148 \%$. If the Unladen data was corrected to the Laden test weight their would be a $43 \%$ increase. So there is a difference between the calculated and actual results, but the different test weights are comparable when corrected for the Cruise Mode.

The PM emissions for all the vehicles tested at the Laden and Unladen test weights are presented in Figure 40. The emissions are fairly low for all the vehicles except for the 1979 heavy-duty vehicle that produced very high levels of PM emissions under Laden conditions. The 1979 vehicle was E55CRC-16 that produced consistently high PM levels and had noticeable black smoke during testing. The maximum percent increase in Table 5 was $485.35 \%$ for E55CRC-16. The rest of the data followed a slight downward trend as Engine Model Year increased and the average percent increase between the Unladen and Laden test weights was 55\%. 
Figure 39: $\mathrm{NO}_{\mathrm{x}}$ emissions for the Laden and Unladen Cruise Modes. The graph is also divided up into groups based on California Emissions Regulations.

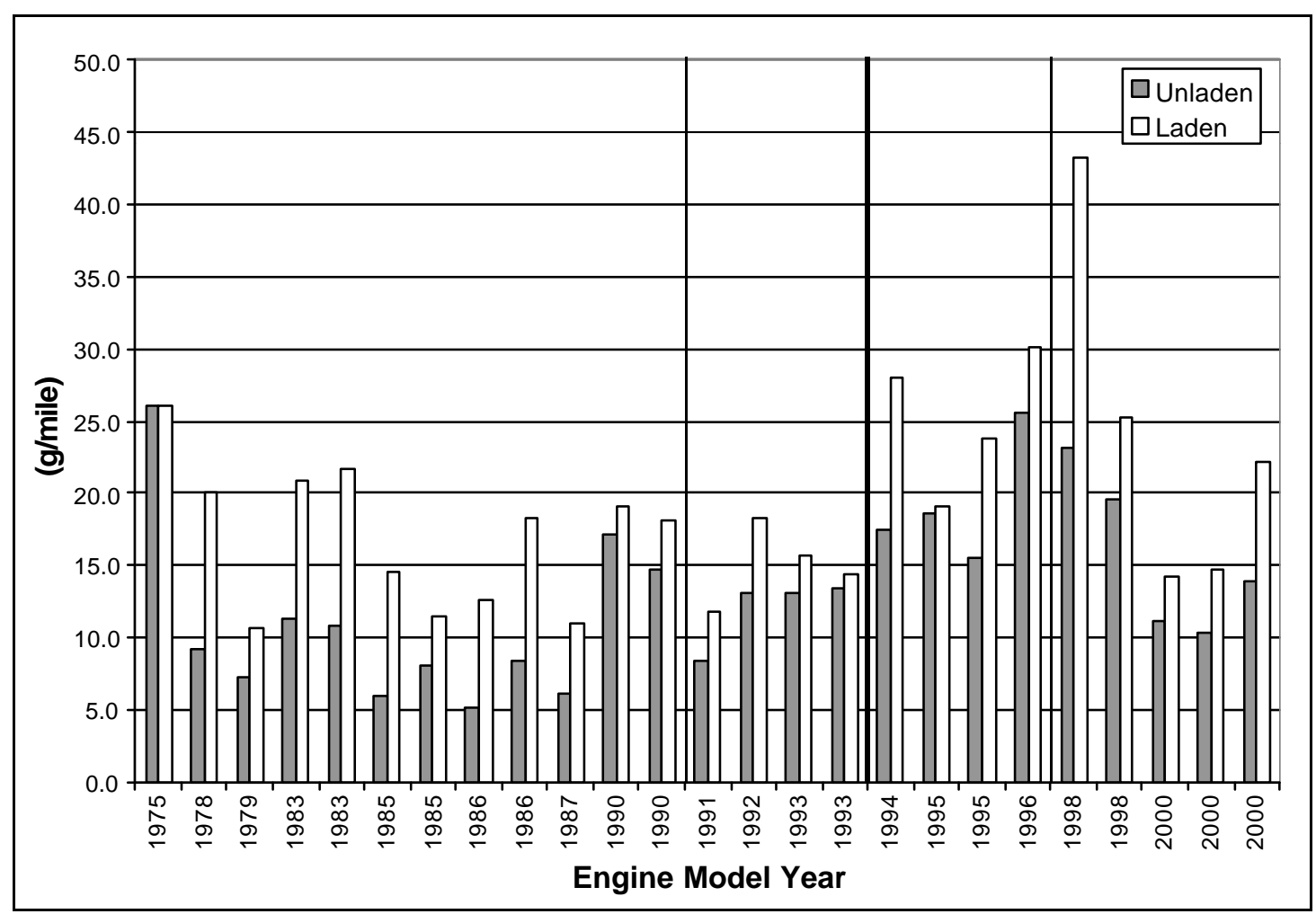

Figure 40: PM emissions for the Laden and Unladen Cruise Modes. The graph is also divided up into groups based on California Emissions Regulations.

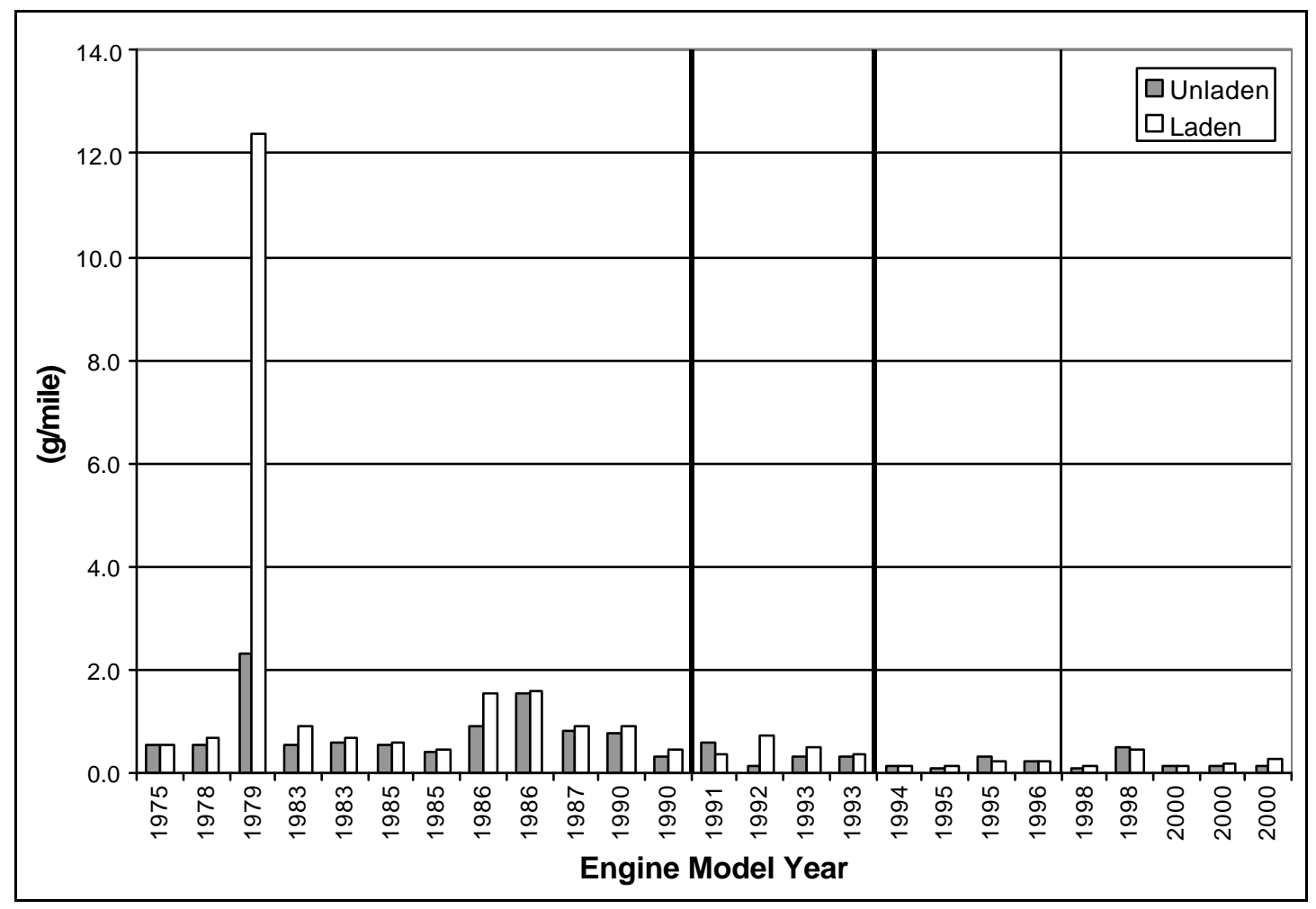


The $\mathrm{NO}_{\mathrm{X}}$ and $\mathrm{CO}_{2}$ emissions were compared for the Cruise Mode just like the Transient and Creep Mode previously. The results are presented in Figure 41 and the Unladen and Laden test weights results follow more closely to the Creep Mode then the Transient Mode relationship. The Unladen and Laden data tended to group together in separate groups. The Creep Mode $\mathrm{NO}_{\mathrm{X}}$ to $\mathrm{CO}_{2}$ comparison tended to have overlapping data for the Unladen and Laden data, the Transient Mode started to show separations between the Unladen and Laden $\mathrm{CO}_{2}$ data. The Cruise Mode produced similar results in comparison to the Transient Mode with even more separation between the Unladen and Laden $\mathrm{CO}_{2}$ data.

\section{Figure 41: Relationship between Unladen and Laden test weights for the Cruise} Modes. The linear fit is poor.

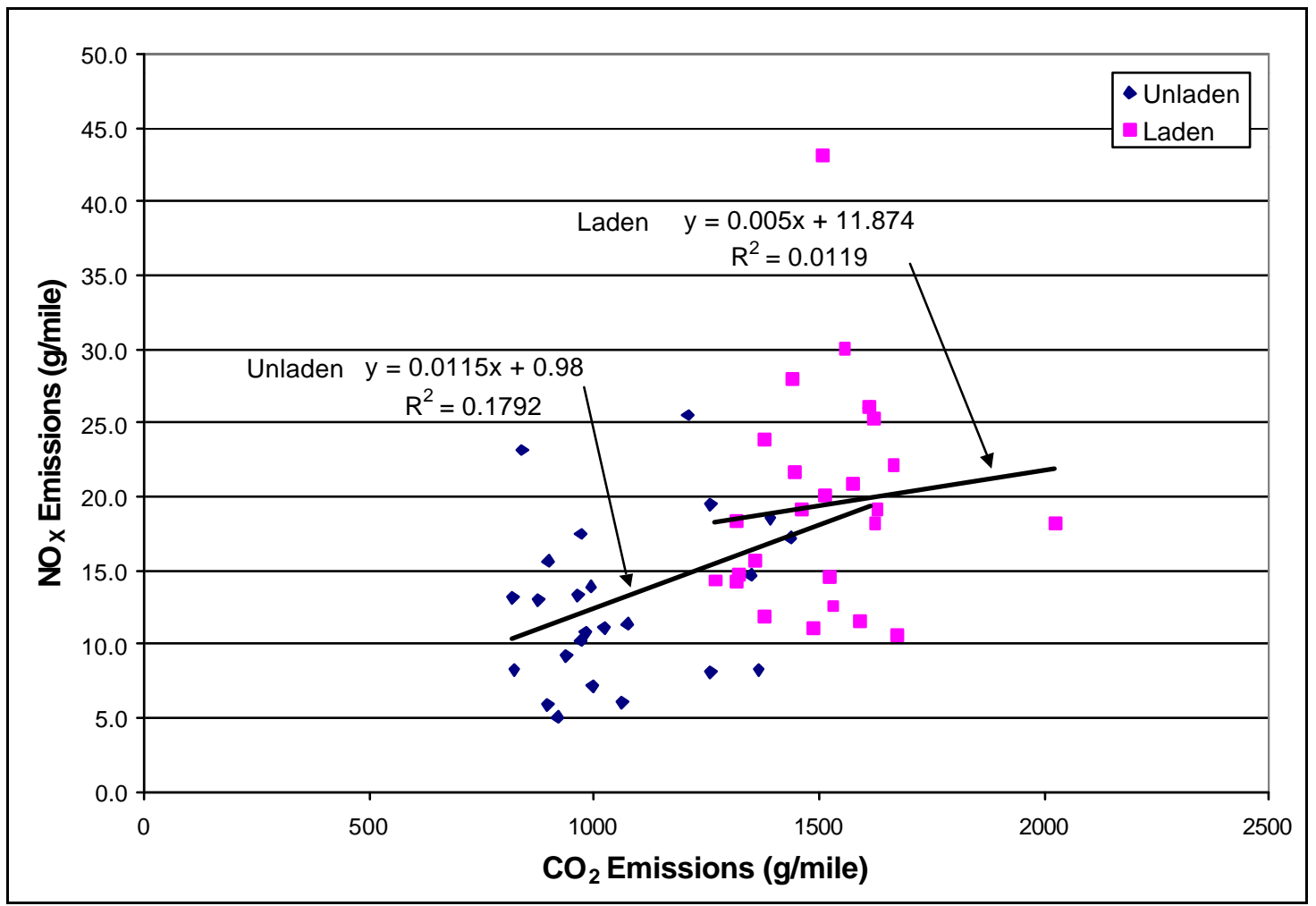

The emissions of $\mathrm{CO}_{2}, \mathrm{CO}$ and $\mathrm{HC}$ were also examined for the differences between Laden and Unladen test weights and Engine Model Year. The relationship 
between the Unladen and Laden test weights for $\mathrm{CO}_{2}$ followed the same trend as the Transient Mode. All the vehicles had higher $\mathrm{CO}_{2}$ emissions except for the first vehicle tested. The average $\mathrm{CO}_{2}$ emissions are presented in Table 5 and the average percent increase was $44 \%$ between the Unladen and Laden test weight. The $\mathrm{CO}$ emissions followed a similar downward trend as the Transient Mode data, when the Engine Model Year increased. The emissions of $\mathrm{CO}$ were higher for the Laden test weight in comparison to the Unladen test weight for all except two vehicles. Three of the older vehicles had some of the highest increase in $\mathrm{CO}$ emissions between the Laden and Unladen Test weights. The maximum CO increase was over 550\% (Table 5). The HC emissions tended to be low with some high emitters in the Pre-1990 group. CO and HC are less of a concern because diesel engines produce low levels of $\mathrm{HC}$ and $\mathrm{CO}$ emissions in relation to $\mathrm{PM}$ and $\mathrm{NO}_{\mathrm{X}}$. It was expected that $\mathrm{CO}$ and $\mathrm{HC}$ emissions would either decrease slightly because of improvements in technology or stay the same because of emissions standards. 
Figure 42: $\mathrm{CO}_{2}$ emissions from the Laden and Unladen Cruise Modes. The graph is also divided up into groups based on California Emissions Regulations.

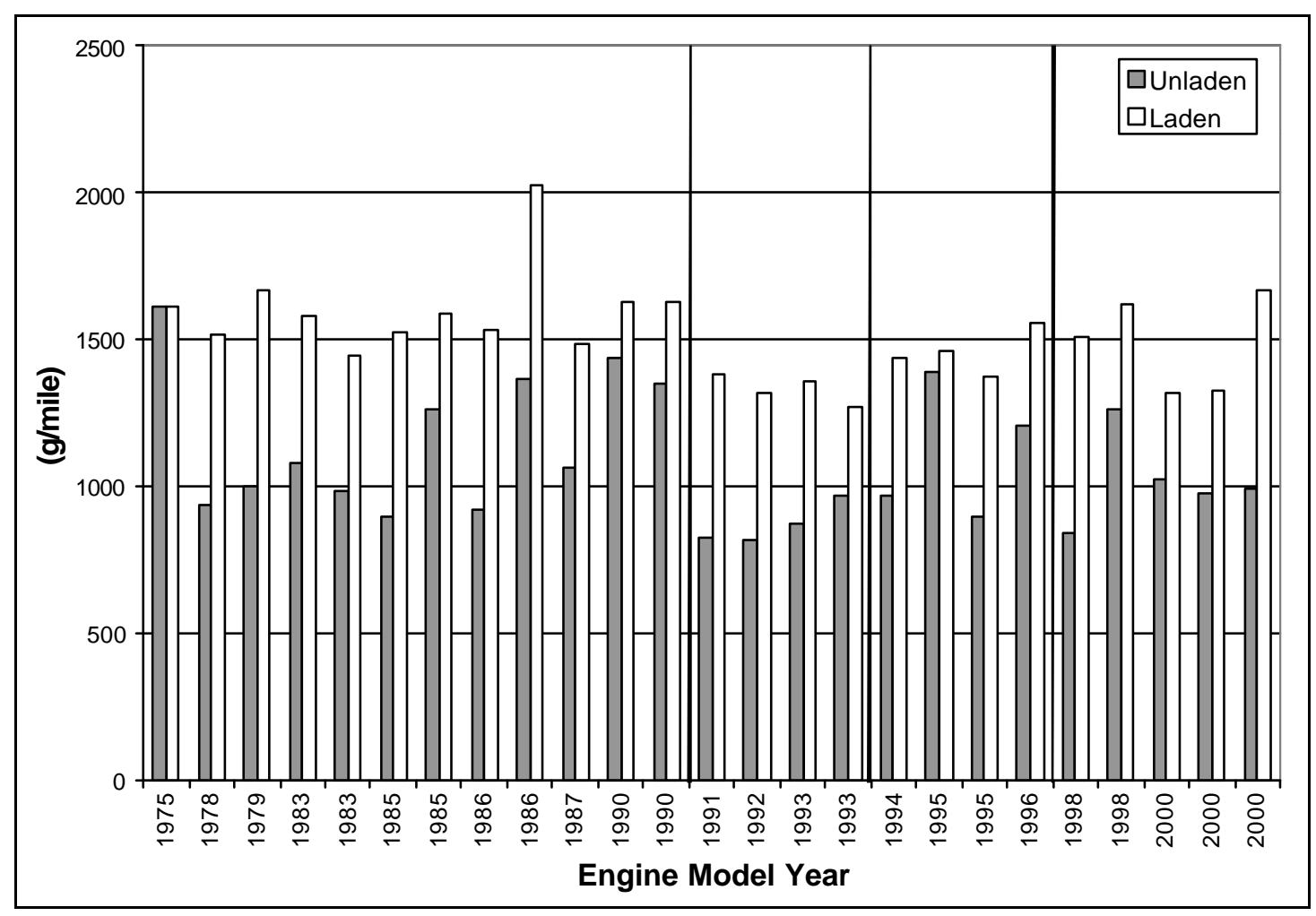

Figure 43: CO emissions for the Laden and Unladen Cruise Modes. The graph is also divided up into groups based on California Emissions Regulations.

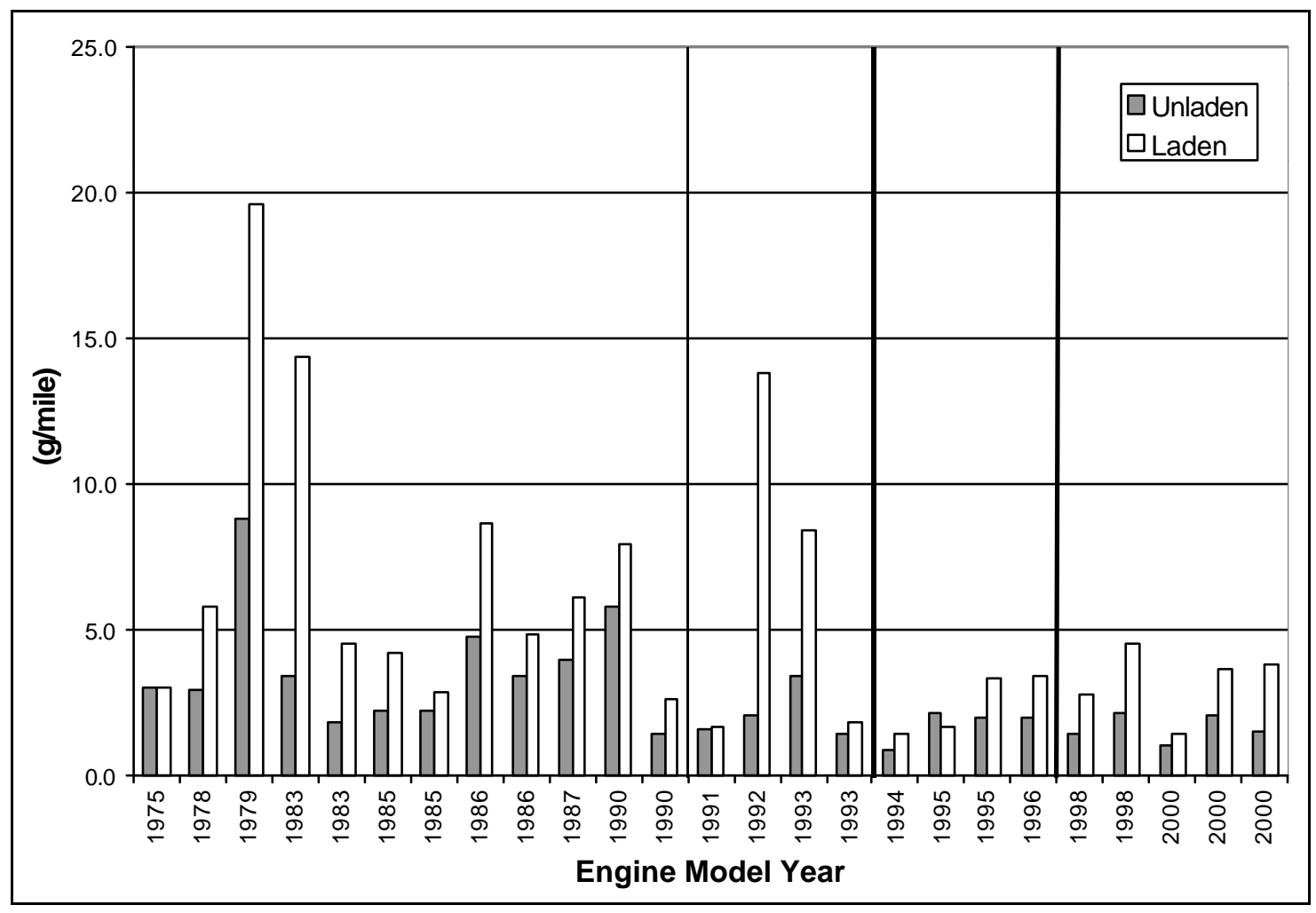


Figure 44: HC emissions for the Unladen and Laden Cruise Modes. The graph is also divided up into groups based on California Emissions Regulations.

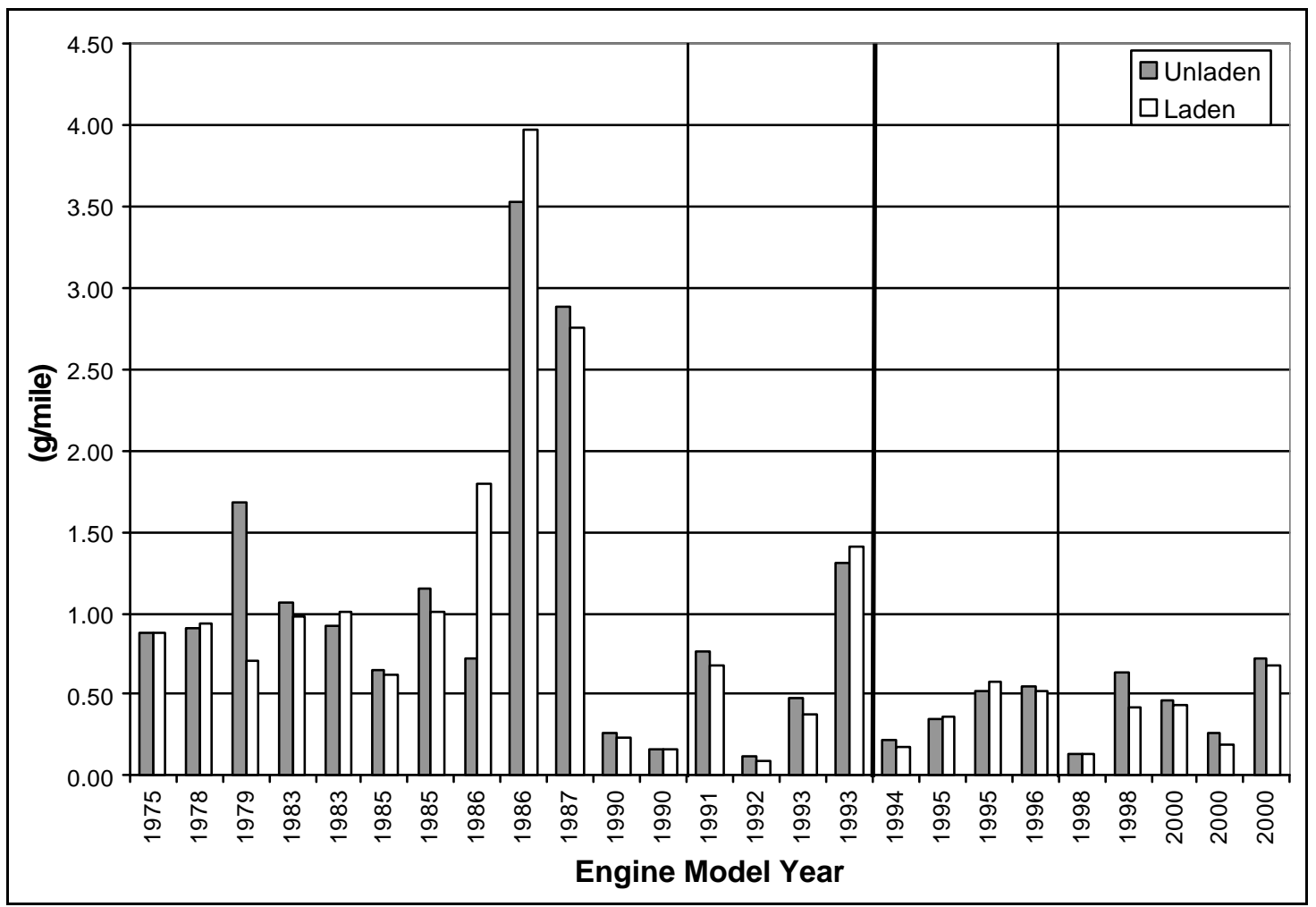

Table 5: Average, maximum and minimum percent difference between the Laden and Unladen Cruise Mode.

\begin{tabular}{|l|c|c|c|c|c|}
\cline { 2 - 6 } \multicolumn{1}{c|}{} & $\mathrm{CO}$ & $\mathrm{NO}_{\mathrm{x}}$ & $\mathrm{HC}$ & $\mathrm{PM}$ & $\mathrm{CO}_{2}$ \\
\hline Average Percent Difference & 100.09 & 56.46 & -2.21 & 55.23 & 44.00 \\
\hline Maximum Percent Difference & 556.02 & 148.11 & 150.79 & 485.35 & 79.91 \\
\hline Minimum Percent Difference & -21.34 & 0.00 & -57.77 & -39.10 & 0.00 \\
\hline
\end{tabular}

\subsection{Comparison Between the Test Length for the Idle and Creep Mode}

\subsubsection{Comparison Between the Idle and Long Idle Mode}

The first thirteen vehicles in the CRC E55/59 Phase I study were evaluated on the Idle Mode and the Long Idle Mode. The Long Idle Mode was twice as long as the Idle Mode. Figure 45 through Figure 49 present the gaseous emissions and PM in units of $\mathrm{g} / \mathrm{min}$. 
The $\mathrm{NO}_{\mathrm{X}}$ emissions for the Idle and Long Idle Mode are presented in Figure 45. The $\mathrm{NO}_{\mathrm{X}}$ values are lowest for the oldest vehicles. The highest emissions levels came from the most recently produced engines and shows that idling heavy-duty vehicles manufactured in the 1990's produce more $\mathrm{NO}_{\mathrm{X}}$ idle emissions than vehicles in the 1970's and 1980's. Timing advance on idle may be employed to improve combustion on idle, and this can raise $\mathrm{NO}_{\mathrm{X}}$. There was a large amount of variability in the data set for the Idle Modes and could affect the emissions results.

The emissions of PM from the thirteen vehicles are illustrated in Figure 46. One of the lowest PM emitters for Idle and Long Idle is the 1990 vehicle and one of the highest emitters is the 1986 vehicle. Overall the PM data tended to vary from vehicle to vehicle and run-to-run. The PM emissions data for the Idle and Long Idle Modes do not show a downward slope, but because of the variability between tests on the same vehicle, it is difficult to make this comparison. However, in general, the results for the Idle and Long Idle Modes tended to be similar. The uncertainty was examined for E55CRC-8 on one of the Idle Modes and Long Idle Modes. The uncertainty in the $\mathrm{PM}_{\text {mass }}$ calculation, Equation 1, was determined by taking the partial differential method presented in Error! Reference source not found.] to determine the uncertainty in the PM measurement for the Idle and Long Idle Modes. The flow rates were sampled from the results of the Idle Mode and Long Idle Mode and a $2 \%$ variation was used, since the Code of Federal Regulations 20] states that the flow rates of the unnel and across the PM filters can vary by $2 \%$. The Dilution Factor was also allowed to have a variation of $2 \%$ in the calculation. The variation in the flow rate had a small effect on the outcome of the PM results, about $1-2 \%$. Two reference filters is kept in the environmental chamber and 
weighed each day to observe the day to day variation in PM filter weight. The results from the reference filter weights were gathered over several days and averaged to determine the variation in filter weight measurement. The average variation was .032 mg. The average was entered into the measurement uncertainty equation and the results between the Idle Mode test and Long Idle Mode test were compared. The results produce a measurement uncertainty of $17.5 \%$ for the Idle Mode and $10.7 \%$ for the Long Idle Mode. A longer test produced less uncertainty in the PM measurement. There is still a 10.7\% variation in the Long Idle Mode data, but the results are more accurate then the Idle Mode. The Long Idle Mode would be a better test for sampling idle emissions from a heavy-duty vehicle because more sample can be gathered in relation to the Idle Mode. The downfall to the Long Idle Mode is that it lengthens the HHDDT Schedule, which is already a considerably lengthy test.

Some of the reasons for the variation between the Idle and Long Idle Mode along with test-to-test variation are due to the auxiliary loads. The auxiliary loads can account for some of the variation and it is expected that the longer test would produce a larger average sample of operation because the vehicle is tested for a longer period of time. The displacement of the engine can also have an effect on the PM emissions produced from the engine. The displacement of an engine can also vary since there are several engine manufacturing companies that produce diesel engines. The displacement and the idle speed would effect the engine's emissions. A third issue that could cause a variation between the Idle and Long Idle Mode is the low emissions levels. The 1990 rehicle has relatively lower emissions then most of the other vehicles in the study. The variation 
between the Idle and Long Idle Mode could increase because of accuracies in measurement.

Figure 45: Comparison of $\mathrm{NO}_{\mathrm{x}}$ emissions between the Idle and Long Idle Modes.

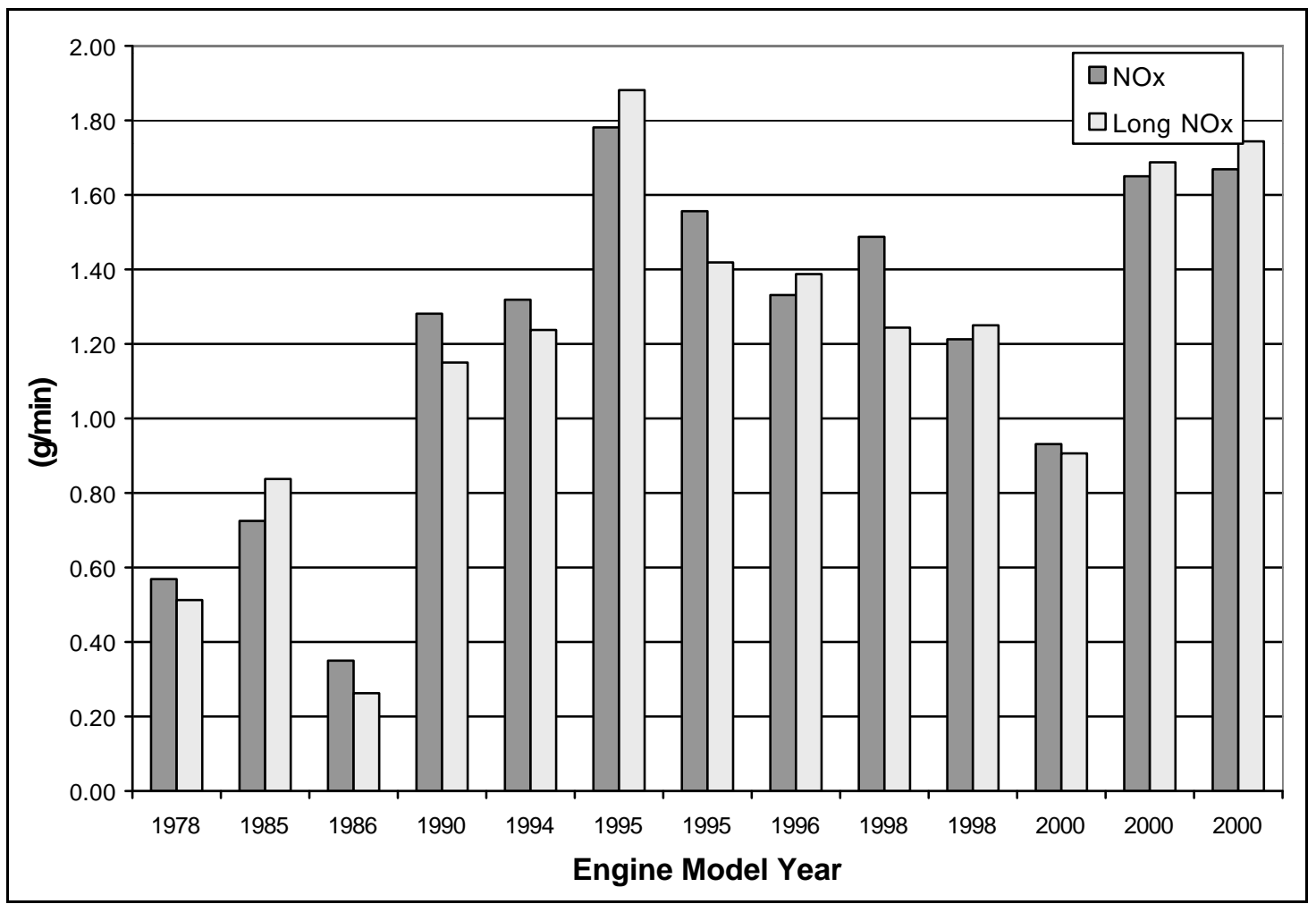


Figure 46: Comparison of PM emissions between the Idle and Long Idle Modes.

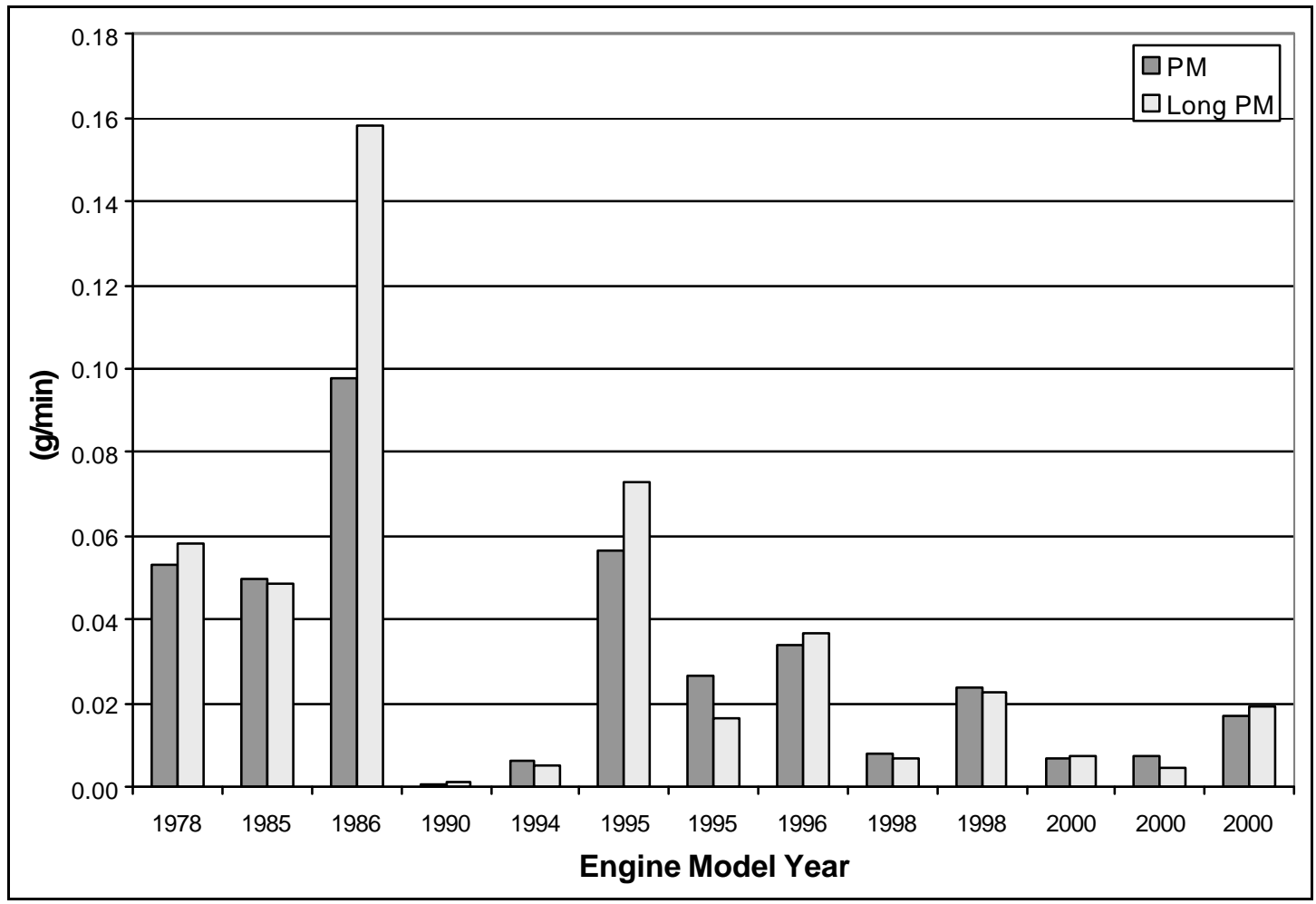

The emissions of $\mathrm{CO}_{2}$ are presented in Figure 47 for the thirteen vehicles tested on the Idle and Long Idle Modes. There was some run-to-run variability between the tests. One of the 2000 vehicles had a high $\mathrm{CO}_{2}$ value for the Idle Mode, but fell in line with the rest of the data for the Long Idle Mode. The CO and $\mathrm{HC}$ data is also presented for the Idle and Long Idle Modes in Figure 48 and Figure 49. The CO and HC show variability between the Idle and Long Idle Modes similar to the $\mathrm{CO}_{2}, \mathrm{PM}$ and $\mathrm{NO}_{\mathrm{X}}$ emissions. It is difficult to draw any clear conclusions from the Idle Mode other than that an average of $0.9 \mathrm{~g} / \mathrm{min}$ of $\mathrm{HC}$ and $0.2 \mathrm{~g} / \mathrm{min}$ of $\mathrm{CO}$ is produced for all thirteen vehicles tested. It is important to understand the average amount of emissions produced from a vehicle while idling, since a number of heavy-duty diesel vehicles are allowed to idle in truck stops over night while the driver rests. A number of states is looking at limiting heavy-duty vehicles from idling in truck stops by providing accessory power and heat 
from a source other than the vehicle to reduce the amount of emissions produced in truck stops.

Figure 47: Comparison between the $\mathrm{CO}_{2}$ emissions produce during the Idle and Long Idle Modes.

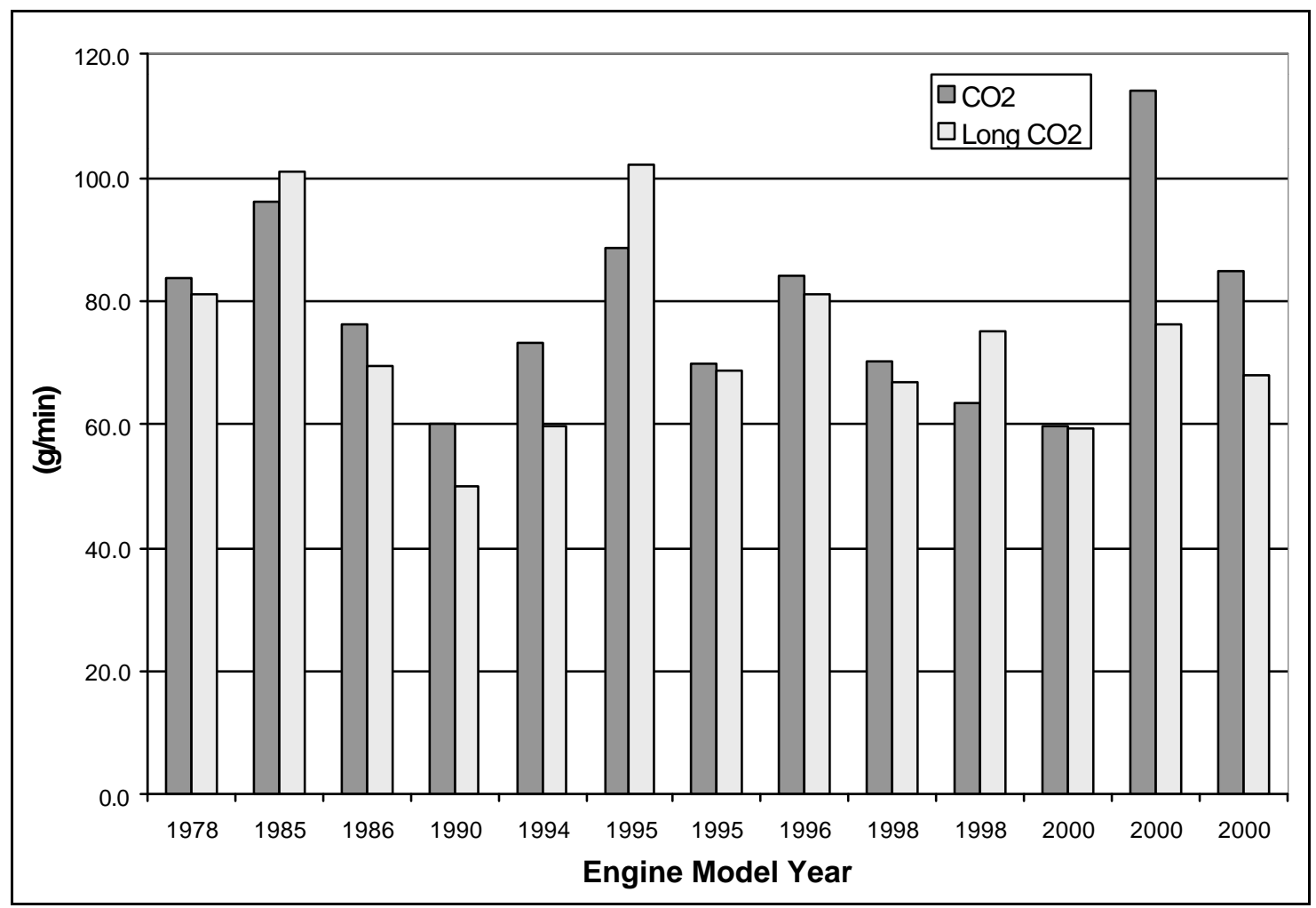


Figure 48: Comparison between the Idle and Long Idle Modes for CO emissions.

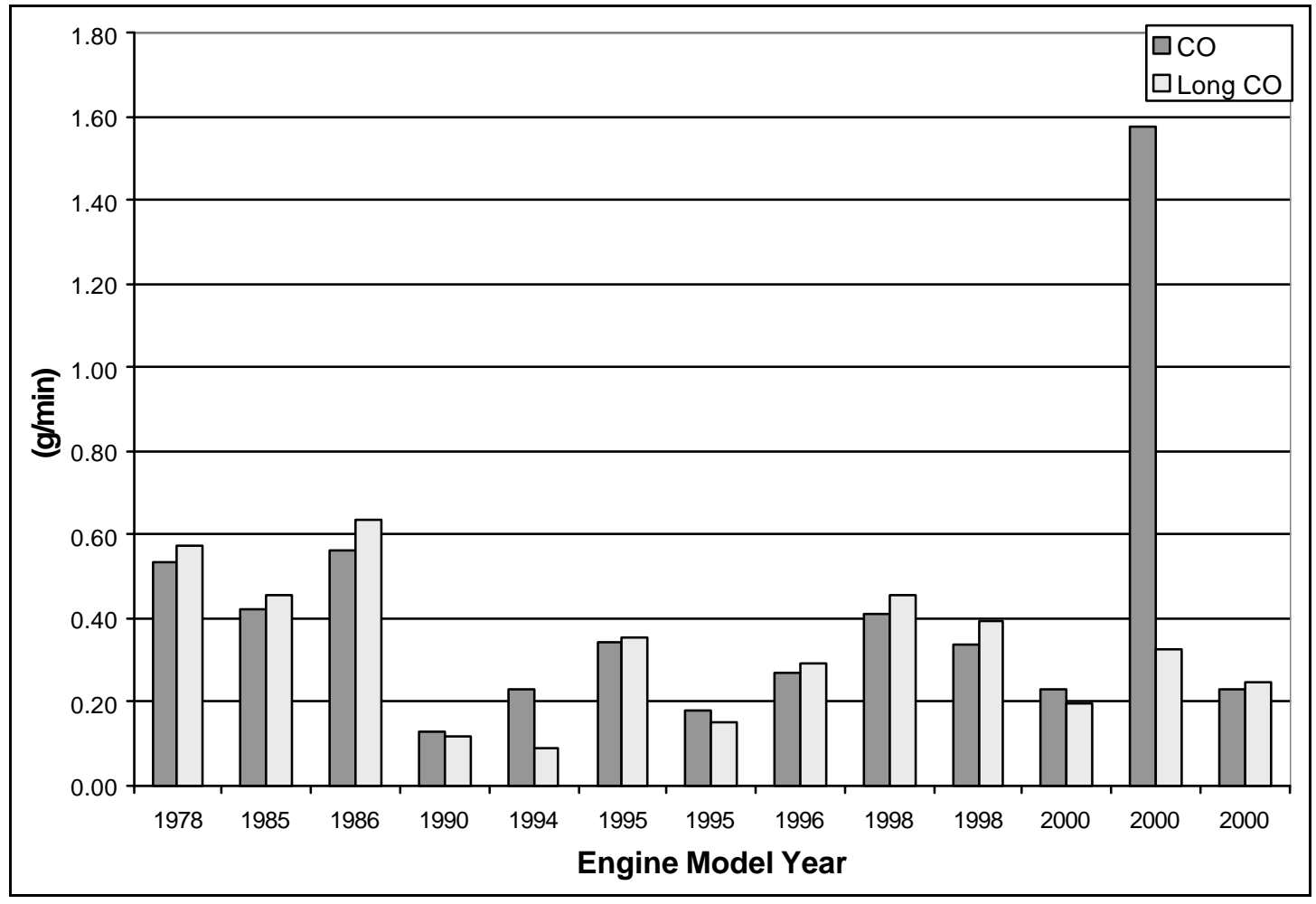

Figure 49: Comparison between the Idle and Long Idle Modes for $\mathrm{HC}$ emissions.

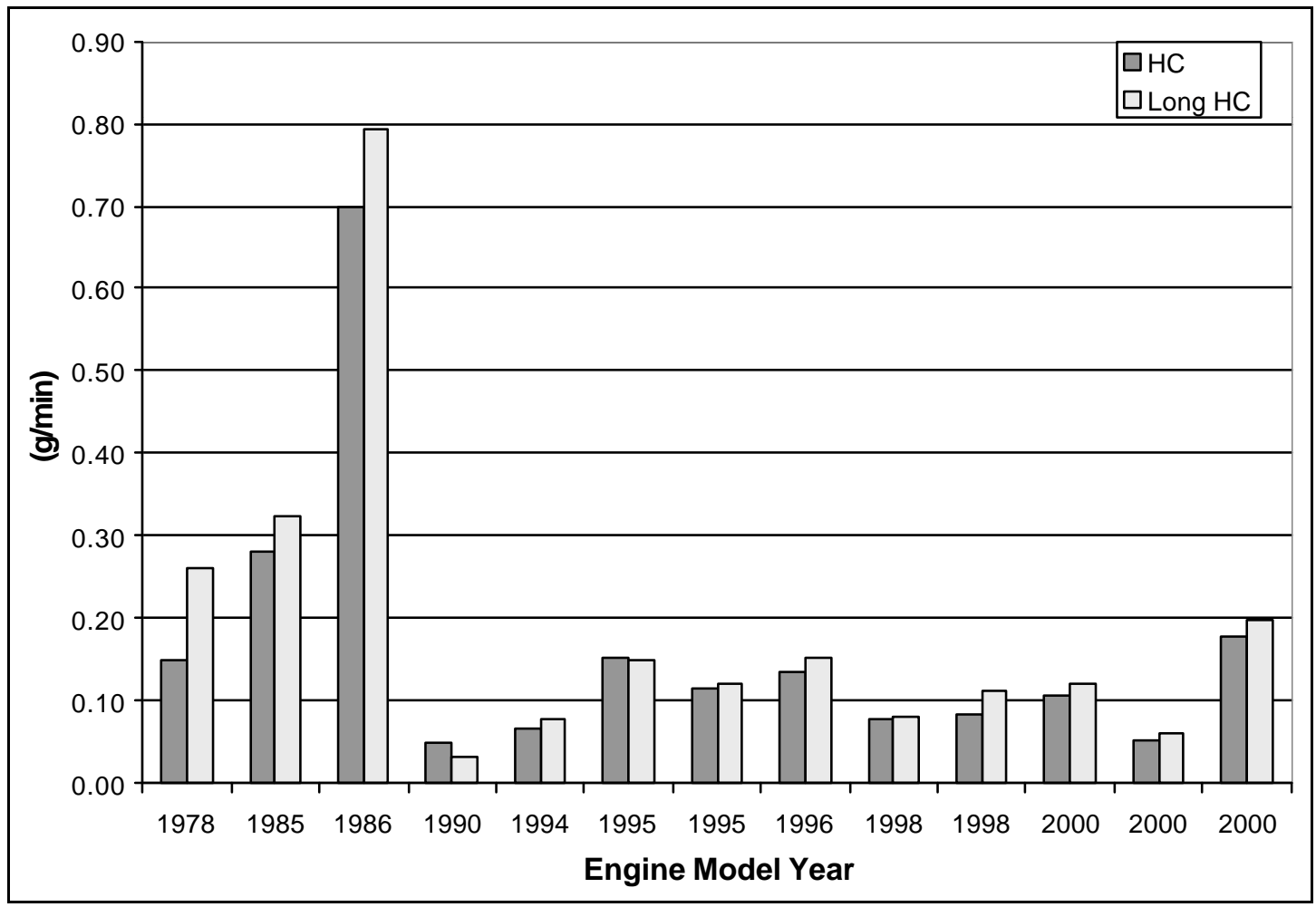




\subsubsection{Comparison Between the Creep and Long Creep Mode}

Thirteen heavy-duty vehicles were tested on the Creep Mode and Long Creep Mode to see if the test length affects the results. The long creep is four Creep Modes put together. The $\mathrm{NO}_{\mathrm{X}}, \mathrm{PM}, \mathrm{CO}_{2}, \mathrm{CO}$ and $\mathrm{HC}$ emissions results for the Creep and Long Creep Mode are presented in Figure 50 through Figure 54. Each of the thirteen heavyduty vehicles tested had more than one test run and the average was taken and presented below. There was some run-to-run variation in the Creep Mode data, but not as high as the Idle Mode.

The emissions of $\mathrm{NO}_{\mathrm{X}}$ for the Creep Mode and Long Creep Mode are in Figure 50. There is a slight difference between the Creep and Long Creep data for the $\mathrm{NO}_{\mathrm{X}}$ emissions. Some of the lowest $\mathrm{NO}_{\mathrm{X}}$ emissions were the earliest vehicles tested and the highest emitter was one of the newest vehicles tested. The PM emissions in Figure 28 show a slight decrease as Engine Model Year increased, similar to California Emissions Standards. 
Figure 50: $\mathrm{NO}_{\mathrm{x}}$ emissions comparison between the Creep Mode and the Long Creep Mode.

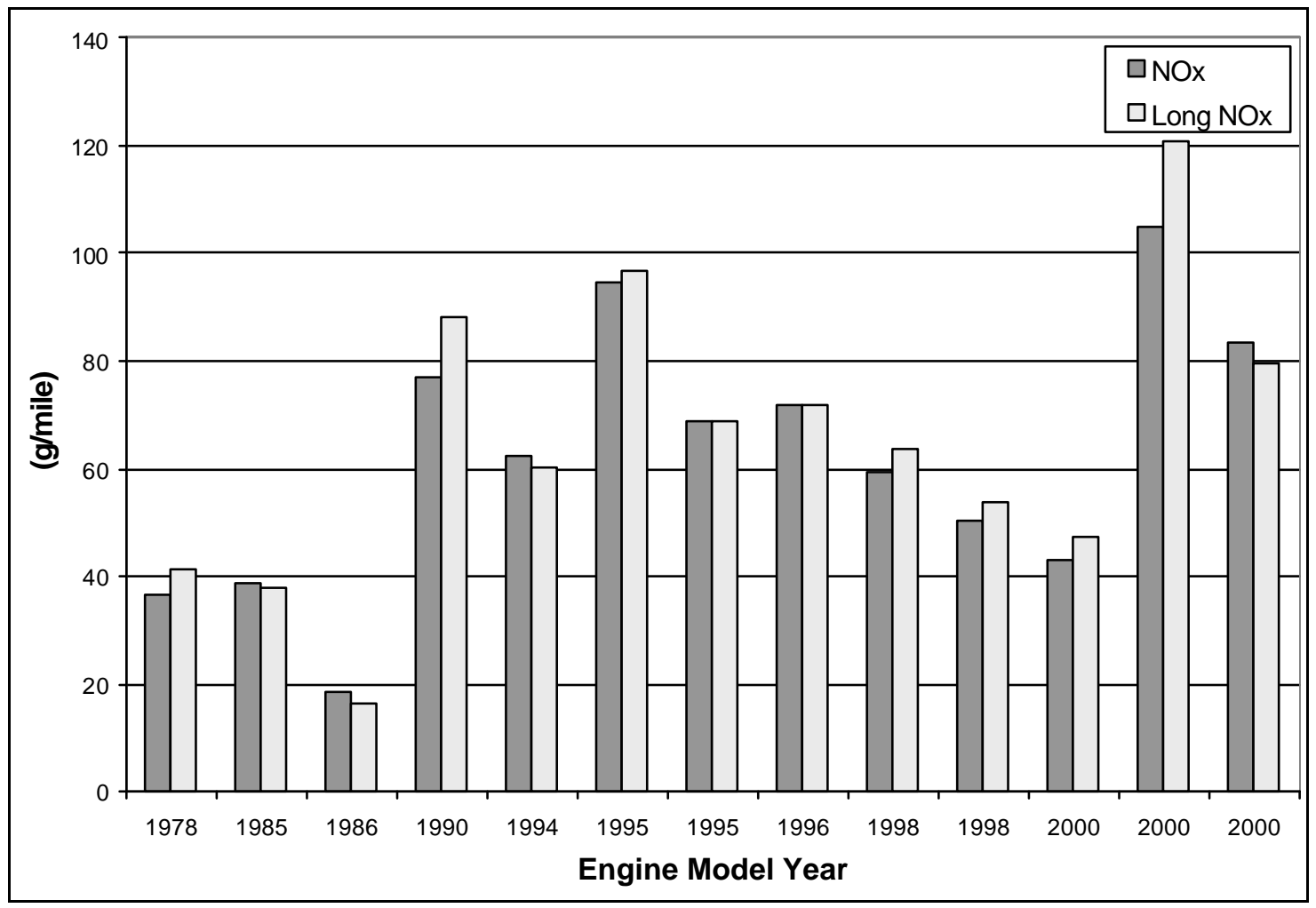


Figure 51: PM emissions comparison between the Creep and Long Creep Modes.

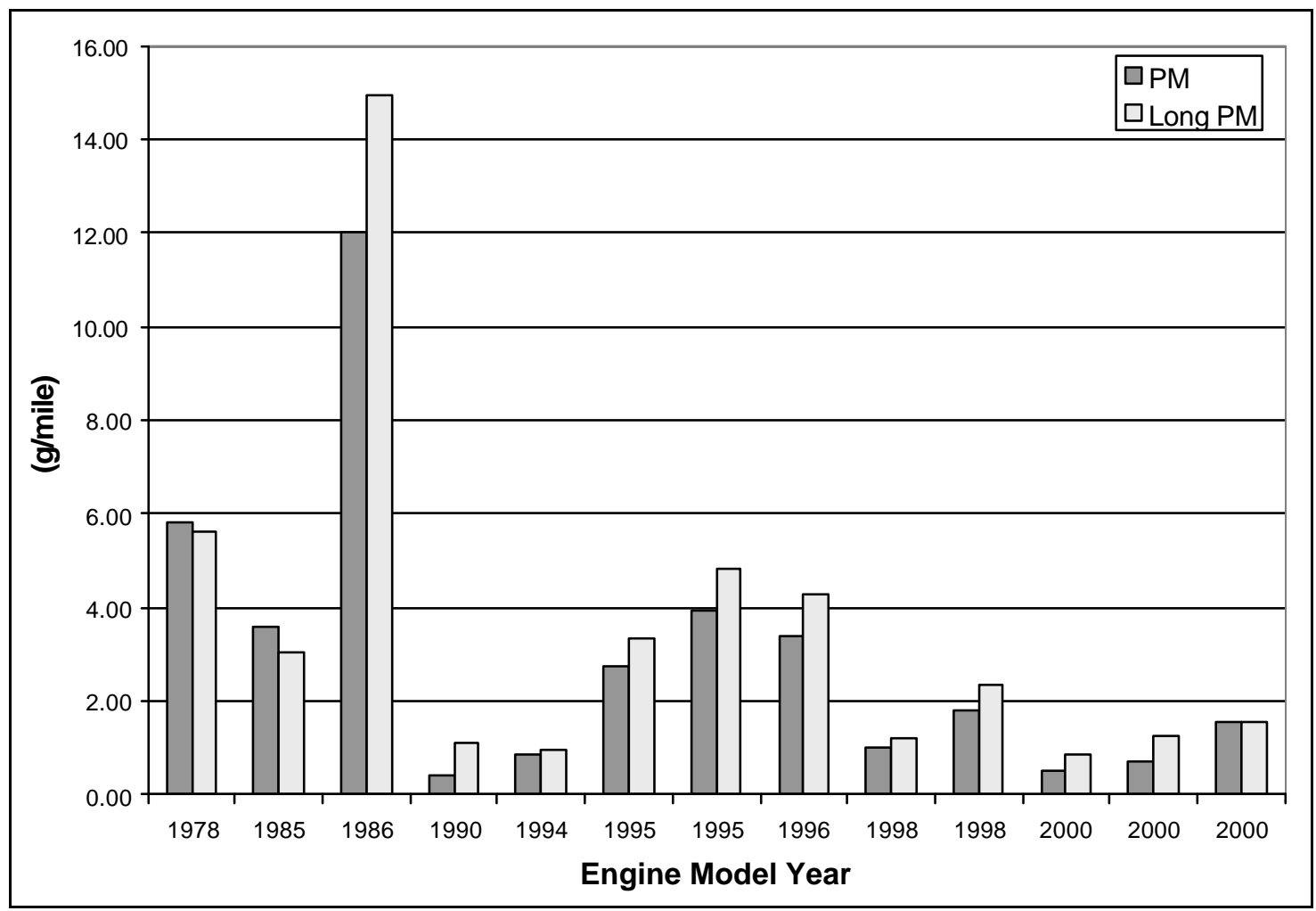

The emissions of $\mathrm{CO}, \mathrm{HC}$ and $\mathrm{CO}_{2}$ are presented in Figure 52 through Figure 54. The CO emissions showed no decline as model year increased and that there was a slight difference in the averages for each vehicle between the Creep Mode and Long Creep Mode. The average emissions production for the thirteen heavy-duty vehicles was approximately $15 \mathrm{~g} / \mathrm{mile}$. The $\mathrm{HC}$ emissions followed the same trend as the $\mathrm{CO}$ emissions. There were some high emitters and some low emitters of HC for the thirteen vehicles tested. The average $\mathrm{HC}$ for the thirteen vehicles tested was approximately 5 $\mathrm{g} /$ mile. There was a slight difference between the $\mathrm{CO}_{2}$ Laden and Unladen emissions, but no trend was prevalent. The Creep Mode is a relatively short test dominated by idle operation and the Long Creep Mode would produce a larger sample in relation to the Creep Mode. The Long Creep Mode makes for a better test over the Creep Mode, but 
because the HHDDT Schedule is a long test for measuring emissions from heavy-duty vehicles it is more practical to use the Creep Mode.

Figure 52: CO emissions comparison for the Creep and Long Creep Modes.

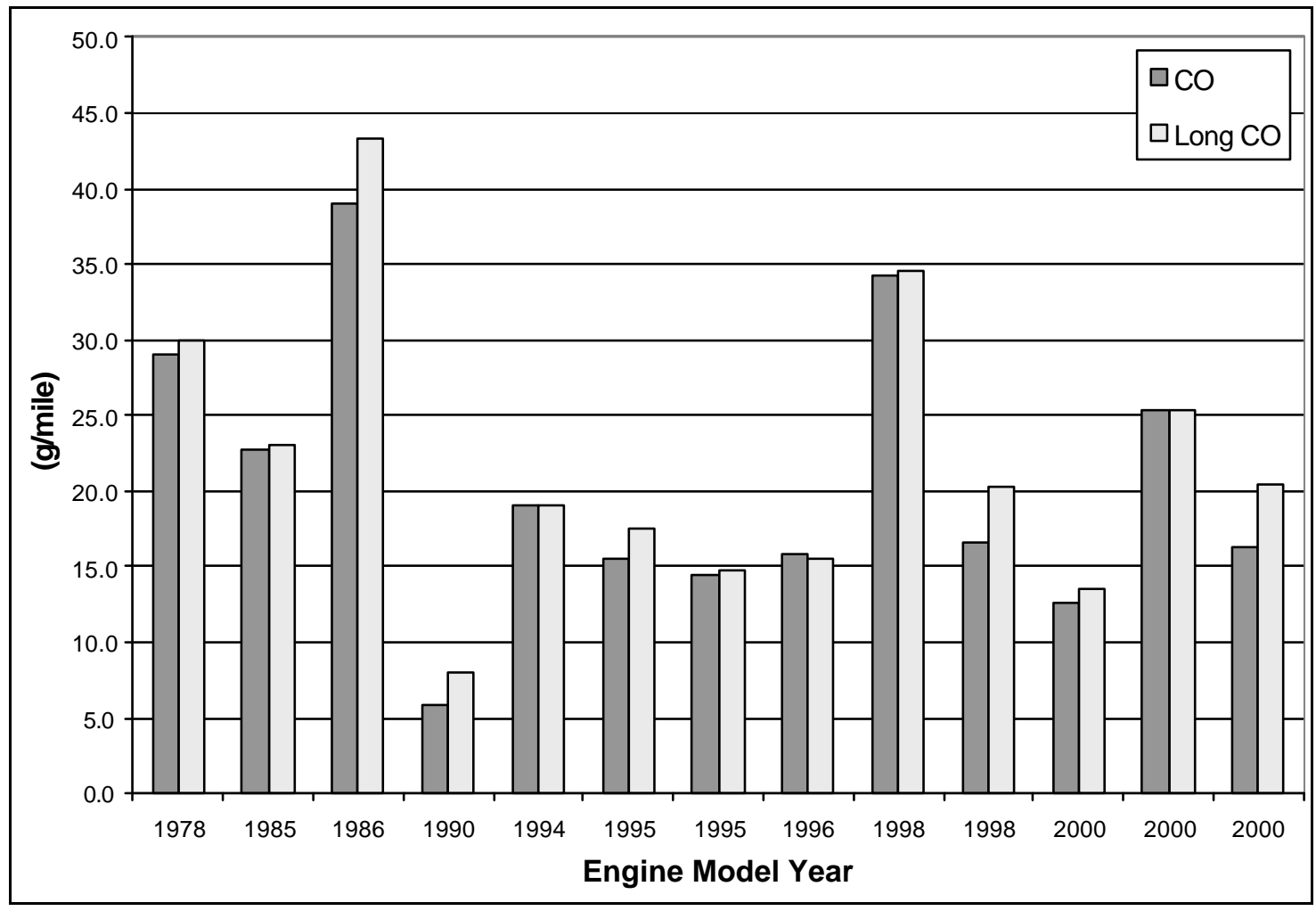


Figure 53: Comparison between the Creep and Long Creep Modes HC emissions.

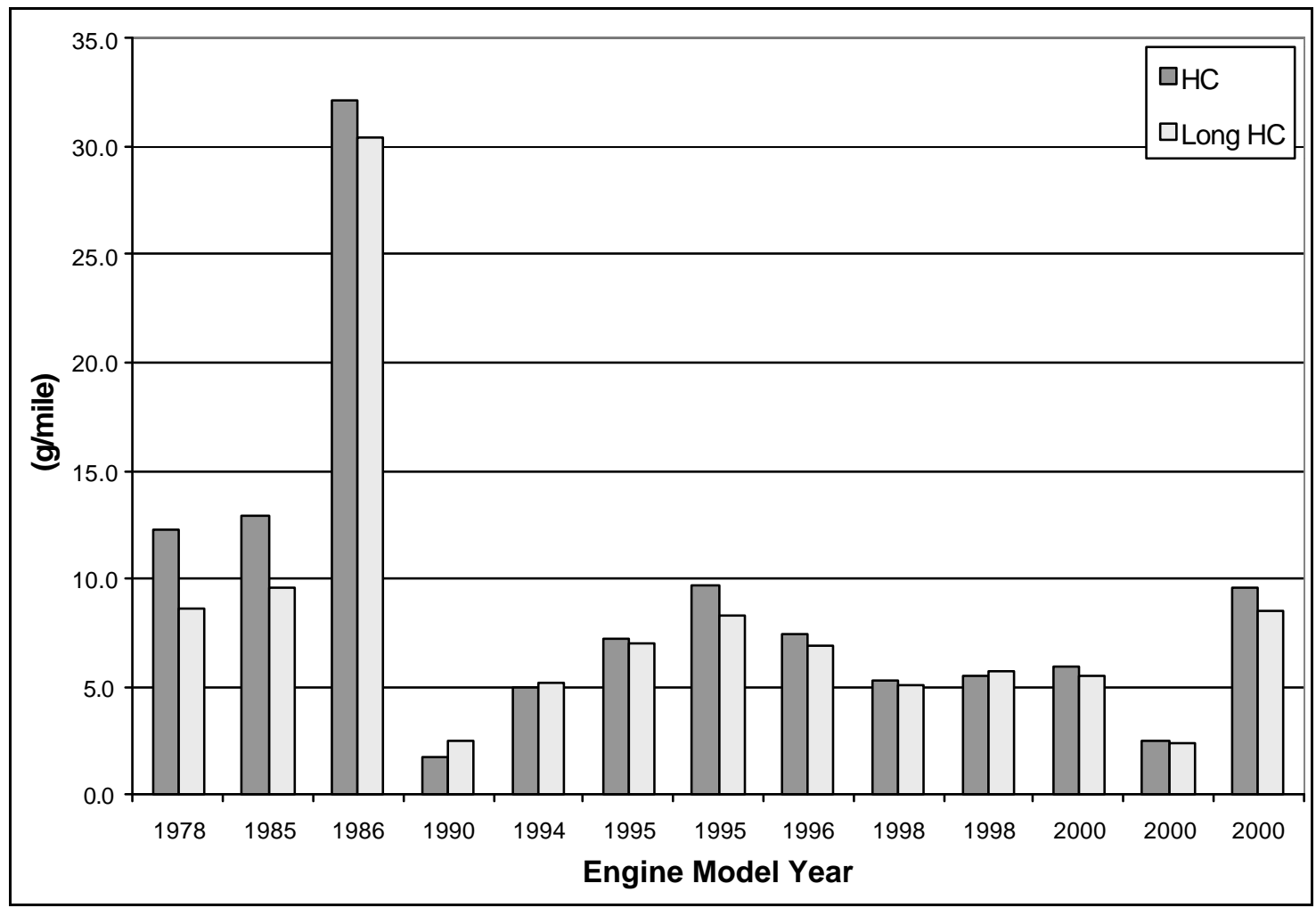

Figure 54: Comparison between the Creep and Long Creep Modes $\mathrm{CO}_{2}$ emissions.

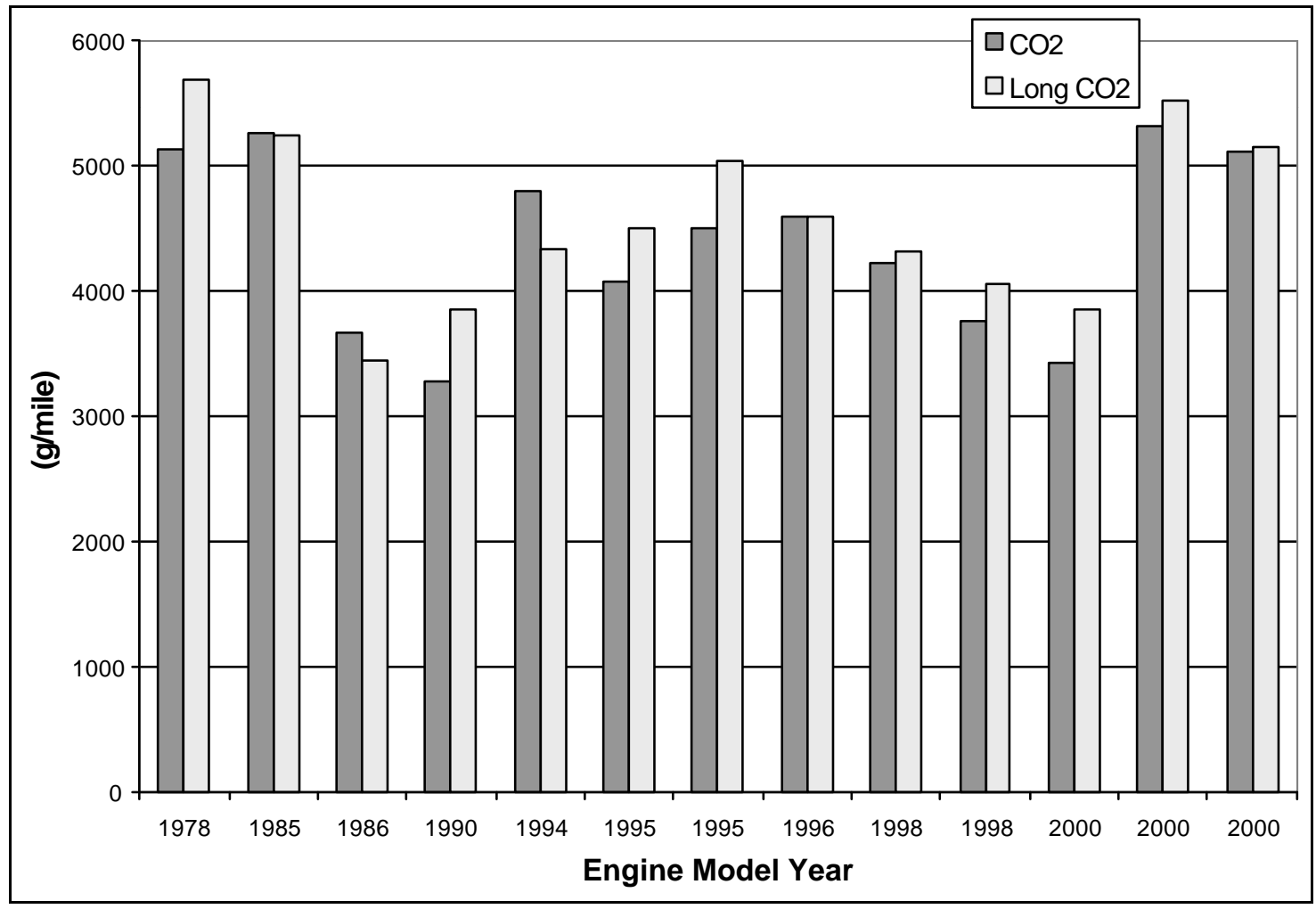




\subsection{Cycle Comparisons}

The AC50/80 test is a short test that was designed for vehicle emissions inspection in Australia and the UDDS and the HHDDT are relatively longer tests, but most likely represent on-road travel. The AC50/80 could be used as a screening test so it is important to see how it relates to other cycles. A comparison between the AC50/80, UDDS and HHDDT was assessed to see if the AC50/80 could produce comparable data in relation to the UDDS and HHDDT. The HHDDT is a new test and probably the best of the group of tests for determining the emissions produced from a heavy-duty vehicle. The HHDDT Schedule reflects real-world driving in California, since it was created from vehicle activity in California. So it is important to compare the results from the FourMode HHDDT to the UDDS and the AC50/80. There has always been an issue over how the tests compare to each other and which one most closely relates to real world driving conditions.

\subsubsection{Comparison Between the AC50/80 and the Creep Mode of the HHDDT}

The AC50/80 was compared to the Creep Mode using the same method presented earlier. The averages from each heavy-duty vehicle were grouped based on California Emissions Standards and then averaged. In Figure 55 and Figure 56 the gaseous emissions and PM are presented for the AC50/80 and the Creep Mode. The Creep Mode emissions were higher across the board for all emissions. The Creep Mode resembles a vehicle moving slowly in heavy traffic, operating on a congested street, or operating in a yard. It is important to note that the emissions produced from a heavy-duty diesel engine in this situation produces more emissions than a vehicle operating under the conditions of 
the AC50/80. The AC50/80 only represents a vehicle accelerating to $50 \mathrm{Km} / \mathrm{h}$ and then accelerating to $80 \mathrm{Km} / \mathrm{h}$ and cruising at 50 and $80 \mathrm{Km} / \mathrm{h}$. Therefore, it only represents a small amount of the typical vehicle operation and the weighting of these various types of activity may not reflect real use. However, the Creep Mode also only represents a small amount of vehicle activity and doesn't represent the total amount of vehicle travel without the other three modes of the HHDDT Schedule. The $\mathrm{CO}, \mathrm{HC}$ and $\mathrm{CO}_{2}$ emissions between the Creep Mode and the AC50/80 are presented in Figure 56. The vehicle emissions are much higher in units of $\mathrm{g} /$ mile for the Creep Mode than the AC50/80. Later on a comparison between the combined HHDDT and the AC50/80 is made to see how well the two different tests relate.

Figure 55: Cycle comparison between the $\mathrm{AC50/80}$ and Creep Mode for $\mathrm{NO}_{\mathrm{x}}$ and PM.

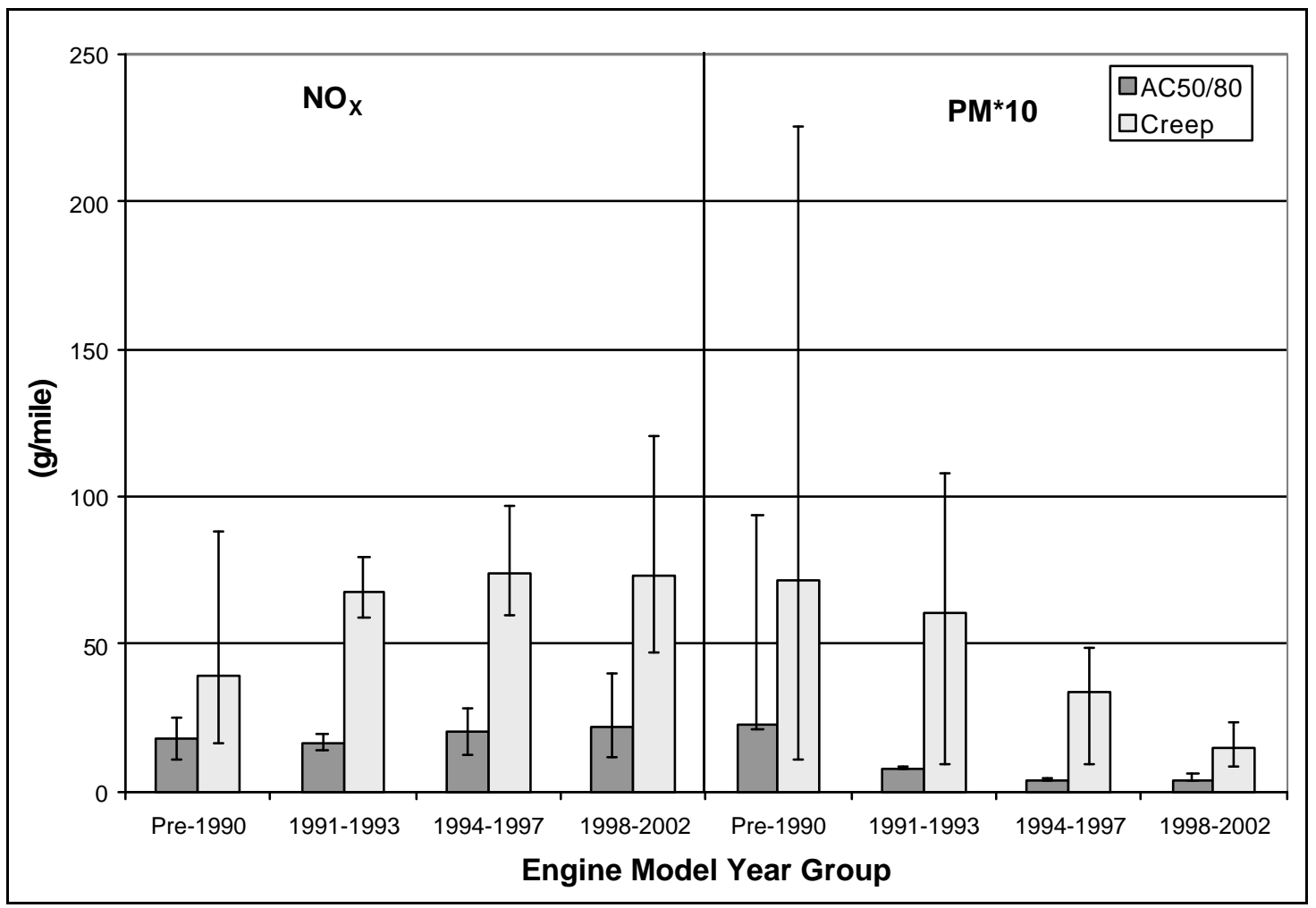


Figure 56: $\mathrm{CO}, \mathrm{HC}$ and $\mathrm{CO}_{2}$ emissions for the $\mathrm{AC50/80}$ and Creep Mode.

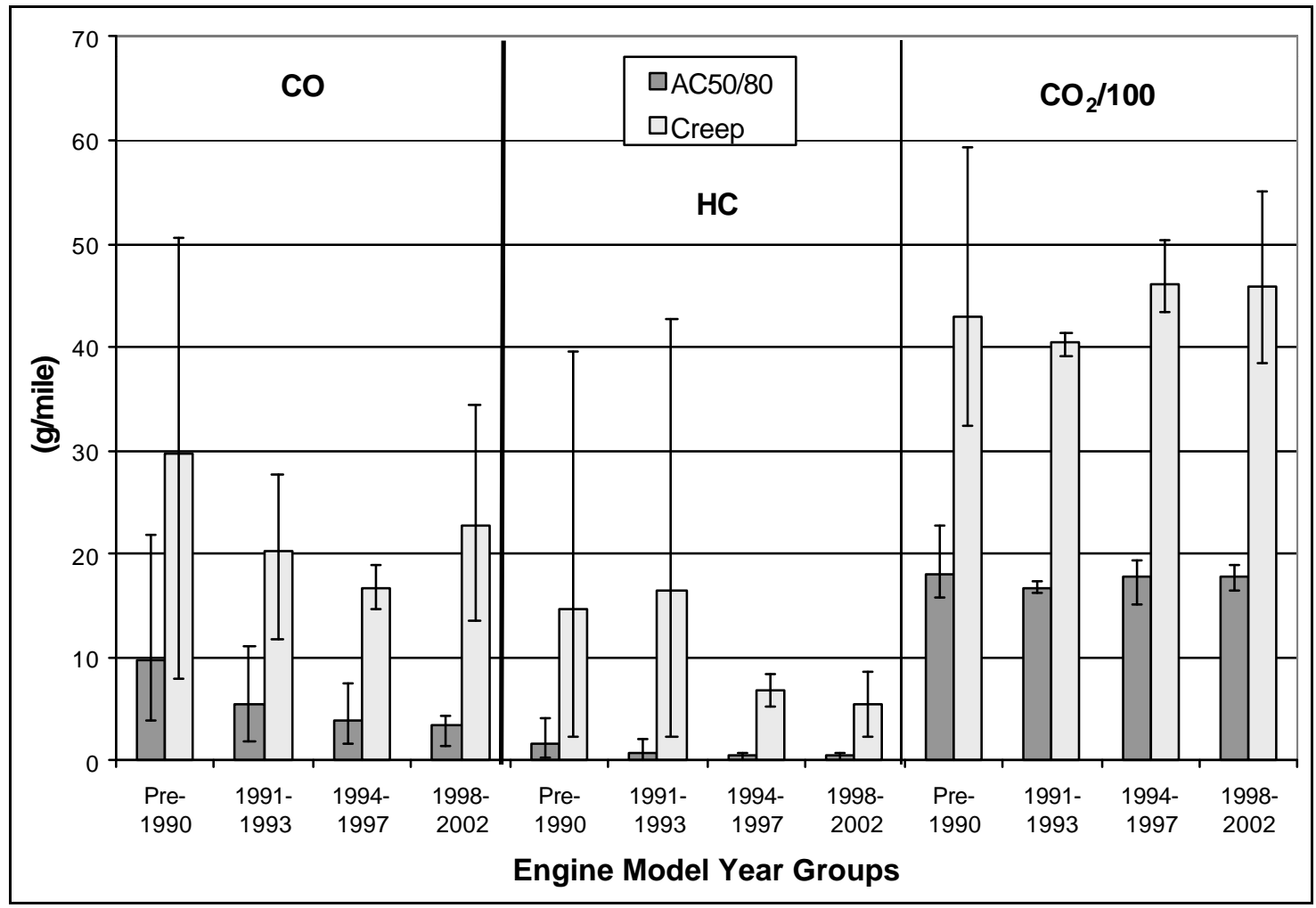

The emissions of $\mathrm{NO}_{\mathrm{X}}$ from the Creep Mode and the AC50/80 were compared in

Figure 57. No reliable correlation could between the Creep Mode and the AC50/80 for the $\mathrm{NO}_{\mathrm{X}}$ emissions. However, the Creep Mode is mainly dominated by idle operation and produces higher g/mile emissions when compared to a cycle that is in almost constant motion. The $\mathrm{NO}_{\mathrm{X}}$ emissions should not be the same between the AC50/80 and the Creep Mode. The same comparison was done for the PM emissions for the AC50/80 and the Creep Mode and the results are presented in Figure 58. The PM emissions tended to group together at the bottom with a few high emitters such as E55CRC-16, but no strong correlation could be made between the PM emissions for the two tests. 
Figure 57: Comparison between NO $_{x}$ emissions for the Creep Mode and the AC50/80. No reliable correlation exists since the Creep Mode is more dominated by idle operation than the AC50/80.

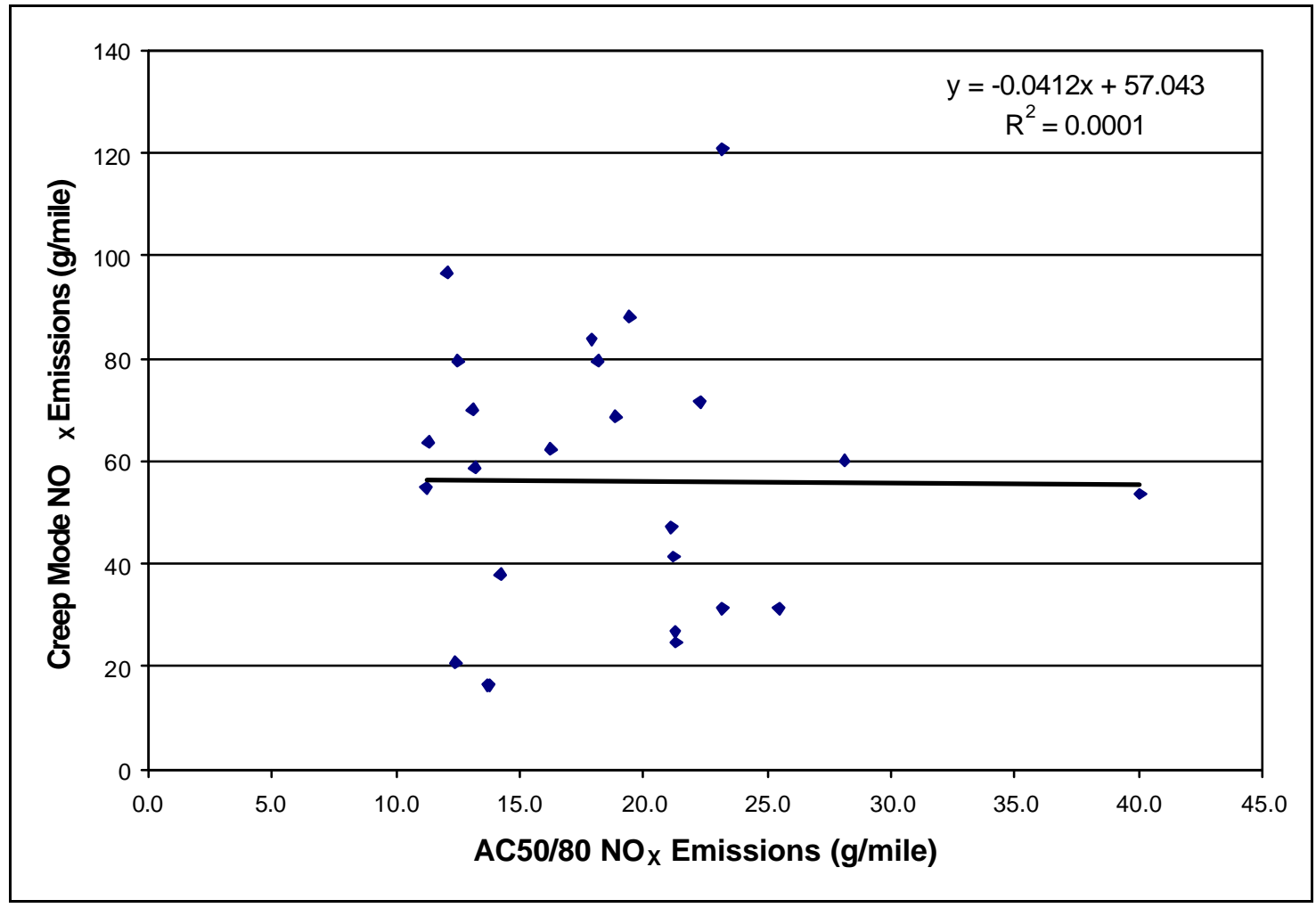


Figure 58: Comparison between the Creep Mode and AC50/80 for PM emissions. No Correlation exists between the PM emissions for the Creep Mode and the AC50/80.

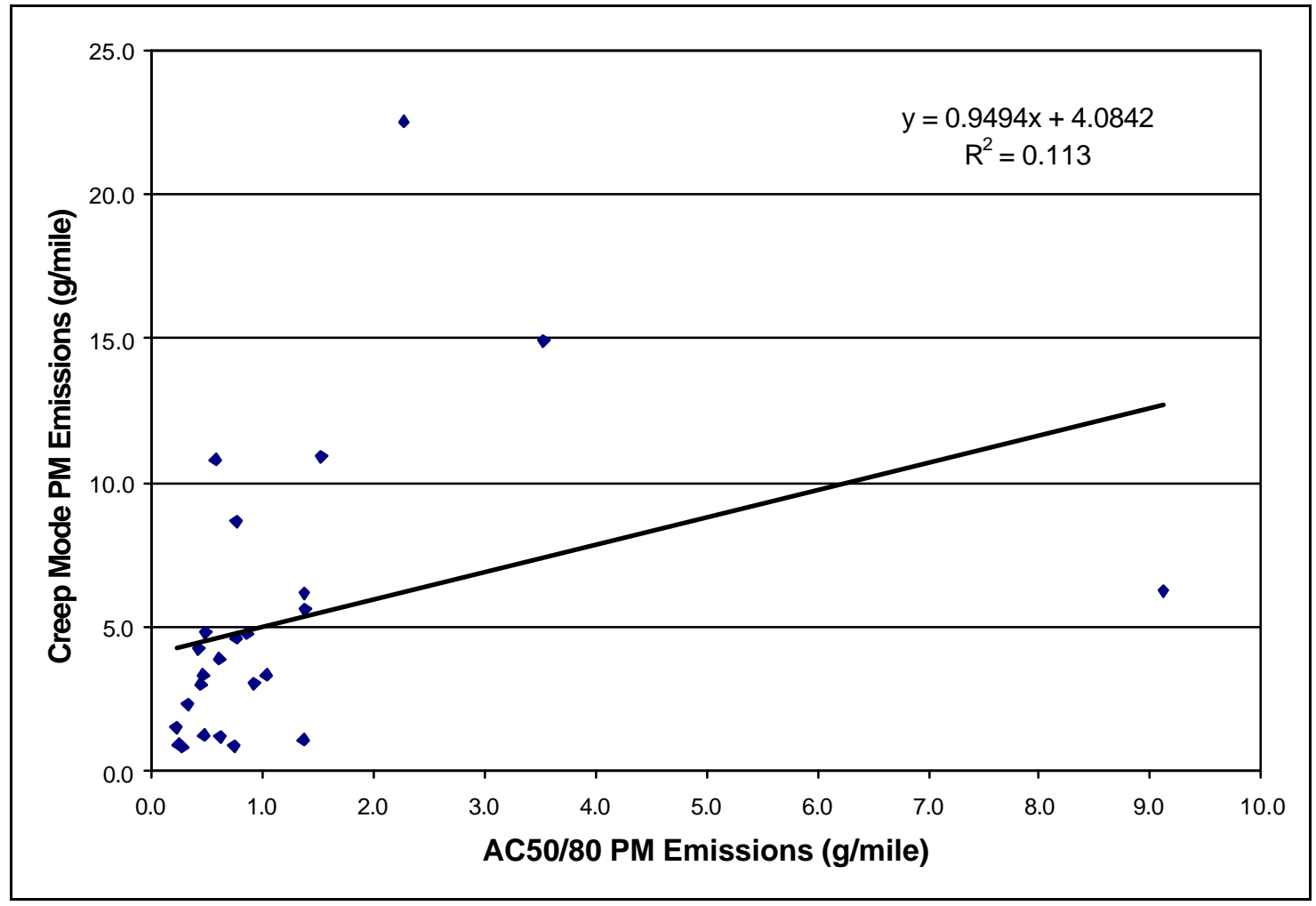

\subsubsection{Comparison Between the AC50/80 and the Transient Mode of the HHDDT}

The AC50/80 was compared to the Transient Mode to see how the two tests correlated and if they produce comparable results. It was anticipated that the results from the two different tests would correlate much more closely than the Creep Mode did to the AC50/80, since it has more transient operation then the Creep Mode. The vehicles were divided into Engine Model Year Groups to see if the averages between the AC50/80 and the Transient Mode would relate. The gaseous emissions and PM are illustrated in Figure 59 and Figure 60. The $\mathrm{NO}_{\mathrm{X}}$ and $\mathrm{PM}$ values were higher for the Transient Mode then the AC50/80. The Transient Mode more closely represents typical travel of a heavy-duty vehicle in California then the Creep Mode, but the combined HHDDT Schedule should represent the closest to real world operations and will be evaluated later on. The CO, 
$\mathrm{CO}_{2}$ and $\mathrm{HC}$ were all higher for the Transient Mode than the AC50/80. Since the Transient Mode operates the vehicle through more transient operation, it is expected that $\mathrm{CO}, \mathrm{CO}_{2}$ and $\mathrm{HC}$ would increase because of higher fuel consumption.

Figure 59: $\mathrm{NO}_{\mathrm{X}}$ and PM emissions for the AC50/80 and Transient Mode.

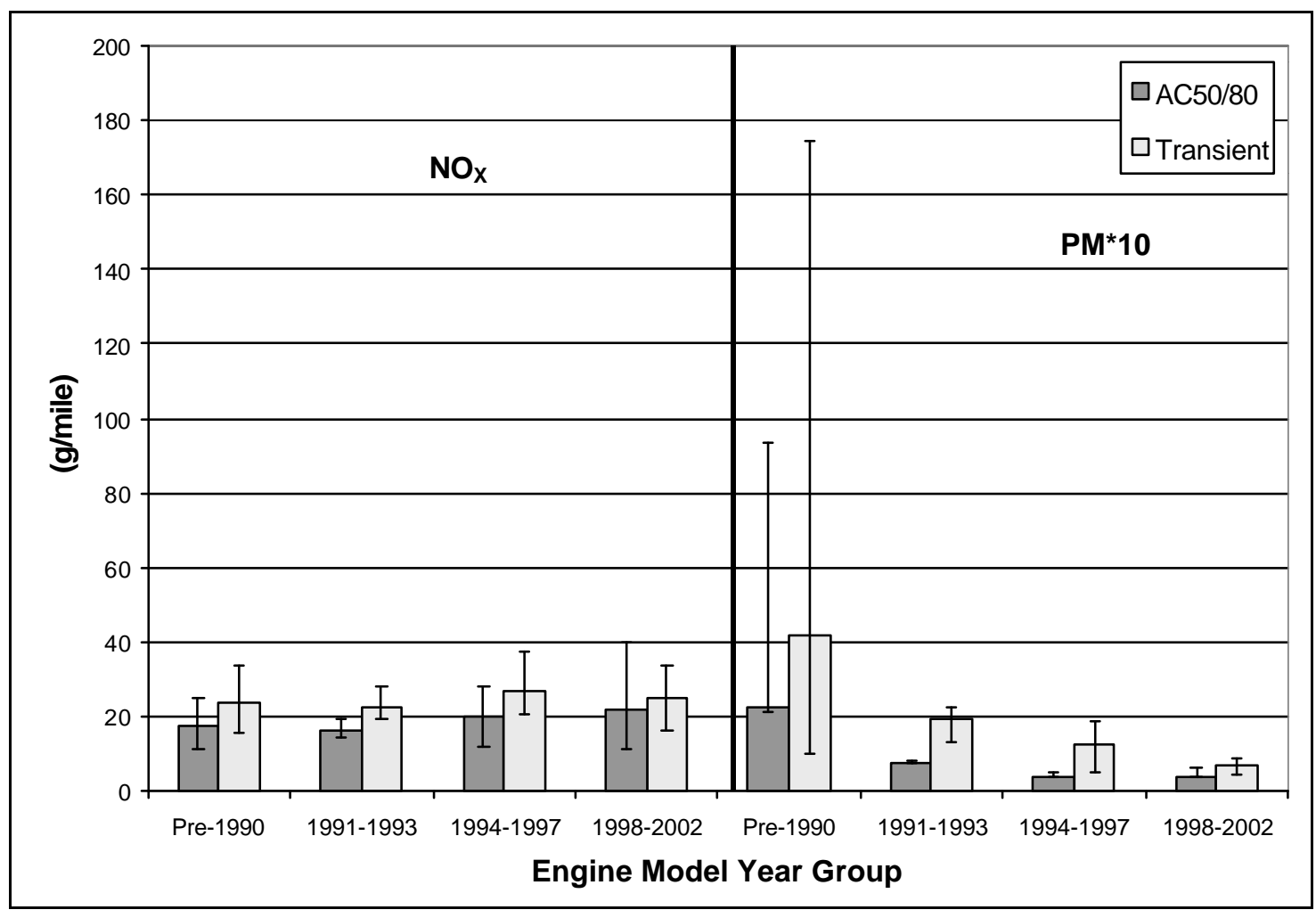


Figure 60: Vehicle emissions vs. Engine Model Year Group for the AC50/80 and Transient Mode.

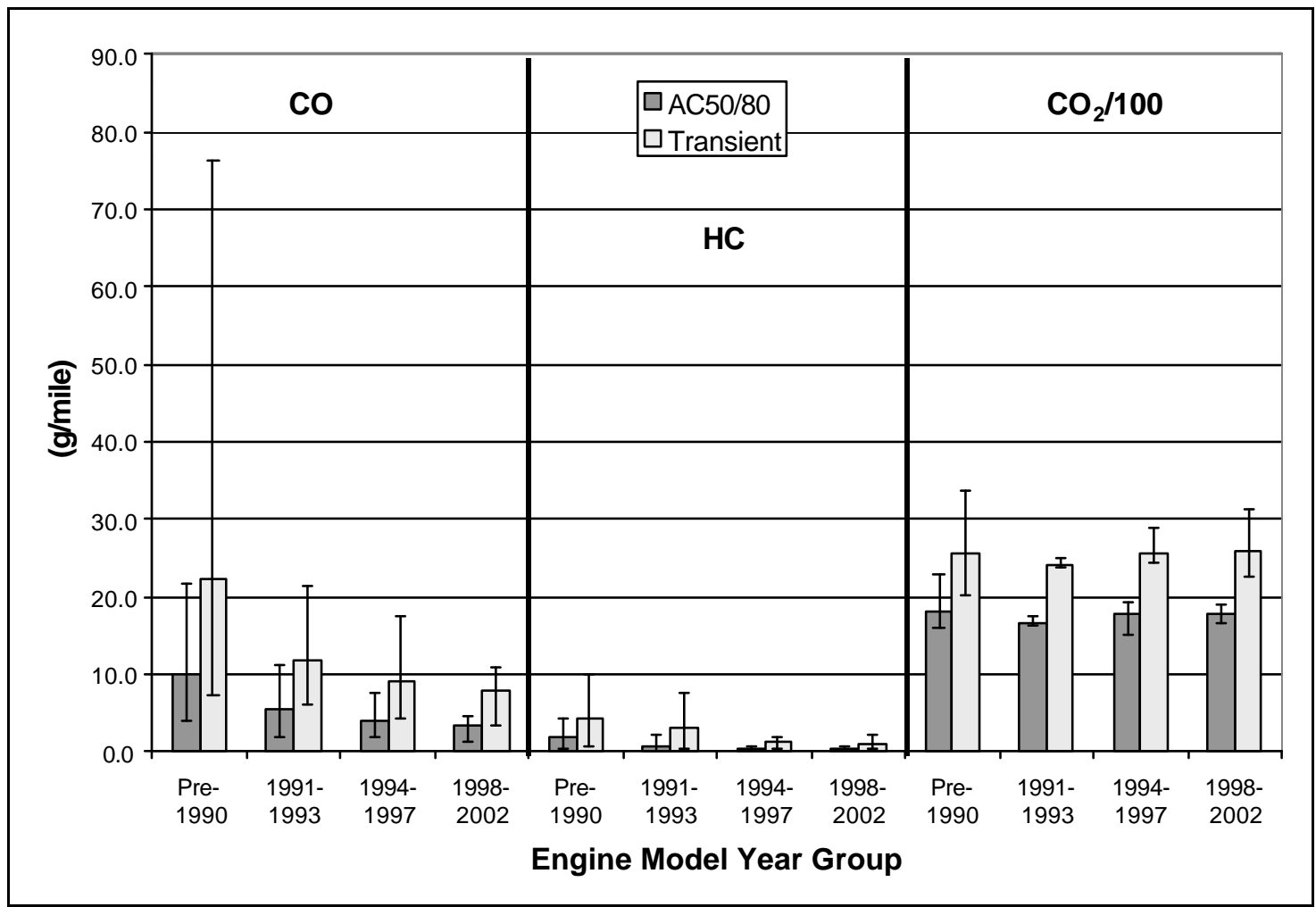

A comparison was also made between the $\mathrm{NO}_{\mathrm{X}}$ emissions of the AC50/80 and the

Transient Mode. A "best-fit" line was fitted through the $\mathrm{NO}_{\mathrm{X}}$ emissions data for the two cycles and produced a poor correlation. The line supports the data in Figure 60 with the Transient Mode producing more $\mathrm{NO}_{\mathrm{X}}$ emissions on average then the AC50/80. A stronger correlation between the two cycles would support the idea of using the AC50/80 as an inspection test, but the AC50/80 and Transient Mode do not relate. As mentioned with the Creep Mode, it only represents a portion of the vehicle activity and the combined HHDDT will have the strongest determining factor of whether the AC50/80 relates to vehicle activity in California. 
Figure 61: Comparison between the AC50/80 and the Transient Mode for $\mathrm{NO}_{\mathrm{x}}$ emissions. No Correlation exists between the $\mathrm{NO}_{\mathrm{x}}$ emissions for the Transient Mode and the $\mathrm{AC50/80}$.

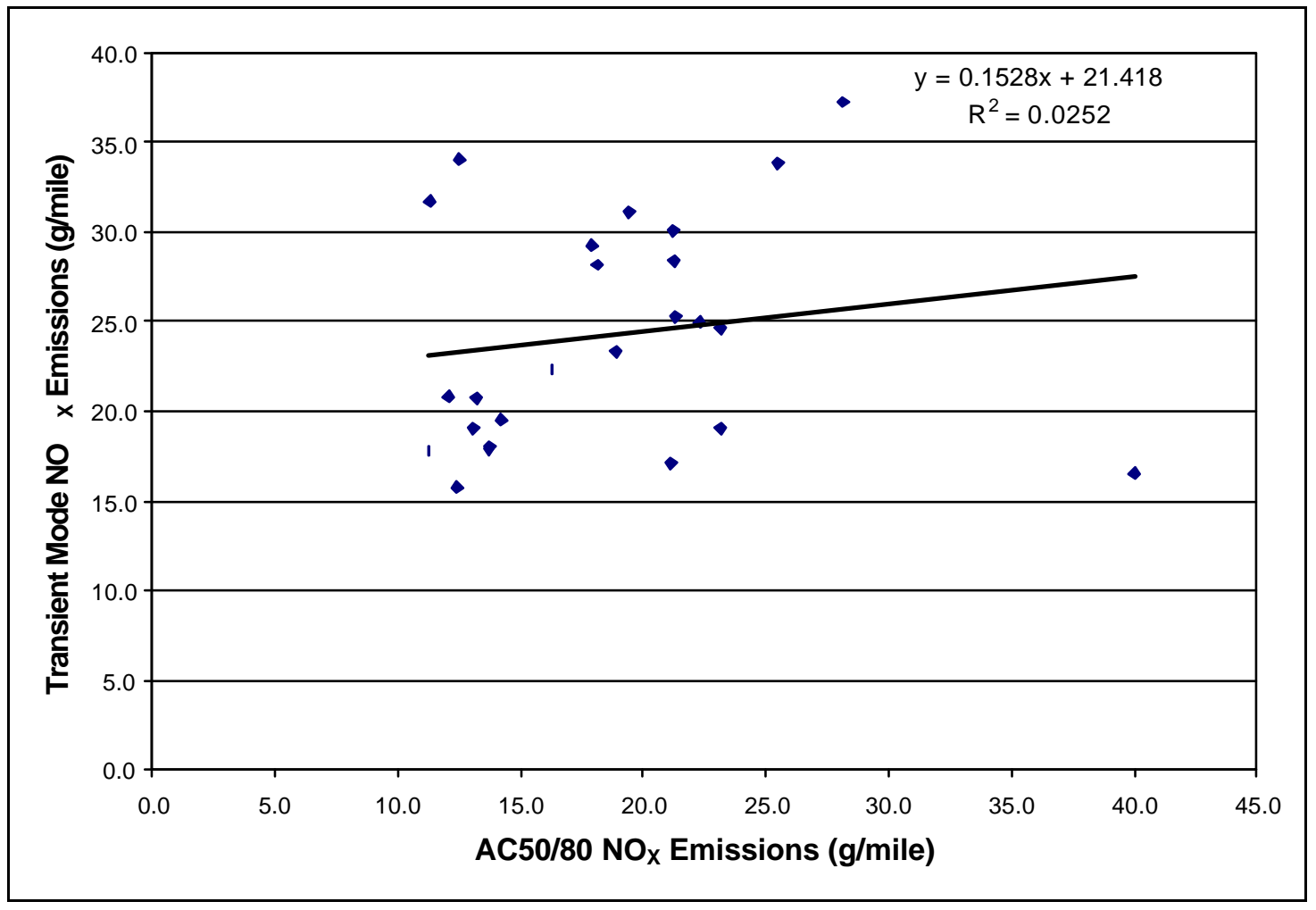

The PM emissions for each of the vehicles in the study were compared in the same manner as the $\mathrm{NO}_{\mathrm{X}}$ emissions for the AC50/80 and the Transient Mode. The correlation between the AC50/80 and the Transient PM emissions was strong when E55CRC-16 was included in the "best-fit" line. When E55CRC-16 was removed and a "best-fit" line was fitted through the data the $\mathrm{R}^{2}$ value dropped. The E55CRC-16 vehicle produced a high level of PM emissions and effected the overall data set comparison. The "best-fit" line for the data set without E55CRC-16 showed that on average more PM emissions were produced during the transient operation in comparison to the AC50/80 which supports the results in Figure 59. 
Figure 62: Comparison between the AC50/80 and the Transient Mode for the PM emissions. E55CRC-16 is responsible for producing a high $\mathbf{R}^{2}$ value.

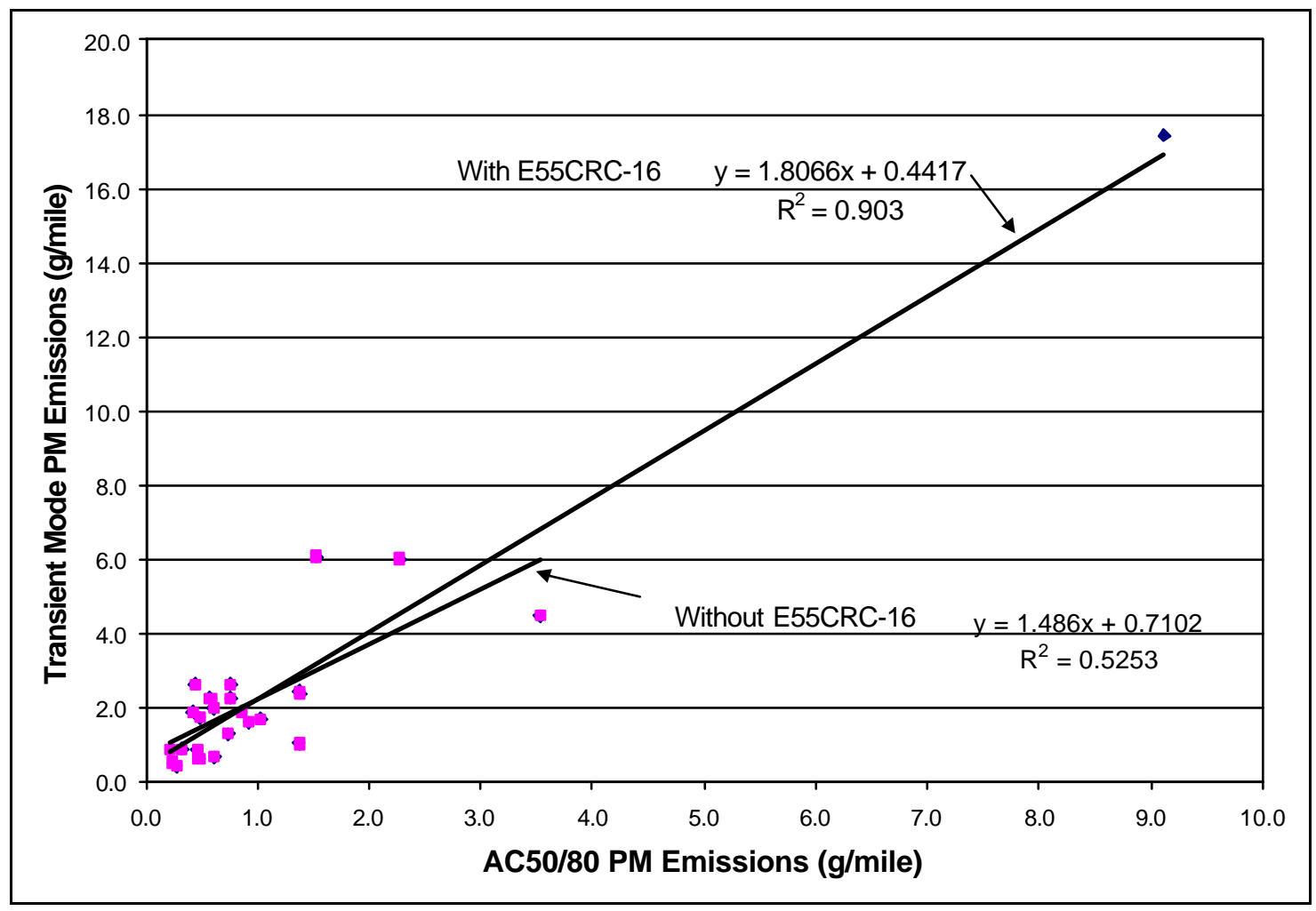

\subsubsection{Comparison Between the AC50/80 and the Cruise Mode of the HHDDT}

The Cruise Mode represents mainly steady-state operation and was compared to the AC50/80. The vehicles were separated based on California Emissions Standards and the gaseous emissions and PM are illustrated in Figure 63 and Figure 64. The $\mathrm{NO}_{\mathrm{X}}$ values were highest for the Cruise Mode in the most recent Engine Model Year Groups. The AC50/80 followed the same trend with lower emissions levels. The same trend continued, being the fact that the lowest emissions group was the 1991-1993 and then jumping up in the 1994-1997 and 1998-2002 Engine Model Year Group. The PM levels showed a decline as model year increased to the present. The decline in PM follows California Emissions Regulations, but the $\mathrm{NO}_{\mathrm{X}}$ emissions do not decline for the AC50/80 and the Cruise Mode. The $\mathrm{CO}$ and $\mathrm{HC}$ emissions showed a decline as Engine Model 
Year Group increased to the present for both the AC50/80 and the Cruise Mode. The higher level of $\mathrm{CO}$ between the AC50/80 and Cruise Mode varied from Engine Model Year Group to Engine Model Year Group. The $\mathrm{CO}_{2}$ was higher for the AC50/80 test in comparison to the Cruise Mode. It is expected that more fuel burned in relation to distance travel during the AC50/80 test, which is expected since it is a short test with two accelerations. The Cruise Mode generally has an acceleration ramp up to a cruising speed, a long period of cruise operation and then a deceleration. The vehicle does not have to work as hard in the Cruise Mode in comparison to the AC50/80 based on time, because not as much energy is needed at cruising speeds in relation to accelerations.

Figure 63: PM and $\mathrm{NO}_{\mathrm{x}}$ emissions for the AC50/80 and Cruise Mode.

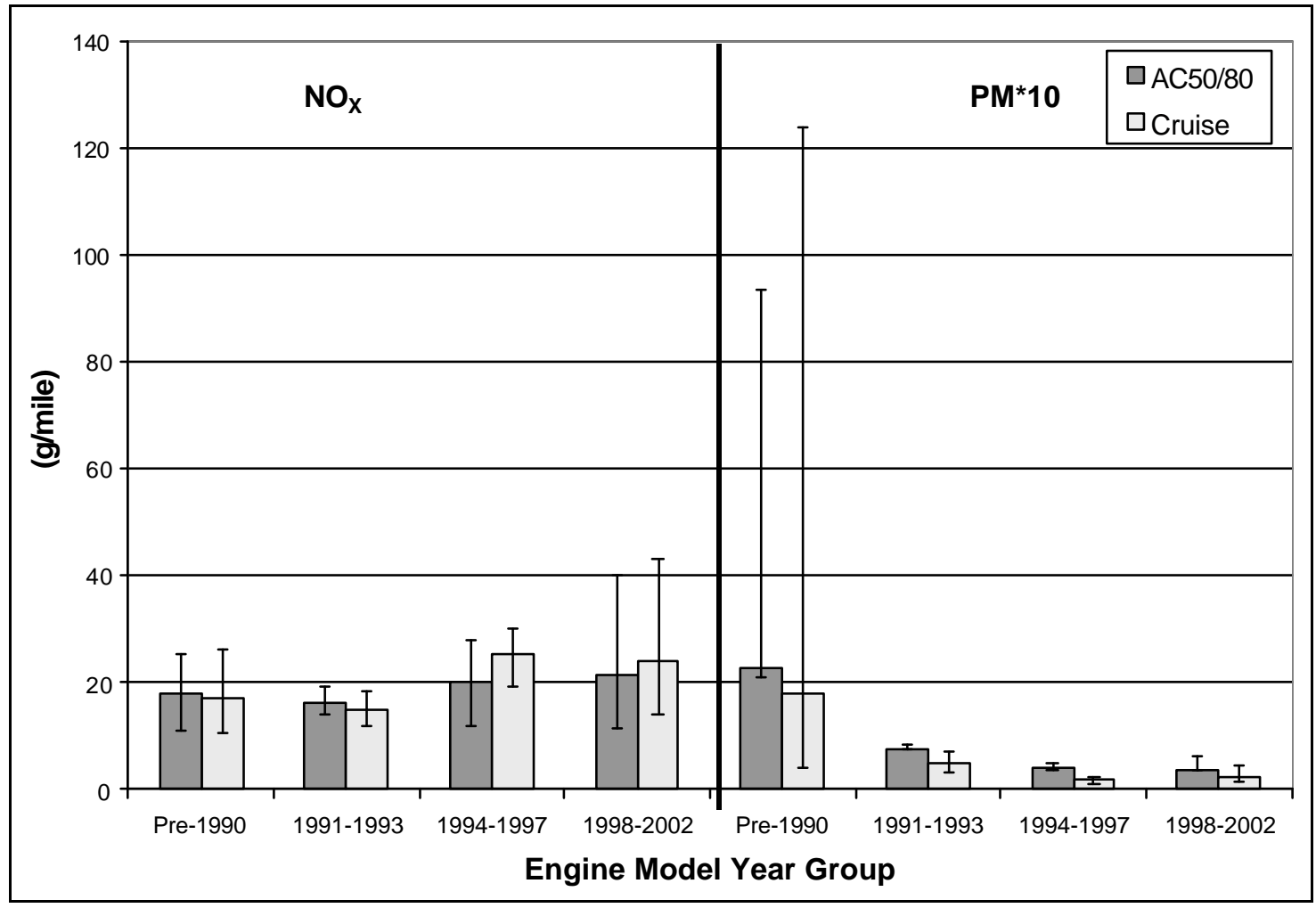


Figure 64: $\mathrm{CO}, \mathrm{HC}$, and $\mathrm{CO}_{2}$ emissions for the $\mathrm{AC50/80}$ and Cruise Mode.

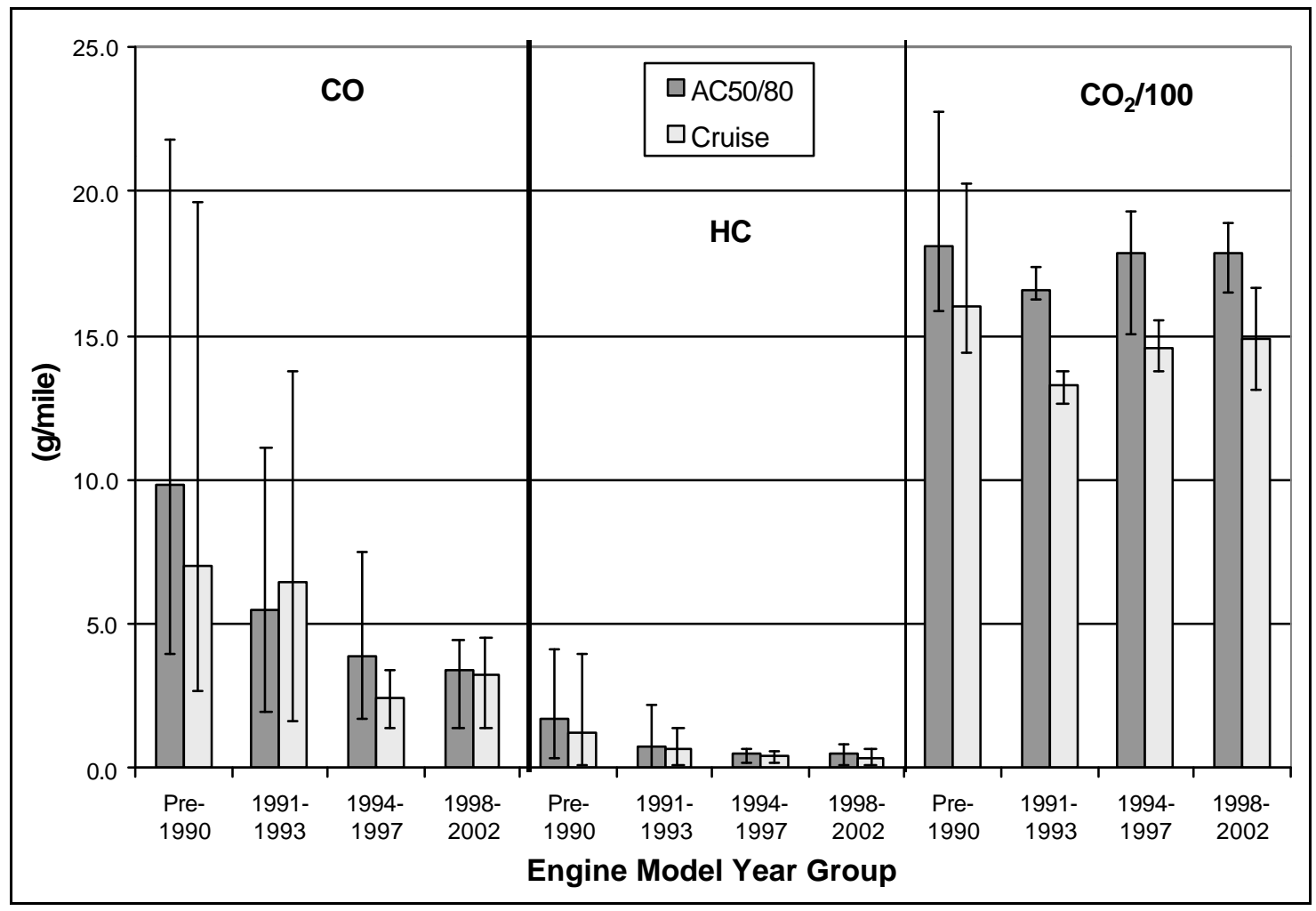

The $\mathrm{NO}_{\mathrm{X}}$ emissions produced from all twenty-five heavy-duty vehicles were compared to see if the emissions from the AC50/80 and the Cruise Mode were comparable. The results for the $\mathrm{NO}_{\mathrm{X}}$ emissions are presented in Figure 65 and a "bestfit" line was fitted through the data. There was no strong correlation between the $\mathrm{NO}_{\mathrm{X}}$ emissions produced from the Cruise Mode and the $\mathrm{NO}_{\mathrm{X}}$ emissions produced for the AC50/80. The Cruise Mode produced higher $\mathrm{NO}_{\mathrm{X}}$ levels in the 1994-1997 and 19982002 then the AC50/80, but the AC50/80 produced higher $\mathrm{NO}_{\mathrm{X}}$ emissions then the Cruise Mode for the Pre-1990 and 1991-1993 Engine Model Year Group. This lead to a poor correlation between the two cycles and since the Cruise Mode only represents a small portion of the total activity a better comparison could be made between the Combined HHDDT Schedule and the AC50/80. 
The same method used for comparing $\mathrm{NO}_{\mathrm{X}}$ emissions was also used to compare PM emissions. The results from the PM emissions comparison are presented in Figure 66. A majority of the data tended to group together at the bottom of the graph. E55CRC16 was the highest emitter out of the twenty-five heavy-duty vehicles and is the one furthest away from the rest of the data. The "best-fit" line showed a strong correlation between the AC50/80 and the Cruise Mode PM emissions. A "best-fit" line was fitted through the data set without E55CRC-16 to see how the results compared and the correlation between the two cycles dropped. This supports the fact that the Cruise Mode does not represent all of the activity a vehicle is put through and would lead to a poor correlation between the AC50/80 and the Cruise Mode.

Figure 65: Comparison between the AC50/80 and the Cruise Mode for $\mathrm{NO}_{\mathrm{X}}$ emissions. No Correlation exists between the $\mathrm{NO}_{\mathrm{X}}$ emissions for the Cruise Mode and the $\mathrm{AC50/80.}$

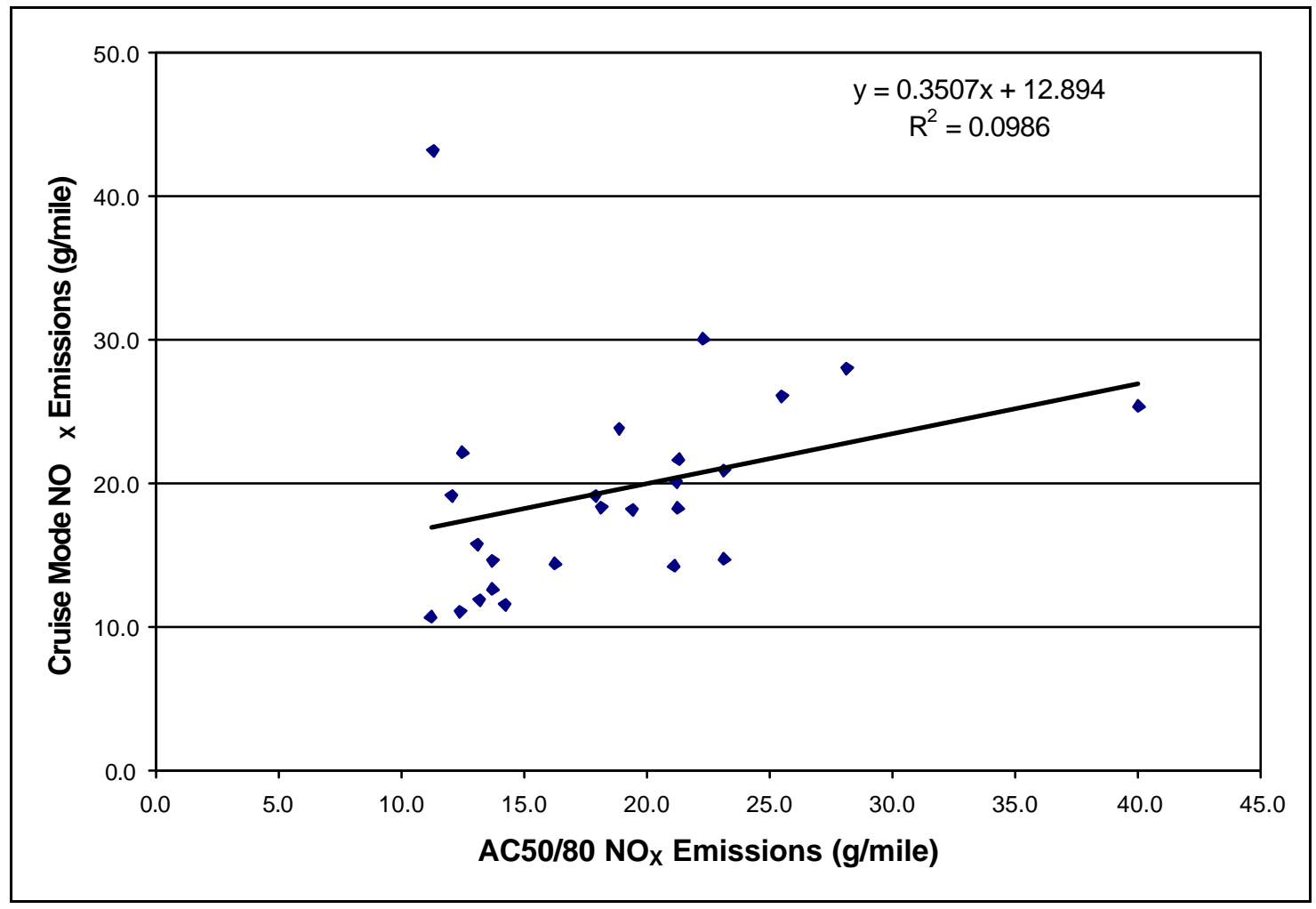


Figure 66: Comparison between the AC50/80 and the Cruise Mode for PM emissions.

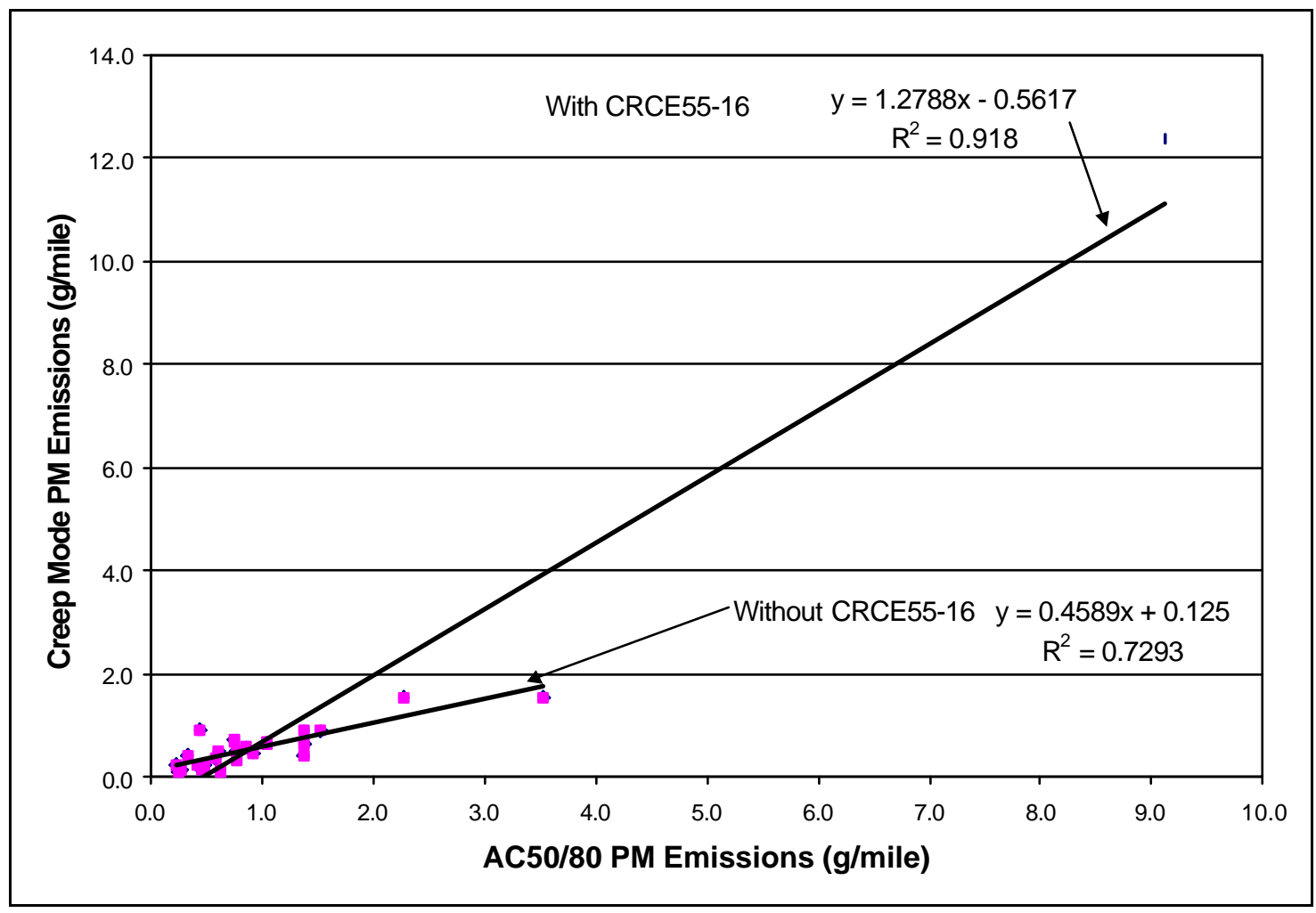

\subsubsection{Comparison Between the AC50/80, UDDS and the Combined HHDDT}

A comparison between the AC50/80, the UDDS and the Combined HHDDT Schedule is illustrated in Figure 67 and Figure 68. The Combined HHDDT test was determined by taking the g/cycle emissions for each of the four modes, adding them together and then dividing them by the total distance traveled for the three modes since the first mode is an idle period. See Equation 8 for an explanation.

\section{Equation 8:}

$$
\begin{aligned}
\text { Emissions }(g / \text { mile })= & \frac{\sum([\text { IdleMode }(g)]+[\text { Creep Mode }(g)]}{\sum([\text { IdleMode }(\text { mile })]+[\text { CreepMode }(\text { mile })]} \cdots \\
& +\frac{[\text { TransientMode }(g)]+[\text { CruiseMode }(g)])}{[\text { TransientMode }(\text { mile })]+[\text { CruiseMode }(\text { mile })])}
\end{aligned}
$$


The emissions from the AC50/80 and UDDS tests showed that the level of $\mathrm{NO}_{\mathrm{X}}$ for the UDDS were higher for each of the Engine Model Year Groups. The $\mathrm{NO}_{\mathrm{X}}$ emissions for the combined HHDDT Schedule in the most recent Engine Model Year Groups were higher than the other two tests, but were lower in comparison to the UDDS test for the two oldest Engine Model Year Groups.

The PM emissions followed a general downward trend as Engine Model Year Groups increased to the present. The UDDS test produced the highest evel of emissions in relation to the AC50/80 and the combined HHDDT Schedule. The $\mathrm{CO}$ and $\mathrm{HC}$ followed a similar downward trend in relation to Engine Model Year Group and the UDDS test produced the highest level of emissions. $\mathrm{CO}_{2}$ was highest for the UDDS test when compared to the combined HHDDT Schedule and the AC50/80. There was no clear comparison between the AC50/80, UDDS and the combined HHDDT, but the AC50/80 did follow the same trend as the UDDS and the combined HHDDT. Several AC50/80 tests performed on a heavy-duty vehicle could be used as an inspection test in the United States to determine high emitters, but several tests would need to be performed on the same vehicle to limit run-to-run variability in the testing. The combined HHDDT Schedule is a much longer test and like the AC50/80 test, several repeat tests would have to be performed if it was to be used as an inspection test. The combined HHDDT most accurately represents real-world emissions, but takes long time to perform on a vehicle in relation to the AC50/80 and the UDDS. 
Figure 67: Comparison of the AC50/80, UDDS, and the combined HHDDT for $\mathrm{NO}_{\mathrm{x}}$ and PM emissions.

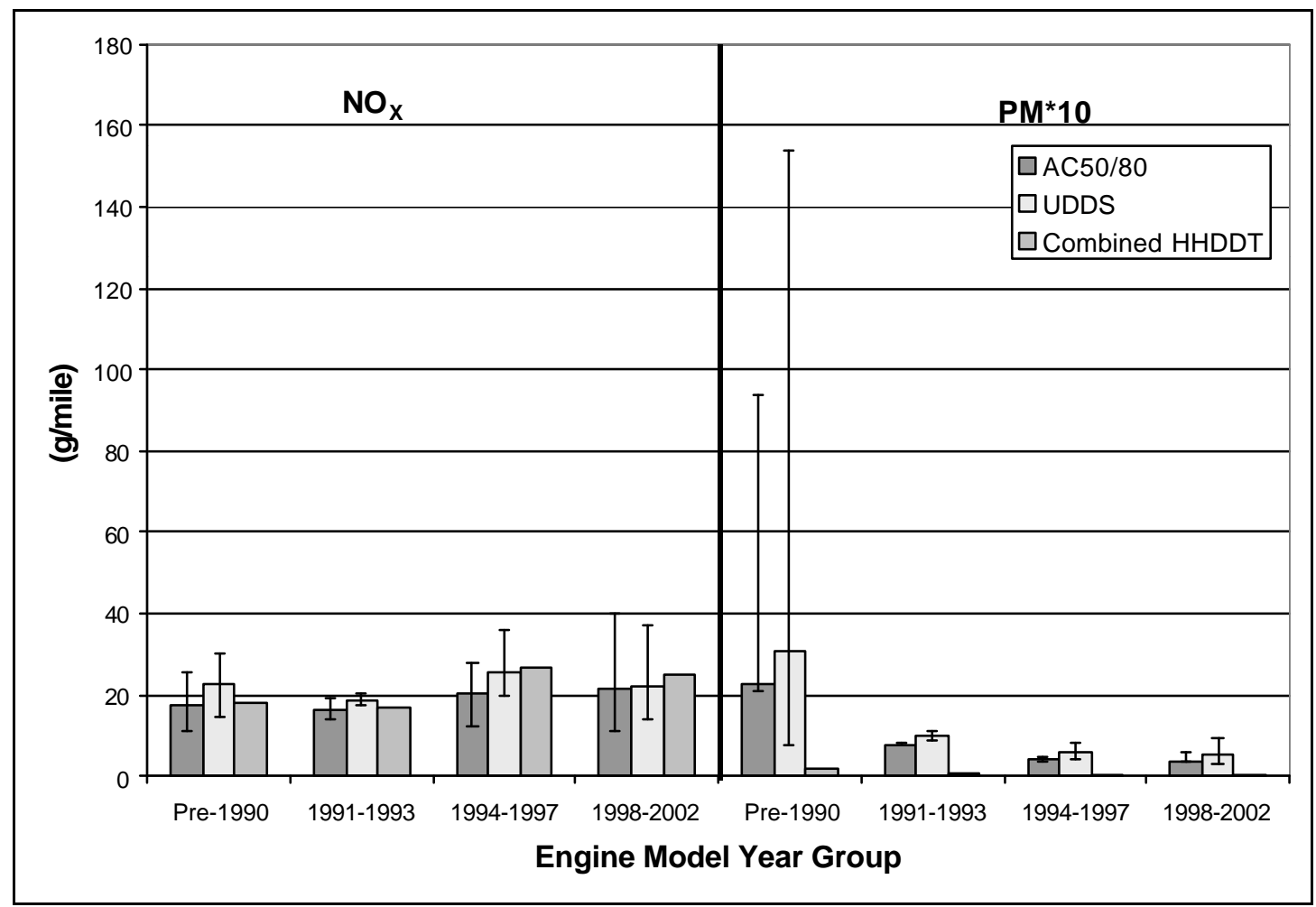

Figure 68: Comparison of the AC50/80, UDDS, and the combined HHDDT for CO, $\mathrm{HC}$, and $\mathrm{CO}_{2}$ emissions.

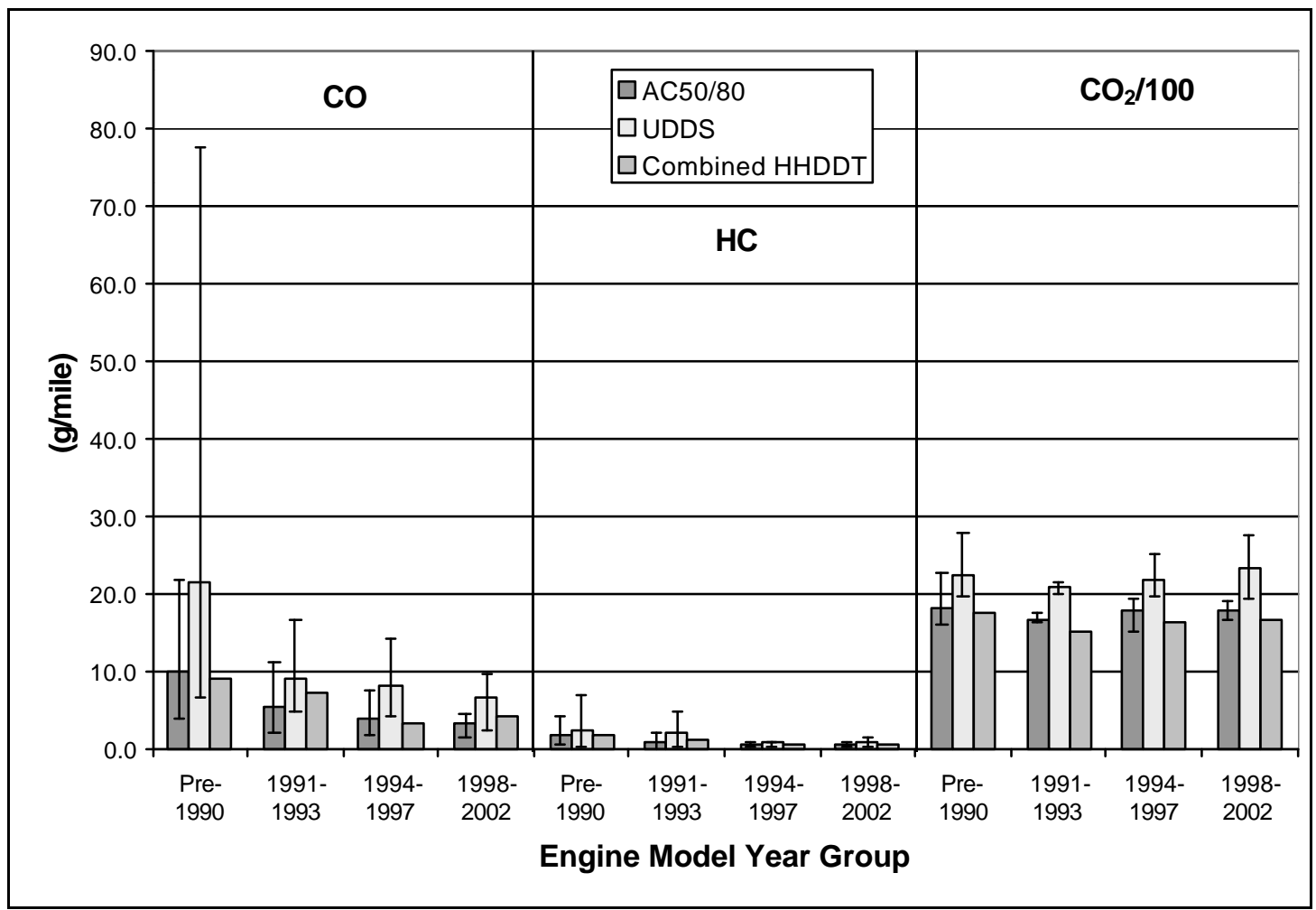


The $\mathrm{NO}_{\mathrm{X}}$ emissions from all twenty-five vehicles were compared between the AC50/80, combined HHDDT and the UDDS. The results are presented in Figure 69 and the relationship for $\mathrm{NO}_{\mathrm{X}}$ emissions between the AC50/80 and UDDS correlated well with a $\mathrm{R}^{2}=0.86$. The relationship for $\mathrm{NO}_{\mathrm{X}}$ between the AC50/80 and the combined HHDDT Schedule were poor and the data tended to scatter more then the comparisons between the AC50/80 and the UDDS. The PM emissions were also examined in the same manner as the $\mathrm{NO}_{\mathrm{X}}$ emissions. The results of the relationship between the AC50/80, combined HHDDT and the UDDS are presented in Figure 70. The AC50/80 test correlated well with the combined HHDDT and the UDDS with a $\mathrm{R}^{2}$ greater then .90 . The same results found the comparisons between the AC50/80 and the Transient and Cruise Mode with E55CRC-16 effecting the correlation also applies to the comparison between the AC50/80 and the combined HHDDT Schedule. If E55CRC-16 was removed the, $\mathrm{NO}_{\mathrm{X}}$ emissions for the AC50/80 would be higher in relation to the combined HHDDT Schedule. 
Figure 69: Comparison between the AC50/80, the combined HHDDT and the UDDS for $\mathrm{NO}_{\mathrm{x}}$ emissions.

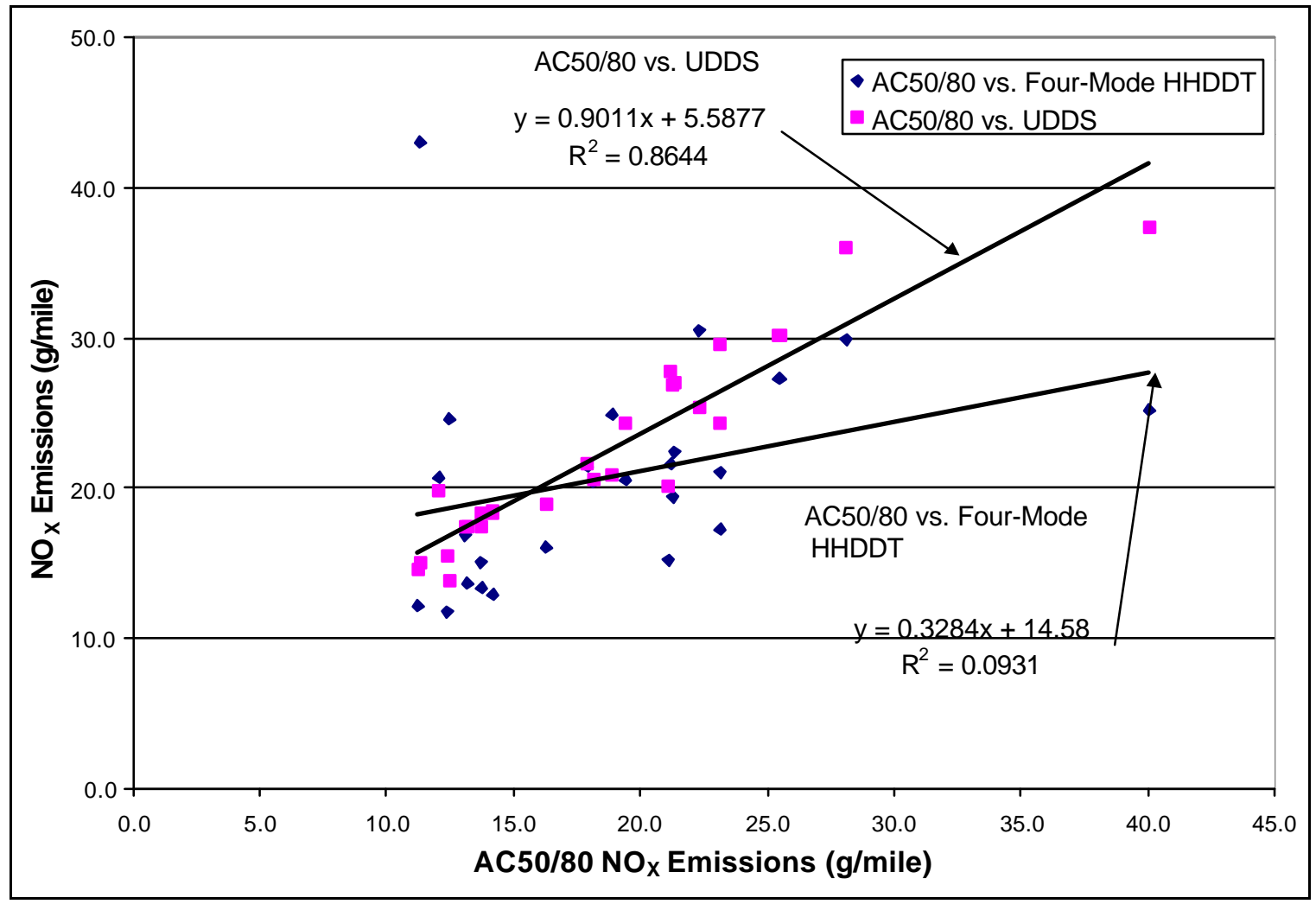


Figure 70: Comparison between the AC50/80, the combined HHDDT and the UDDS for PM emissions.

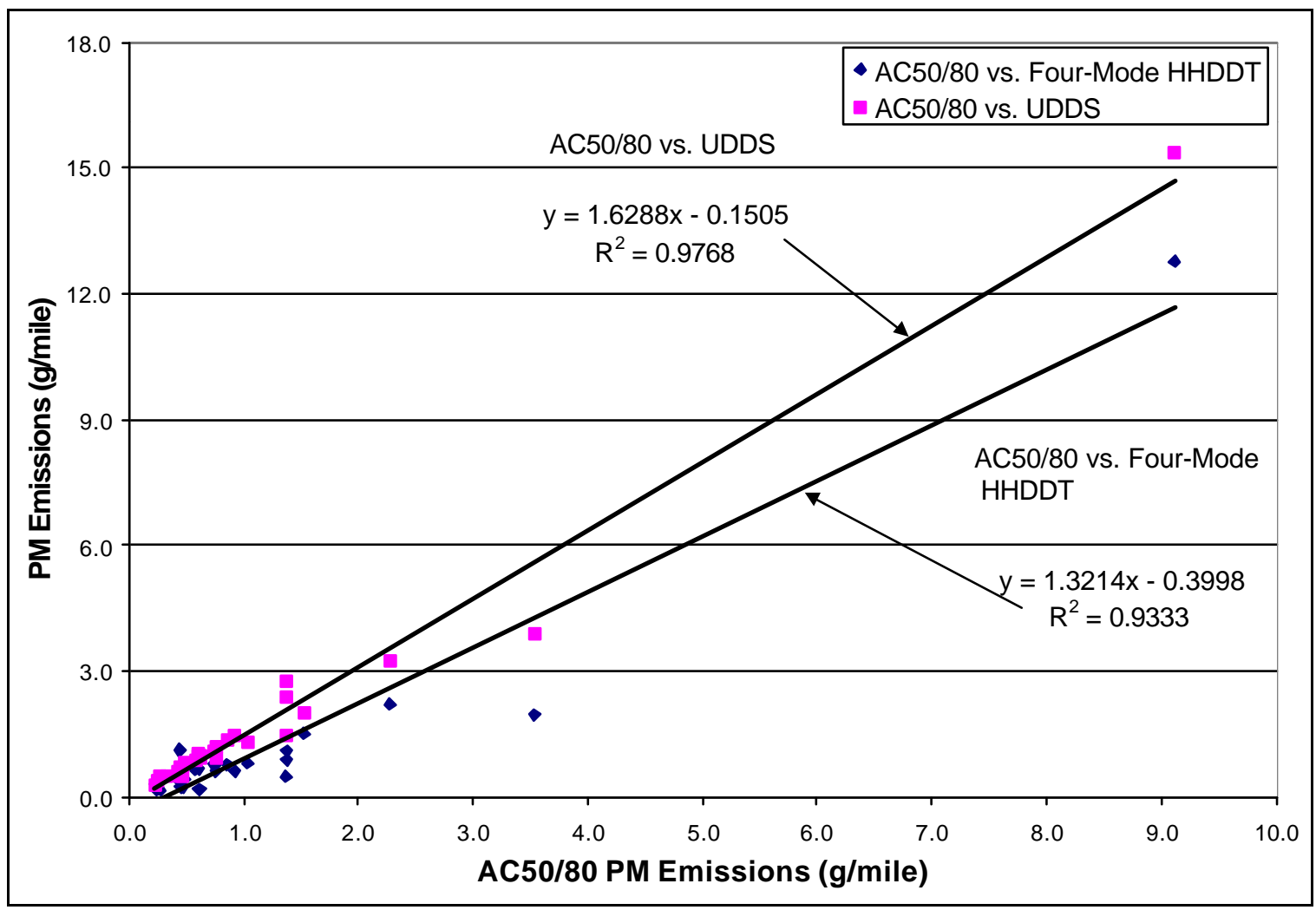

\subsubsection{Comparison Between the Transient Mode and the Cruise Mode From the HHDDT}

The Transient and Cruise Modes were compared to see how the results related since the two tests operate the heavy-duty vehicle under different driving conditions. The twenty-five vehicles were separated in to Engine Model Year Groups, based on California Emissions Standards. The emissions of $\mathrm{NO}_{\mathrm{X}}, \mathrm{PM}, \mathrm{HC}, \mathrm{CO}$ and $\mathrm{CO}_{2}$ are compared between the Transient and Cruise Modes in Figure 71 and Figure 72. The Transient Mode appeared to produce slightly higher emissions in relation to the Cruise Mode. The Transient Mode operates the heavy-duty vehicle at various speeds and contains several accelerations. The Cruise Mode on the other hand is mainly high-speed steady operation and could be the reason for lower emissions levels for all of the gaseous emissions and PM. 
Figure 71: Comparison between the Transient and the Cruise Modes for $\mathrm{NO}_{\mathrm{x}}$ and PM emissions.

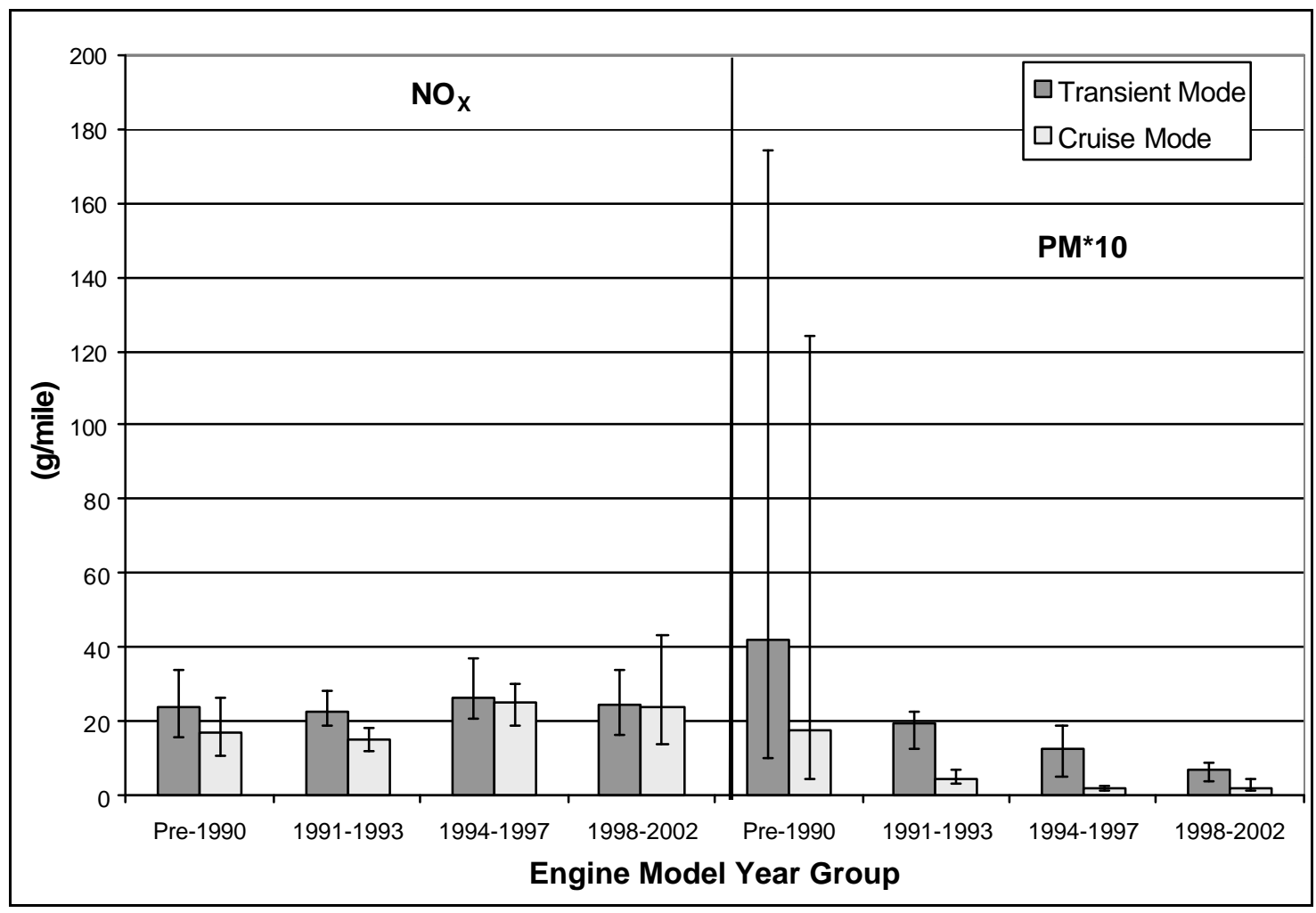


Figure 72: Comparison between the Transient and Cruise Modes for $\mathrm{CO}, \mathrm{HC}$ and $\mathrm{CO}_{2}$ emissions.

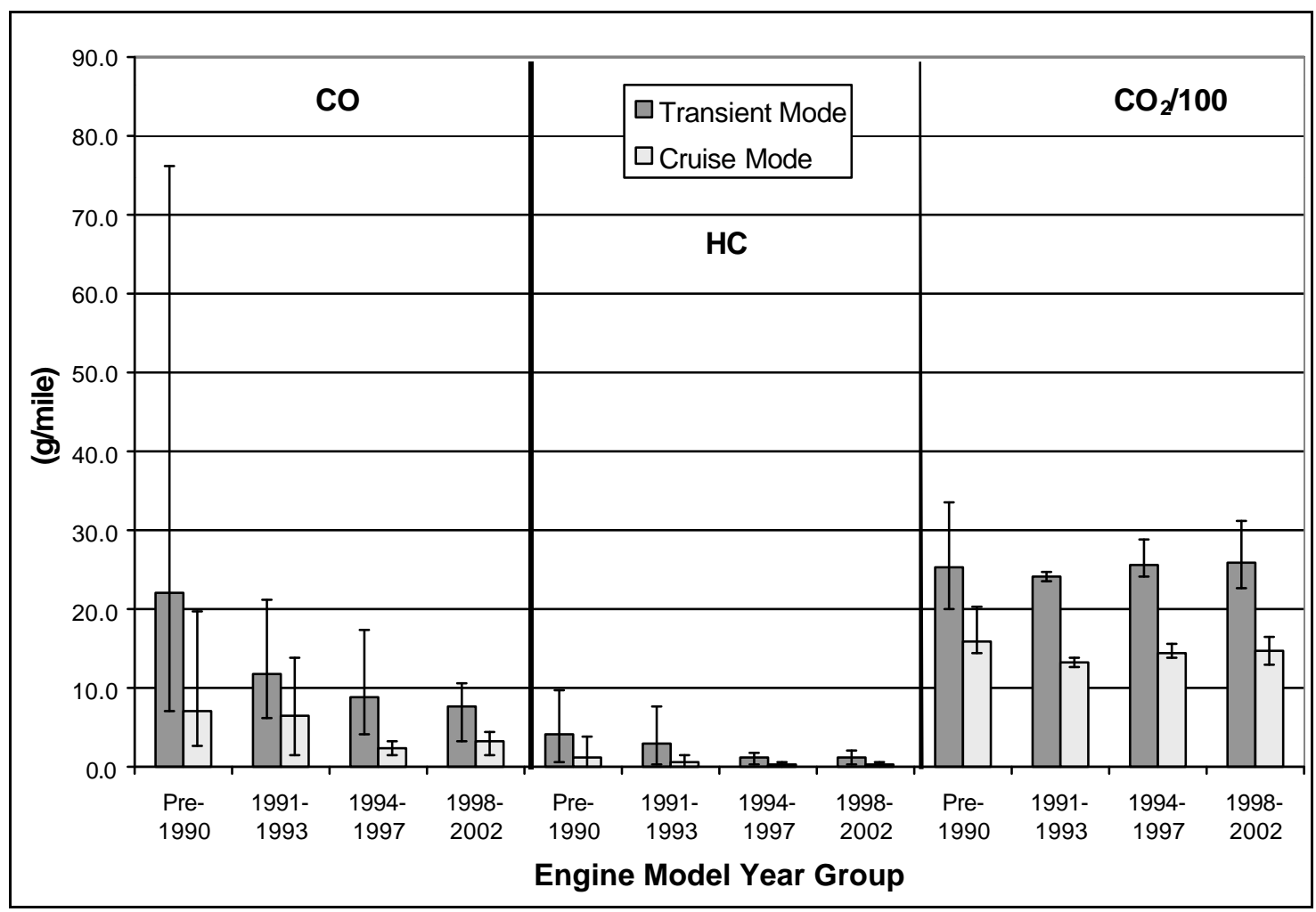

The $\mathrm{NO}_{\mathrm{X}}$ and $\mathrm{PM}$ emissions for the twenty-five vehicles were compared between the Transient and Cruise Mode. The results from the $\mathrm{NO}_{\mathrm{X}}$ comparison are presented in Figure 73. The $\mathrm{NO}_{\mathrm{X}}$ emission correlated to each other for the Transient and Cruise Mode better then the AC50/80 versus Creep, Transient, Cruise or combined HHDDT Schedule, but the comparison was still poor and the data was scattered. The $\mathrm{NO}_{\mathrm{X}}$ emissions were also higher for the Transient Mode than the Cruise Mode, which is supported by Figure 71. The PM emissions correlated better than the $\mathrm{NO}_{\mathrm{X}}$ emissions with an $\mathrm{r}^{2}$ value of .895 when E55CRC-16 was included in the data set. When E55CRC-16 was removed the correlation was lower and more PM was produce during the Transient Mode than the Cruise Mode. 
Figure 73: Relationship between the Transient and Cruise Modes for $\mathrm{NO}_{\mathbf{x}}$ emissions from the twenty-five heavy-duty vehicles tested.

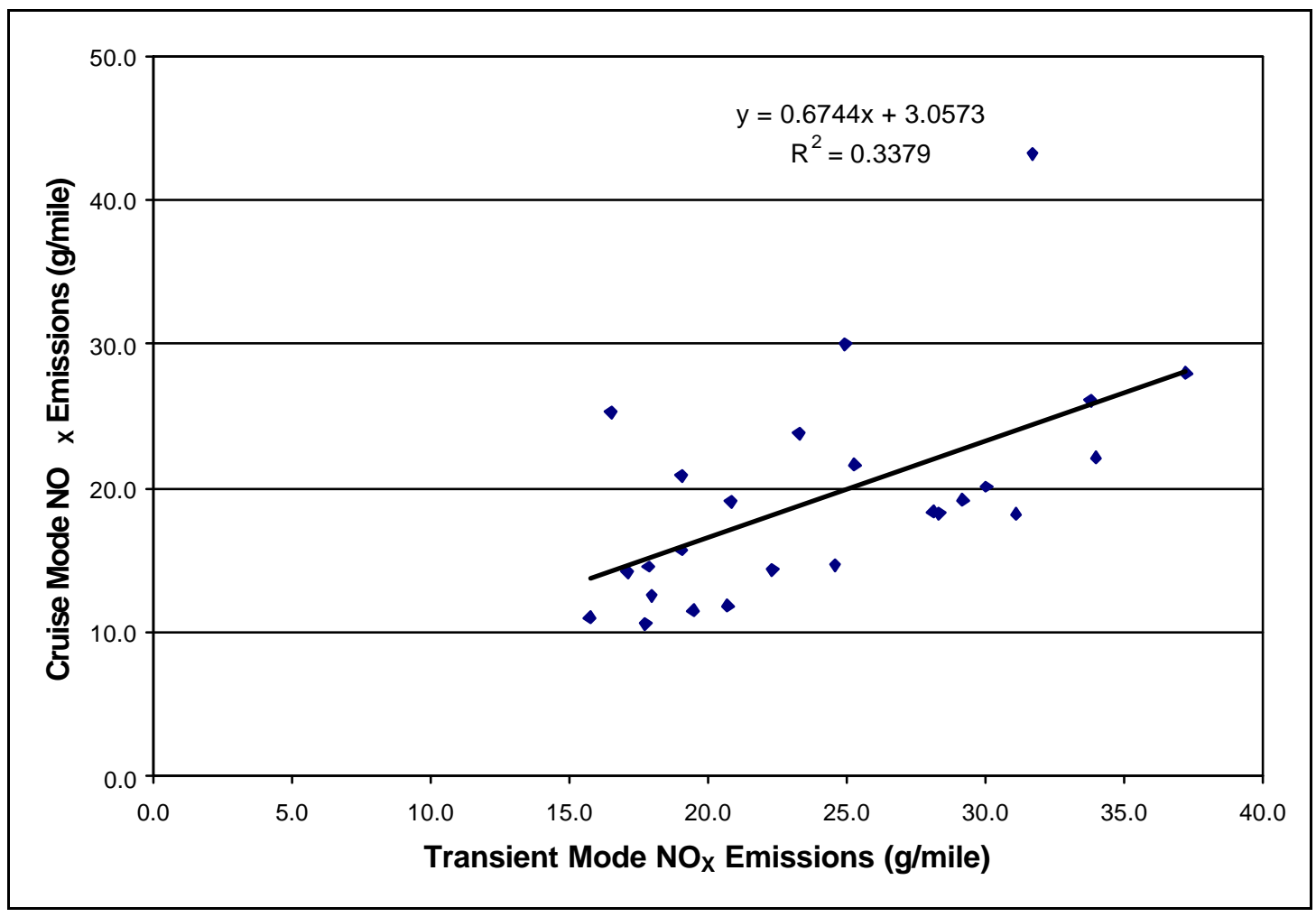

Figure 74: Relationship between the Transient and Cruise Modes for PM emissions from the twenty-five heavy-duty vehicles tested.

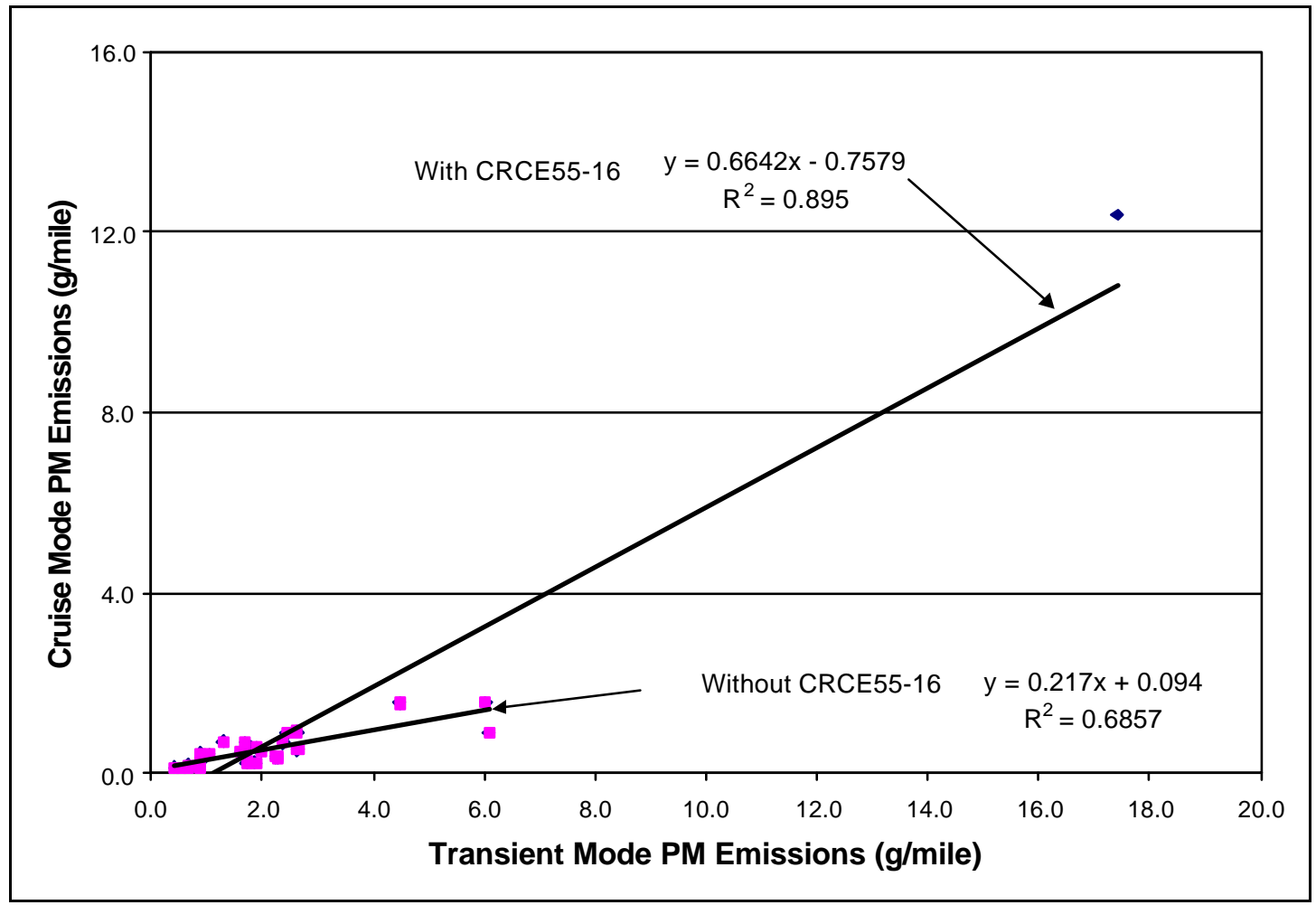




\subsection{Comparison Between $\mathrm{NO}_{\mathrm{x}}$ and PM Emissions When Comparing Several Different Cycles Performed on the Same Heavy-Duty Vehicle}

Two vehicles were sampled from each Engine Model Year Group. E55CRC-13 and E55CRC-12 were selected for the Pre-1990 Engine Model Year Group. E55CRC-20 and E55CRC-22 were selected from the 1991-1993 Engine Model Year Group. E55CRC-1 and E55CRC-6 were selected from the 1994-1997 Engine Model Year Group and E55CRC-9 and E55CRC-11 were selected from the 1998-2002 Engine Model Year Group. The vehicles were selected based only on the criteria that they did not have problems with tampering and/or malmaintenance. The $\mathrm{g} /$ mile emissions for $\mathrm{NO}_{\mathrm{X}}$ and $\mathrm{PM}$ were compared to see if there was a relationship when several different cycles are performed on the same vehicle.

E55CRC-13 and E55CRC-12 were selected from the Pre-1990 Engine Model Year Group and the results are presented in Figure 75 and Figure 76. E55CRC-13 had a 1978 Cummins 350 diesel engine tested on the UDDS, AC50/80 and the HHDDT Laden and Unladen Schedules. The two highest values were from the Laden and Unladen Creep Modes in the HHDDT. The other cycles were scattered in the bottom half of the plot and showed no clear relationship. CRC-12 was a 1986 Cummins 300 diesel engine. The 1986 engine showed the similar results to the 1978 heavy-duty vehicle with the two highest points produced from the Laden and Unladen Creep Mode. The two heavy-duty vehicles have relatively old engines and could have engine wear and poorly operating fuel injectors. This would lead to unburned fuel in the exhaust along with particulate matter. 
Figure 75: Comparison between $\mathrm{NO}_{\mathrm{X}}$ and PM for the E55CRC-13 heavy-duty vehicle. The heavy-duty vehicle had a 1978 model year Cummins 350 diesel engine.

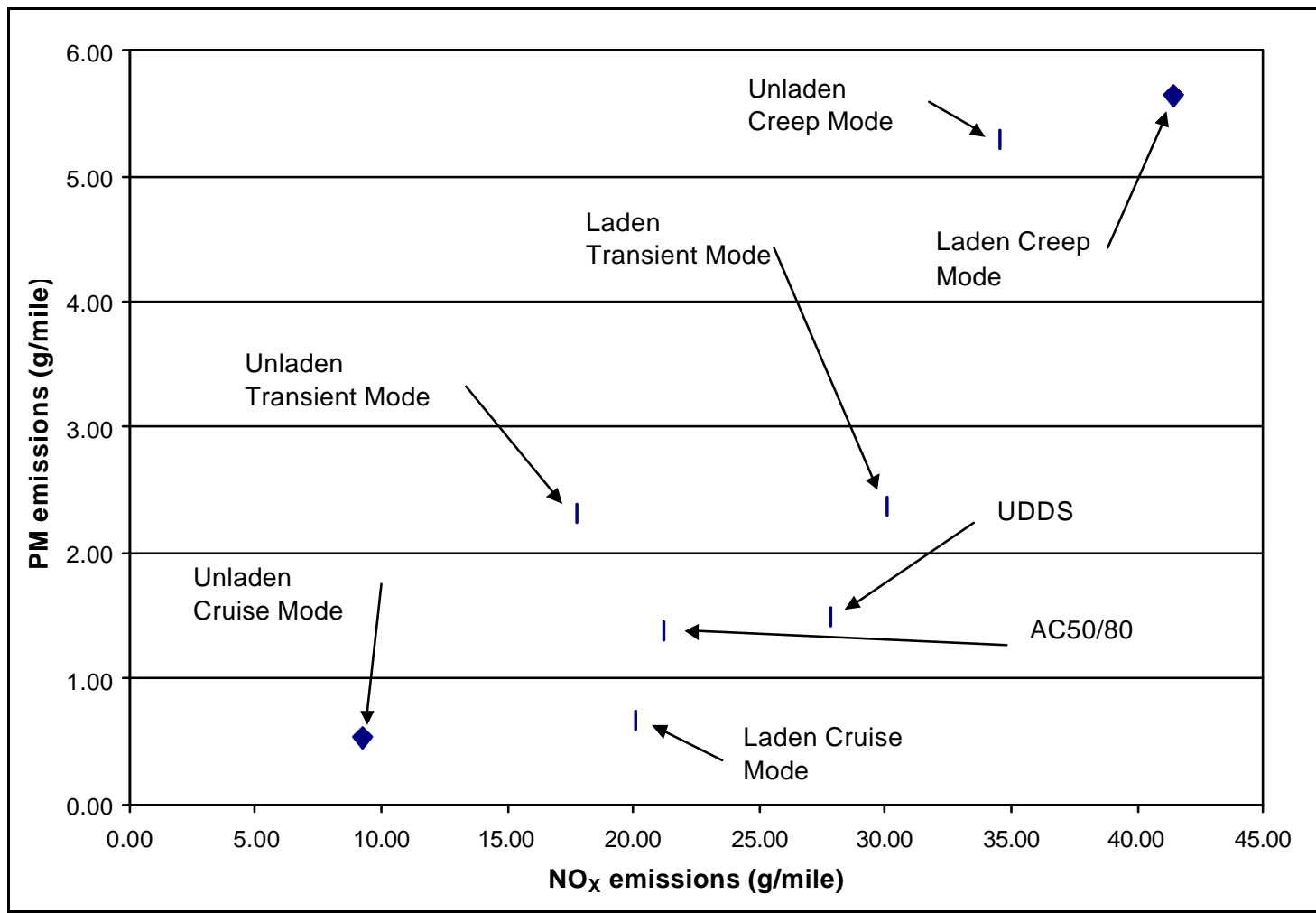


Figure 76: Comparison between NOx and PM emissions for the E55CRC-12 heavyduty vehicle. The heavy-duty vehicle had a 1986 model year Cummins 300 diesel engine.

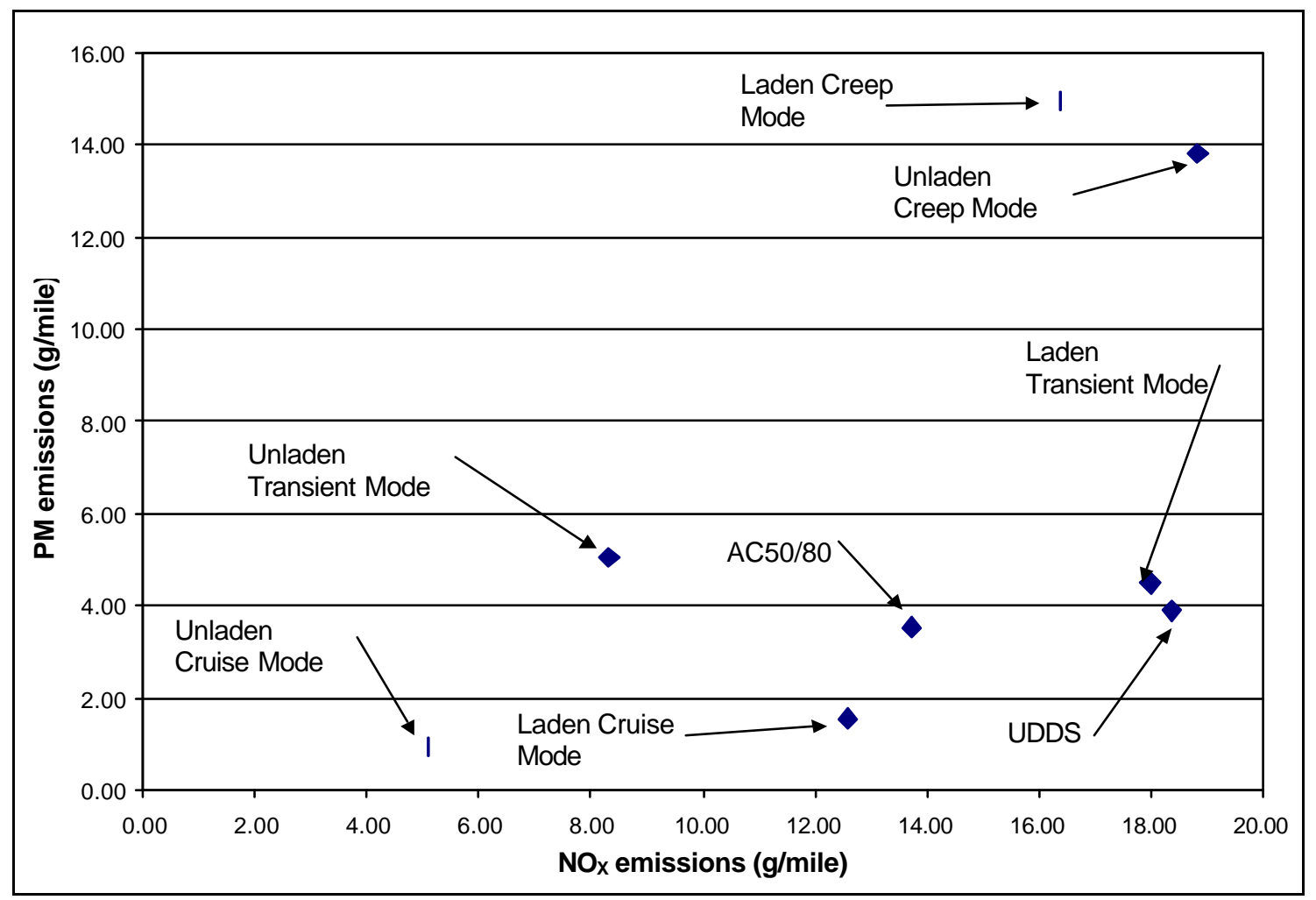

In the 1991-1993 Engine Model Year Group, heavy-duty vehicles E55CRC-20

and E55CRC-22 were evaluated to see if a better relationship could be made than the Pre1990 Engine Model Year Group. The E55CRC-20 heavy-duty vehicle had a 1992 Detroit Diesel Series 60 engine. All tests except the Idle Mode are presented in Figure 77. The Detroit Diesel Series 60 engine followed the same trend as the Pre-1990 Engine Model Year Group. The highest values were for the Laden and Unladen Creep Modes. Overall, the PM levels were lower in the E55CRC-20 in comparison to the two older heavy-duty vehicles. The E55CRC-22 was a 1993 Cummins L10-280 diesel engine and followed the older heavy-duty vehicles by having the Laden and Unladen Creep Modes producing the highest $\mathrm{PM}$ to $\mathrm{NO}_{\mathrm{X}}$ emissions. The $\mathrm{NO}_{\mathrm{X}}$ values for the Creep Modes increased for the 1991-1993 Engine Model Year Group also. 
Figure 77: Comparison between NOx and PM emissions for the E55CRC-20 heavyduty vehicle. The heavy-duty vehicle had a 1992 model year Detroit Diesel Series 60 engine.

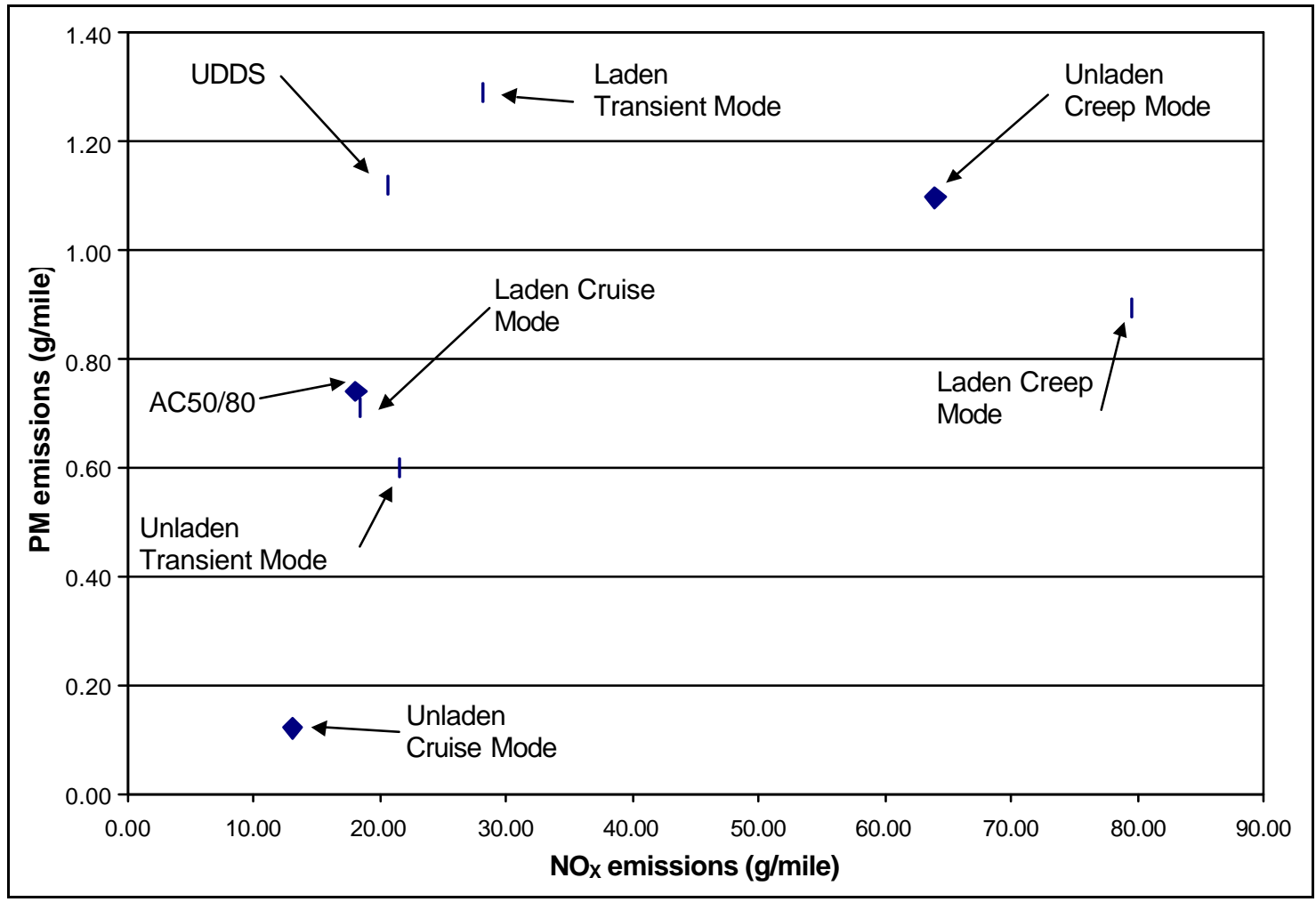


Figure 78: Comparison between NOx and PM emissions for the E55CRC-22 heavyduty vehicle. The heavy-duty vehicle had a 1993 model year Cummins L10-280 diesel engine.

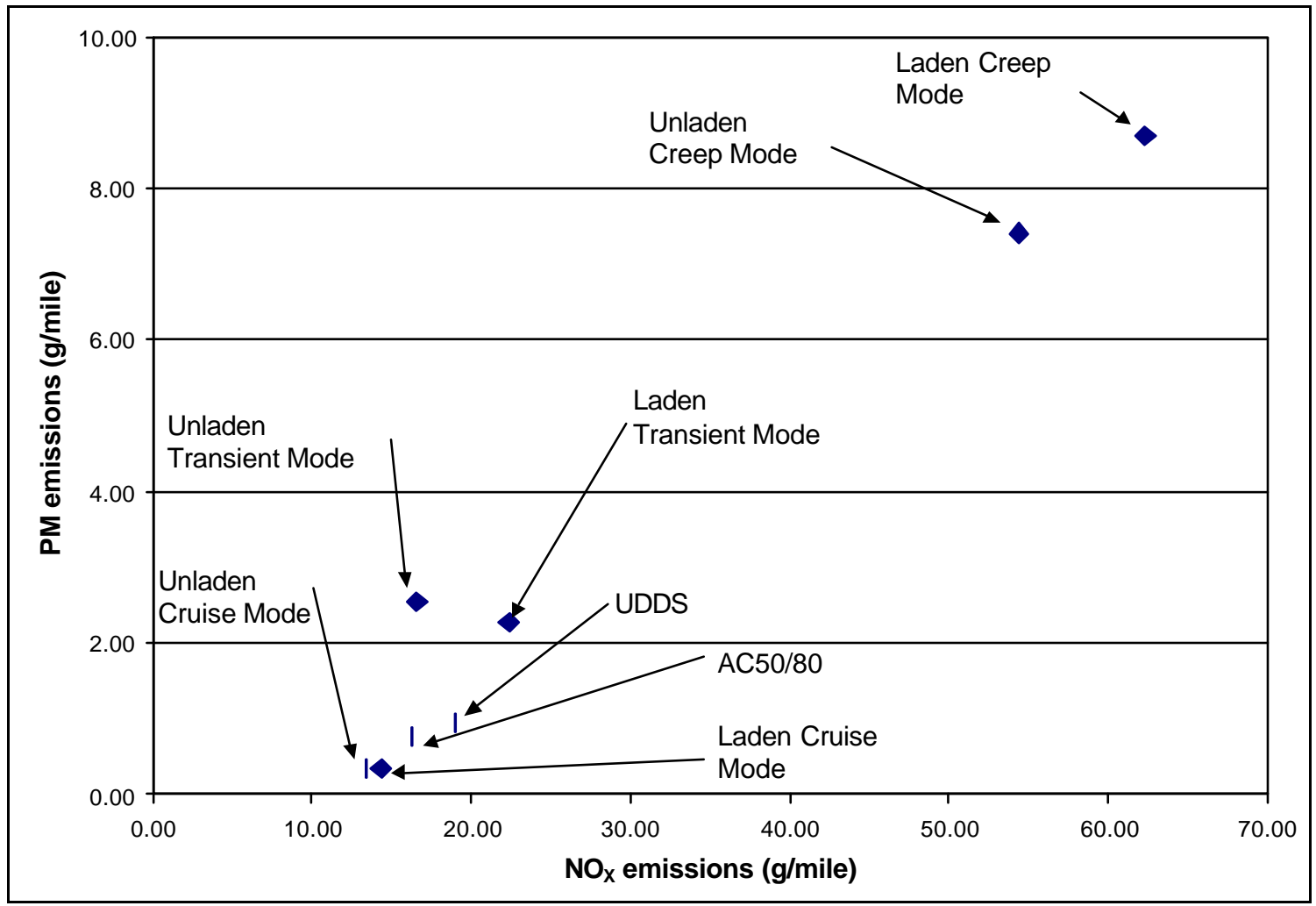

E55CRC-1 and E55CRC-6 represented the 1994-1997 Engine Model Year Group. E55CRC-6 had a 1995 Cummins M11-370 diesel engine and the results are presented in Figure 79. The 1995 Cummins engine followed the same pattern as all of the previous heavy-duty vehicles with the highest $\mathrm{NO}_{\mathrm{X}}$ to $\mathrm{PM}$ ratio coming from the Unladen and Laden Creep Modes. The 1995 engine has a similar pattern in relation to E55CRC-22. All of the cycles tend to stay grouped together with the exception of the Creep Modes. E55CRC-1 was a 1994 Detroit Diesel Series 60 engine with the two highest emitters being the Laden and Unladen Creep Mode. The $\mathrm{NO}_{\mathrm{X}}$ emissions for the 1994-1997 Engine Model Year Group were much higher than the other groups. It is also noticeable with the 1994 heavy-duty vehicle that the PM stays fairly close and the $\mathrm{NO}_{\mathrm{X}}$ values are spread out from $18.0 \mathrm{~g} / \mathrm{mile}$ to $60.0 \mathrm{~g} / \mathrm{mile}$. 
Figure 79: Comparison between NO and PM emissions for the E55CRC-6 heavyduty vehicle. The heavy-duty vehicle had a 1995 model year Cummins M11-370 diesel engine.

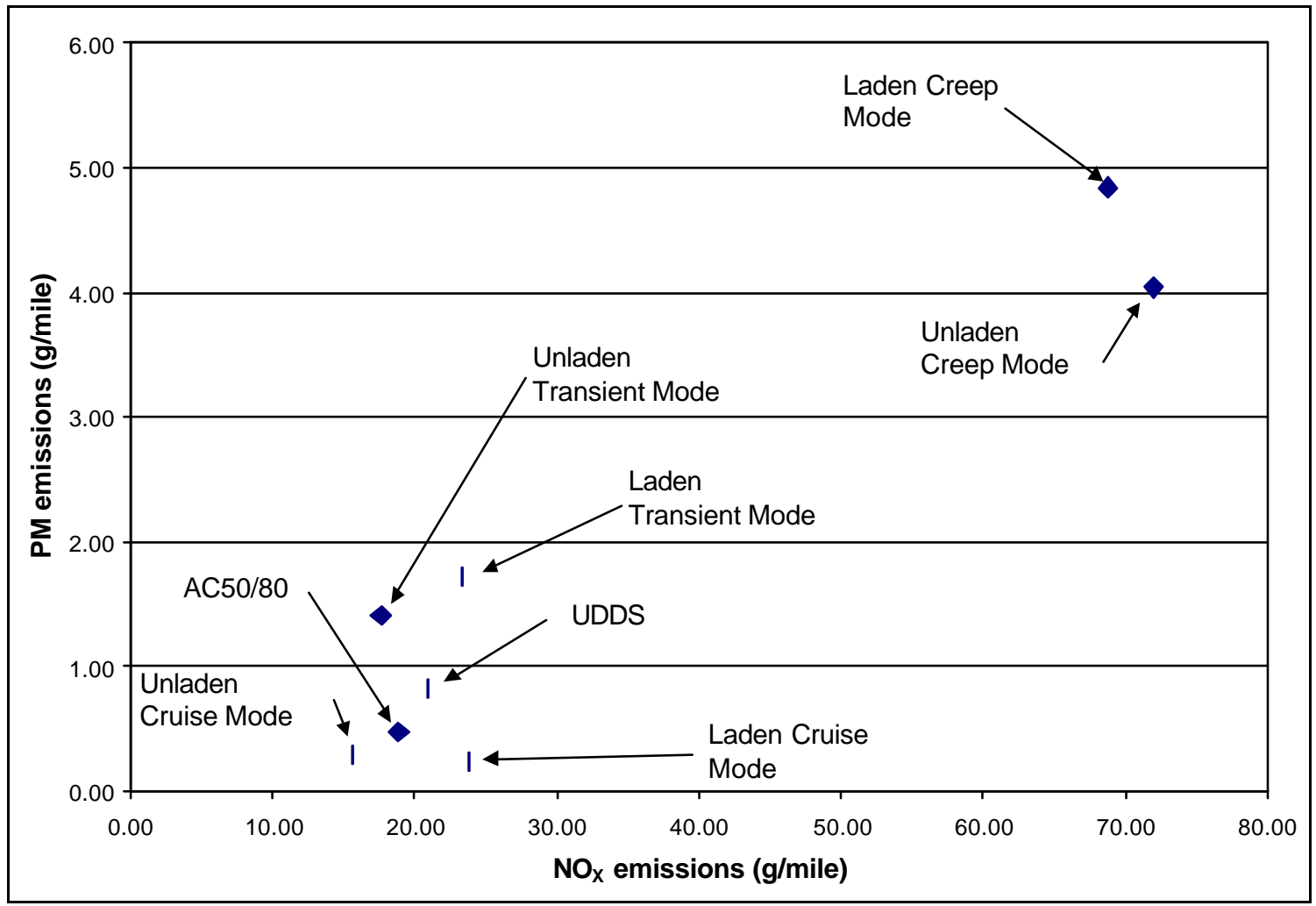


Figure 80: Comparison between $\mathrm{NO}_{\mathrm{X}}$ and PM emissions for the E55CRC-1 heavyduty vehicle. The heavy-duty vehicle had a 1994 model year Detroit Diesel Series 60 diesel engine.

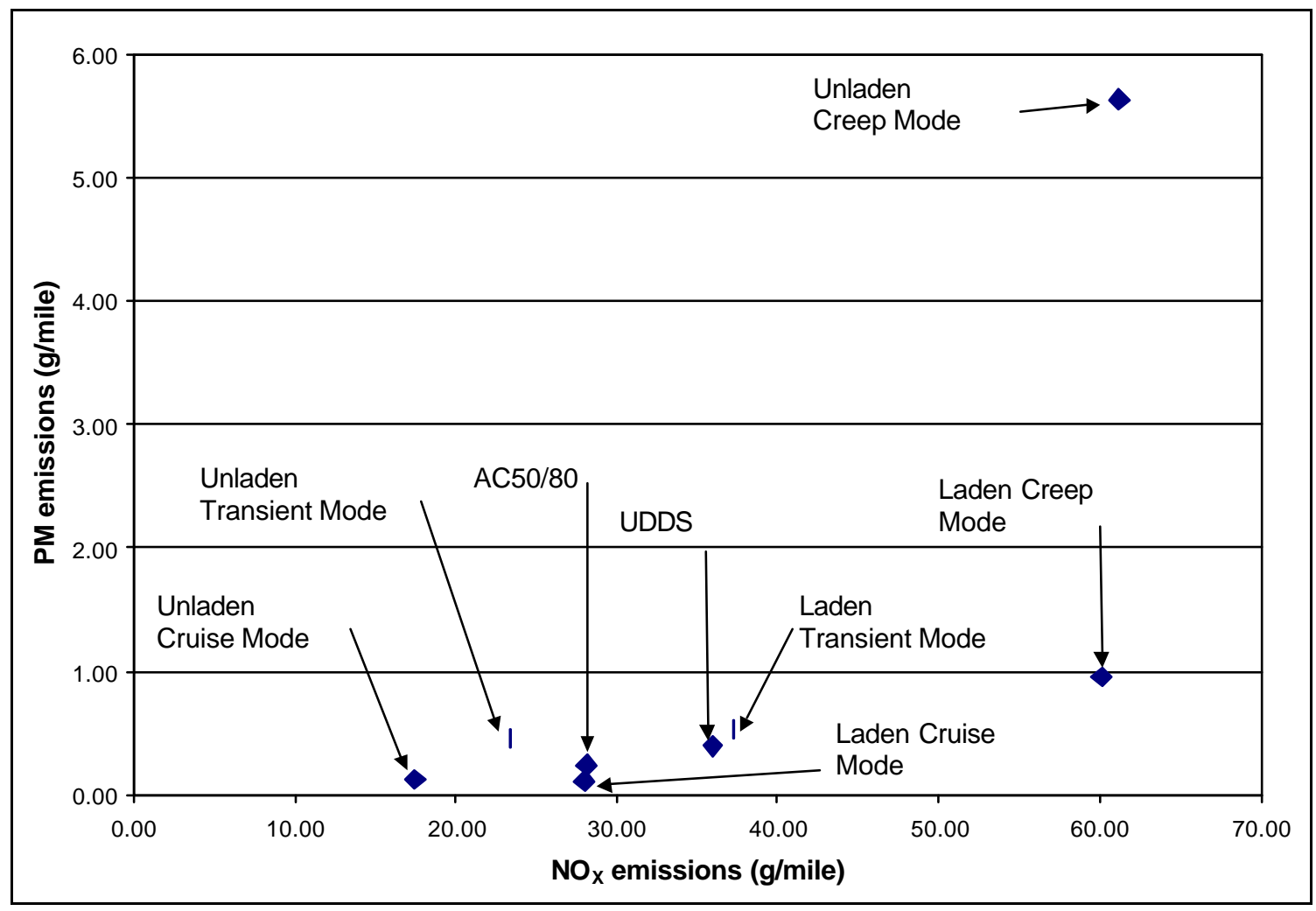

E55CRC-9 and E55CRC-11 represented the 1998-2002 Engine Model Year Group. E55CRC-9 was a 1998 Cummins C12 diesel engine and the $\mathrm{NO}_{\mathrm{X}}$ to $\mathrm{PM}$ relationship is presented in Figure 81. The highest emissions producing cycles were the Laden and Unladen Creep Mode and the rest of the data tended to stay closer together. When the Unladen and Laden Creep Modes are removed from the plot the rest of the data tends to follow a $\mathrm{NO}_{\mathrm{X}} / \mathrm{PM}$ Tradeoff with a downward sloping hyperbolic curve. The ratios tended to stay close together when the Unladen and Laden Creep Modes are removed, similar to E55CRC-6, E55CRC-22. The E55CRC-11 heavy-duty vehicle tended to follow the same trend as previously mentioned. All of the data stays fairly close together except for the Unladen and Laden Creep. 
Figure 81: Comparison between NO and PM emissions for the E55CRC-9 heavyduty vehicle. The heavy-duty vehicle had a 1998 model year Cummins C12 diesel engine.

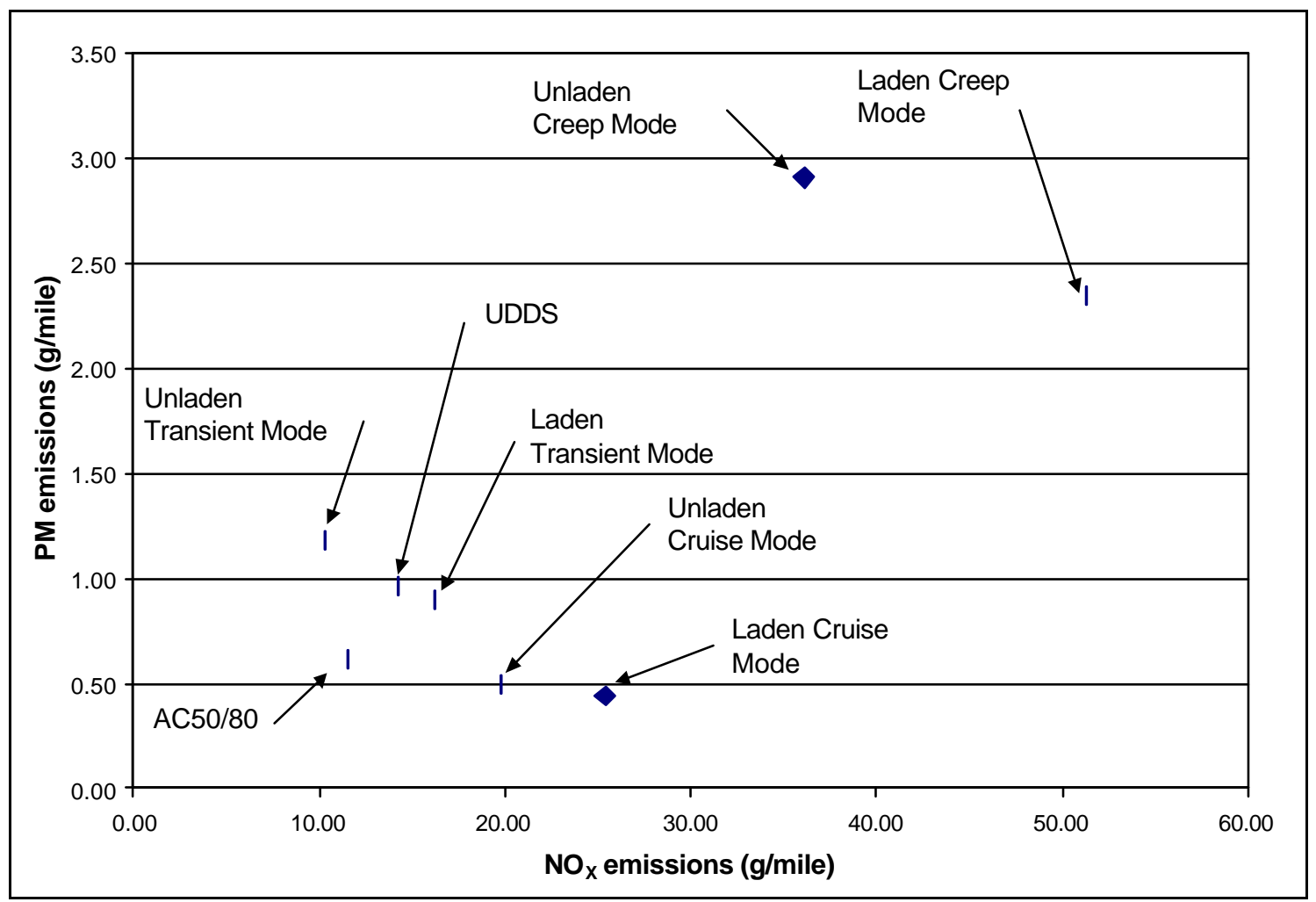


Figure 82: Comparison between $\mathrm{NO}_{\mathrm{X}}$ and PM for the E55CRC-11 heavy-duty vehicle. The heavy-duty had a 2000 model year Cummins ISM diesel engine.

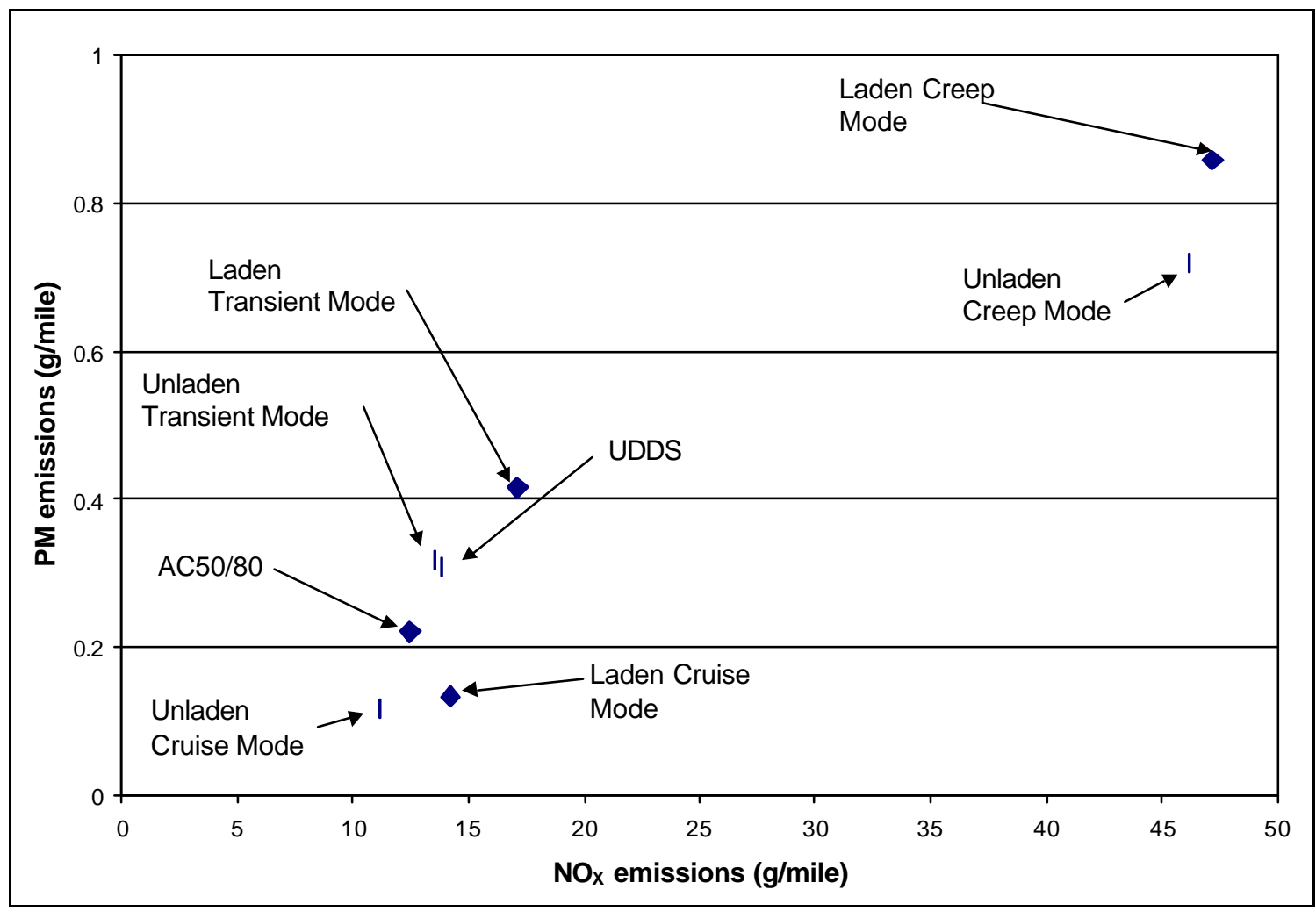

Overall the heavy-duty vehicles in the 1994-1997 Engine Model Year Group

produced some of the highest ratios for $\mathrm{NO}_{\mathrm{X}}$ versus PM. The Unladen and Laden Creep Modes also produced considerable higher ratios when compared to other cycles. From 1993 up the comparison between $\mathrm{NO}_{\mathrm{X}}$ and $\mathrm{PM}$ emissions tended to stay fairly close to each other. In order to make a clear comparison between $\mathrm{NO}_{\mathrm{X}}, \mathrm{PM}$ and various cycle, a number of various tests needs to be performed on each heavy-duty vehicle to better understand how different cycles produce different emissions. 


\section{Conclusions}

A literature review revealed that the emissions from heavy-duty diesel vehicles have been known to contribute to poor air quality in the United States of America and regulations need to be enforced in order to lower heavy-duty diesel emissions. Emissions affect the human body by causing lung cancer, emphysema and tumors in the respiratory system. Heavy-duty diesel emissions can also lead to respiratory problems like asthma attacks and allergies. In some cases it can even lead to premature death. So it is important to lower the production of emissions from heavy-duty vehicles to improve the air, water and land that the people of the United States of America call home. Lowering

the production of emissions from heavy-duty vehicles could also have benefits all over the world. South America, especially Mexico City, several major cities in Southeast Asia, and Europe could improve their air quality by lowering the emissions produced from heavy-duty vehicles.

In the CRC E55/59 Phase I study, twenty-five heavy-duty vehicles operating in the state of California were examined for gaseous emissions and PM production. The vehicles were tested on the UDDS, AC50/80 and the HHDDT Schedule. The vehicles were also tested at a test weight of 30,000 lbs. (Unladen) and 56,000 lbs. (Laden) to examine how the weight of the material a heavy-duty vehicle is carrying affects the amount of emissions produced from the engine. The Idle and Creep Modes of the FourMode HHDDT Schedule were lengthened to see if the results from the Idle and Creep Mode produce the same emissions as the Long Idle and Creep Mode.

In the first part of the analysis, the test vehicles were divided up into Engine Model Year Groups that were based on California Emissions Standards since the vehicles 
were certified to operate in the state of California. The emissions of $\mathrm{HC}, \mathrm{CO}, \mathrm{CO}_{2}$ and $\mathrm{NO}_{\mathrm{X}}$ were examined in relation to Engine Model Year Groups to see how emissions have changed over the years. The emissions standards for $\mathrm{NO}_{\mathrm{X}}$ and $\mathrm{PM}$ have decreased to the present and the emissions produced from the vehicles tested should show the same trend. The emissions of $\mathrm{HC}$ and $\mathrm{CO}$ have not seen the same decrease in emissions standards as $\mathrm{NO}_{\mathrm{X}}$ and PM, but because of improvements in engine technology and fuel delivery systems a decreased in $\mathrm{HC}$ and $\mathrm{CO}$ emissions was expected.

PM emissions decrease in relation to Engine Model Year, which correlated to California Emissions Standards. There was also a decrease in $\mathrm{HC}$ and $\mathrm{CO}$ emissions in relation to Engine Model Year. The decrease in $\mathrm{HC}$ emissions is most likely due to improvements in the fuel delivery to the cylinders and the improved atomization of fuel in the cylinder. The emissions of $\mathrm{NO}_{\mathrm{X}}$ did not decrease in relation to Engine Model Year Group. The trends found in the $\mathrm{PM}$ and $\mathrm{NO}_{\mathrm{X}}$ emissions are similar to the trends presented by Clark et. al. [14] that compared the emissions produced from vehicles operating in the state of California. Several heavy-duty vehicles were evaluated in the PM Split study and PM emissions were compared to model year in relation to California Emissions Standards. In the PM Split study the PM emissions followed a downward trend when compared to model year, similar to the trend found in the CRC E55/59 Phase I study. The $\mathrm{NO}_{\mathrm{X}}$ emissions also followed the same trend presented in the PM Split study, namely that the $\mathrm{NO}_{\mathrm{X}}$ emissions did not change appreciably as vehicle model year approached the present. In relations to model year there was a small amount of variation in the $\mathrm{CO}$ and $\mathrm{HC}$ data in the PM Split study. The $\mathrm{CO}$ and $\mathrm{HC}$ emissions in the CRC E55/59 Phase I study had only a small reduction in emissions in relation to model year. 
There is less concern over $\mathrm{HC}$ and $\mathrm{CO}$ emissions from diesel engines since they produce relatively small amounts of these emissions.

It is expected that the $\mathrm{NO}_{\mathrm{X}}$ did not decrease because of strategies leading to "offcycle" behavior. Several heavy-duty engine manufactures altered the control strategies during operation and allowed the heavy-duty vehicle to operate on two different engine maps, one map emphasized for certification and the other map emphasized for some real world driving. The second map allowed for improved fuel economy, but also allowed for an increase in $\mathrm{NO}_{\mathrm{X}}$ emissions. The emissions defeating devices in the electronic fuel injection system controls were discovered by the EPA and the companies were forced to remove the control strategies from the newer engines, unless the engine was operating under conditions that would damage the engine. The engine manufacturers in the United States signed a consent decree and they were forced to meet current emissions standards. More information about the consent decree can be found on the EPA website, http://www.epa.gov/compliance/resources /decrees /civil/caa. The engine manufacturers were obliged to reduce emissions and limit off-cycle operation from all of their new engines. Some of the 1998 and newer vehicles may still have some emissions defeating devices, but the 1998-2002 groups for the AC50/80, UDDS and HHDDT show a slight decrease in relation to the 1994-1997 groups. The $\mathrm{NO}_{\mathrm{X}}$ emissions values are still not as low as the Pre-1990 and 1991-1993 Engine Model Year Groups.

All twenty-five heavy-duty vehicles were tested at a Laden test weight of 56,000 lbs. and an Unladen test weight of 30,000 lbs. on the HHDDT to see how test weight affects emissions production. The Unladen and Laden test weight data were compared and the results were presented in the analysis section. The Creep Mode for the Unladen 
and Laden test weight showed a decrease in PM emissions in relation to model year, but no relations could be made between Unladen and Laden test weight effects for PM. $\mathrm{NO}_{\mathrm{X}}$ usually has a linear relationship to test weight, but the Laden and Unladen test weight data did not follow the linear relationship for the Creep Mode. The Transient and Cruise Mode showed no clear relation between PM emissions and test weight, but the $\mathrm{NO}_{\mathrm{X}}$ did have a linear relation to test weight. The $\mathrm{NO}_{\mathrm{X}}$ emissions increased when tested at a higher test weight.

The first thirteen heavy-duty vehicles were tested on the Idle Mode and the Long Idle Mode to see if the length of the test would improve the accuracy of the measurement of the emissions produced from the heavy-duty vehicle. The Idle Mode tended to have run-to-run variability and the Long Idle Mode produce closer run-to-run repeatability. The Long Idle Mode improves the accuracy of the test, but also lengthens the amount of time it takes to test a heavy-duty vehicle. When the values were averaged for each test vehicle, the Idle and Long Idle Modes produced similar results. The first thirteen test vehicles were also tested on the Creep Mode and Long Creep Mode to see if the test length improved the accuracy of the test. The Creep Mode showed a closer run-to-run repeatability in relation to the Idle Mode, but there was still some run-to-run variability. Overall, the Long Idle and Long Creep are better tests for testing heavy-duty vehicles at low operating speeds, but the Idle and Creep Mode are a shorter test.

Several different tests were performed on each vehicle tested in the CRC E55/59 Phase I study. The AC50/80 was a short test developed for Australia to inspect their heavy-duty vehicles for emissions. The UDDS is a longer test than the AC50/80 and is found in the CFR 20]. The Four-Mode HHDDT tests the heavy-duty vehicle under four 
different types of driving conditions and is a fairly new test. The AC50/80 was compared to the UDDS, Creep Mode, Transient Mode, and Cruise Mode. The AC50/80 and UDDS were also compared to the combined HHDDT. When the average emissions are compared for each Engine Model Year Group, the combined HHDDT produced the most accurate test out of the group, because it is the longest test when combined and operates the vehicle through four common types of operation. When the AC50/80 test was compared based on Engine Model Year Group, the results were similar to the Combined HHDDT Schedule. Based on the data, the AC50/80 could be used to inspect vehicles operating in the state of California, but more than one test would need to be performed on each vehicle inspected to insure run-to-run repeatability.

A comparison between $\mathrm{NO}_{\mathrm{X}}$ and $\mathrm{PM}$ was also examined for two heavy-duty vehicles in each Engine Model Year Group. The older heavy-duty vehicles produced more scatter in the data in relation to the newer heavy-duty vehicles. The newer heavyduty vehicles tended to clump together more except for the Unladen and Laden Creep Modes. The relations presented little information in relation to the concept of the $\mathrm{NO}_{\mathrm{X}} / \mathrm{PM}$ trade-off. More tests of the same cycles and other cycles need to be performed to generate a better understanding of the $\mathrm{NO}_{\mathrm{X}} / \mathrm{PM}$ relationship.

Overall, the emissions of PM have shown a decrease in relation to Engine Model Year, which coincides with the California and Federal Emissions Standards. The emissions of $\mathrm{HC}$ and $\mathrm{CO}$ has shown a slight decrease in most of the tests in relation to Engine Model Year. The reduction in $\mathrm{HC}$ and $\mathrm{CO}$ are most likely due to the improvements in engine design and fuel delivery systems. Improved atomization of the diesel fuel in the cylinder has improved over the last decade. The emissions of $\mathrm{NO}_{\mathrm{X}}$ have 
shown no decline in relation to Engine Model Year. The 1998-2002 Engine Model Year Group showed a decrease in relation to the 1994-1997 Engine Model Year Group, but is still higher then the Pre-1990 and 1991-1993 Engine Model Year Groups. 


\section{References}

1. www.epa.gov/history/ (accessed January, 2003).

2. Www.dieselnet.com/standards/us/hd.html (accessed January, 2003).

3. Environmental Protection Agency, "Emissions Standards Reference Guide for Heavy-Duty and Nonroad Engines," Department of Air and Radiation, EPA420F-97-014, September 1997.

4. Gautam, M., Thompson, J., Carder, D. K., Clark, N. N., Shade, B. C., Riddle, W. C., Lyons, D. W., "Measurement of In-Use, On-Board Emissions from HeavyDuty Diesel Vehicles: Mobile Emissions Measurement System," SAE Paper 2001-01-3643.

5. McCormick, R. L., Ryan, L., B., A., Daniels, T., L., Yanowitz, J., Graboski, M., S., "Comparison of Chassis Dynamomter In-Use Emissions with Engine Dynamometer FTP Emissions for Three Heavy-Duty Diesel Vehicles," SAE Paper 982653, 1998.

6. Stewart, K., "Health effects of Diesel Exhaust", Presentation to the CleanAir Council, Director of environmental health from the American Lung Association of Pennsylvania, November 13, 2001, www.cleanair.org/diesel/health_effects.pdf.

7. Lloyd, A. C., Cackette, T. A., "Diesel Engines: Environmental Impact and Control," Journal of Air and Waste Management Association, Vol. 51, pg. 809847,June 2001.

8. Scheepers, P. T. J., Bos, R. P., "Combustion of diesel fuel from a toxicological perspective". Occupational and Environmental Health, Vol. 64, pg. 163-177, April, 1992.

9. Diaz-Sanchez, D., "The Role of Diesel Exhaust Particles and Their Associated Polyaromatic Hydrocarbons in the Induction of Allergic Airway Disease," Allergy, Vol. 52, pg 52-56, 1997.

10. Nauss, K., "Health Effects Institute (HEI) Diesel Exhaust: A Critical Analysis of Emissions, Exposure, and Health Effects Summary of a Health Effects Institute (HEI) Special Report HEI Diesel Working Group," DieselNet Technical Report, October 1997, www.dieselnet.com/papers/9710nauss.html. (accessed February, 2003).

11. Riley, W. J., McKone, T. E., Lai, A. C. K., Nazaroff, W. W., "Indoor Particulate Matter of Outdoor Origin: Importance of Size-Dependent Removal Mechanisms", Environmental Science technology, Vol. 36, pg. 200-207, 2002. 
12. EPA press release-April 30, 1971, "EPA Sets National Air Quality Standards", http://www.epa.gov/history/topics/caa70/01.htm (accessed January, 2003).

13. Hall, T., "Effects of Vehicle Weight and Model Year on Vehicle Contribution to Atmospheric Pollutant Inventories", Thesis submitted to the College of Engineering and Mineral Resources at West Virginia University, Morgantown WV, 2002.

14. Clark, N., Wayne, W. S., Nine, D., Buffamonte, T., Hall, T., Rapp, B., Thompson, G., Lyons, D., "Emissions from Diesel-Fueled Heavy-Duty Vehicles in Southern California”. SAE Paper 2003-01-1902, May, 2003.

15. Norton, T., Tucker, S., Smith, R. E., Lawson, D., "The Northern Front Range Air Quality Study,” EPA Environmental Management, pg. 13-19, January, 1998.

16. Clark, N. N., Kern, J. M., Atkinson, C. M., Nine, R. D., "Factors Affecting Heavy-Duty Diesel Vehicle Emissions," Journal of Air \& Waste Management Association, Vol. 52, pg. 84-94, January, 2002.

17. Graboski, M. S., McCormick, R., Yanowitz, J., Ryan, L., "Heavy-Duty Vehicle Testing for the Northern Front Range Air Quality Study," Final Report, Colorado Institute for Fuels and High-Altitude Engine Research, Colorado School of Mines, February, 1998.

18. Gautam, M., Clark, N., Lyons, D., Long, T. Jr., Howell, A., Loth, J., Palmer, G., Wang, W. and Bata, N. "Design Overview of a Heavy Duty Mobile Vehicle Emissions Testing Laboratory," Proceedings of the ASME Annual Meeting, Atlanta, GA, December, 1991. Also in Advanced Automotive Technology, DEVol. 40, ASME, Special Publication, 1991.

19. Clark, N., Gautam, M., Bata, R., Wang, W., Loth, J., Palmer, G. M., and Lyons, D., "Design and Operation of a new Transportable Laboratory for Emissions Testing of Heavy Duty Trucks and Buses," Heavy Vehicle Systems, International Journal of Vehicle Design, Vol. 2: Nos. 3/4, 1995.

20. Code of Federal Regulations, Title 40, Part 86, Subpart N - Emission Regulations for New Otto-Cycle and Diesel Heavy-Duty Engines; Gaseous and Particulate Exhaust Test Procedures, Washington, D.C., 1998.

21. Clark, N., Gautam, M., Thompson, G., Wayne, W. S. and Lyons, D., "HeavyDuty Vehicle Chassis Dynamometer Testing For Emissions Inventory, Air Quality Modeling, Source Apportionment and Air Toxics Emissions Inventory, Phase 1," Phase 1 Report for the CRC E55/59 Project, submitted to the Coordinating Research Council, Inc., September, 2002. 
22. Gautam, M., Clark, N., Riddle, W., Nine, R. Wayne, W. S., "Development and Initial Use of a Heavy-Duty Diesel Truck Test Schedule for Emissions Characterization," SAE Paper 2002-01-1753, 2002.

23. Doebelin, E. O., "Measurement Systems Application and Design," McGraw-Hill, Inc., New York, NY, 1990.

24. Heywood, J. B., "Internal Combustion Engine Fundementals", McGraw-Hill, Inc., New York, NY, 1988.

25. Rosemount Analytical Inc. Model 880A (NDIR) Analyzer, Instruction Manual 748250-L, Rosemount Analytical Inc., La Habra, California, 1999.

26. Rosemount Analytical Inc. Model $955 \mathrm{NO} / \mathrm{NO}_{\mathrm{x}}$ Analyzer Instruction Manual 015-555479, Rosemount Analytical Inc., La Habra, California 1991.

27. Horiba Instruments Model AIA-210 NDIR Analyzer Instruction Manual 091215, Horiba Instruments Inc., Irvine, California, 1995.

28. Rosemount Analytical Inc. $\mathrm{NO}_{\mathrm{X}}$ Efficiency Tester Manual, Rosemount Analytical Inc., La Habra, California, 1991.

29. Rosemount Analytical Inc. Model 402 Hydrocarbon Analyzer Instruction Manual 015-082132-L, Rosemount Analytical Inc., La Habra, California, 1993.

30. Clark, N. N., Gautam, M., Riddle, W., Nine, R. and Wayne, W. S., "Examination of a Heavy Heavy-Duty Truck Chassis Dynamometer Schedule" Abstract and Paper submitted to SAE Journal of Automobile Engineering, in review.

31. http://www.epa.gov/compliance/resources/decrees/civil/caa (February, 2003). 